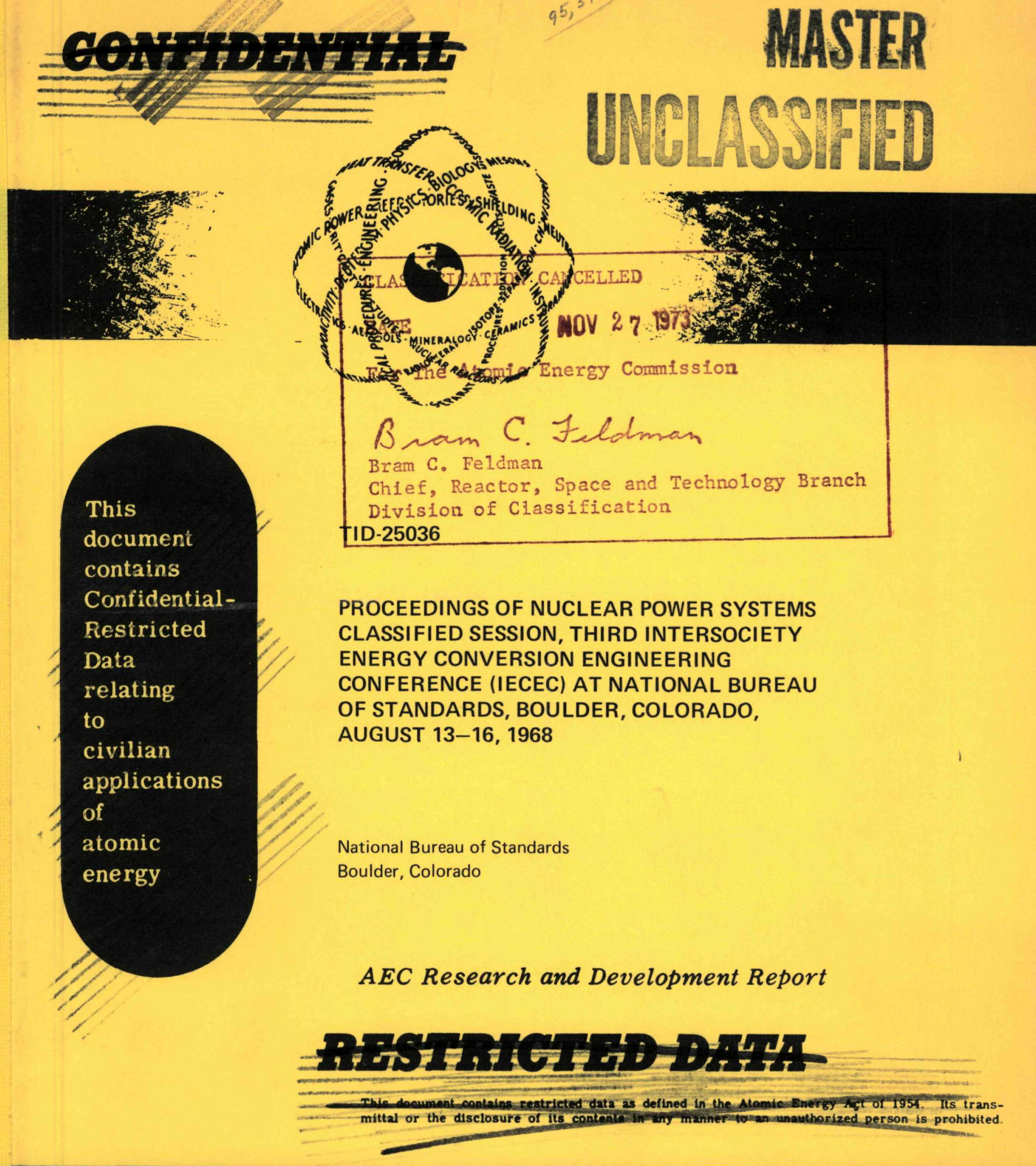

UNITED STATES ATOMIC ENERGY COMMISSION

Division of Technical Information 


\section{DISCLAIMER}

This report was prepared as an account of work sponsored by an agency of the United States Government. Neither the United States Government nor any agency Thereof, nor any of their employees, makes any warranty, express or implied, or assumes any legal liability or responsibility for the accuracy, completeness, or usefulness of any information, apparatus, product, or process disclosed, or represents that its use would not infringe privately owned rights. Reference herein to any specific commercial product, process, or service by trade name, trademark, manufacturer, or otherwise does not necessarily constitute or imply its endorsement, recommendation, or favoring by the United States Government or any agency thereof. The views and opinions of authors expressed herein do not necessarily state or reflect those of the United States Government or any agency thereof. 


\section{DISCLAIMER}

Portions of this document may be illegible in electronic image products. Images are produced from the best available original document. 


\section{LEGAL NOTICE}

This report was prepared as an account of Government sponsored work. Nelther the United States, nor the Commission, nor any person acting on behalf of the Commission:

A. Makes any warranty or representation, expressed or implied, with respect to the accuracy, completeness, or usefulness of the information contained in this report, or that the use of any information, apparatus, mechod gr process disclosed in this report may not infringe privately owned rights; or

B. Assumes any liabilities yith respect to the use of, or for damages resulting from the use of any information, apparatus, method, or process disclosed in this report.

As used in the aboye "person acting on behalf of the Commission" includes any employee or contractor of the Commission, or employee of such contractor, to the extent that such employee or contractor of the Commission, or employee of such contractot prepares, disseminates, or provides access to, any information pursuant to his employment of contract with the Commission, or his employment with such contractor.

This report has been reproduced directly from the best available copy.

Printed in USA. Charge \$3.45 Available from the Division of Technical Information Extension, P. O. Box 62, Oak Ridge, Tennessee 37831. Please direct to the same address inquiries covering the procurement of classified $\mathrm{AEC}$ reports.

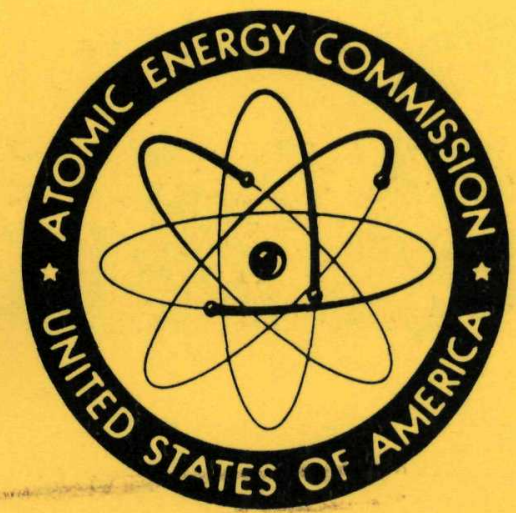




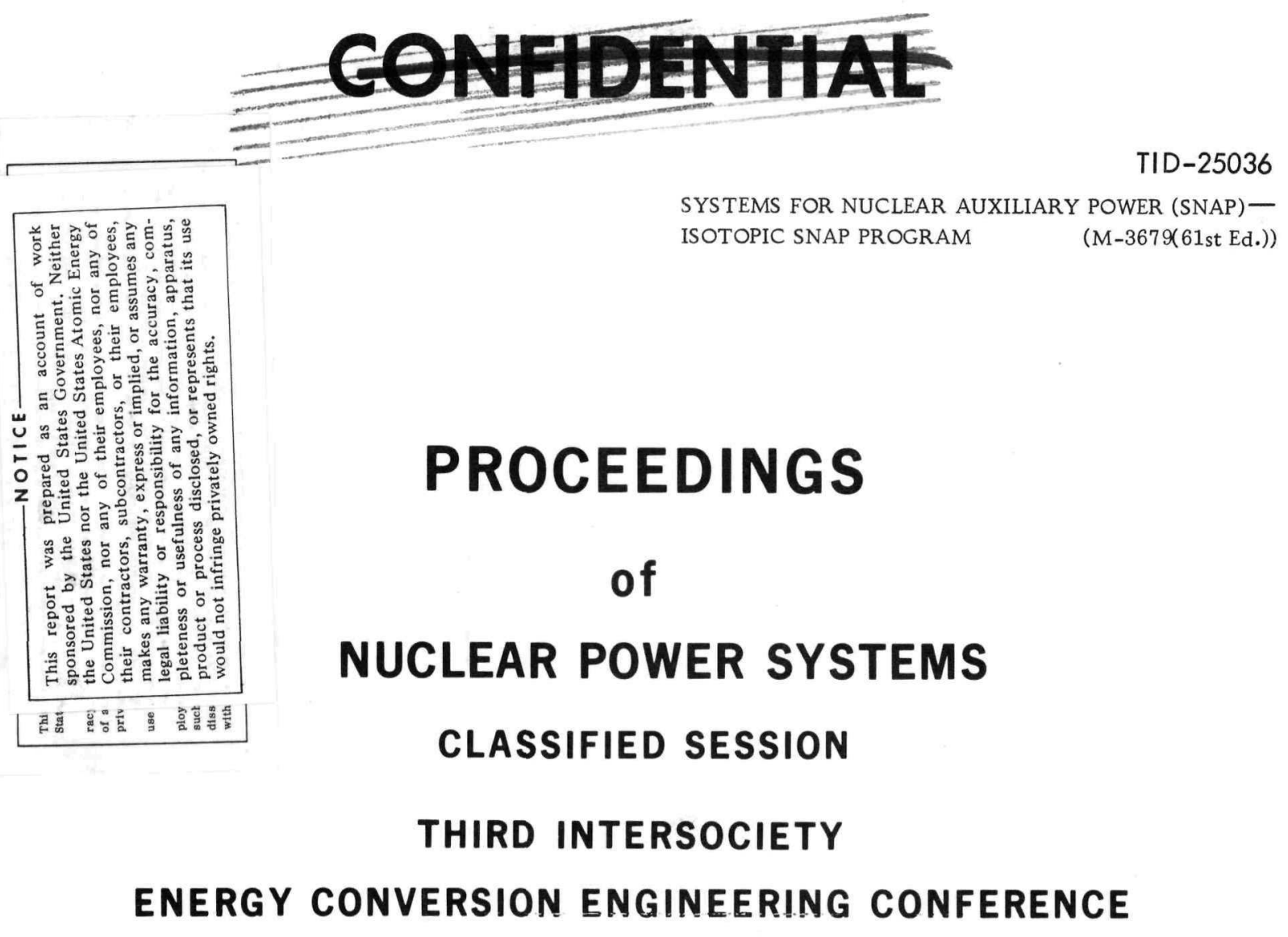

(IECEC)

\author{
NATIONAL BUREAU OF STANDARDS \\ BOULDER, COLORADO
}

AUGUST 13 TO 16, 1968

\begin{tabular}{|c|llc|}
\hline SPECIAL REREVIEW & Reviewers & Class. & Date \\
FINAL & KAW & 4 & 127.81 \\
DETERMINATION & HFC & 4 & $12-7.81$ \\
\hline
\end{tabular}

GROUP 1

Excluded from automatic downgrading and declassification
RECTRICTEA PATA RESAREAED - AAA

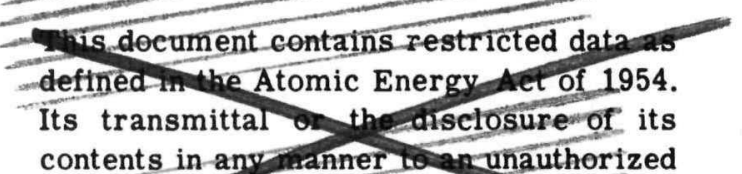

contents in any manner to ancunauthorized

DIspersenticipohibited. 
The classified Session Chairman extends his thanks to all who helped in preparing and presenting the classified session. Most particularly I acknowledge the technical, administrative, and security assistance of the following:

Dr. A. I. Mlavsky, Tyco Laboratories, Inc.

Dr. Joseph D. LaFleur, USAEC/SNS

Edward J. Brosnan, USAEC/DS

R. G. Bulgin, National Bureau of Standards

Dr. Jerome G. Morse, Martin Marietta Corporation

R. H. Hodgin, Martin Marietta Corporation

John J. Sullivan, Cambridge Nuclear Corporation

H. Eugene Rexford, Sanders Nuclear Corporation

The United States Atomic Energy Commission

Martin Marietta Corporation, Industrial Co-ordinator for

Security Arrangements 
This document contains published papers of the Nuclear Power Systems Classified Session of the Third Intersociety Energy Conversion Engineering Conference (IECEC) held August 13 to 16, 1968 at the National Bureau of Standards, Boulder, Colorado.

General Chairman of the Conference was Dr. Paul Rappaport, Radio Corporation of America; Technical program Chairman was Arnold A. Sorensen, Martin Marietta Corporation; Classified Session Chairman was Charles R. Fink, Sanders Nuclear corporation. Member societies of the IECEC are IEEE, AIAA, ASME, AIChE, ANS, SAE and the ACS. 


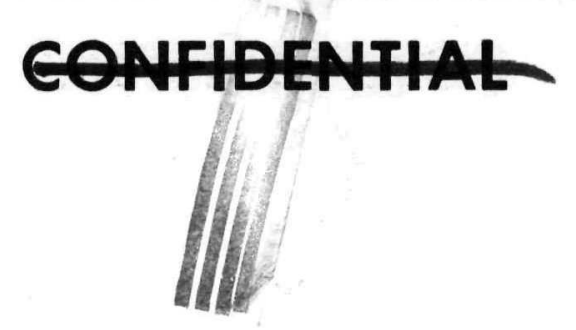

T A B L OF C O N T E N T S ( 1$)$

\section{Titles}

Pages

Programmatic Evaluation of SNAP 19 Intact Re-entry

Heat Source Development Program

SNAP 19 Aerospace Nuclear Safety Evaluation

Aerothermal Analysis and Testing of the SNAP 19

Intact Re-entry Heat Source

SNAP 27 Radioisotopic Thermoelectric Generators

Compact Thermoelectric Converter Program

Experimental Evaluation of an Automatic Temperature controlled Heat Pipe

Conceptual Design of a Radioisotope Heat Pipe Thermionic Space Power System

Fast Reactor Systems for Secondary Space Power

(1) Presented at conference but not published:

a. Design of a Sige Tubular PbTe Cascaded Radioisotope Thermoelectric Generator, J. E. Schmidt, W. G. Parker, Westinghouse Astronuclear Laboratory.

b. Design Features of External-Fuel Thermionic Reactors, B. Raab, M. Abbate, C. Eisen, A. Shock, Fairchild Hiller/Republic Aviation Division.

c. Development of High Temperature Radioisotope Capsules, L. Topper, USAEC/SNS. 
This document contains restricted data as defined in the Atomic Energy Act of 1954. Its transmittal or the disclosure of its contents in any manner to an unauthorized person is prohibited. Group 1

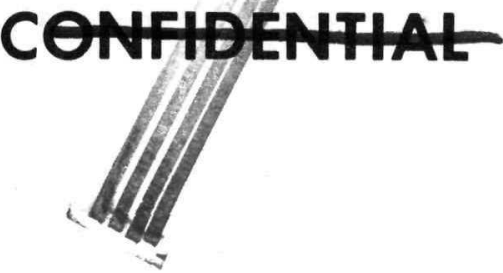

Excluded from automatic regrading.

PROGRAMALTIC EVALUATION OF SNAP 19 INTACT RE-ENTRY HEAT SOURCE DEVELOPMENT PROGRAM *

By

Paul J. Dick and William A. McDonald

Nuclear Systems Division, Isotopes, Inc. Middle River, Md. 21220

and

Thaddeus J. Dobry, SEPO-SNS

USAEC Headquarters

Washington, D. C. , 20545

\section{\$LMMARY}

Development of a SNAP 19 power system to provide 50 watts(e) for the NASA Nimbus-B weather satellite has been accomplished. During the latter stages of the program a $\mathrm{Pu}-238$ isotope heat source having intact atmospheric re-entry capabilities was developed. The results of an extensive effort in the design, development and qualification of the intact re-entry heat source (IRHS) are describe $\bar{d}$.

Development objectives and advanced concepts in design approach are conveyed in the heat source description. Significant developments are examined in detail along with test methods and results.

The scope of a testing program to qualify the heat source as an intact re-entry body and the integration technique employed with the previously qualified SNAP 19 RTG subsystem are summarized.

\section{INTRODUCTION}

During the past four years, with the cooperation of NASA and the Nuclear Systems Division, Isotopes as prime contractor, the AEC has actively supported the development of a 50-watt(e) Pu-238 fueled SNAP 19 power system for use on board a Nimbus-B weather satellite. Objectives of this flight program are to provide 24 hour weather coverage on a global basis and to determine the operational suitability of nuclear powered electrical systems as a primary power source on NASA operational weather systems.

The Nimbus-B spacecraft was to be launched from the Air Force Western Test Range by a Thorad/Agena D vehicle into a near polar circular orbit of 600 nautical miles altitude which should provide as orbital lifetime greater than 1600 years. Figure 1 is the nominal launch profile that was selected for the spacecraft.

Spacecraft weight is approximately 1360 pounds, and it contains about 200 pounds of experiments including an infrared interferometer, satellite infrared spectrometer, high resolution infrared radiometer, medium resolution infrared radiometer, monitor of ultraviolet solar energy, image-dissector camera system, and interrogation, recording and location systems. For electrical power, it is equipped with a solar array and battery power supply which provides an average power of 210 watts. This power is augmented by the SNAP 19 power system through a power conditioning unit. Nuclear power provides the capability of sustaining spacecraft power during the launch phase and also provides a source of radiationimmune power for sustaining spacecraft operational life. As the solar power degrades in time, the nuclear power system is used to supplement the required spacecraft power demands throughout the mission life. In the unlikely event of a malfunction of the solar array drive mechanism, the solar power system would provide only 85 watts of a required minimum spacecraft power need of 110 watts; hence, the nuclear system would provide the difference to maintain satellite operability.

The SNAP 19 nuclear power system has a design lifetime power requirement of one year in orbit following a two-year storage life on Earth. Figure 2 is a view of the two generators in the SNAP 19 system. The generators convert thermal energy from 2840 grams of $\mathrm{PuO}_{2}$ microsphere fuel into electrical energy through the use of leadtelluride thermoelectric couples. Encapsulated fuel and couples for each generator are contained in a magnesium-thorium alloy, right circular cylinder housing, 6-1/2 inches in diameter and 10-3/4 inches high. The radiating surface is increased by six fins which give each unit an overall diameter of 22 inches. The fuel is housed in a single superalloy capsule in each generator and contains 17,200 curies of Pu-238 having a halflife of 87.5 years.

This superalloy fuel containment capsule, with its protective graphite heat shield, are the primary components of the intact re-entry heat source. Evaluation of the design development program as conducted for the isotopic heat source is the subject of this paper. 
PROGRAM OBJECTIVES AND DESIGN CRITERIA

\section{Program Objectives}

The primary nuclear safety objectives of the SNAP 19 IRHS development program were to provide a heat source assembly which would be capable of:

(1) Preventing dispersal of the isotopic fuel subsequent to a launch abort and resulting Earth impact by containment within the fuel capsule wherein no sensible aerodynamic heating had occurred.

(2) Preventing atmospheric dispersal of the isotopic fuel prior to earth impact subsequent to launch or orbit aborts wherein aerodynamic heating has occurred.

(3) Minimizing chemical reactions among the IRHS components which could lead to potential ancilliary hazards, or compromise structural integrity of the heat shield.

In addition to the primary nuclear safety objectives, physical constraints were also imposed requiring that the heat source be capable of installation into the SNAP 19B generator without any physical change or modification to the previously qualified thermoelectric core or generator housing.

\section{Heat Source Design Criteria}

The program objectives and physical constraints demanded the selection of unusual design criteria which were beyond the current state of the art. Most significant was the essential need to reduce the fuel capsule size appreciably below the existing capsule dimensions to accommodate the additional need of a re-entry heat shield assembly. To achieve the program objectives and physical constraints, design criteria were imposed as follows:

(1) The capsule would be vented to eliminate the need for about $100 \%$ void volume required in the sealed capsule to accommodate the gaseous helium decay produce of plutonium-238. Furthermore, the uncertainties of long term creep-to-rupture predictions would also be eliminated.

(2) The capsule filter vent assembly while passing helium gas, would allow no particulate matter to escape under all normal operating or early abort conditions.

(3) A single-wall Haynes-25 capsule without the usual liner, would be employed to maximize available space and to minimize development complexity. The capsule would contain a dual fuel weld closure port to facilitate surface decontamination.

(4) Graphite would be used as the heat shield material because of its known materials compatibility with the generator and its desirable physical and thermal high temperature properties.

(5) A barrier system would be required on the interior of the graphite heat shield to prevent potential reaction with a molten Haynes-25 capsule or the $\mathrm{Pu}$ $238 \mathrm{O}_{2}$ fuel during the re-entry heat pulse, should it occur.

\section{HEAT SOURCE DESCRIPTION}

The heat source as it was developed and qualified to meet the stated program objectives and design criteria is described here. The basic functional components of the IRHS are the $\mathrm{PuO}_{2}$ fuel bed which provides the thermal power

for the generator, a metallic fuel capsule for containing the fuel during normal operation and early abort situations, a heat shield or outer shell for containing the internal constituents during all modes of re-entry and a barrier system to prevent chemical reaction between the graphite heat shield and the internal materials during extremes of reentry. Figure 3 is a cutaway of the overall IRHS assembly.

$\mathrm{PuO}_{2}$ Fuel Bed

The $\mathrm{Pu}-238 \mathrm{O}_{2}$ fuel bed contains a nominal thermal power of 570 watts. Fuel particles are in the form of plasma-fired microspheres with a manufactured size range of 50 to 250 microns. Any void remaining withing the metallic capsule was filled with plasma-fired $\mathrm{ZrO}_{2}$ microspheres with a size range of 300 to 590 microns. The $\mathrm{ZrO}_{2}$ is a high temperature material (melts at $4500^{\circ} \mathrm{F}$ ) and tests have shown it to be compatible with the $\mathrm{PuO}_{2}$ microspheres. Though the $\mathrm{ZrO}_{2}$ microspheres are initially placed on top of the fuel bed, normal handling causes them to disperse among the $\mathrm{PuO}_{2}$ particles.

\section{Fuel Capsule}

The fuel capsule is a nominal 0.050 inch thick single-containment, Haynes -25 material made from two deep drawn cups with hemispherical en

*IManufactured by C. B. Kaupp and Sons, Inc. 
Two equal length cups are jointed with a full penetration TIG weld to form a 2.1-inch outside diameter by 5.4 -inch long fuel container. This unique single-containment fuel envelope was made possible by development of a double-seal fueling port at one end. This feature, in conjunction with a special fueling fixture developed by Mound Laboratory (ML), which protected the external surface of the capsule from contamination, provided the ability for radioactive decontamination of the fueling port area between the seal disc weld and the end plug final closure weld.

The opposite hemispherical end of the Haynes25 capsule contains a combination filter assembly/ helium vent. Note from Fig. 3 that the filter assembly is shown in the lower end of the heat source. Figure 4 is an enlarged view showing a cutaway of the filter assembly and a portion of the Haynes-25 capsule.

The filter assembly consists of a nailhead shaped Haynes -25 receptacle into which a 0.040 inch diameter by 0.090 inch long platinum-plated $\mathrm{ZrO}_{2}$ filter element is installed. A 0.010 inch thick seal disc is welded into the end of the receptacle as a temporary seal for fueling purposes. Following seal welding of the fueling port and decontamination, the filter assembly seal disc is punctured. The filter is then operational; i. e., helium, which is generated from the decay of the radioisotope, will vent from the capsule and prevent a buildup of pressure, while at the same time preventing the egress of radioactive particulate matter.

The configuration of the filter assembly was selected primarily to prevent damage to the filter element in the event of impact. Impact distortion energy tends to flow from the capsule wall through the larger diameter section without distorting the barrel around the filter element.

The fuel capsule will contain the $\mathrm{PuO}_{2}$ fuel for normal operation or for early abort situations wherein no sensible aerodynamic heat is encountered. It is anticipated that the Haynes -25 capsule will melt under orbital decay conditions and certain late launch abort situations where significant aerodynamic heating occurs because of the relatively high hypersonic re-entry body ballistic parameter

$$
\left(\frac{\mathrm{W}}{\mathrm{C}_{\mathrm{D}} \mathrm{AR}_{\mathrm{n}}} \approx 280 \mathrm{lb} / \mathrm{ft}^{3}\right) .
$$

\section{Heat Shield}

The outer shell of the IRHS is a heat shield made fine grain graphite and is designated as POCO
Grade AXM-5Q. This container has a right circular external configuration defined by a 3 -inch diameter and 6.56-inch length. The internal surface is roughly the shape of the capsule, however, the hemispherical ends have a diameter of 2.35 inches which blends with the smaller 2.22-inch diameter cylindrical bore. This bulbous, hemispherical end has been coined the onion-shape and was included in the design to provide adequate room for the capsule compliant support members which are described later.

The heat shield halves are threaded together at the mid-section with Acme stub threads to form a container for the internal materials. The threaded joint is dimensioned so that the flat on the end of the male threaded piece bottoms internally on a land in the female half of the heat shield.

\section{Chemical Coating Barrier System}

A barrier coating system is provided within the heat source to preclude chemical reaction between the molten Haynes -25 and the graphite during the re-entry heat pulse. This reaction would compromise the integrity of the heat shield. An additional requirement is to keep the fuel microspheres from contacting the graphite should the capsule melt, since there is the possibility of some reaction between the $\mathrm{PuO}_{2}$ and carbon at the higher temperatures.

Investigations showed that zirconium oxide does not react with the molten Haynes-25 or the $\mathrm{PuO}_{2}$ at the predicted temperature extremes of re-entry. A coating of flame-sprayed $\mathrm{ZrO}_{2}$ was therefore selected for the inside of the graphite heat shield as the primary barrier against reaction. Development led to a nominal 0.015 inch thick composite sprayed coating consisting of tantalum, molybdenum and $\mathrm{ZrO}_{2}$.

A secondary or redundant barrier to reaction was provided by a 0.010 -inch thick tantalum canister with a 0.005 -inch $\mathrm{ZrO}_{2}$ sprayed coating on the inside. The canister was made up from a cylinder and a welded hemispherical closure at one end. The other end of the cylinder was closed with a hemispherical end cap having a mechanical slip fit. The coated tantalum canister will retard the flow of molten material to the coated graphite, thereby providing further assurance of heat source intact re-entry.

\section{Capsule Compliant Support Members}

The selected design utilizes unsintered tantalum felt pads at each end of the canistered capsule. The pads provide: 
(1) Flexibility for take-up of manufacturing tolerances.

(2) A compliant member for absorption/of differential thermal expansion between the Haynes-25 and the graphite heat shield under all conditions including reentry.

(3) A cushioning member to attenuate the dynamic loads between the capsule and the graphite heat shield.

Dynamic development testing of dummy IRHS assemblies resulted in a bulbous internal contour for the graphite heat shield. This shape was necessary to provide annular space for the felt over the entire hemispherical end of the canistered capsule for lateral support.

The felt is made from 25-micron, hardened tantalum fibers fabricated by the Brunswick Cor- poration. The fibers are oriented in a planar direction (rather than random orientation), needle punched to establish the desired density and thickness and then calendered to remove the needle holes. Material that is a nominal 1/8 inch thick and $6 \%$ dense was selected for the IRHS. The stock material was cut in a modified rosette pattern to form pads which could be fitted into the hemis pherical heat shield configuration. The pad material and configuration proved to be flexible from an application and functional standpoint.

\section{DEVELOPMENT TEST PROGRAM}

\section{Development Plan}

The development test program was divided into two categories; those relating primarily to nuclear safety; and, those dealing with structural and performance integrity. In the first category of nuclear safety, the concern is with specific abort conditions. Implied tests were formulated as follows:

$\begin{array}{ll}\begin{array}{ll}\text { Abort Condition } \\ \begin{array}{l}\text { Transportation } \\ \text { accident }\end{array}\end{array} & \text { Environmental Input } \\ \begin{array}{ll}\text { Launch pad abort } \\ \text { Bmpact, fire } \\ \text { abort }\end{array} & \text { Impact, fire } \\ \begin{array}{l}\text { Upper stage early } \\ \text { abort }\end{array} & \text { Impact } \\ \begin{array}{l}\text { Upper stage late } \\ \text { abort }\end{array} & \begin{array}{l}\text { Re-entry, capsule } \\ \text { melt, fuel impact } \\ \text { dispersion }\end{array} \\ \text { Orbit abort } & \begin{array}{l}\text { Re-entry, capsule } \\ \text { melt, fuel impact } \\ \text { dispersion }\end{array}\end{array}$

\section{Tests Conducted}

\author{
Impact--booster propellant \\ fire \\ Impact--booster propellant \\ fire \\ Impact \\ Impact
}

Hypersonic wind tunnel; plasma arc; furnace meltdown; free-fall drop

Hypersonic wind tunnel; plasma arc; furnace meltdown; free-fall drop

For the second category, called structural and performance integrity, operating conditions and resultant development tests conducted are tabulated as follows:

\section{Operating Condition}

Helium production

\section{Environment Input}

Filter vent long term elevated temperature and vibration

Heat shield gas permeation

Generator gas permeation

\section{Tests Conducted}

Elevated temperature flow stability, thermal shock, push-out, particle retention, impact and vibration

Graphite helium diffusion (coated; uncoated)

Generator argon/helium gas leak rate

Generator argon/helium gas mixture performance

Vibration, shock 


\section{Development Test Results}

The results of nuclear safety development tests may be summarized as follows:

(1) Preliminary and development impact tests of 13 full-scale heat sources conducted at $260 \mathrm{fps}$ produced no failures. Table I is a tabulation of individual test results. Since the nominal RTG terminal velocity is in the range of $120 \mathrm{fps}$, an adequate margin was demonstrated by the series of tests.

(2) A fire test was conducted by Sandia Corporation wherein a SNAP 19 RTG containing a preheated IRHS and a preheated bare IRHS were subjected to a JP4/ magnesium fire for 30 minutes. Temperature response and the condition of the IRHS test specimens showed that the graphite heat shield contained the fuel with a wide margin of protection.

\section{TABLE 1}

Heat Source Development Impact Tests

Conditions: Test temperature $=1000^{\circ} \mathrm{F}$ Impact medium = granite

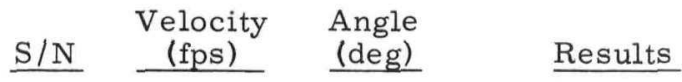

Preliminary Series

$101259.13 \quad 36 \quad$ Passed

$102 \quad 262.37 \quad 29 \quad$ Small transverse surface crack at girth weld; no penetration of capsule wall. Passed

\begin{tabular}{lrrl}
103 & 261.53 & 27 & Passed \\
104 & 258.2 & 22 & Passed \\
& \multicolumn{3}{c}{ Development Series } \\
201 & 258.4 & 25 & Passed \\
202 & 258.1 & 145 & Passed \\
203 & 257.6 & 48 & Passed \\
204 & 253.5 & 152 & Passed \\
205 & 255.6 & 13 & Passed \\
206 & 257.1 & 143 & Passed \\
$207 *$ & 260.8 & 0 & Passed \\
501 & 258.0 & 171 & Passed \\
502 & $\mu 58.7$ & 150 & Passed
\end{tabular}

*Aged at $1470^{\circ} \mathrm{F}$ for 100 hours.
(3) Mach 20 wind tunnel tests (56 shots) of an $80 \%$ scale model heat source provided static and moments coefficients for the total angle of attack from 0 to 170 degrees and for roll angles of 0,30 , 60 and 90 degrees. Static coefficients and pitch and roll moments were in general agreement with theory. Yaw moments were different from theory in magnitude and sign. Re-entry motions are therefore not expected to differ appreciably from the theoretical coefficients used in the analog analyses.

(4) Instrumented plasma arc tests of nine full-scale heat sources showed good correlation with aerothermal analyses. One test specimen, exposed to the low probability side-on stable re-entry mode for analytical data correlation cracked at the thread relief in the graphite heat shield. Cracking was attributed to one or more of the following:

(a) Excess application of graphite cement at the joint, preventing normal thermal expansion

(b) Large temperature gradients associated with the side-on-stable test mode

(c) Over-exposure of the graphite to molten Haynes - 25 through removal of threads from the female joint to facilitate installation of test instrumentation.

(Later side-on stable tests showed the crack was peculiar to the particular test specimen. )

Full-scale heat source plasma arc design verification tests at orbital decay re-entry conditions for the side-on spin mode were completed on nine additional noninstrumented models without a failure or adverse condition. Six of the units contained all components and treatments of the selected flight system. Sequential test exposure, including prepressurizing to simulate a blocked capsule filter vent, aging at operating temperature for 180 hours and vibration were conducted on two units prior to plasma test.

(5) A materials development program for protective barrier coatings on the graphite heat shield and tantalum canister were conducted which resulted in the selection of $\mathrm{ZrO}_{2}$ on a multilayer substrate of $\mathrm{Ta}-\mathrm{Mo}-\mathrm{ZrO}_{2} / \mathrm{Ta}$ for 
graphite and $\mathrm{ZrO}_{2}$ on a substrate of $\mathrm{Ta}$ for the tantalum canister. Hot fuel tests were ultimately conducted at Mound Laboratory to demonstrate the final configu ration in furnace temperature excursion tests.

(6) A series of four IRHS free-fall drop tests were conducted by Sandia Corporation to determine the dispersion of a finely divided fuel simulant on impact with hard packed earth and a softer dry lake bed. In the case of the dry lake bed, the fuel simulant for both heat sources, after free-falling from a 10,000-foot drop altitude to the 5000-foot altitude terrain, remained within the three- to four-inch deep cratered outline of the graphite heat shield fragments. Two other IRHS units, dropped under similar conditions onto hard packed soil, dispersed the simulated fuel less than 20 feet.

The results of structural and performance integrity development tests are summarized as follows:

(1) Capsule filter vent tests for the selected zirconium oxide element have produced no negative results in terms of particle retention, flow stability, pushout, thermal cycling, vibration and impact in tegrity. Tests conducted are summarized in Fig. 5 and a cross section of a typical filter assembly is shown in Fig. 6 .
(2) Helium diffusion tests of coated and uncoated graphite specimens showed that diffusion rates are four orders of magnitude above the fuel decay helium production rate $\left(3 \times 10^{-5} \mathrm{~cm}^{3} / \mathrm{sec}\right.$ STP $)$ at pressures of 5 to $10 \mathrm{psig}$.

(3) Graphite vacuum bonding tests (4 units) to demonstrate compatibility of the ATJ graphite heat accumulator block and the AXM-5Q graphite heat shield in direct pressure contact showed no bonding or interaction at an operating temperature of $1500^{\circ} \mathrm{F}$ and vacuum of $10^{-6}$ torr after one week exposure.

(4) Hard-mounted vibration and shock tests on full-scale heat sources ( 7 vibration test sequences; 1 shock test sequence) verified design of tantalum compliance pads. Capsule response accelerations during early tests of candidate compliance materials reached over $100 \mathrm{~g}$ on several occasions without cracking or damage to the graphite heat shield.

(5) RTG housing helium/argon leak tests showed that the helium leak rate was about three times greater than the argon leak rate and was directly proportional to gas partial pressure.

(6) RTG performance tests with helium/ argon mixtures provided performance data reference for the predictions given in Table 2.

TABLE 2

Predicted SNAP 19 Generator Nominal Performance with IRHS*

\begin{tabular}{|c|c|c|c|c|c|}
\hline \multirow[b]{2}{*}{ Event } & \multirow[b]{2}{*}{$\begin{array}{l}\text { Cumulative Time } \\
\text { After Generator } \\
\text { Fueling (mo) } \\
\end{array}$} & \multicolumn{4}{|c|}{$\begin{array}{c}\text { Initial Generator Gas Fill } \\
\text { of } 100 \% \text { Argon }\end{array}$} \\
\hline & & $\begin{array}{l}\operatorname{Argon}^{2} \\
\text { (psia) } \\
\end{array}$ & $\begin{array}{c}\text { Helium }^{2} \\
\text { (psia) }\end{array}$ & $\begin{array}{l}\mathrm{T}_{\mathrm{HJ}} \\
\left({ }^{\circ} \mathrm{F}\right) \\
\end{array}$ & $\begin{array}{c}\operatorname{Po}^{1} \\
\text { (watts(e)) } \\
\end{array}$ \\
\hline New generator & 0 & 14. 7 & 0 & 920 & 30.0 \\
\hline $\begin{array}{l}\text { After flight } \\
\text { acceptance } \\
\text { testing }\end{array}$ & 2 & 12.5 & 2.0 & 905 & 27.8 \\
\hline $\begin{array}{l}\text { After } 10 \text { months } \\
\text { of storage }\end{array}$ & 12 & 11.7 & 7.4 & 876 & 24.6 \\
\hline $\begin{array}{l}\text { After } 1 \text { year } \\
\text { in orbit }\end{array}$ & 24 & 6.5 & 7.3 & 864 & 20.7 \\
\hline $\begin{array}{l}\text { After } 2 \text { years } \\
\text { in orbit }\end{array}$ & 36 & 4. 7 & 7.3 & 852 & 18.0 \\
\hline
\end{tabular}

Notes:

${ }^{1}$ All powers are with generator housing fin temperature root of $337^{\circ} \mathrm{F}$.

${ }^{2}$ Based on fuel decay helium generation rate $3.1 \times 10^{-5} \mathrm{~cm}^{3} / \mathrm{sec} \mathrm{STP}$.

*All values are for one generator; multiply by two for system performance. 
(7) Heat source vibration and acceleration prototype level tests using tantalum compliance pads in an unheated RTG subsystem configuration were completed. Disassembly inspection revealed no damage to the heat source graphite heat shield or loosening of the fuel capsule.

\section{Development Problem Areas}

Success of the IRHS program can be mainly attributed to selection of a design approach which was configured upon a sound development technology base and the provision in detail design to accept relatively large tolerances for machining, deep drawing of capsule components, TIG welding and coating of detail parts. By teaming the vast knowledge of the AEC, Sandia, ML and other AEC laboratories in this intensive effort, a basic design concept was evolved and developed without change from program inception except for the filter vent element. Here, a physically interchangeable switch from a Haynes -25 powder pressed element to a zirconium oxide element was necessitated due to interstitial oxidation of the Haynes-25, thereby causing short term close-down of the finite but torturous helium gas flow path.

Other than the above, the more significant problem areas centered around the development of:

(1) Protective barrier coatings and procesșes thereof

(2) Detail processing and metallurgically affixing of the $\mathrm{ZrO}_{2}$ filter vent element to the filter housing

(3) Capsule/heat shield compliance for differential thermal expansion and environmental structural integrity

(4) Heat shield/fuel capsule assembly process development, a ML fueling facility operation.

\section{QUALIFICATION AND FAILURE MODE TESTS}

Following the development test program, several other tests were conducted to qualify the heat source for flight. In addition, some tests were conducted to determine the effect of certain component failures on the heat source or to determine the effect of overtest. Since the prime safety objective was to prevent atmospheric dispersal of the fuel during re-entry, all failure modes and overtesting were designed to determine the effect on the graphite heat shield.

\section{Heat Source Impact Test}

Following the successful development impact testing of 13 intact re-entry heat sources at various selected impact angles between the filter assembly end to the fuel fill port end, two additional heat sources were impacted which contained the newly developed $\mathrm{ZrO}_{2}$ filter element in the Haynes25 capsule.

Since all previous impact tested capsules had shown no evidence of helium leakage following the test, this test was designed to determine the adequacy of the $\mathrm{ZrO}_{2}$ filter to contain the fuel in the event of impact. Figure 7 is a view of several impacted development capsules showing typical deformations. The hole shown in the side of some is for post-test helium leak checking.

One of the heat sources was impacted at approximately 8 degrees and the other at 21 degrees from head-on. Following the impact test both capsules showed no detectable helium leak in the shell. Both $\mathrm{ZrO}_{2}$ filter assemblies had a helium diffusion rate in the $10^{-2} \mathrm{scc} / \mathrm{sec}$ decade with an applied pressure between 1 and $10 \mathrm{psia}$. This value is comparable with the pre-impact values. Filter assembly particle retention tests were also successfully passed with the use of 0.1 to 0.5 micron size $\mathrm{UO}_{2}$ particles spiked with a Sr-90 tracer. These specially prepared particles are considerably smaller than the 50-250 micron $\mathrm{PuO}_{2}$ particles and constitute a conservative test.

\section{Heat Source Barrier System Tests}

Numerous $\mathrm{ZrO}_{2}$-coated tantalum canisters and graphite crucibles were used in developing the barrier system which is designed to prevent the molten Haynes-25, should it occur, from attacking the graphite heat shield. Following development of the barrier system, a total of 13 intact re-entry heat sources were subjected to plasma arc tests simulating various re-entry conditions. Six of the heat source specimens were tested under a side on-spinning mode and the remaining seven were tested at a side on-no spin mode. There was no evidence of Haynes-25 escaping from any of the models.

\section{IRHS Tests with Pressurized Capsules}

The filter element originally chosen for the IRHS was a pressed and sintered Haynes -25 powder. This element showed rapid reduction of the helium flow rate when exposed to oxygen bearing environments at $1450^{\circ} \mathrm{F}$. While filter element redesign 
and development was in progress on the $\mathrm{ZrO}_{2}$ element, a series of burst tests was designed and completed to investigate the results of a continuous pressure increase in an IRHS capsule. The primary objective of these tests were to determine the probable effect of capsule failure on heat shield integrity resulting from a slow increase in pressure. Three specimens were tested under nonre-entry conditions: two as bare capsules and one as a complete heat source assembly. In each case the capsule failed because a slow leak developed through the longitudinal microcracks in an area of local yielding. The IRHS assembly specimen showed no adverse effects on the heat shield due to capsule rupture, and the oxide coatings on the heat shield and tantalum canister were in excellent condition.

Four plasma arc test IRHS assemblies were made and tested with helium pressurized capsules to demonstrate that rapid heating and sudden release of the gas pressure would not compromise the integrity of the heat shield. Capsule pressures were set to simulate the helium pressure due to radioisotope decay for approximately seven months after complete filter blockage. In two of the tests the capsule melted, releasing helium at approximately 500 psi. No heat shield failure resulted. The other two assemblies, tested with lower total heat input, did not result in the capsule melting but gammagraphs showed that the capsule did assume the general contour of the heat shield without causing heat shield damage.

\section{IRHS Prototype Qualification and Revibration \\ Testing in Fueled RTG}

Two fueled IRHS assemblies completed prototype qualification testing as a component within SNAP 19 RTG Subsystem 6A. (Two generators stacked in tandem on a support assembly.) The test consisted of random and sinusoidal vibration in three axes, acceleration in the yaw axis and thermal vacuum testing for approximately 300 hours. Inspection of the heat sources and the generators revealed no damage to either as a result of the overstress type test. One of the fueled heat sources was reinstalled in a generator and the assembly subjected to flight acceptance level vibration in each orthagonal axis. Subsequent diagnostic disassembly of both IRHS assemblies to the component level showed that the graphite heat shield was undamaged as a result of the overtest.

Plasma Arc Side On-Stable Design Verification Test

Four graphite heat shield assemblies were returned to the Nuclear Systems Division, following defueling, for plasma arc verification testing.
Two of the heat shield assemblies had been exposed to flight acceptance testing in RTG Subsystem 8 and the remaining two had been subjected to prototype qualification tests in RTG Subsystem 6A. One heat shield from each generator subsystem was reassembled with a dummy Haynes -25 capsule (containing $\mathrm{ZrO}_{2}$ powder as a fuel simulant) and

subjected to plasma arc tests in a side on-stable mode under an Agena I abort condition. The remaining two heat shields were subjected to the same type of plasma arc test but the heat flux and test duration were adjusted to simulate an orbital decay condition.

The success of these four tests demonstrated the capability of the IRHS heat shield to contain the inner constituent materials even under a worse case side on-stable re-entry condition. There was no evidence of inner constituents being lost from the graphite shield as evidenced by visual and weight change observations. Further, careful examination revealed no cracks in the heat shield as a result of the imposed thermal gradient. Figure 8 is a view of a sectioned heat shield which was subjected to side on-stable testing at orbital decay conditions. Note the graphite recession on the stagnation side.

\section{Extended Plasma Arc Test of IRHS to Failure}

One plasma arc specimen* was subjected to a planned test to failure to derive an understanding of the margin of safety under orbital decay side onstable conditions. The heating rate from the plasma arc was increased in steps to $250 \mathrm{Btu} / \mathrm{ft}^{2}-\mathrm{sec}$ after a period of 50 seconds, but for this test the peak heating rate was maintained for 710 seconds. Figure 9 is a family of curves showing: the predicted heating rate curve for an IRHS assembly reentering from orbit in a side on-stable mode; a stepped heating rate outline for test simulation; and, a dotted line extension at the peak rate to show the imposed overtest.

The IRHS specimen did not completely fail even at this extended overtest condition. There was evidence that some Haynes -25 was being released from the heat shield after approximately $490 \mathrm{sec}-$ onds at the peak heating rate ( 1820 seconds into the test), but post-test examination led to the conclusion that little or no fuel would have been released from the graphite container, even at the time of test termination. The test indicated a large margin of safety against an atmospheric release of the $\mathrm{PuO}_{2}$ fuel inventory.

*Previously subjected to a side on-spinning orbital decay plasma test in which there was approximately 0.043 graphite recession. 


\section{CONCLUSIONS}

It has been demonstrated, both by analyses and tests, that the heat source developed for the SNAP 19 system will:

(1) Contain the fuel during all operational and abort conditions wherein no aerodynamic heating has occurred

(2) Prevent atmospheric dispersal of the fuel prior to Earth impact subsequent to aborts wherein sensible aerodynamic heating has occurred.

(3) Minimize chemical reactions among the heat source component materials during re-entry and after earth impact.

Hence, the design objectives have been met with a very high probability of system success.

Details of the design which led to a flightqualified heat source include a continuously vented capsule that prevents pressure failures during all operations including re-entry, a ceramic-coated tantalum canister which delays exposure of the molten Haynes -25 to the graphite re-entry body material, a ceramic coated multilayer barrier having metal-like structural properties which prevent chemical reaction between molten Haynes-25 alloy and the heat shield body, and an external graphite re-entry body which is capable of sustaining aerothermodynamic environments while maintaining containment of the isotopic inventory during all adverse abort conditiond including the highly improbable side on-stable re-entry mode. 

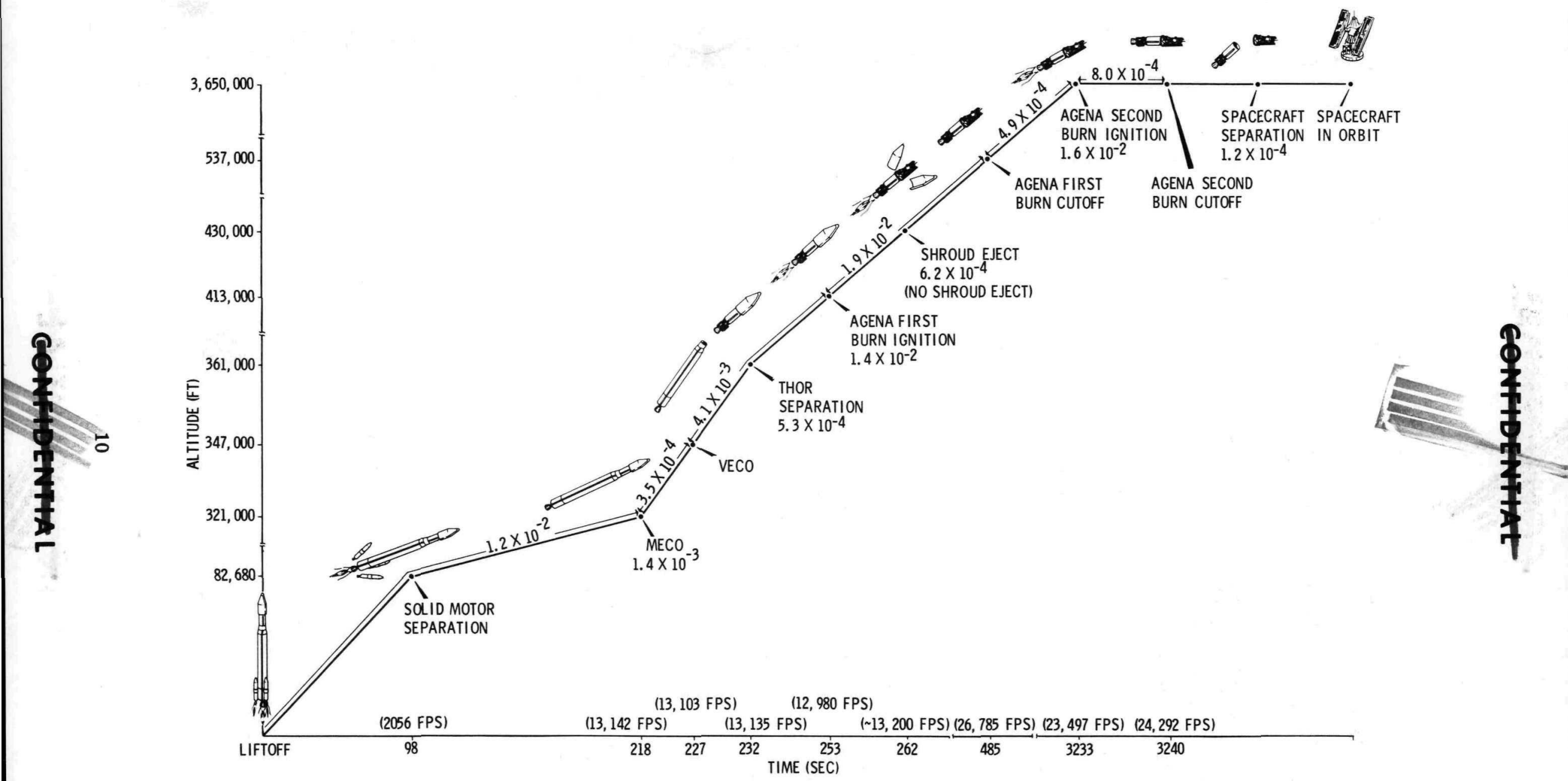

FIG. 1. SNAP 19/NIMBUS B FLIGHT ARRAY 


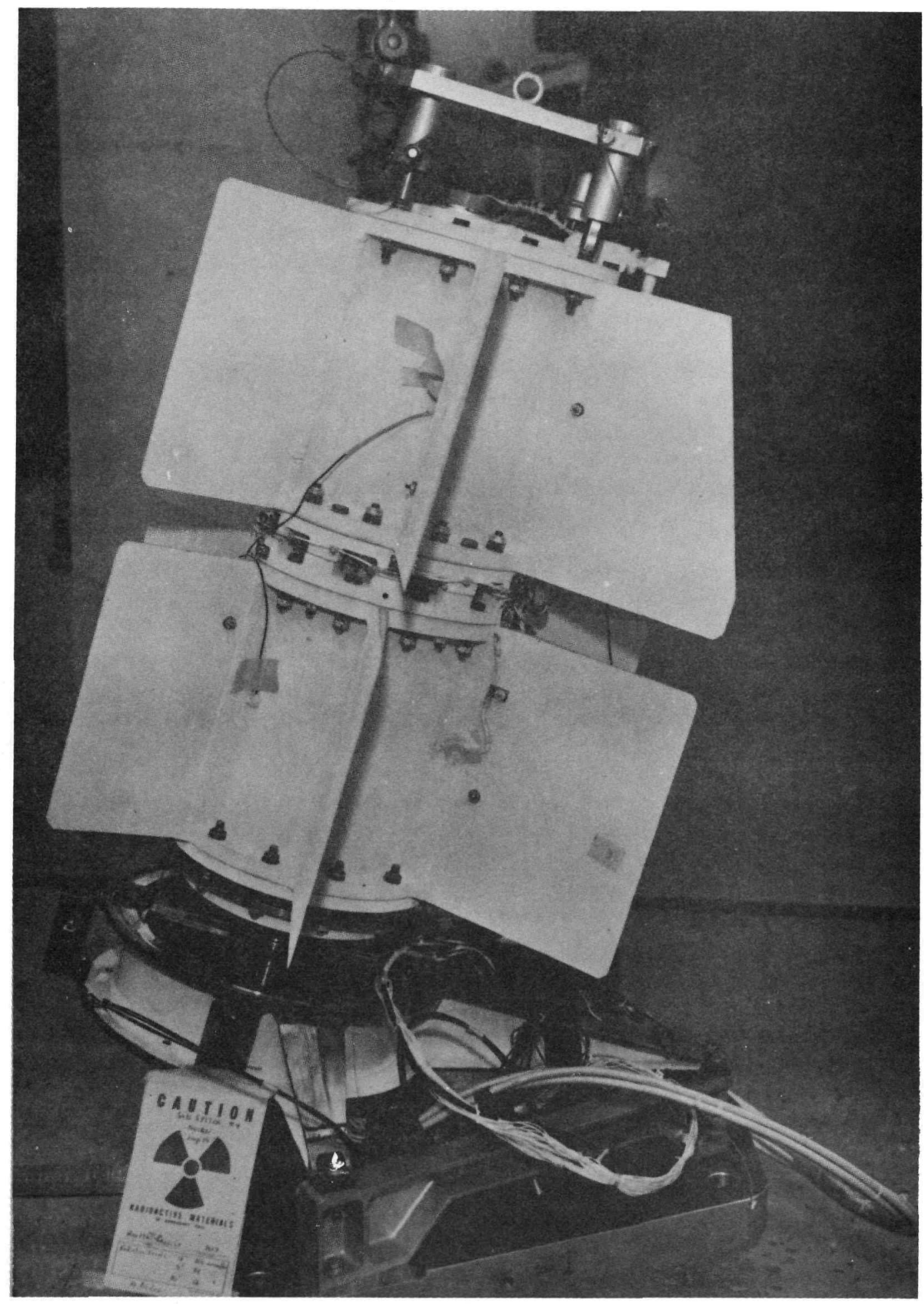

FIG. 2. SNAP 19B 

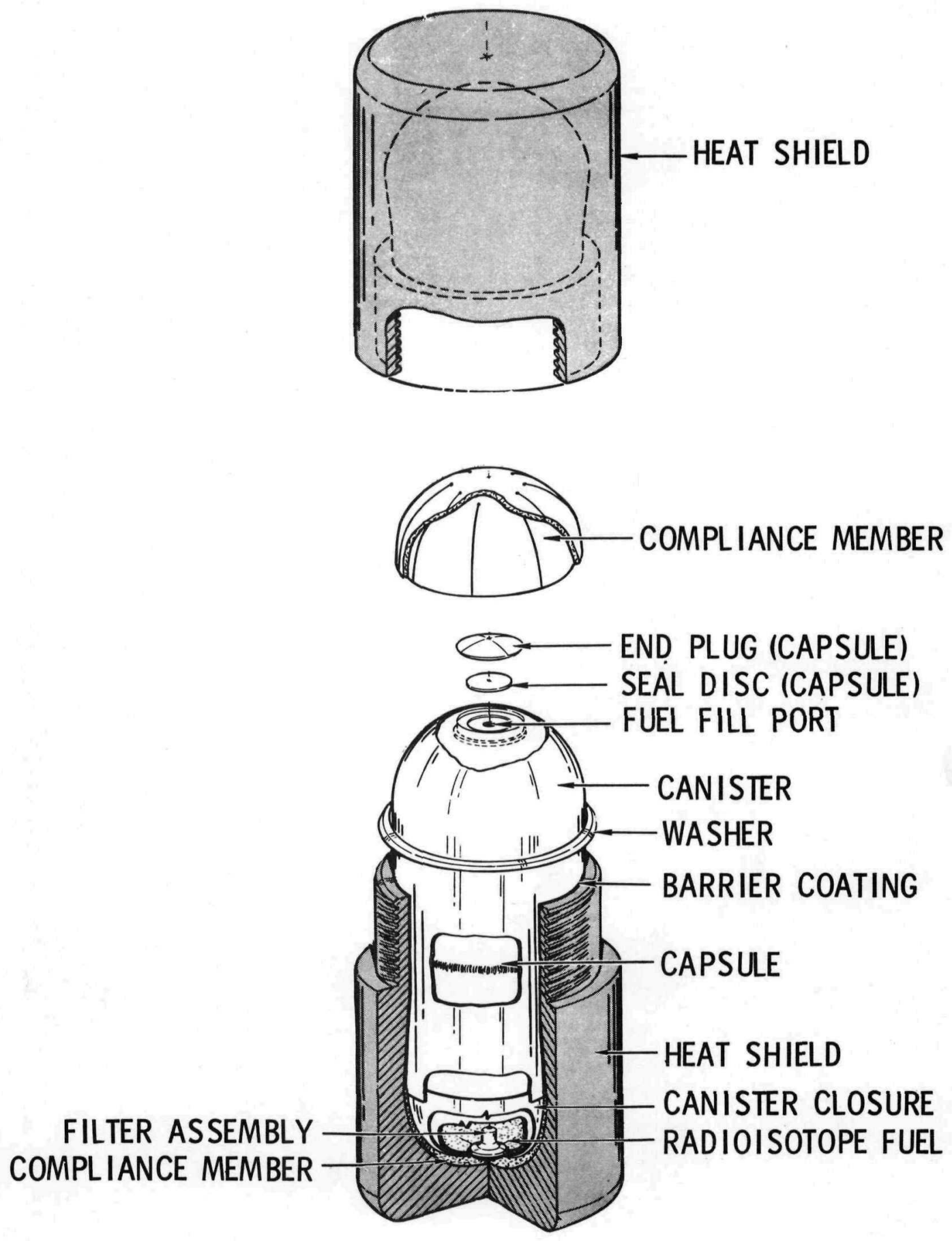

FIG. 3. IRHS OVERALL VIEW 


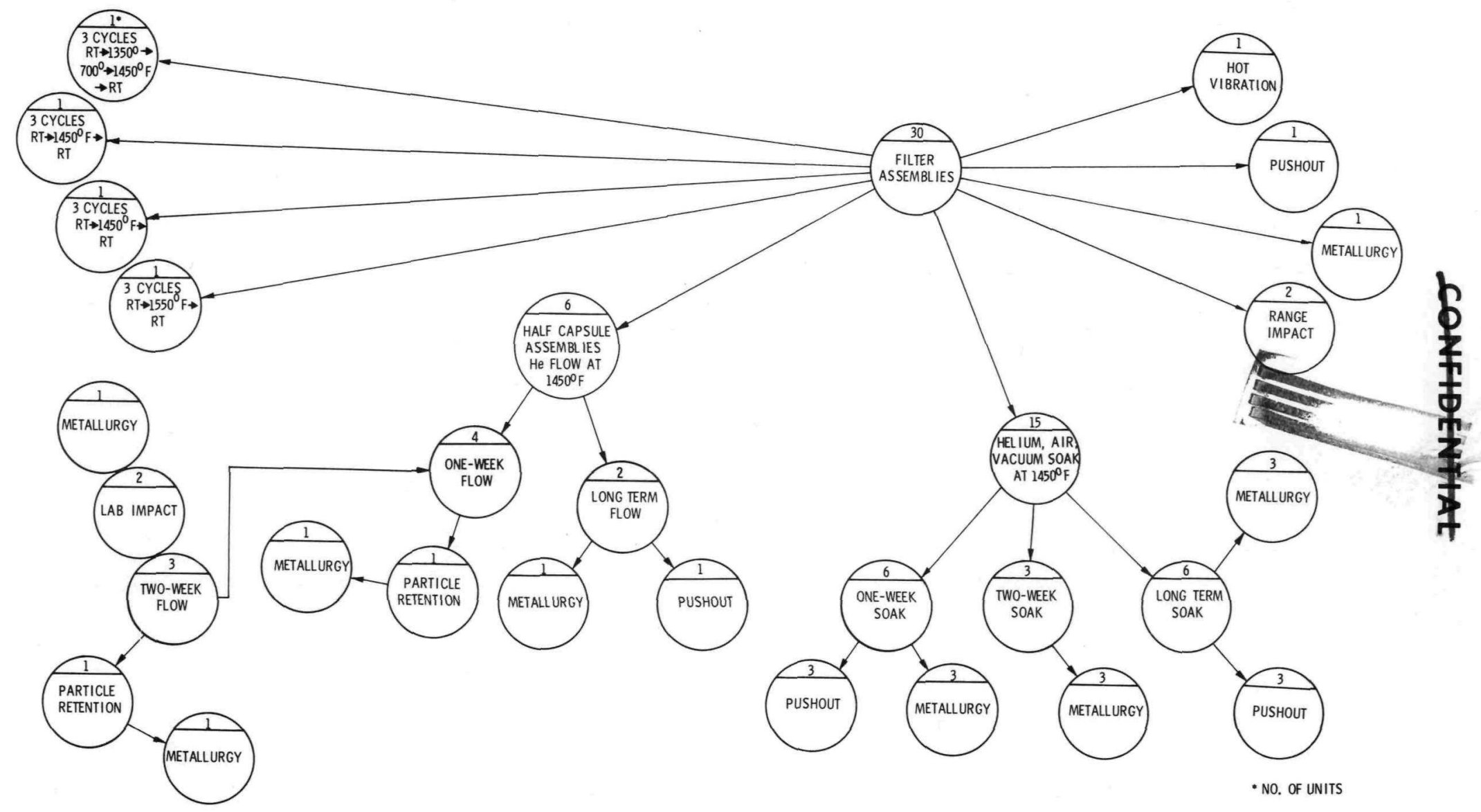

FIG. 5. $\mathrm{ZrO}_{2}$ FILTER DEVELOPMENT PROGRAM 


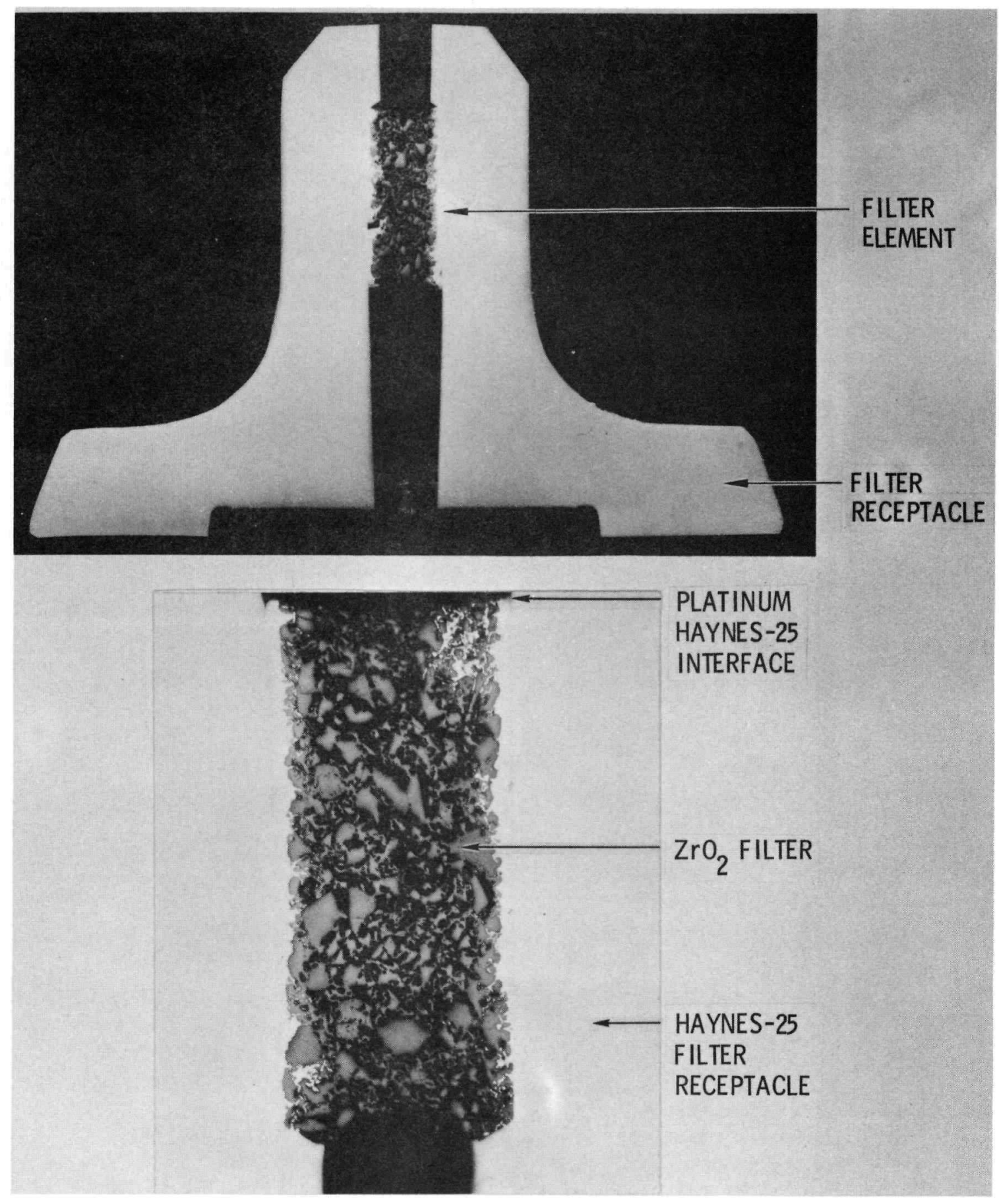

FIG. 6. SECTION THROUGH FILTER ASSEMBLY 


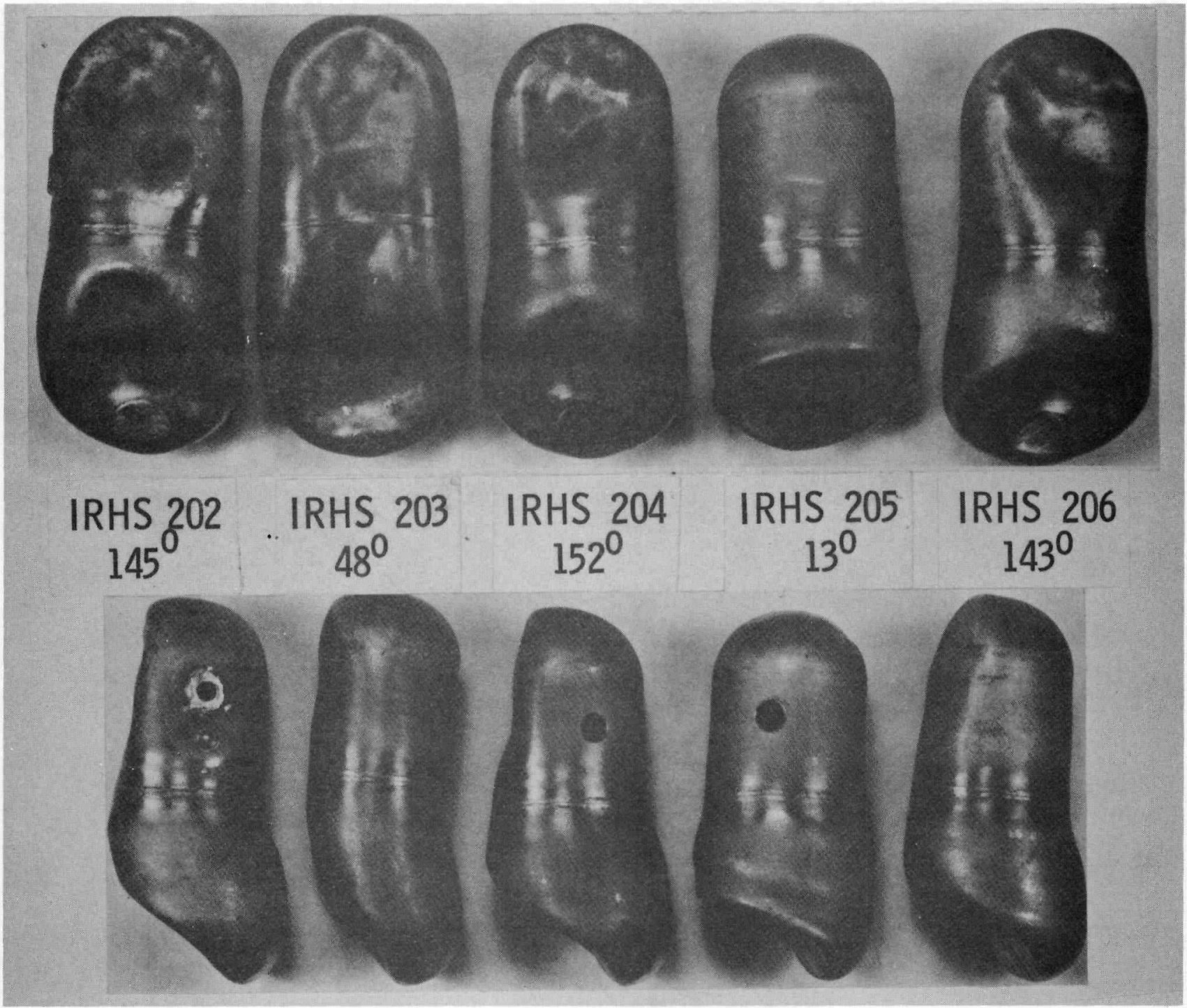

FIG. 7. TWO VIEWS OF IRHS CAPSULE IMPACT SPECIMENS 

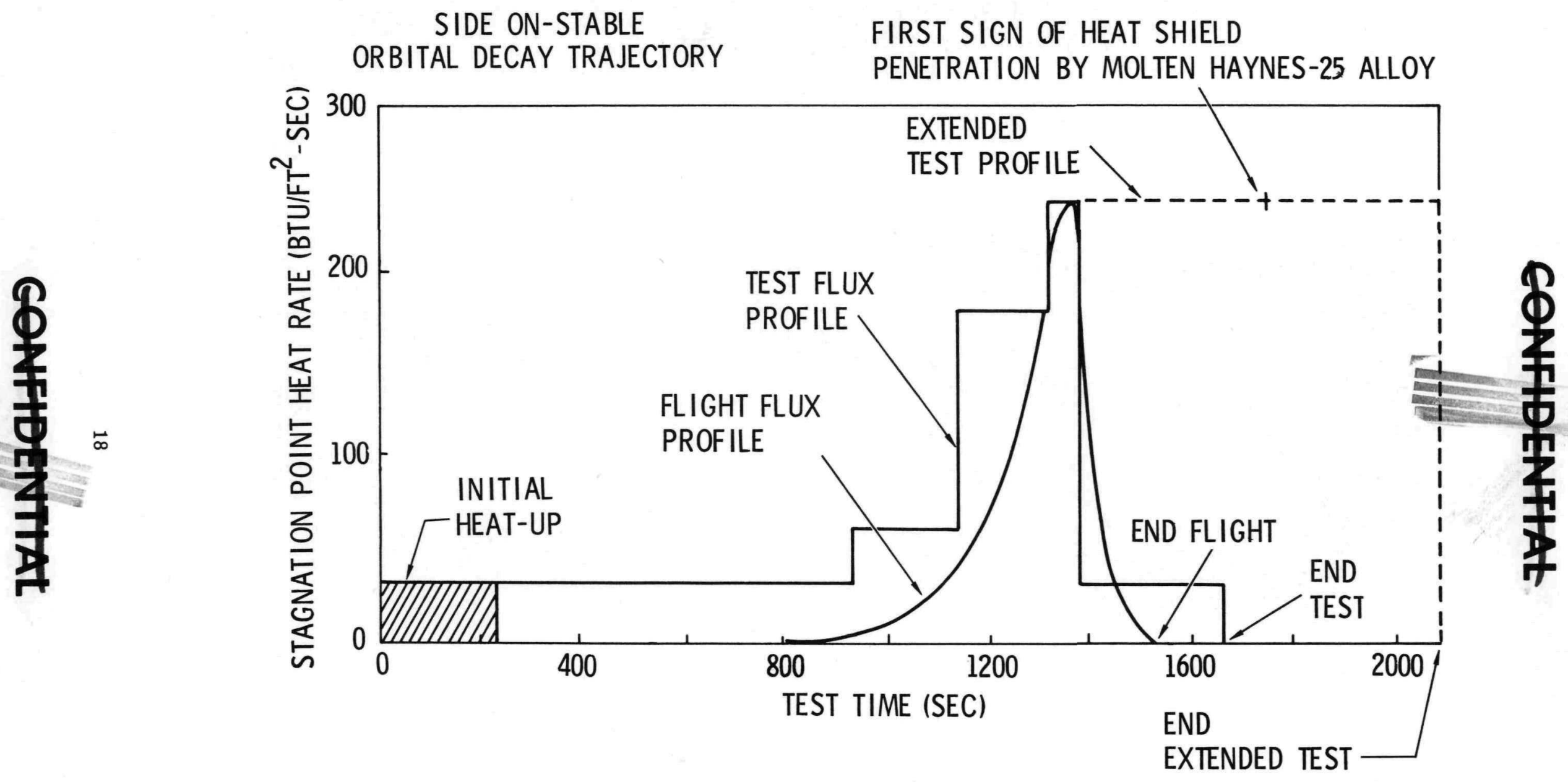

FIG. 9. PHASE II SNAP 19 IRHS PLASMA ARC TESTS 


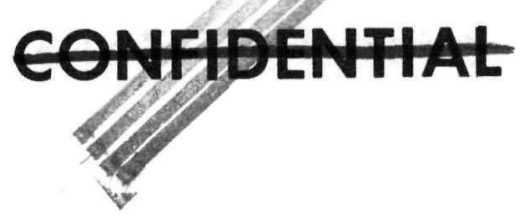

SNAP 19 AEROSPACE NUCLEAR SAFETY EVALUATION*

\author{
W. B. Weber and T. W. Conway \\ Nuclear Systems Division, Isotopes, Inc. \\ Middle River, Maryland 21220 \\ and \\ J. J. Jicha, Jr., USAEC, Washington, D. C.
}

\section{SUMMARY}

To evaluate the acceptability of radioisotope applications it is necessary to determine the response of the system to both planned and unplanned environments that lead to interactions with the population. The aerospace nuclear safety analysis of the SNAP 19 Intact Re-entry Heat Source (IRHS)/Nimbus B mission employed a quantitative assessment of risk which consisted of combining potential hazardous accidents, the associated dose rates and the effect on the population into a single evaluation parameter. This approach places environmental, ecological and biological response characteristics into relative perspective by utilizing accident occurrence and fuel release probabilities in conjunction with fuel transport mechanisms and statistically based dose determinations. The biological response to the calculated dose is presented consistent with the ICRP recommendation for nuclear programs. Advantages of this approach are that the high risk events are identified in time to affect remedial design action and a single hazard parameter can be developed that can be compared to the safety criterion established for the mission. The aerospace nuclear safety study has demonstrated the feasibility of the intact re-entry heat source to preclude the atmospheric release of the SNAP 19 fuel form.

\section{INTRODUCTION}

\section{Background}

The Nimbus B/SNAP 19 application marks the first use of a nuclear power system in a NASA spacecraft. The SNAP 1919 system augments the spacecraft solar array and battery power supply, and is defined by NASA as "... an experiment to assess the operational capability of radioisotope power for long-life meteorological satellites."

The generator subsystem includes two genertors mounted in tandem and is attached to the

*Work conducted under USAEC Contract (30-1) 3607 by Isotopes, Inc. sensory ring of the Nimbus B spacecraft as shown in Fig. 1. Upon burnup of the generator housing during abort or re-entry, disassembly of the radioisotopic thermoelectric generator (RTG) follows with subsequent exposure of the heat source to aerodynamic heating. The radioisotope fuel is a form of plutonium-238 microspheres.

Recognizing the inherent passive reliability of aerothermodynamic destruction, a dispersal design was initially considered. Comprehensive ANS studies were performed to determine the possible hazard consequences of an atmospheric release of fuel during abort or re-entry. It was determined that the acceptability of the system would be enhanced if the heat source were instead designed for intact re-entry in order to reach the surface of the Earth while maintaining containment of the fuel. The resultant IRHS design is the subject of this paper. The paper illustrates the coalescence of such disciplines as aerophysics, aerothermal and hazards analysis into a probabilistic framework that permits objective decisions of the kind described above. This approach also enables the definition of system design objectives early in the development of the program.

\section{$\underline{\text { Design Criteria }}$}

For the Nimbus B/SNAP 19 configuration and mission, primary safety objectives were established and are reflected in the design. Specifically, the SNAP 19 heat source is designed to:

(1) Preclude dispersal of the fuel subsequent to a Nimbus B launch abort and resulting Earth impact, wherein no sensible aerodynamic heating has occurred, by containment within the Haynes- 25 capsule.

(2) Prevent atmospheric dispersal of the fuel prior to Earth impact subsequent to a Nimbus B abort or short-lived orbit wherein sensible aerodynamic heating has occurred.

(3) Minimize chemical reactions among the heat source component materials, 


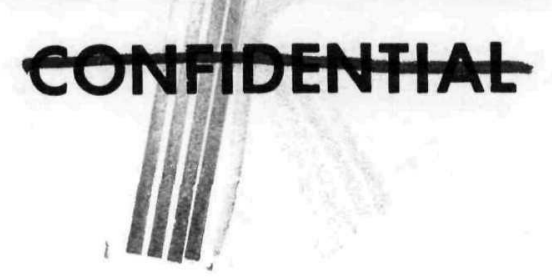

during re-entry and after Earth impact, which could increase the potential hazards.

\section{Design Description}

The heat source shown in Fig. 2 makes use of a capsule that is continuously filter-vented in order to retain even submicron size fuel particles yet eliminating pressure failures dueing operation, re-entry or abort conditions. The capsule is contained within a tantalum canister that is internally barrier-coated and acts in concert with an internally barrier-coated re-entry body to minimize chemical reactions that could lead to atmospheric release of fuel or undesirable postimpact chemical products. The capsule/canister assembly is nested between compliant members at each end when placed within the graphite reentry body. The graphite provides an aerothermodynamic capability during re-entry or abort, thereby maintaining containment of the isotopic inventory until impact.

The generator itself consists of a right circular cylinder housing that is $6-1 / 2$ inches in diameter and 10-3/4 inches high. The radiating surface is increased by the addition of six fins which give the unit an overall effective diameter of 22 inches.

\section{Mission Profile}

For most space nuclear applications, the mission can generally be profiled into what amounts to five basic operational phases. These phases are:

(1) Transportation

(2) Launch pad

(3) Preorbit

(4) Orbit

(5) Post-orbit.

The SNAP 19 generator subsystem will be transported in its shipping container by AEC courier van over public roads. The consequences of truck accidents yielding environments of capsule impact, fire, puncture, Earth burial and chemical attack were evaluated.

The launch pad phase includes activities during the period initiated by the fueling of the
Thorad vehicle through several seconds after launch. During this period any catastrophic abort is assumed to result in pad deposition with fireball, impact and residual fire comprising the characteristic environment.

The preorbit phase begins several seconds after launch and continues to the attainment of orbital velocity. In this phase the critical typical environments are aerothermally induced and consist of abort conditions (high heat flux, low integrated total heat input) through orbital decay conditions (low heat flux, high integrated heat input) (Fig. 3).

The orbital phase includes the period of flight after initial orbit is achieved but before the desired mission orbit has been realized. Similar abort and orbital decay thermal environments are considered as were preorbit, with emphasis on orbital decay.

The post-orbit portion of the profile is of primary interest since this is the design mode. Orbit duration in excess of 1600 years can be anticipated, and indicates that materials deterioration will significantly influence the hazard consequences that are predicted.

\section{METHODOLOGY}

\section{General Approach}

The objective of this evaluation is to determine the effect to be expected on population groups as a result of using the SNAP 19 generator for the Nimbus B mission. Recent papers (Refs. 1, 2 and 3) have emphasized the nondeterministic nature of both cause and effect of incidents involving radiobiological exposures. The need, therefore, is to assess within the present limits of knowledge the risk involved in the aerospace nuclear application and to adjudge whether the potential benefits justify this risk.

In order to evaluate the risk associated with the safety of the Nimbus/SNAP 19 system it is necessary to determine the ultimate disposition of the fuel for nominal and abort situations. In the nominal re-entry from orbital decay, it is necessary to study the aerodynamic heating environment experienced by the RTG throughout the re-entry assuming a satellite/RTG initial configuration. If the Nimbus starts to breakup before destruction of the SNAP 19 releases the fuel capsules, the successive partial Nimbus configurations must be analyzed until such time as the hea 
sources are released. Thence, the flight of the heat sources must be studied until intact impact or the fuel is released, and then, of course, the flight of the fuel must be studied.

There are several possible partial Nimbus configurations which must be considered. These various configurations may result depending upon the flight motions experienced by the Nimbus. For example, if the Nimbus tumbles or oscillates through a large angular range the solar panels may disintegrate due to aerodynamic heating and/ or the struts between the sensory ring and control housing may fail and result in a configuration consisting of the sensory ring with the SNAP 19 attached. On the other hand, if the Nimbus flies with the sensory ring forward and performing small oscillations, the SNAP 19 will experience very little heating and the thermal breakup of the sensory ring must be studied to determine when the SNAP 19 is released. For various abort situations, such as explosion of the Agena during either the first or second burn phase, it is conceivable that the Nimbus may be released with the solar panels in their stowed position or that the SNAP 19 or the heat source may be freed due to the action of shrapnel. Thus, it is apparent that several possible configurations having quite different aerodynamic characteristics must be studied. In addition, there are a large number of conceivable abort situations which may occur at various times while the vehicle is traversing any one of many possible trajectories.

For the abort cases each of the configurations must be studied for each abort point, while also considering that the motion history of a body reentering the atmosphere depends on the initial motions present at the start of the re-entry. This also applies when a configuration change occurs during the flight, such as when the Nimbus support struts fail or when the heat source is released from the generator. During the destruction sequence of a re-entering body, its aerodynamic characteristics, and therefore, its motions will vary drastically. Because it is impossible to simulate analytically the complex breakup process of the satellite, the initial conditions of motion for each subsequent configuration are undetermined. To study the destruction process, a number of initial conditions must be selected arbitrarily so that the sensitivity of the re-entry dynamics to these initial conditions can be evaluated.

It is apparent that the combination of the number of trajectories, confiruations, abort points and initial conditions of motion amounts to a very large number of trajectory computations (runs on a analog/digital hybrid computer)-literally thousands for the complete set.

The aerodynamic heating experienced by the SNAP 19 and the heat source during re-entry from nominal orbital decay and due to the various possible abort situations is of course the primary parameter of interest. The heating is a function of the trajectory parameters and of the motions experienced by the body as it re-enters. The motions, produced by the initial conditions and modified by the aerodynamic characteristics, determine the manner in which the heating is distributed on the body, and also, the effective aerodynamic drag which in turn influences the trajectory. Thus a reasonably regorous analysis of these devices requires that the six-degree-offreedom aerodynamic characteristics be determined and employed in a six degree-of-freedom trajectory analysis. In the case of the Nimbus configuration with the extended solar panels free to rotate, seven degree of freedom are presumed.

It should be obvious that the configurations of interest to this study are by no means what might be termed "aerodynamic shapes." Even for socalled aerodynamic shapes present theory is very limited for predicting aerodynamic characteristics and aerodynamic heating rate distributions. Thus it is customary for the flight dynamicist, whenever possible, to obtain basic aerodynamic characteristics for his configuration from wind tunnel tests, and indeed, more often than not, to obtain redundant data from several facilities in order to increase his confidence in the data. During this study the aerodynamic characteristics and aerodynamic heating distributions were obtained experimentally (see Fig. 4 and Refs. 4 through 15) for most of the configurations of interest. In a few cases, redundant data have been obtained. The measurements were conducted in a variety of facilities. Certain basic information, such as the aerodynamic characteristics of the heat source in free molecular flow, which could not be measured experimentally, were calculated using theoretical procedures. For the larger configurations (Nimbus, SNAP 19) which spend sometime during re-entry in the transitional flow regime, the lack of experimental facilities and applicable theoretical procedures necessitated the use of continuum flow experimental data throughout the trajectories. The procedure involved the computation of trajectories for all of the configurations appropriate for the nominal orbital decay mission and for the abort situations discussed 
below in six degrees-of-freedom (seven for Nimbus with solar panels extended). A few were based on constant ballistic parameters $\left(W / C_{D} A\right)$, such as these that prevail with the end-over-end tumbling or side on stable flight mode. In conjunction with stagnation point heating rate on a unit sphere, surface averaging factors, consistent with the flight motions, are used to describe the thermal environment. The thermal environment is then used with appropriate analytical thermal models to predict failure times of each configuration. Correlation of the failure times with the trajectories yields the sequence of breakup and ultimately the fuel release locations (in space) and flight conditions--velocity, altitude, flight path angle--for use in the fuel hazard analysis. Also determined via this process, are the intact and partial burnup zones on the Earth's surface.

Figure 4 shows the interaction of the various technical disciplines required to define the ultimate disposition of the fuel which is fundamental to determine its biological effect on people. In order to reduce this task to a manageable size and still cover the full range of breakup and fuel release conditions, the following representative abort cases were studied.

The tabulation of the nominal, $3 \sigma$, headwind and crosswind launch trajectories were provided by Lockheed Missiles and Space Company (LMSC) as well as the sequence of events for the Nimbus B mission as presented in Ref. 16. In Ref. 17, LMSC reports on an extensive investigation of all possible malfunctions and their probabilities. From this study the malfunctions have been lumped into the following five categories:

(1) Agena assumes incorrect attitude at first burn

(2) Agena first burn thrust terminates prematurely

(3) Agena explodes during first burn

(4) Agena assumes incorrect attitude at second burn

(5) Agena explodes during second burn.

For Items 1, 2 and 4, it has been assumed that the configuration of immediate interest is the Agena/Nimbus/SNAP 19. If the support struts fail, the configuration becomes Agena/sensory ring/SNAP 19. For Items 3 and 5, no rational way of determining the configuration which might contain the SNAP 19 as the resultant configuration of the SNAP 19 itself is known. However, for the purpose of this study the following configurations have been postulated:

(1) Nimbus (solar panels folded)/SNAP 19

(2) Nimbus (solar panels removed/SNAP 19

(3) Sensory ring/SNAP 19

(4) SNAP 19 generator

(5) Heat source

It is necessary in the probabilistic approach to describe occurrence of malfunctions and the potential initiation of hazards from the system and subsystem standpoints. These events were analyzed sequentially and in detail for two reasons. The first is that this is a true representation of a chronological process culminating in radiobiological exposure. The second is that confidence in the results of a probability determination depends upon use of experimental data or, lacking these, a believable physical model. It is difficult to obtain such confidence for composite events occurring with frequencies of one in a million, for example, unless these events are realistically describable in terms of sequenced events, each having probabilities of one in a hundred or so.

As an example, consider the occurrence of fuel release on the launch pad that might result from exposure of the nuclear system to the severe thermal environment of a fireball. Fuel release, in this case, depends upon creation of the fireball, separation of the heat source from the generator and deposition within the fireball at the proper conditions of heat flux and elapsed time so that enough energy is availabel to destroy containment. The respective probabilities are about $10^{-3}, 10^{-3}$ and $10^{-1}$, yielding a composite occurrence probability of about $10^{-7}$. Despite the fact that the composite probability is quite small, the sequential analysis, in terms of factors which may be measured by finite experiments, yields confidence in the overall probability estimate.

Following initiation of the hazard in terms of uncontrolled release of fuel or fuel capsules, the location of the fuel as a function of space and time coordinates must be determined. If the 
source remains encapsulated, its location must be determined with respect to population groups so that external radiation may be taken into account properly in evaluating public exposure. In the case of released fuel, the surface and volume both external and internal radiative exposures. This portion of the analysis is referred to as the transport phase. This phase deals primarily with the phenomena of gravity-controlled settling of small particles according to empirical fallout data, resuspension and subsequent diffusion from a land dispersion and shallow water diffusion.

A specific concern during the transport process deals with changes in the physical state of the fuel. Nominally, the fuel particles are confined to between 50 and 250 microns in size and are relatively insoluble. If the particles remain in this size range, the chief hazards are expected to be from external radiation and exposures to the gastro-intestinal (GI) tract resulting from direct ingestion and impaction-inhalation of the particles. However, size degeneration through aerodynamic effects on particles which initially settle on land after high altitude release and by comminution of particles as a result of capsule impact can result in potentially more serious pulmonary and lymph exposures. There are few experimental data available predicting the physical requirements of size degradation and consequential particle distributions. Semi-empirical representations have been formulated to evaluate the change-of-state phenomena (Ref. 18).

The penultimate phase of the investigation is that of determining the probabilistics of public exposure. For external radiation from a 10calized source, the roving receptor model developed under the Rover program (Ref. 19) was used. External radiation from small particles was treated by determining the average dose rate at one meter above a fallout field for particles of a given size and, therefore, having a characteristic dose distribution. Since relatively large areas were involved, motion of people was irrelevant; only the total number of people affected was considered.

Representation of the inhalation exposure hazard was necessary. Preliminary evaluations indicated that mean numbers of particles inhaled tended to be small compared with unity so that cases involving two or more particles per individual could largely be ignored. The probabilisics of one-particle dose consequences cannot be valuated conveniently using standard techniques (Ref. 20) which deal with the distribution of activity continuously throughout the body, rather than contained in a single discrete particle. A Monte Carlo technique was developed to treat the motion and residence time of particles in the body regions. Results of the Monte Carlo study were obtained in the form of probability (per particle deposited in specified regions of the body) of exceeding any given dose.

In evaluating ingestion exposures, results were obtained for the consumption of contaminated fish and for particulate residues on leafy vegetables. In the former case, probabilistics were defined in terms of variations from the mean consumption rate and with the dependence of population density on the distance from fishing ports.

The final task is combining the results of occurrence probabilities, activity transport and subsequent radiative exposure to determine the expected number of people to be exposed in excess of a given dose deposition. Knowledge in this area is limited except, perhaps, in the dose region exceeding 100 rems for early and late responses to external whole body irradiation. Consequences arising from all exposure situations for the SNAP 19 mission are determined based on the recommendations of the International Committee on Radiological Protection (ICRP) (Ref. 21).

\section{Occurrence Probabilities}

This evaluation was initiated with the grouping of the potentially hazardous areas into mission phases, e.g., transportation, launch pad operations, preorbit ascent trajectory, orbital decay and post-mission history. The occurrence probabilities for the transportation phase were calculated based on statistical and test data. Three phases were used to describe the flight of the Thorad/Agena vehicle segment of the mission profile. These encompassed preorbit, orbit and post-orbit re-entry. Occurrence probabilities for these phases were based on vehicle reliability data. A summary of accident and abort occurrence probabilities is shown in Table 1.

The abort sequence and associated occurrence probability pertaining to high altitude fuel release are enumerated specifically in Table 2. The representative release conditions listed in Table 2 were determined from aerothermodynamic analyses related to aborts for Agena first burn, Agena second burn deorbit (i.e., a guidance failure resulting in powered re-entry) and orbital decay from a short-lived orbit. 


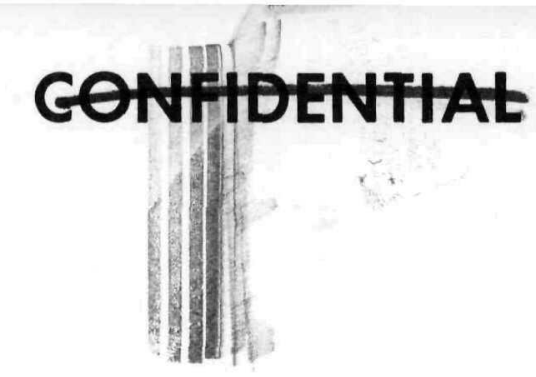

TABLE 2

Occurrence Probabilities for Representative Release Conditions

Release

Condition Case

$1+1$

$2+2$

$3+3$

$4+4$

$5+5$

$6+6$

$7+7$

$8+8$

$9+9$

$10+10$

$11+11$

$12+12$

$1+6$

$2+6$

$3+6$

$4+6$

$1+4$

Cause

Agena first

burn abort

Agena first

burn abort

Short orbit decay

Agena second burn deorbit

Short orbit decay

Agena second burn deorbit

\begin{tabular}{|c|c|c|}
\hline Probability & $\begin{array}{c}\text { Release } \\
\text { Altitude } \\
\text { (kft) }\end{array}$ & $\begin{array}{c}\text { Release } \\
\text { Speed } \\
(\mathrm{m} / \mathrm{sec})\end{array}$ \\
\hline 0.0021 & 115 & 3720 \\
\hline
\end{tabular}

0. 0021

0. 0021

0.0024

0.0024

0.0024

0.00093

0.0034

0. 0017

0. 0017

0.0068

0.0034

1. $0 \times 10^{-6 * * *}$

$6.8 \times 10^{-6 * * *}$

$6.8 \times 10^{-6 * *}$

$6.8 \times 10^{-6 * *}$

$6.8 \times 10^{-6 * * *}$

137

159

182

210

235

260

253

241

231

317

278

115

137

159

182

115
Release

Longitude

(deg)

124. $8 \mathrm{~W}$

125. 0W

125. $6 \mathrm{~W}$

126. 0W

126. $4 \mathrm{~W}$

129. $2 \mathrm{~W}$

133. $5 \mathrm{~W}$

7774

7683

7408

7256

7835

7713

7317

7317

7317

7317

5732
Release

Latitude (deg)

19. $8 \mathrm{~N}$

18. $2 \mathrm{~N}$

17. $0 \mathrm{~N}$

15. $2 \mathrm{~N}$

11. $0 \mathrm{~N}$

$3.8 \mathrm{~S}$

15. $4 \mathrm{~S}$

Release

Azimuth

(deg)

194. 0

193. 9

193. 8

193.5

193. 4

193.3

193. 2

*Random re-entry

***Taken over equal time intervals

The Agena first burn fuel release conditions (Cases 1 to 7 , Table 2 were determined as follows.

For each re-entry configuration, the locus of the fuel release conditions were determined by selection of the flight motions for the re-entry bodies that resulted in extreme fuel release boundaries, e.g., side on-no spin flight motion would result in the highest fuel release altitudes while side on-spin and tumble-spin motions result in lower altitude releases. The time increment and the associated abort probability of the fuel release portion of the Agena first burn was divided into seven segments. For each segment, release conditions (altitude and velocity) which represented the mean between the extremes were established. The probability associated with the time segment was assigned to the mean release conditions.

The short orbit probabilities (Cases 8 to 12) were assigned by relating the configuration probability to the resultant fuel release conditions for each motion. The configuration probability is the instantaneous probability assigned to each re-entry configuration as a function of time (i.e remaining propellant) between liftoff and success ful achievement of the nominal orbit. 
The Agena second burn deorbit probabilities (Cases 13 to 17) were established using the same procedure as was used for the short orbit cases.

\section{Activity Transport}

Included in the transport process is the motion and the change in physical form (primarily size distribution) during movement from the point of release until the activity ceases to be a hazard. In the typical flow diagram in Fig. 5, release situations are separated according to high altitude or ground release.

In the case of high altitude release, size degradation caused by aerodynamic heating and mechanical effects of the atmosphere was a major consideration. Ablation and breakup models, e.g., critical Weber Numbers approach describing vaporization and instability of partially and fully molten particles were developed. The further transport of vaporized material was evaluated according to the two-stage fallout approximation derived from empirical weapons fallout data, which has also been applied in previous investigations of nuclear space systems (Ref. 22). This model determines directly the time integrai of the activity density in the atmosphere at breathing height (exposure). Curie intake by inhalation and subsequent dose deposition were determined using the NRDL and the Monte Carlo dose models, respectively.

The transport of discrete particles, including any material degraded in size owing to mechanical instability were treated using a model which basically determines the motion of the center of mass of a cloud of particles in an atmosphere characterized by horizontal air movement. The results of Hage, (Ref. 23) relating atmospheric dispersion of clouds to fall time, were used to determine the size of the cloud on settling, from which deposition densities were deduced as a function of particle size. Subsequent transport following initial deposition after an atmospheric release was determined to be a negligible contributor to the hazard severity compared to that resulting from the initial inhalation. This conclusion was drawn based upon approximate evaluation of the effects of resuspension. The potential exception to this conclusion involved consideration of further size degradation of the settled particulate owing to crushing by pedestrian and vehicular traffic.

In the case of ground release of activity, the most likely mechanism was impact of the heat source on the earth subsequent to the intact reentry.
Degradation in size of fuel particles during the impact process was estimated from impact experiments which were performed at a speed of about $100 \mathrm{fps}$. Downwind exposure was determined using a model including the application of Gifford's (Ref. 24) equation for approximating the diffusion of a cloud of fine particulate emitted by a point source. Gifford' $\mathrm{s}$ formalism determines the time integrated activity density at breathing height, which was modified to the form of an artificial surface density, permitting computerized determination of uptake by inhalation and internal deposition as a function of particle size.

\section{Internal Expsoure}

The exposure mechanisms evaluated included inhalation during first flight in the case of atmospheric and ground releases and that following resuspension of crushed particulate. Ingestion mechanisms considered were uptake of particles deposited on the foliage of edible plants and fish contamination following dissolution of the radioactive fuel in shallow seawater. The flow diagram in Fig. 5 illustrates the logic behind such calculations.

The expected number of particles to be deposited in the nasopharygeal, tracheobronchial and pulmonary regions of the respiratory system following an inhalation exposure were determined according to the NRDL model. In this model, the surface density of particles settled from the air and the settling speed are used to compute the time integrated particle density at breathing height (exposure). For particles less than 10 microns in diameter (in suspension), inhalation intake is determined by multiplying the calculated exposure by the average breathing rate (about 20 $\mathrm{m}^{3} /$ day) for humans. Intake of particles greater than 10 microns in diameter was determined by considering the impaction efficiency of the breathing apertures for particles falling at terminal speed and driven by horizontal winds. Regional deposition in both cases was determined using deposition fractions as a function of particle size developed by the ICRP.

From the expected number of particles deposited in respiratory regions, the Poisson distribution was used to calculate the probability that any number of particles would be deposited during a given inhalation exposure.

The final step in evaluating the dose exposure following inhalation is the determination of probable dose distributions if particles are deposited 
in one of the separate regions of the respiratory tract. This calculation was performed by a Monte Carlo technique. The method employs region-toregion transfer fractions and appropriate half residence times obtained from recent publications. Two random samplings are performed for each point of residence of a particle within the body, one to determine its actual residence time during a single history and the second to determine the next region of deposition. Sampling is done from exponential time distributions defined by the residence time constants and from the transfer fractions. The dose is calculated at each region of residence, once the residence time has been selected, by the following sequence of steps:

(1) Dividing the total particle energy emission by the mass of the organ

(2) Converting to rems

(3) Converting (ultimately) to whole body equivalency by multiplying the computed rem dose in the organ by the ratio of maximum permissible doses (MPD) for whole body and for the organ of deposition.

The history is then continued through a sequence of organ depositions, in which the equivalent whole body dose is accumulated until the particle is eliminated or the 50-year integration period is exceeded. From 20, 000 to 100, 000 single particle histories were run, depending upon the region of initial deposition, to provide adequate statistics for the probability function, that is, the probability of exceeding a given accumulated whole body dose. All of the results presented make use of the average dose determined from this distribution.

The results obtained in terms of expected numbers of particles inhaled and deposited in the respiratory tract and the average dose following internal deposition of a particle when combined with the number of people exposed by the descending cloud of particles fully describe the inhalation exposure mechanism.

Primary uncertainties exist in the case of internal exposures, the dominant contributor to SNAP 19 hazards, owing to lack of detailed data describing particle movement in the body. No size dependence has been determined for residence times and region-to-region transfer fractions. Evaluation of the uncertainty in residence time distributions must await exploratory calculations using appropriate size-dependent data. Apart from uncertainties in input data, the Monte Carlo technique appears wuite well adapted to determining the probabiliistics of the distribution of energy deposition.

Exposure by means of ingestion is treated for vegetation, fresh water uptake and shallow ocean release. In the case of particle deposition on leafy vegetables, the probability of a person's ingesting a single particle was determined by considering random deposition of particles following release from a deorbiting system subsequent to a ground release after impact, and from uniform global deposition of particles following a release in orbit. This probability was calculated from particle surface densities, the fraction of the Earth's area in which leafy vegetables are grown, fallout data on fractional deposition of particles on plants, removal of particles by weathering as a function of time, an estimated further removal by processing and the fresh vegetable consumption rate by humans.

The dose distribution average dose resulting from particle ingestion was determined again by the Monte Carlo technique. Dose deposition in the GI tract was estimated by considering only $1 \%$ of the energy emitted during residence to account for energy deposition in other than vulnerable tissue. This is a standard means within the ICRP of evaluating GI doses, and was used in all Monte Carlo calculations involving the GI tract, regardless of the region of initial deposition.

The average dose following particle ingestion, probability of ingesting a single particle and number of people involved cases provide all the requisite data to perform the PDN evaluation for this exposure mechanism.

The uptake of dissolved material by ingestion, as expected, contributes little to human exposure.

\section{External Exposure}

Exposure to external radiation involves the uncontrolled intact capsule or the distributed particulate resulting from disintegration of fuel containment during re-entry or ground release subsequent to impact. The logic of calculations involved is also illustrated in the flow diagram of Fig. 5.

In the case of dispersed microspheres (Fig. the external exposure was estimated by determining 
the dose rate from $\mathrm{X}$-rays, neutrons and gammas at three feet above an infinite plane source. Particle surface densities obtained as described under transport mechanisms were used to define the source strength. Dose rates from individual particles in air were used in the plane source calculations. Dose estimates to the individuals exposed were obtained by multiplying these plane source dose rates by the effective time during which particles radiate without significant attenuation by burial and other removal mechanisms. The probabilistic exposure from distributed microspheres is thus determined by occurrence probabilities for events giving rise to such dispersions, the number of people in the contaminated region and the dose calculation.

\section{$\underline{\text { Biological Response }}$}

The previous treatment of occurrence probabilities, activity transport and exposure probabilistics yields data from which the expected number of people receiving doses in excess of a given dose, D, may be computed. Approximate results in this form are presented (Table 4) in the case of inhalation exposures following release of the fuel subsequent to intact impact. However, results in this form are intermediate; the effect anticipated as a result of these exposures is the matter of principal concern.

From the standpoint of biological effect, the results are apt to be misleading. Under certain conditions, an individual might be exposed to a commensurated dose exceeding 100 rems. If this is interpreted in terms of response to acute, uniform, whole body exposure, the biological response or individual risk would be greatly overestimated. Exposures concomitant with a malfunction of the SNAP 19 system are chronic exposures from localized point sources.

Estimated risks were therefore based upon the data presented the the ICRP (Ref. 21), which suggests a value for individual risk of $4 \times 10^{-5}$ / rad. The further assumption of a linear variation with equivalent, whole body dose determines the response function in the form

$$
\mathrm{P}_{\mathrm{T}}=4 \times 10^{-5} \mathrm{D}
$$

where $\mathrm{P}_{\mathrm{T}}$ is the risk per individual exposed and is the equivalent whole body dose in rems. Commensuration (Ref. 25) is accomplished by weighting each effective organ dose by the ratio of maximum permissible whole body dose to the maximum permissible dose in that organ, and assuming over all body organs. The maximum permissible doses referred to are those recommended by the International Commission on Radiological Protection. The assumed linear dose response function is discussed later in this paper. In the case of inhalation exposures, the dose evaluated was that from alpha particles.

Using Eq (1), the associated relationship can be determined between numbers of people and level of risk from the approximate relationship between total number of people exposed as a function of dose. Here the total risk is determined as the product of occurrence probability for the exposure event, the individual risk for a person exposed to D rems, and the probability that, given the event, a person exposed to the inhalation hazard will inhale one or more particles.

\section{HAZARD EXPECTATION}

The results of the safety evaluation of the SNAP 19 IRHS are presented in two ways. The probability, $P$, of occurrence of fuel release conditions are coupled with the resulting dose, $D$, to numbers of people, N. This is used to generate the risk expectation utilizing the probabilistic approach described previously.

The aerospace nuclear safety assessment indicated that the predominate hazard was that associated with a post re-entry release at the surface of the Earth. Therefore, results are also presented in the form of ground radiation densities and inhalation expsoures subsequent to Earth impact. The characteristic hazard for this type of release is one of exposing relatively few people over a relatively small area. This probabilistic assessment of public exposure is determined for a period of 50 years and includes occurrence probabilities for accident events, exposure probabilities once an accident occurs and biological response probabilities.

The results of the evaluation of each phase of the mission profile are presented in chronological sequence in Table 3 . The predicted somatic effects resulting from the potentailly hazardous situations encountered during the flight sequence, i.e., launch pad operations through post-mission re-entry, are presented for inhalation of fuel particulate matter and vapor for the fuel breakup parameter of Weber number $=5$.

Also presented in Table 3 are the accident occurrence and fuel release probabilities. 
TABLE 3

Mission Profile Hazard Assessment

\begin{tabular}{|c|c|c|c|}
\hline Mission Phase & $\begin{array}{c}\text { Accident } \\
\text { Occurrence } \\
\text { Probability }\end{array}$ & $\begin{array}{l}\text { Fuel Release } \\
\text { Probability* }\end{array}$ & $\begin{array}{c}\text { Risk } \\
\text { Expectation }\end{array}$ \\
\hline Transportation & $5.4 \times 10^{-3}$ & $1.4 \times 10^{-6}$ & $1.6 \times 10^{-4}$ \\
\hline Launch pad abort & $1.5 \times 10^{-3}$ & $2 \times 10^{-6}$ & $2.7 \times 10^{-4}$ \\
\hline Ascent aborts & $1.3 \times 10^{-2}$ & $\begin{array}{l}\left(1 \times 10^{-4}\right) \\
1.3 \times 10^{-6}\end{array}$ & $1 \times 10^{-2}$ \\
\hline $\begin{array}{l}\text { Short-lived orbit } \\
\text { aborts }\end{array}$ & $1.7 \times 10^{-2}$ & 1 & 0.9 \\
\hline $\begin{array}{l}\text { Post-mission fuel } \\
\text { release }\end{array}$ & 0.9 & $10^{-2}$ & $5 \times 10^{-5}$ \\
\hline
\end{tabular}

The extent of potential land contamination subsequent ot an intact re-entry and Earth impact is shown in Table 4. These results are presented in the form of ground density $\left(\mathrm{ci} / \mathrm{m}^{2}\right)$ and inhalation exposure $\left(\mathrm{ci}-\mathrm{sec} / \mathrm{m}^{3}\right)$ as a function of wind speed and meteorological condition. The exposure for the first flight and subsequent resuspension is essentially the time integral of the downwind particle air concentration.

\section{TABLE 4}

Inhalation Exposure from Ground Impact

Spectrum: $250 \mathrm{fps}$ impact spectrum with Tracerlab definition below 10 microns

\begin{tabular}{|c|c|c|c|c|c|}
\hline Wind speed & 4.47 & 4.47 & 8.94 & 8.94 & $(\mathrm{~m} / \mathrm{sec})$ \\
\hline $\begin{array}{l}\text { Meteorological } \\
\text { condition }\end{array}$ & $\mathrm{F}$ & $\mathrm{F}$ & $\mathrm{C}$ & $\mathrm{C}$ & $\begin{array}{l}\text { Stability } \\
\text { condition }\end{array}$ \\
\hline $\begin{array}{l}\text { Area } \\
\left(m^{2}\right) \\
\end{array}$ & $\begin{array}{l}\text { Ground } \\
\text { Density } \\
\left(\mathrm{ci} / \mathrm{m}^{2}\right) \\
\end{array}$ & 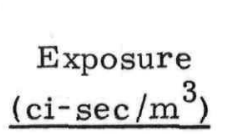 & $\begin{array}{l}\text { Ground } \\
\text { Density } \\
\left(\mathrm{ci} / \mathrm{m}^{2}\right) \\
\end{array}$ & 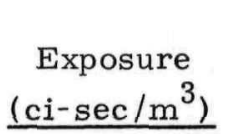 & $\begin{array}{c}\text { Effective } \\
\text { Particle Size } \\
\text { (microns) } \\
\end{array}$ \\
\hline $10^{6}$ & $1.0 \times 10^{-6}$ & $9.0 \times 10^{-5}$ & $9.7 \times 10^{-5}$ & $4.4 \times 10^{-4}$ & 6 \\
\hline $10^{7}$ & $2.8 \times 10^{-8}$ & $1.1 \times 10^{-5}$ & $8.2 \times 10^{-6}$ & $4.3 \times 10^{-5}$ & 3 \\
\hline $10^{8}$ & $2.8 \times 10^{-9}$ & $1.4 \times 10^{-6}$ & $5.4 \times 10^{-7}$ & $3.6 \times 10^{-6}$ & $<2.5$ \\
\hline $10^{9}$ & $1.6 \times 10^{-10}$ & $7.9 \times 10^{-8}$ & $3.0 \times 10^{-8}$ & $2.7 \times 10^{-7}$ & $<<2.5$ \\
\hline
\end{tabular}

Table 4 shows that personnel expsoure and ground contamination are significantly influenced by meteorological conditions. The two categories investigated, i.e., Conditions $\mathrm{C}$ and $\mathrm{F}$, represent slightly unstable conditions (sunny weather) and moderately stable conditions (clear night).

\section{CONCLUSIONS}

A quantitative assessment of the risk associated with the use of radioisotopes in space has been developed which consists of combining, into a single evaluation parameter, potential 
hazardous accidents, the associated dose rates and the effect on the population. The merits of this approach are two-fold. First, it identifies during the design phase high risk events which can be mitigated by remedial design action; and second, it leads to a single evaluation parameter that can be compared to the basic safety criterion for the mission.

The risk expectation for the SNAP 19-IRHS system is approximately six orders of magnitude less than that estimated for the risk associated with natural background radiation. Both estimates were derived using the same technique.

Application of the probabilistic safety evaluation technique clearly indicates that previous criteria developed in terms of permissible levels of exposure are not meaningful. The severity of human exposure is limited only by the curie inventory of the source and the probabilities for incidents culminating in massive exposure. Therefore, it may not be possible to show that permissible exposures cannot be exceeded in missions involving large curie inventories. This situation is completely consistent with the Federal Radiation Council (Ref. 26) which states "... there can be no single 'permissible' or acceptable level of exposure, without regard to the reasons for permitting exposure. The radiation dose to the population which is appropriate to the benefits derived will vary widely depending upon the importance of the reason for exposing the population to a radiation dose."

\section{REFERENCES}

1. "SNAP 19 Fuel Form Selection and Capsule Configuration." Martin Marietta Corporation, MND-3169-77, December 1966.

2. Delegazio, A. W., "Dose Calculation Models for Re-entering Nuclear Rocket Debris." NUS-229 (Ref.) Nuclear Utility Services, Washington, D.C., May 1965.

3. Farmer, F. R., "Reactor Safety and Siting: A Proposed Risk Criterion," Nuclear Safety, Vol. 8, No. 6, November-December 1967.

4. Szelo, D. S. and Gettlieb, S. M., "SNAP 19 Tandem Generator Force and Stability Test at Mach 20." Martin Marietta Corporation, MND-3607-87, August 1966.

Adams, R. C., "Results of $10 \%$ Nimbus Force and Stability Test-Mach 8." Martin Marietta Corporation, MND-3607-88, January 1967.
6. Stauffer, C. G., "SNAP 19 Capsule Low Reynolds Number Force Test." Martin Marietta Corporation, MND-3607-89, October 1966.

7. Stauffer, C. G., "SNAP 19 Capsule Force and Stability Test-Mach 10." Martin Marietta Corporation, MND-3607-90, December 1966.

8. Stauffer, C. G. and Fluet, C. A., " SNAP 19 Generator Force and Stability Test-Mach 8." Martin Marietta Corporation, MND-3607-91, February 1967.

9. Adams, R. C. and Fluet, C. A., "SNAP 19 Generator Heat Distribution Test-Mach 8." Martin Marietta Corporation, MND3607-92, February 1967.

10. Lambert, N. and Coughlin T., "Distribution of Heat and Pressure on the SNAP 19 Fuel Capsule in Hypersonic Flow." Martin Marietta Corporation, MND-3607-93, March 1967.

11. Shih, C. and Rowe, Jr., W. H., "Results of the 10\% Thermal Model Test, Nimbus B Sensory Ring." Martin Marietta Corporation, MND-3607-94, February 1967.

12. Olsen, D. N., "Heat Distribution on $10 \%$ Scale Model Nimbus B Sensory Ring and SNAP 19 Generator at Mach 10." Martin Marietta Corporation, MND-3607-95, January 1967.

13. Nickel, H. S. and Rice, W. R., "Results of SNAP 19 Capsule Disintegration Test." Martin Marietta Corporation, MND-360796, September 1967.

14. Shih, C., "SNAP 19 Thermal Performance of Materials and Mechanical Joints." Martin Marietta Corporation, MIND-3607112, November 1966.

15. Woolf, W. and Grim, G., "SNAP 19 Feasibility Tests, High Enthalpy Disintegration of Magnesium." Martin Marietta Corporation, MND-3607-114, October 1966 .

16. Lockheed Missiles and Space Company, Nimbus/SNAP 9A Hazard Study, Phase I, Trajectories and Performance Analysis, LMSC A819805, 6 June 1966. 


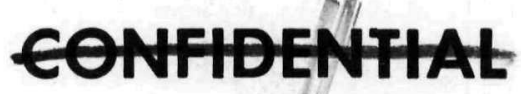

17. "Nimbus/SNAP 9A Hazard Study, Phase II,

Launch Vehicle Failure Mode Analysis."

Lockheed Missiles and Space Company,

LMSC A826526, August 15, 1966.

18. "SNAP 19 Safety Analysis Report, IRHS

Supplement." Martin Marietta Corporation, MND-3607-133S.

19. Roving Receptor Model from ROVER

Program.

20. Dionne, P. J., Harvey, R. A. and Watson, E. C. , "Model Development and Simulation of the Translocation of Radionuclides in Mammals." Battelle Memorial Institute, BNWL-SA-683, 1966.

21. "The Evaluation of Risks from Radiation. " International Commission on Radiological Protection, ICRP Publication 8, 1966.

22. "Safety Analysis for Transit Mission." Martin Marietta Corporation, MND-2775-2, March 1963, SECRET.

23. Hage, K. D., et al., "Particle Fallout and Dispersion in the Atmosphere." Final Report,'SC-CR-66-2031, July 1966.

24. Gifford, F. A., et al., "Atmospheric Dispersion Calculations using the Generalized Gaussian Plume Model." Nuclear Safety 2, 1960.

25. Recommendations of Internation Commission on Radiological Protection, ICRP Publication 6, 1962.

26. "Report No. 1, Background Material for the Development of Radiation Protection Standards." Staff Report of the Federal Radiation Council, May 13, 1960. 


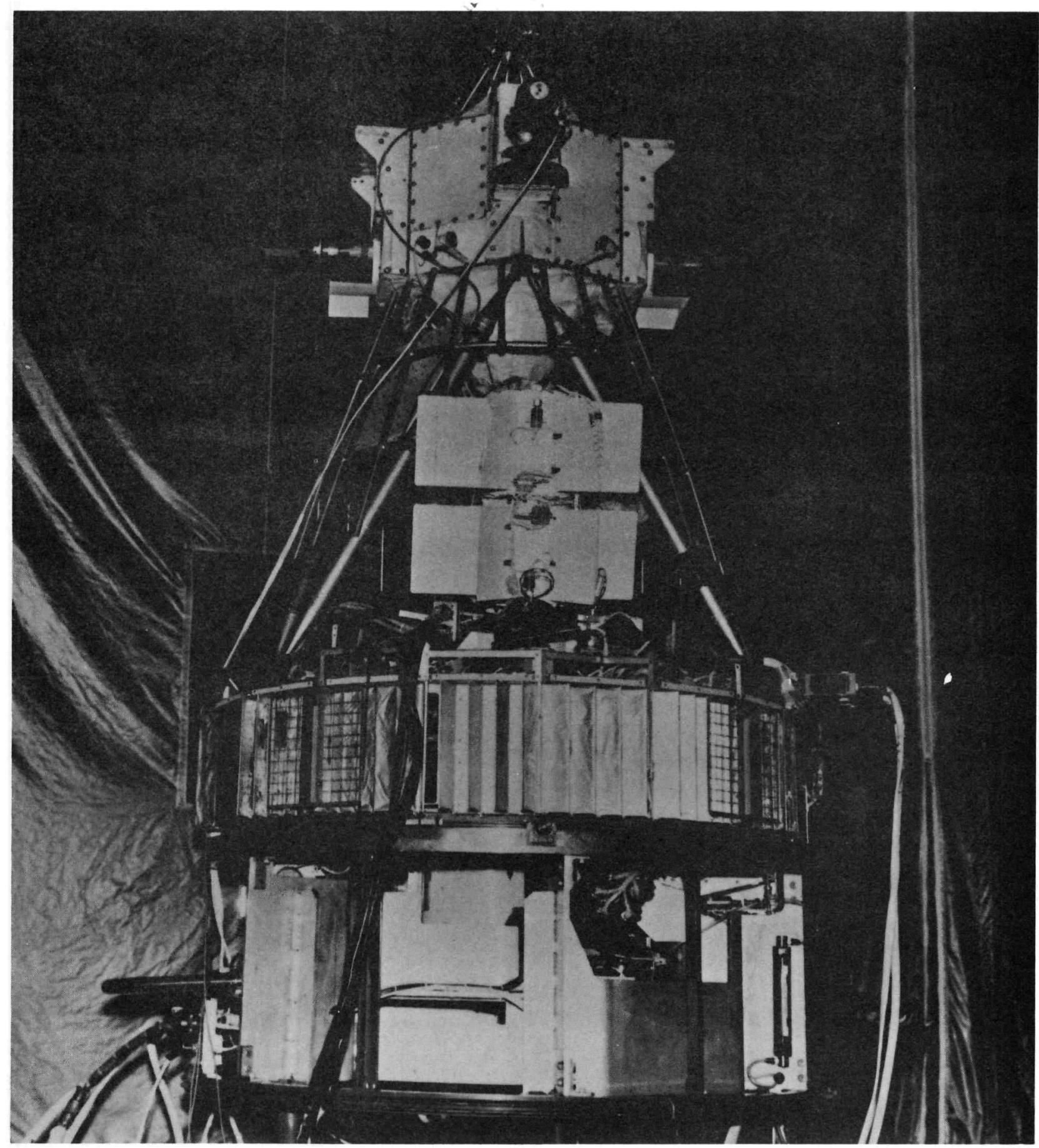

FIG. 1. SNAP 19 MOUNTED ON SATELLITE 
HEAT SHIELD
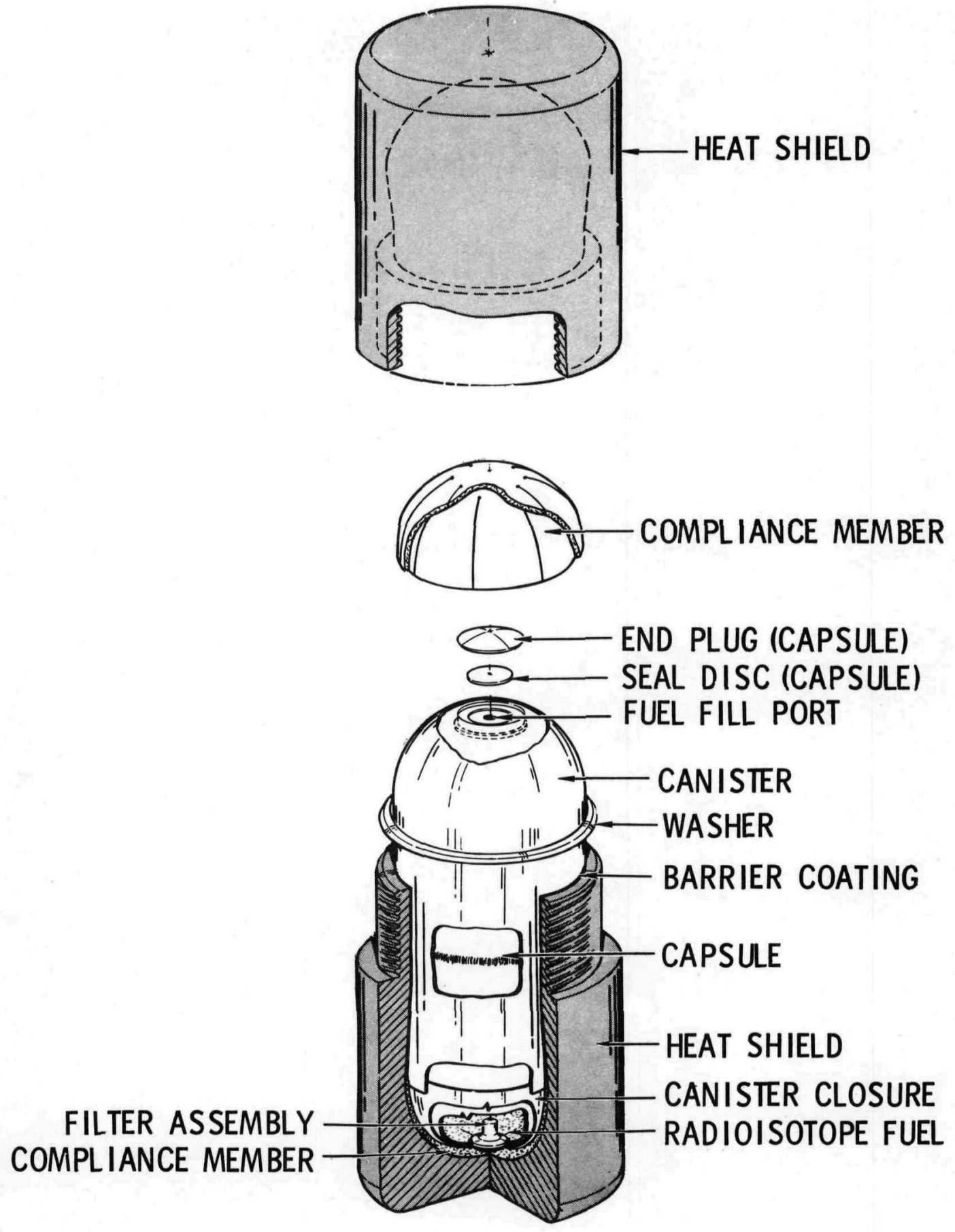

FIG. 2. IRHS OVERALL VIEW 


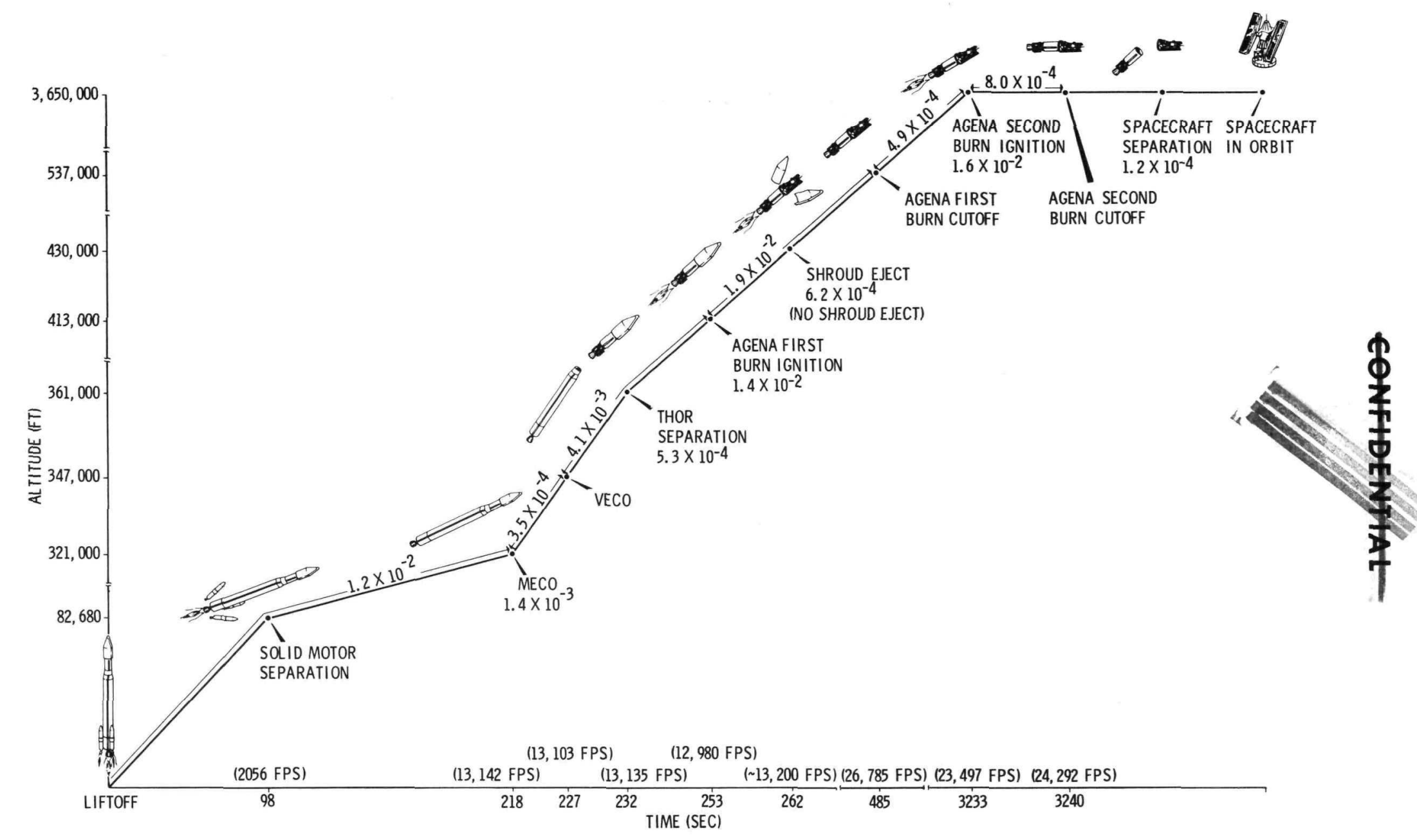

FIG. 3. SNAP 19/NIMBUS B FLIGHT ARRAY 

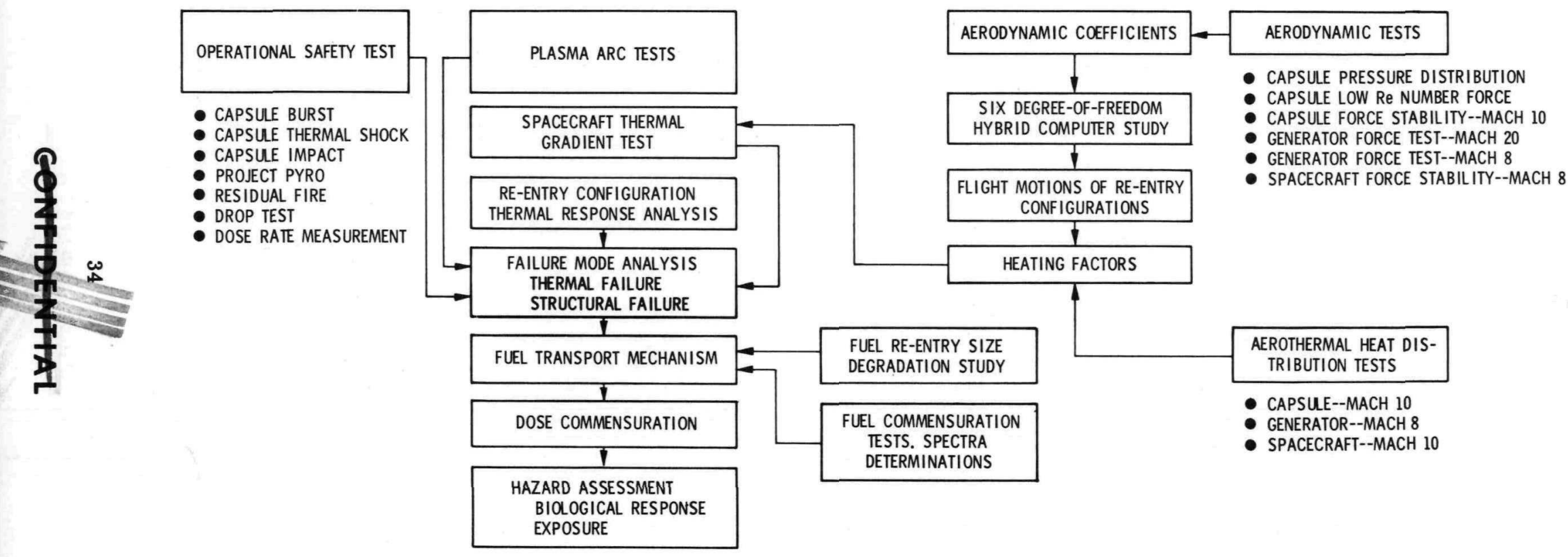

\section{FIG. 4. SNAP 19 AEROSPACE NUCLEAR SAFETY ASSESSMENT LOGIC}




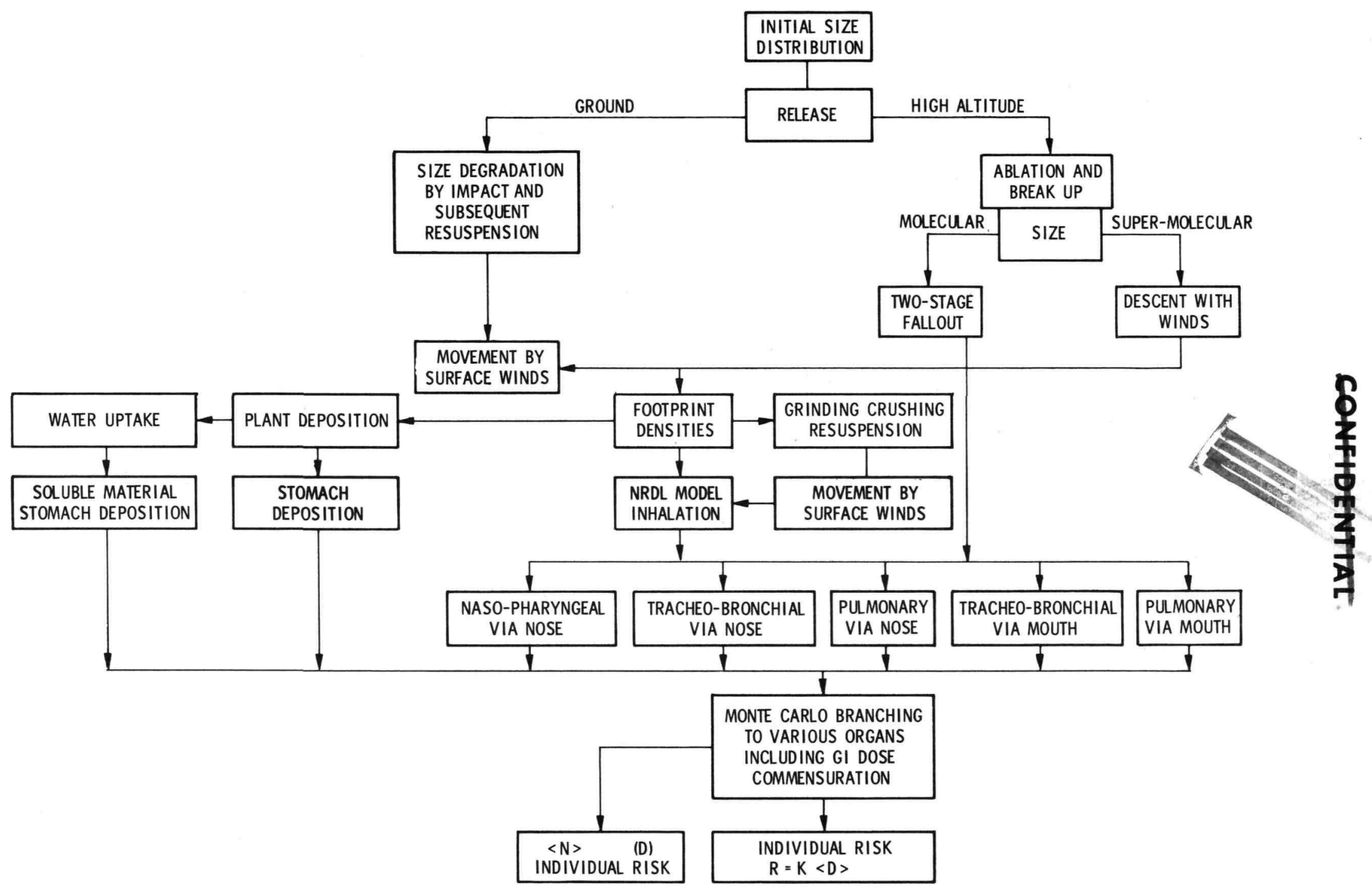

FIG. 5. ANALYSIS DIAGRAM FOR RISK DETERMINATION 


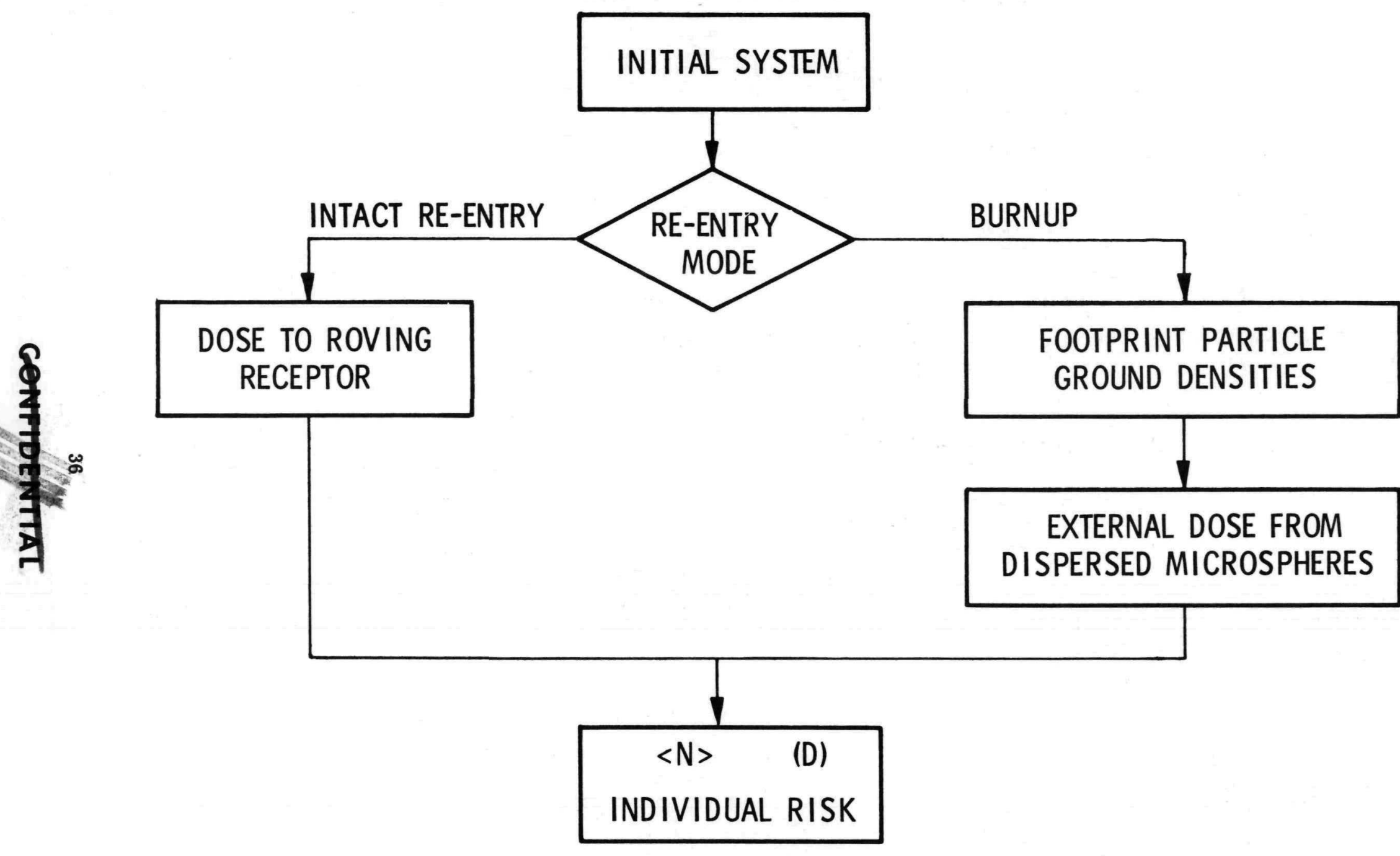

FIG. 6. ANALYSIS FLOW FOR COMPUTATION OF EXTERNAL DOSE 
AEROTHERMAL ANALYSIS AND TESTING OF THE SNAP 19

INTACT RE-ENTRY HEAT SOURCE ${ }^{*}$

John Segletes, William Shadis and Victor Lougheed

Martin Marietta Corporation, Nuclear Division

Baltimore, Maryland 21203

\section{SUMMARY}

Nuclear safety tradeoff studies conducted for the SNAP 19 program pointed out advantages in returning an intact heat source to the Earth's surface. The original design, which passively released plutonium dioxide fuel during re-entry, was modified to include an intact re-entry capability.

The fuel inventory of the intact system is protected from the re-entry thermal environment by a graphite heat shield which envelopes the fuel capsule. An aerothermal analysis was performed in which it was shown that the Intact Re-entry Heat Source (IRHS) design was adequate. A plasma arc test program was initiated to sup plement the aerothermal analysis by further demonstrating the intact capability of the IRHS. Also, the test data were used as a basis for an analytical correlation. Good agreement between analysis and test was shown to exist.

\section{INTRODUCTION}

Nuclear safety tradeoff studies conducted for the SNAP 19 program pointed out advantages in returning an intact heat source to the Earth's surface and provided the impetus to develop the intact re-entry heat source. A significant portion of this effort was devoted to demonstrating, through analysis and test, that the heat source will remain intact during re-entry. Aerothermal analyses and tests were initiated in the Spring of 1967 to accomplish this task. Since the IRHS is not aerodynamically stable, it was necessary that analyses and tests include a variety of re entry modes that would bracket all probable modes. The four selected modes are descriptively defined as:
(1) Side-spin
(3) Tumble-spin
(2) Side-stable
(4) End-on.

The test program was conducted at the OneMegawatt Plasma Arc Facility in the Middle River complex. A total of 24 models were exposed to a variety of thermal environments. Nine of these models were instrumented with thermocouples. The data obtained provided a basis for a correlation study in which temperature and recession histories of five models were computed using the same analytical methods as those utilized in the aerothermal analysis.

This paper describes the analytical and test methods, presents pertinent results and demonstrates the degree of simulation that was achieved in the correlation study.

\section{AERODYNAMIC HEAT TRANSFER}

The IRHS re-entry trajectories were obtained using the following basic assumptions:

(1) A spherical nonrotating earth model (used for most trajectory calculations).

(2) Free molecular flow occurs from 400,000 -foot altitude down to 300,000 feet, transition flow from 300,000 to 200,000 feet and continuum flow below 200,000 feet.

(3) The IRHS could re-enter in any of the following modes: side-spin, sidestable, tumble-spin or end-on. The mode of entry remains constant, how ever, throughout the entire descent.

A three-degree of freedom computer program was used to calculate all re-entry trajectories. Cold wall stagnation point heating rates to a $1-1 / 2$-inch radius sphere were simultaneously computed using the theory of Detra, Kemp and Riddell. (1) Free molecular heating effects were accounted for by modifying the initial portion of the heat fluxes (altitude $<200,000 \mathrm{ft}$ ) in accordance with the theory presented in Ref. 2 .

(1)Detra, R. W. , Kemp, N. H. and Riddell, F. R., Addendum to "Heat Transfer to Satellite Vehicles Re-entering the Atmosphere." Jet Propulsion, December 1957, p 1256.

(2)Hayes, W. D. and Probstein, R. F. , Hypersonic Flow Theory. Academic Press, New York, 1959, p 404 . 
Some abort cases accounted for disintegration of the generator and spacecraft prior to the direct exposure of the IRHS to aerodynamic heating. However, the orbital decay cases assumed the direct exposure of the heat source at the initiation of re-entry.

Flux distributions over the heat source, used as boundary conditions in the thermal analysis, are shown in Figs. 1 and 2. These values are based in part on wind tunnel data ${ }^{(3)}$ and in part on theory.

\section{AEROTHERMAL ANALYSIS}

\section{Computer Codes and Models}

Two digital computer codes were used in the aerothermal analysis. The Aerothermal Transient Analysis Code (ATAC) did not account for thermochemical effects on the model surface while the second, the Thermo-Chemical Ablation Program ( $T$-CAP) did account for this phenomena.

The ATAC explicitly solves three dimensional thermal problems by finite difference techniques.

The code is sufficiently general to consider all of the following:

(1) Internal generation of heat

(2) Phase change effects

(3) Optional boundary conditions (heat flux, temperature, film coefficient)

(4) Correction of cold wall heat flux for actual wall temperature.

Surface recession was assumed to occur only by oxidation. A preliminary investigation showed the peak shear force $\left(\tau \approx 20 \mathrm{lb} / \mathrm{ft}^{2}\right)$ to be well below the threshold value of $\tau>300 \mathrm{lb} / \mathrm{ft}^{2}$ at which mechanical erosion of high density, fine grain graphites begins, thus eliminating the need of

(3)Lambert, W. and Coughlin, T. , "Distribution of Heat and Pressure on the SNAP 19 Fuel Capsule in Hypersonic Flow. "Martin Marietta, Nuclear Division, MND-3607-93, March 1967. accounting for this phenomena. It likewise showed peak surface temperatures of $\approx 5000^{\circ} \mathrm{F}$ which justified the exclusion of sublimation from the analysis. (4)

Surface recession due to oxidation assumes the process follows a rate law of order $1 / 2$ which is expressed in the form:

$$
\dot{\mathrm{x}}_{\mathrm{W}}=\frac{\mathrm{K}}{\rho_{\mathrm{W}}}\left(\mathrm{P}_{\mathrm{O}_{2}}\right)^{1 / 2}
$$

The reaction rate constant $\mathrm{K}$ is expressed in the standard Arrhenius form,

$$
\mathrm{K}=\mathrm{K}_{\mathrm{o}} \mathrm{e}^{-\mathrm{E} / \mathrm{RT}}
$$

Combining Eqs. (1) and (2), with the partial pressure expressed as total pressure multiplied by mole fraction leads to the following:

$$
\dot{\mathrm{x}}_{\mathrm{W}}=\frac{1}{\rho_{\mathrm{W}}}\left(\mathrm{P}_{\delta}\right)^{1 / 2}\left(\mathrm{X}_{\mathrm{O}_{2}}\right)^{1 / 2} \mathrm{~K}_{\mathrm{O}} \mathrm{e}^{-\mathrm{E} / \mathrm{RT}}
$$

Equation (3) is solved simultaneously with Eq. (4). Equation (4) was developed from the analogy between heat and mass transfer, as given in Ref. 5. Here it is assumed that the mass and mole fractions of oxygen at the wall are equal.

$$
\dot{\mathrm{x}}_{\mathrm{W}}={\frac{(\mathrm{Le})}{\rho_{\mathrm{W}}}}^{-2 / 3}\left(\frac{\mathrm{W}_{\mathrm{c}}}{\mathrm{W}_{\mathrm{O}_{2}}}\right)^{\left(0.23-\mathrm{C}_{\mathrm{O}_{2}}\right)} \frac{\left.{ }_{\mathrm{H}}-\mathrm{H}_{\mathrm{W}}\right)^{(}}{\left.\mathrm{H}_{\mathrm{c}}-\mathrm{q}_{\mathrm{b}}\right)}
$$

While Eq. (3) expresses surface recession in terms of reaction kinetics, Eq. (4) expresses surface recession in terms of the availability of oxygen by diffusion across the boundary layer.

(4)Metzger, J. W. , Engel, M. J. and Diaconis, N. S. , "The Oxidation and Sublimation of Graphite in Simulated Re-entry Environments. " AIAA Paper 65-643 presented at AIAA Thermophysics Specialist Conference, Monterey, California, September 1965.

(5)Holman, J. P., Heat Transfer. McGraw Hill Book Company, New York, N. Y. , pp 261-263, 1963. 
The heat balance at the surface, computed as a function of time, is the following:

$$
\mathrm{k} \frac{\partial \mathrm{T}}{\partial \mathrm{x}}=\dot{\mathrm{q}}_{\mathrm{c}}-\dot{\mathrm{q}}_{\mathrm{b}}+\dot{\mathrm{q}}_{\mathrm{O}}-\epsilon_{\mathrm{W}} \sigma \mathrm{T}_{\mathrm{W}}^{4}
$$

Where the blocked heat flux ${ }^{(6)}$ for laminar flow is expressed by

$$
\dot{\mathrm{q}}_{\mathrm{b}}=0.71\left[\frac{\mathrm{MW} \text { air }}{\mathrm{MW}_{\text {vap }}}\right]^{0.4}\left(\mathrm{H}_{\mathrm{O}}-\mathrm{H}_{\mathrm{W}}\right)
$$

and the heat of oxidation is given by

$$
\dot{\mathrm{q}}_{\mathrm{O}}=\dot{\mathrm{x}}_{\mathrm{W}} \rho_{\mathrm{W}}\left[\mathrm{f}_{\mathrm{CO}}{ }^{\mathrm{H}} \mathrm{CO}+\left(1-\mathrm{f}_{\mathrm{CO}}\right)^{\mathrm{H}_{\mathrm{CO}_{2}}}\right]
$$

$$
\text { SYMBOLS }
$$

$\begin{array}{ll}\mathrm{C} & \text { mass fraction } \\ \mathrm{E} & \text { activation energy } \\ \mathrm{f}_{\mathrm{CO}} & \begin{array}{l}\text { weight fraction of } \mathrm{CO} \text { in combustion } \\ \text { products }\end{array}\end{array}$

$\begin{array}{ll}\mathrm{H} & \text { heat of combustion, enthalpy } \\ \mathrm{k} & \text { thermal conductivity } \\ \mathrm{K} & \text { specific reaction rate } \\ \mathrm{K}_{\mathrm{O}} & \text { effective collision frequency } \\ \mathrm{Le} & \text { Lewis number } \\ \mathrm{MW} & \text { molecular weight } \\ \mathrm{P} & \text { pressure } \\ \dot{\mathrm{q}} & \text { heat flux } \\ \mathrm{R} & \text { universal gas constant } \\ \mathrm{T} & \text { temperature }\end{array}$

(6)Georgiev, S., "Hypersonic Ablation and Interpretation of Test Results. " AF BSD TR 61-31, October 1960.
$\mathrm{W}_{\mathrm{c}} / \mathrm{W} \mathrm{O}_{2} \begin{aligned} & \text { ratio of weight of graphite consumed } \\ & \text { per pound of oxygen }\end{aligned}$

$\dot{x}$

$\mathrm{X}$ mole fraction

$\epsilon \quad$ emissivity

$\rho \quad$ density

$\sigma \quad$ Stefan-Boltzmann constant

$\tau \quad$ shear stress

\section{SUBSCRIPTS}

$\mathrm{b}$

c

blocked

$\mathrm{CO}$ carbon monoxide

$\mathrm{CO}_{2} \quad$ carbon dioxide

oxidation, total

$\mathrm{O}_{2} \quad$ oxygen

W wall

$\delta \quad$ local

The fraction of $\mathrm{CO}$ in the oxidation products as a function of pressure and temperature, together with the heats of combustion, are program inputs.

As will be shown later, temperature histories computed for a typical problem will yield only slightly different results whether they are computed with ATAC or T-CAP.

Both programs require inputs describing model geometry, material thermal properties as functions of temperature and boundary conditions as functions of time. 


\section{Preliminary Analysis}

The preliminary thermal analysis progressed simultaneously with the development of an acceptable design. The first computer model was a simple pie shape as shown in Fig. 3A. Identical problems were solved on both programs using this model and the thermochemical effects on temperatures were negligible as shown in Fig. 4. Comparable peak temperatures were within $80^{\circ} \mathrm{F}$ of each other in the two solutions.

Using the one dimensional model and ATAC, the sensitivity of the temperature response to variations of material properties and boundary conditions was determined. A series of runs were made holding all parameters at their nominal value and varying the following, one at a time:

(1) Heat shield thermal conductivity

(2) Gap effective emissivity

(3) Fuel conductivity

(4) Fuel power density

(5) Gap conductivity

(6) Heat flux.

Typical results are shown parametrically in Fig. 5. These initial runs indicated that capsule melt was unavoidable for an orbital decay reentry trajectory and prompted the inclusion of a compatibility barrier (the canister) into the heat source design. Additional factors such as temperature at the moment of impact, capsule time above melt and usefulness of radiation shields between the heat shield and the capsule were also investigated.

\section{Design Analysis}

After a final design configuration was established, more accurate and complex computer models were constructed. A design case was established as a standard for comparison purposes. This consisted of a side-spin mode, orbital decay re-entry with a factor of 1.3 applied to the heat flux.

A two-dimensional wedge model, shown in Fig. 3B, was used to determine the temperature histories of side-spin, tumble-spin and end-on re-entry modes. The spin-stable mode was investigated with a two-dimensional disc model shown in Fig. 3C, since circumferential temperature profiles would be of primary interest. For several significant cases, a 240 element three-dimensional model representing a quarter of the heat source was used. Fortyeight of these elements included surface areas, thus giving a detailed map of the surface temperature at any time from the initiation of reentry to impact.

The side-stable and design cases were examined with the three-dimensional model. Surface recession was determined by obtaining surface temperatures from ATAC solutions and forcing the surface temperature of the onedimensional T-CAP model to these values. There was negligible error involved in this procedure as was demonstrated by the comparative results shown in Fig. 4. All models used in this study had 45-degree chamfers at opposite extreme edges. These chamfers, included for aerodynamic reasons, were eliminated after the aerothermal analysis and the test effort was completed. Subsequent analysis indicated no significant effect on the temperature or recession histories due to omission of these chamfers.

\section{Analysis Results}

Typical results are shown in Figs. 6 and 7 for the design and side-stable cases. Almost all trajectories resulted in capsule melt prior to impact. Predicted recession in all cases is substantially less than the heat shield thickness. Analytical results are summarized in Table 1 . 


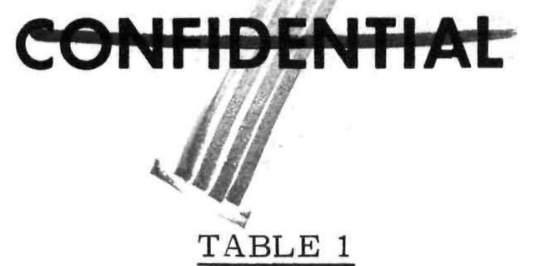

Summary of Analytical Results

Initial

Altitude Velocity Angle Aerodynamic

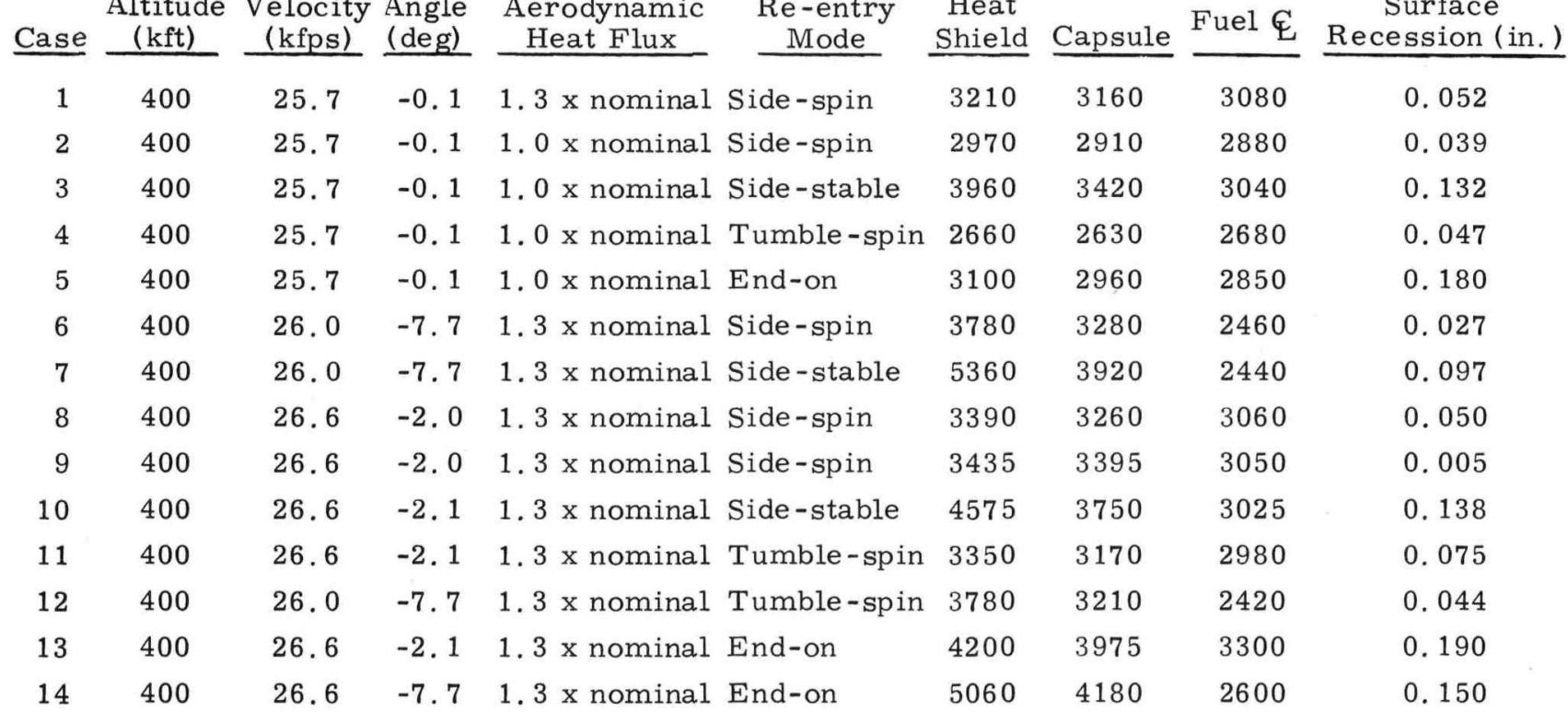

Note: 1. Abort cases as defined herein include cases in which the IRHS is released from the generator during an orbital decay re--entry. Not all trajectories examined are listed; those for which no surface recession was obtained have been omitted.

2. Cases 1 through 5 are orbital decay 6 through 14 are abort

\section{TEST PROGRAMI}

\section{Technical Approach}

Soon after the aerothermal analysis was begun, it was decided to test full-scale models of the IRHS in simulated re-entry thermal environments produced by the plasma arc facility. This was done to determine any design deficiencies which might not otherwise be apparent from the analysis and also to generate temperature and surface recession response data with which a test correlation analysis could be accomplished. The test correlation analysis was performed to determine, by comparison with test data, the accuracy of the computer programs used to predict the IRHS temperature and surface recession response in Section III. A total of 24 models were tested. Of these, nine models were provided with internally located thermocouples.

\section{Test Apparatus}

The Plasma Arc Facility was used to simulate the desired re-entry thermal environments. An F-5000 Thermal Dynamics arc generator was used in conjunction with a 10-inch exit diameter supersonic nozzle and a test media of synthetic air to produce the environment.

In order to hold and rotate the models during test, a spin rig was custom designed and manufactured. A photograph of the detached spin rig with a dummy model in place is shown in Fig. 8.

A water-cooled pitot probe and a full-scale custom-made calorimeter, fabricated by Thermogage, Inc, and equipped with nine Gardon steady state heat flux gages, were used to calibrate the plasma jet. 
Model surface temperature was determined automatically by optical and total radiation pyrometers.

All outputs from thermocouples, pyrometers, calorimeters, etc., were recorded on both Bristol millivolt chart recorders and a SYSTRAC data acquisition system built by Systron-Donner Corporation. The SYSTRAC system output is in a magnetic tape form which is suitable for computer analysis and automatic curve plotting devices.

\section{Test Models}

The plasma arc test models were designed to be as close a simulation of the IRHS as possible. However, the designs had to incorporate a means to support the models during test which would allow for model rotation, if required. Also, there had to be room for the passage of any internal instrumentation wiring.

A diagram of the side-stable instrumented model is shown in Fig. 9. The other three types of instrumented designs, to simulate each of the other three modes, were similar.

The uninstrumented models were all designed to be tested in the side-spin or side-stable flight mode.

The major differences between the flight and test models are:

(1) The radioactive plutonium dioxide fuel was simulated with inert zirconium dioxide powder.

(2) The instrumented models contained nine to 10 strategically located tungsten $-5 \%$ rhenium/tungsten-26\% rhenium thermocouples.

(3) Each model was equipped with a stud for support during test.

(4) The instrumented models, which were the earliest models designed and manufactured, did not include the tantalum canister present in later designs.

\section{Test Description}

Simulation of the re-entry thermal environment during test was accomplished by manually varying the arc parameters in finite time steps. A typical re-entry heat pulse was simulated by up to five changes in flux level during the test.
Extreme values of heat flux, imposed by limitations of the facility, were 30 to $320 \mathrm{Btu} / \mathrm{ft}^{2}-\mathrm{sec}$ at the stagnation line of the side-oriented models.

Total enthalpy levels were generally representative of flight values. However, pressure levels were compromised due to facility limitations. Pressure levels were typically $10 \%$ of corresponding flight values at the time of peak heat flux.

All tests were preceded by facility calibrations of pressure, enthalpy and heat flux. Most test models underwent a preheat cycle which raised the heat shield temperature to approximately $1400^{\circ} \mathrm{F}$. This was accomplished by rotating the models in the low level heating environment.

\section{Test Results}

A summary of the peak heat shield temperature and surface recession for each model tested is presented in Table 2. Included is a comparison of the test results with corresponding predicted flight results.

As can be seen from Table 2, the models attained peak test temperatures and total surface recessions close to predicted values. In this respect, most of the tests can be considered good re-entry simulations.

A comparison of test and flight heat shield temperature histories for Model 7 is presented in Fig. 10. This test did not closely simulate either the early or late stages of the flight but an excellent correlation is obtained from about 100 seconds before to 100 seconds after the peak temperature is attained. This is generally true for all the tests performed.

\section{CORRELATION ANALYSIS}

\section{Technical Approach}

To validate the predicted IRHS flight temperature and surface recession response given in Section III, a correlation analysis was made in which temperatures and surface recession of several of the test specimens were computed utilizing the same codes as were used in the flight analysis. The models and boundary conditions were modified to account for the differences that existed between the test and flight. A total of five tests were correlated in this manner.

The analysis was performed in a manner that permitted problem areas to be quickly identified. 


\begin{tabular}{|c|c|c|c|c|c|c|c|c|c|c|c|}
\hline \multirow[b]{2}{*}{$\begin{array}{r}\text { Model } \\
\text { Number } \\
\end{array}$} & \multirow{2}{*}{\multicolumn{2}{|c|}{$\begin{array}{l}\text { Test } \\
\text { Mode }\end{array}$}} & \multicolumn{6}{|c|}{ Peak Stagnation Point Heat Flux } & \multicolumn{3}{|c|}{ Integrated Heat Flux } \\
\hline & & & $\begin{array}{c}\text { Simulated } \\
\text { Re-entry } \\
\text { Case } \\
\end{array}$ & \multicolumn{2}{|c|}{$\begin{array}{c}\text { Test } \\
\left(\mathrm{Btu} / \mathrm{ft}^{2}-\mathrm{sec}\right) \\
\end{array}$} & \multicolumn{2}{|c|}{$\begin{array}{c}\text { Flight } \\
\left.\text { (Btu } / \mathrm{ft}^{2}-\mathrm{sec}\right) \\
\end{array}$} & $\frac{\dot{\mathrm{q}}_{\text {test }}}{\dot{\mathrm{q}}_{\text {flight }}}$ & $\begin{array}{c}\text { Test } \\
\left(\mathrm{Btu} / \mathrm{ft}^{2}\right) \\
\end{array}$ & $\begin{array}{r}\begin{array}{r}\text { Flight } \\
\left(\mathrm{Btu} / \mathrm{ft}^{2}\right) \\
\end{array} \\
\end{array}$ & $\frac{Q_{\text {test }}}{Q_{\text {flight }}}$ \\
\hline 1 & \multicolumn{2}{|c|}{ Side-stable } & $\begin{array}{l}\text { Orbit } \\
\text { decay }\end{array}$ & \multicolumn{2}{|c|}{203} & \multicolumn{2}{|r|}{252} & 0.86 & 20,300 & 49,000 & 0.41 \\
\hline 2 & \multicolumn{2}{|c|}{ Side-spin } & & \multicolumn{2}{|c|}{187} & \multicolumn{2}{|r|}{252} & 0.74 & 52,500 & 49,000 & 1. 07 \\
\hline 3 & \multicolumn{2}{|c|}{ Side-spin } & & \multicolumn{2}{|c|}{169} & \multicolumn{2}{|r|}{252} & 0.67 & 59,000 & 49,000 & 1.20 \\
\hline 5 & \multicolumn{2}{|c|}{ Side-spin } & & \multicolumn{2}{|c|}{208} & \multicolumn{2}{|r|}{252} & 0.83 & 85,000 & 49,000 & 1.73 \\
\hline 6 & \multicolumn{2}{|c|}{ Side-spin } & & \multicolumn{2}{|c|}{177} & \multicolumn{2}{|r|}{252} & 0.70 & 51,000 & 49,000 & 1. 04 \\
\hline 7 & \multicolumn{2}{|c|}{ Tumble-spin } & & \multicolumn{2}{|c|}{212} & \multicolumn{2}{|r|}{293} & 0.720 & 63,000 & 50,000 & 1.22 \\
\hline $9 \mathrm{~A}$ & \multicolumn{2}{|c|}{ End-on } & & \multicolumn{2}{|c|}{185} & \multicolumn{2}{|r|}{239} & 0.79 & 113,000 & 56,000 & 2. 01 \\
\hline $1 \mathrm{~A}-15$ & \multicolumn{2}{|c|}{ Side-spin } & Orbit & & & & 252 & 0.88 & 83,000 & 49,000 & 1. 69 \\
\hline 53 & Side $-\mathrm{s}$ & table & decay & & & & 252 & 0.97 & 84,500 & 49,000 & 1. 72 \\
\hline 35 & Side $-s$ & table & $\begin{array}{l}\text { Agen } \\
\text { abort }\end{array}$ & & & & 290 & 1.09 & 13,000 & 10,000 & 1. 3 \\
\hline 40 & Side $-\mathrm{s}$ & table & $\begin{array}{l}\text { Orbit } \\
\text { decay }\end{array}$ & & & & 252 & 0.94 & 80,000 & 49,000 & 1.63 \\
\hline $59 \mathrm{R}$ & Side $-\mathrm{s}$ & table & $\begin{array}{l}\text { Exten } \\
\text { orbita } \\
\text { decay }\end{array}$ & & & & 252 & 0.91 & 230,000 & 49,000 & 4. 71 \\
\hline & & & $\begin{array}{l}\text { k Stagn } \\
\text { emperat }\end{array}$ & & $\operatorname{Maxj}$ & $\begin{array}{l}\text { mum Su } \\
\text { Recessi }\end{array}$ & $\begin{array}{l}\text { urface } \\
\text { on }\end{array}$ & & & & \\
\hline & $\begin{array}{l}\text { Model } \\
\text { Number } \\
\end{array}$ & $\begin{array}{l}\text { Test } \\
\left({ }^{\circ} \mathrm{F}\right) \\
\end{array}$ & $\begin{array}{l}\text { Flight } \\
\left({ }^{\circ} \mathrm{F}\right) \\
\end{array}$ & $\frac{\mathrm{T}_{\text {test }}}{\mathrm{T}_{\text {flight }}}$ & $\begin{array}{l}\text { Test } \\
\text { (in.) } \\
\end{array}$ & $\begin{array}{l}\text { Flight } \\
\text { (in.) } \\
\end{array}$ & $\frac{\mathrm{x}_{\text {test }}}{\mathrm{x}_{\text {flight }}}$ & & omments & & \\
\hline & 1 & 3620 & 3960 & 0.91 & 0.026 & 0.132 & 0.40 & $\begin{array}{l}\text { Crack in } \\
\text { test }\end{array}$ & eat shield & ring & \\
\hline & 2 & 3040 & 2970 & 1.02 & 0.027 & 0.039 & 0.69 & $\begin{array}{l}\text { Run abor } \\
\text { due to he } \\
\text { leak }\end{array}$ & $\begin{array}{l}\text { d at } 1328 \\
\text { shield lap }\end{array}$ & $\begin{array}{l}\text { conds } \\
\text { oint }\end{array}$ & \\
\hline & 3 & 3240 & 2970 & 1.09 & 0.035 & 0.039 & 0.90 & Run com & eted & & \\
\hline & 5 & 3380 & 29970 & 1. 14 & 0.040 & 0.039 & 1.03 & Run com & eted & & \\
\hline & 6 & 3330 & 2970 & 1.12 & 0.027 & 0.039 & 0.69 & $\begin{array}{l}\text { Run abor } \\
\text { due to le } \\
\text { lap joint }\end{array}$ & $\begin{array}{l}\text { d at } 1240 \\
\text { in heat sh }\end{array}$ & $\begin{array}{l}\text { conds } \\
\text { ld }\end{array}$ & \\
\hline & 7 & 2920 & 2660 & 1.10 & 0.032 & 0.047 & 0.68 & Run com & eted & & \\
\hline & $9 \mathrm{~A}$ & 2880 & 3100 & 0.93 & 0.165 & 0.180 & 0.916 & Run com & eted & & \\
\hline & $1 \mathrm{~A}-15$ & 3260 & 2970 & 1. 10 & 0.043 & 0.039 & 1. 10 & Run com & ted & & \\
\hline & 53 & 3900 & 3960 & 0.98 & 0.172 & 0.132 & 1. 30 & Run com & eted & & \\
\hline & 35 & $\sim 4200$ & -- & -- & 0.017 & -- & - & Run com & eted & & \\
\hline & 40 & 4050 & 3960 & 1.02 & 0.114 & 0.132 & 0.86 & Run com & eted & & \\
\hline & $59 \mathrm{R}$ & 4200 & 3960 & 1.06 & 0.400 & 0.132 & 3.03 & $\begin{array}{l}\text { Test run } \\
\text { failed fr }\end{array}$ & $\begin{array}{l}\text { atil heat sh } \\
\text { recessior }\end{array}$ & & \\
\hline
\end{tabular}


Using ATAC with the wedge model, the heat shield temperatures were forced to follow the measured heat shield temperatures for each of the tests in question and the capsule and fuel simulant were permitted to respond in accordance with the two-dimensional model thermal characteristics. In this way the accuracy of the internal temperature field could be verified independently of the heat shield response or the imposed heat flux.

Next, the actual calibrated test environment from each of the tests was applied to the heat shield surface and the entire model was permitted to respond.

Finally, the ablative program was used to obtain surface recession values. The test model surface temperatures from each of the five chosen tests were input to the one-dimensional T-CAP model.

\section{Correlation Results}

The correlations results are presented in Figs. 11 through 15. Comparable temperatures are generally within $200^{\circ} \mathrm{F}$ except for Model 9a. At this time, no satisfactory solution to this problem has been determined. The calculated integrated surface recession rate is plotted for each test and the actual value measured after each test is indicated on the curve. In general, the scatter of the surface recession data is significantly greater than either the internal or surface temperature data. A summary of the five correlation analyses and their relative accuracies is presented in Table 3 .

\section{TABLE 3}

Summary of Correlation Results

\begin{tabular}{|c|c|c|c|c|c|c|c|c|}
\hline $\begin{array}{c}\text { Test } \\
\text { Unit } \\
\text { Serial } \\
\text { Number } \\
\end{array}$ & $\begin{array}{c}\text { As - } \\
\text { sembly } \\
\end{array}$ & $\begin{array}{l}\text { Simulated } \\
\text { Heat Flux }\end{array}$ & $\begin{array}{c}\text { Highest } \\
\text { Recorded } \\
\text { Test } \\
\text { Temperature } \\
\left({ }^{\circ} \mathrm{F}\right) \\
\end{array}$ & $\begin{array}{c}\text { Predicted } \\
\text { Temperature } \\
\text { at Same } \\
\text { Time } \\
\left({ }^{\circ} \mathrm{F}\right) \\
\end{array}$ & $\begin{array}{c}\text { Error** } \\
(\%) \\
\end{array}$ & Test & $\begin{array}{c}\text { Total Surfa } \\
\text { Recessior } \\
\text { (in.) }\end{array}$ & $\begin{array}{l}\text { Error } * \\
(\%) \\
\end{array}$ \\
\hline 1 & -009 & $\begin{array}{l}\text { Side- } \\
\text { stable, } \\
203 \text { Btu/ } \\
\mathrm{ft}^{2}-\text { sec }\end{array}$ & 2600 & 2675 & +2.9 & 0.026 & 0.031 & +19.2 \\
\hline 3 & -009 & $\begin{array}{l}\text { Side- } \\
\text { spin } \\
1.0 \text { nom } \\
Q\end{array}$ & 2680 & 2600 & -3.1 & 0.035 & 00.0354 & +1.0 \\
\hline 6 & -029 & $\begin{array}{l}\text { Side- } \\
\text { spin } \\
1.3 \text { nom } \\
Q\end{array}$ & 2840 & 2720 & -4.4 & 0.027 & 0.0205 & -24 \\
\hline 7 & -019 & $\begin{array}{l}\text { Tumble- } \\
\text { spin } 1.0 \\
\text { nom Q }\end{array}$ & 2740 & 2800 & +2.1 & 0.032 & 0.032 & 0.0 \\
\hline $9 a$ & -039 & $\begin{array}{l}\text { End-on } \\
1.0 \text { nom } \\
Q\end{array}$ & 2880 & 2880 & 0.0 & 0.165 & 0.195 & +18 \\
\hline
\end{tabular}




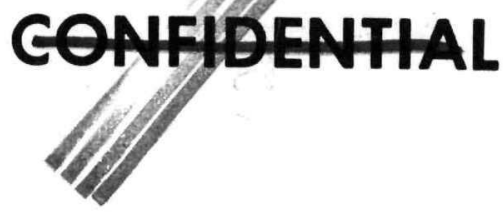

\section{CONCLUSIONS}

Preliminary studies have shown that peak reentry temperatures are relatively insensitive capsule to variations in thermal properties.

Design studies have shown side-stable and end-on re-entry modes are least desirable; a tumble-spin re-entry mode is most desirable.

Of all flight cases evaluated, surface recession is limited to 0.19 inch while peak fuel temperatures remain less than $3300^{\circ} \mathrm{F}$. Melting of the Haynes -25 alloy capsule occurred in almost all cases.

The thermal environments selected for test, within the restraints imposed by the arc facility, reasonably simulated the predicted re-entry thermal environments. The prototype IRHS provides an integrated thermal flux margin of safety of at least $400 \%$ for an orbital decay reentry with a side-stable mode. A greater margin of safety is anticipated for orbital decay re-entry than with any of the other modes.

Correlation of test data with corresponding computer predicted results indicate that the analytical techniques are sufficiently accurate in their prediction of temperature and surface recession responses.

The results of the aerothermal analysis and test and the subsequent confirmation of the analytical techniques demonstrated by the correlation study assure the intact re-entry capability of the IRHS. 


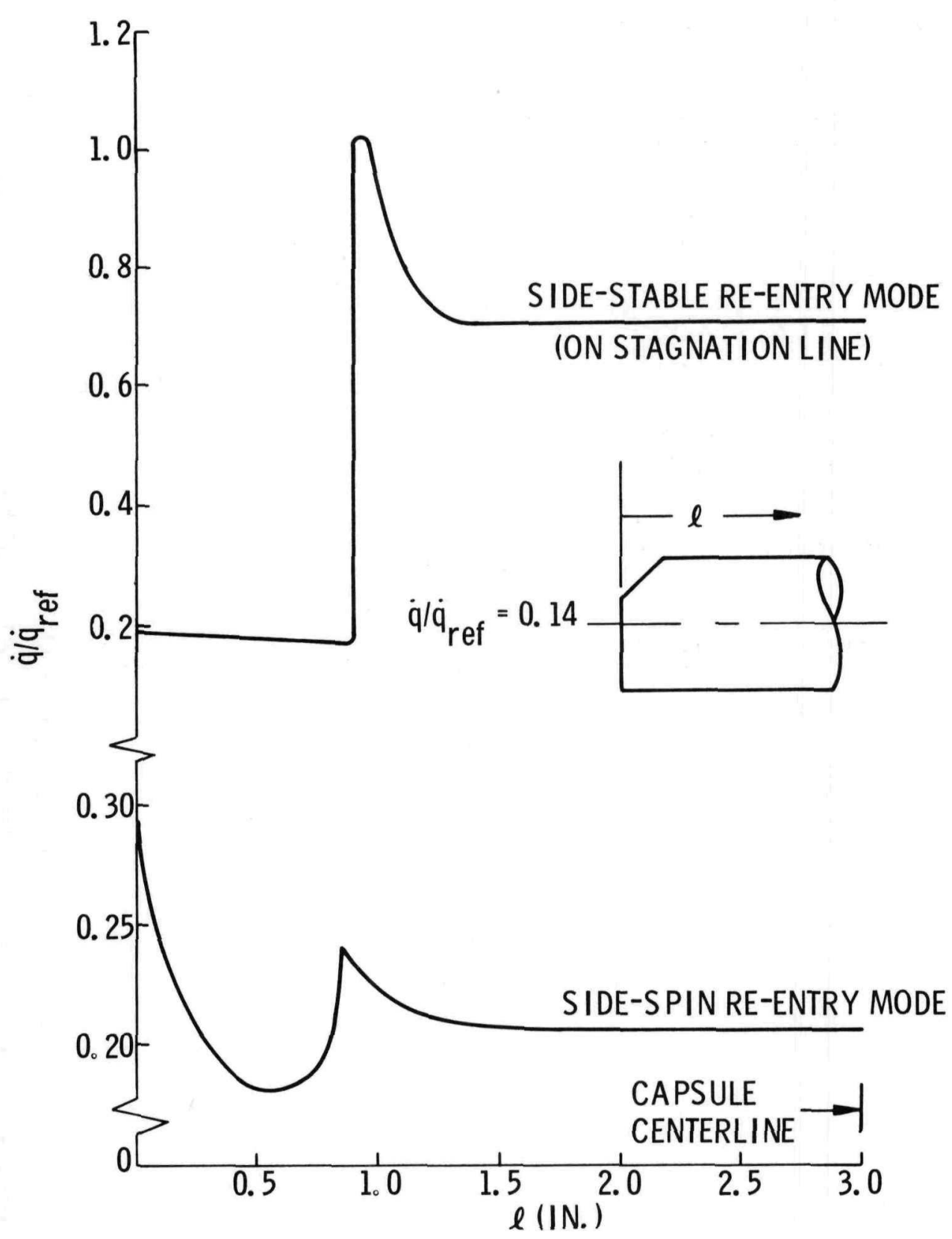

FIG. 1. HEAT FLUX DISTRIBUTION FOR SIDE-SPIN AND SIDE-STABLE RE-ENTRY MODES 


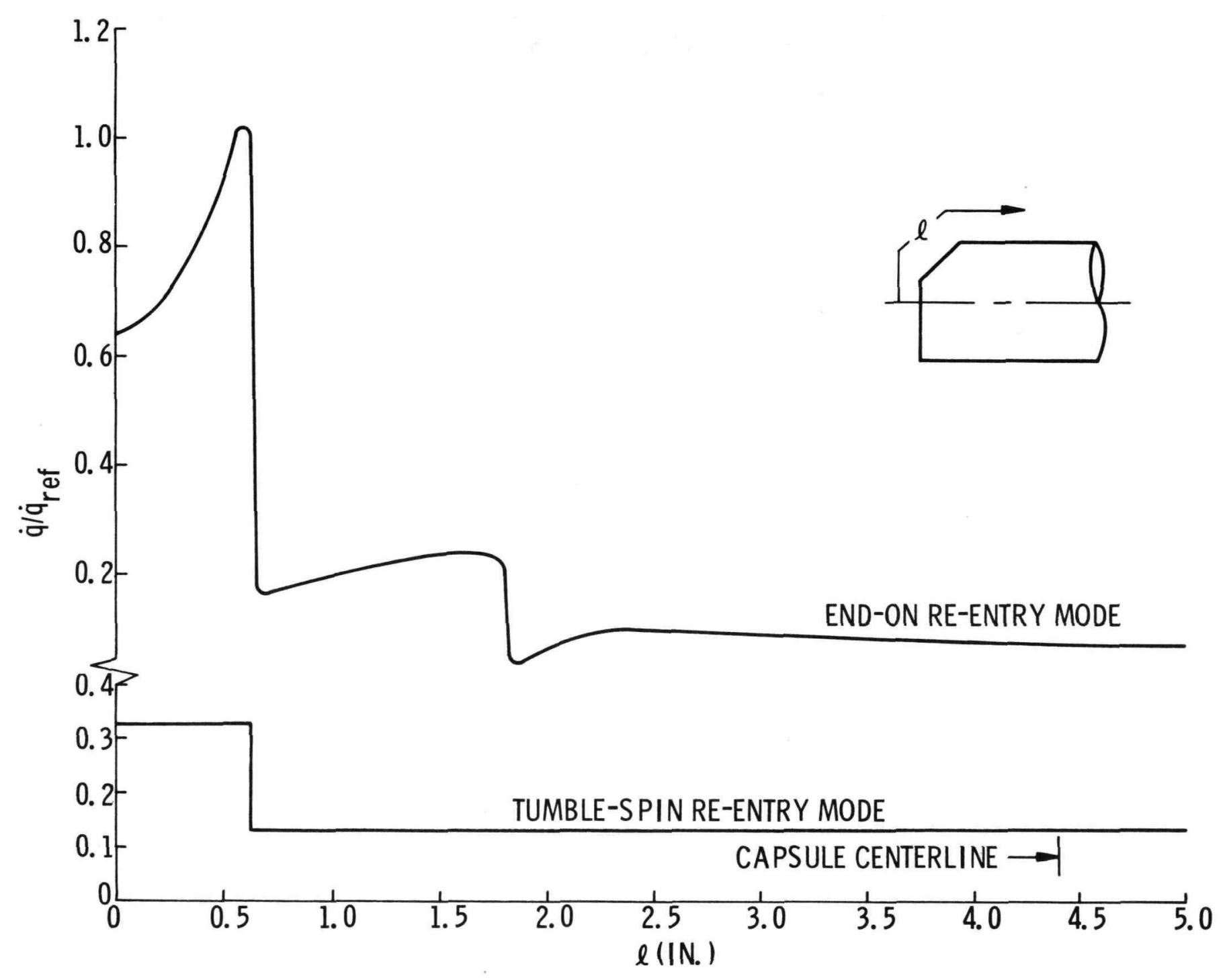

FIG. 2. HEAT FLUX DISTRIBUTION FOR END-ON AND TUMBLE-SPIN RE-ENTRY MODES 


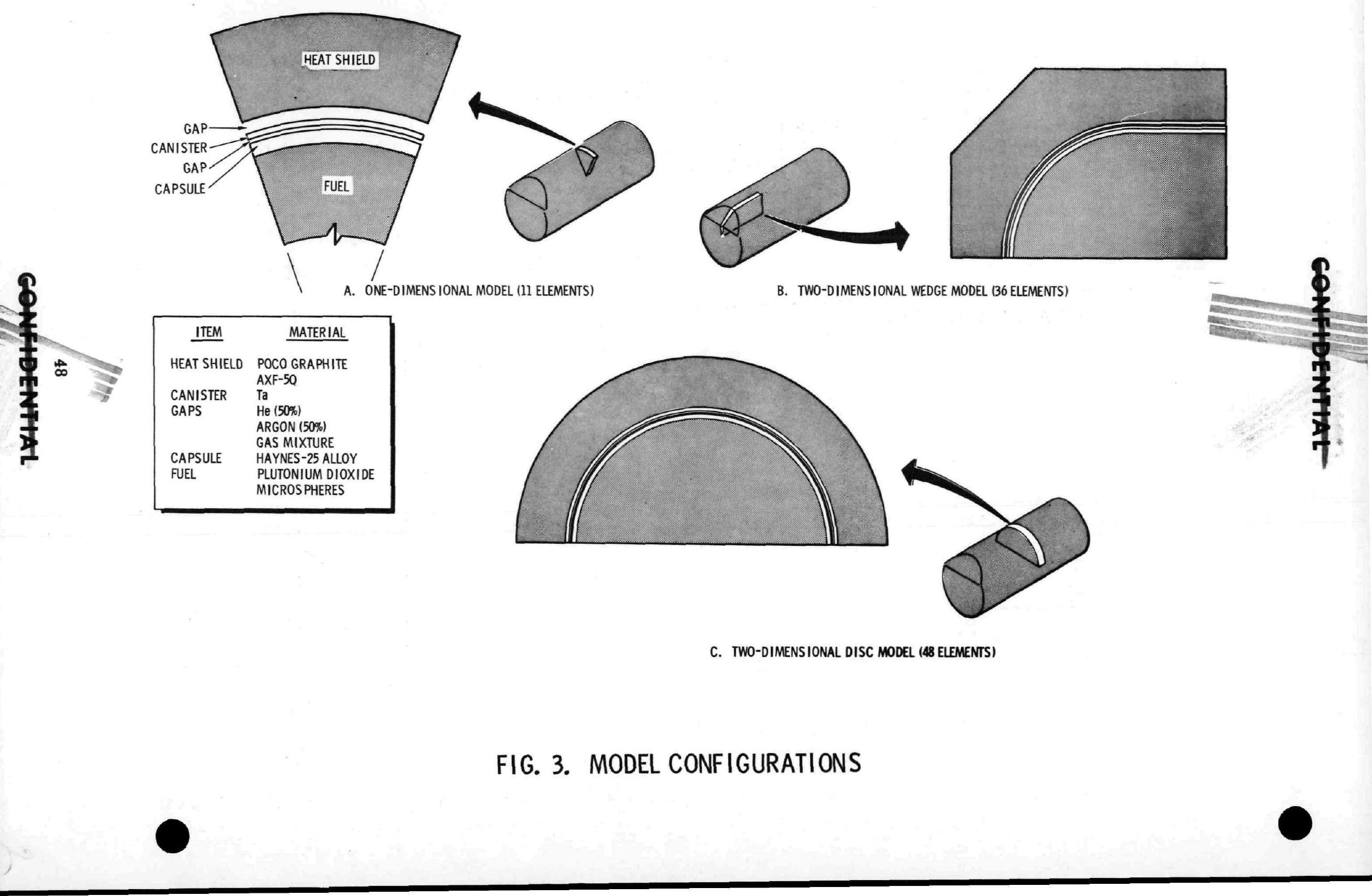




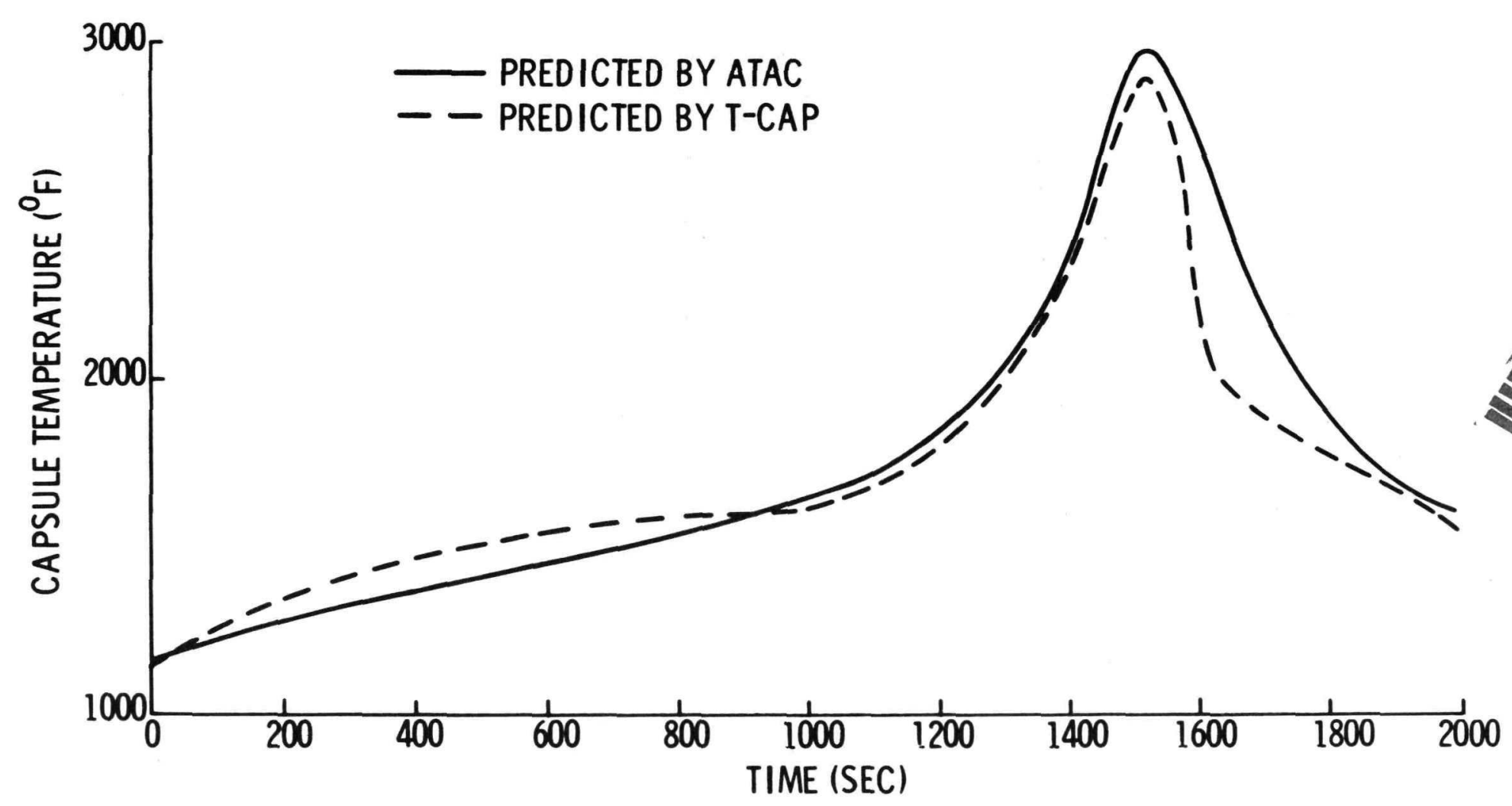

FIG. 4. ATAC AND T-CAP CAPSULE TEMPERATURE HISTORIES 


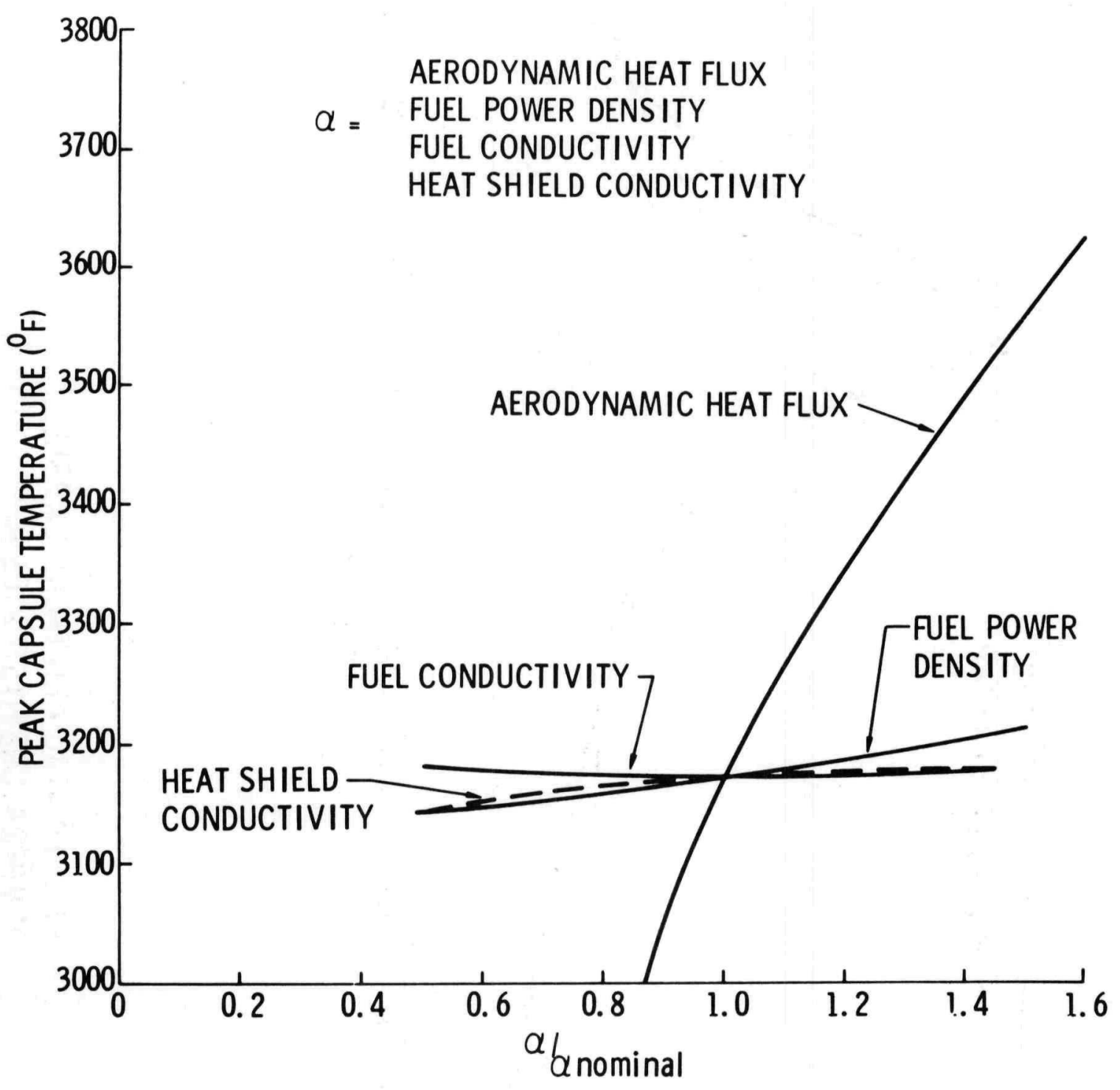

FIG. 5. TRADEOFF COMPARISONS 


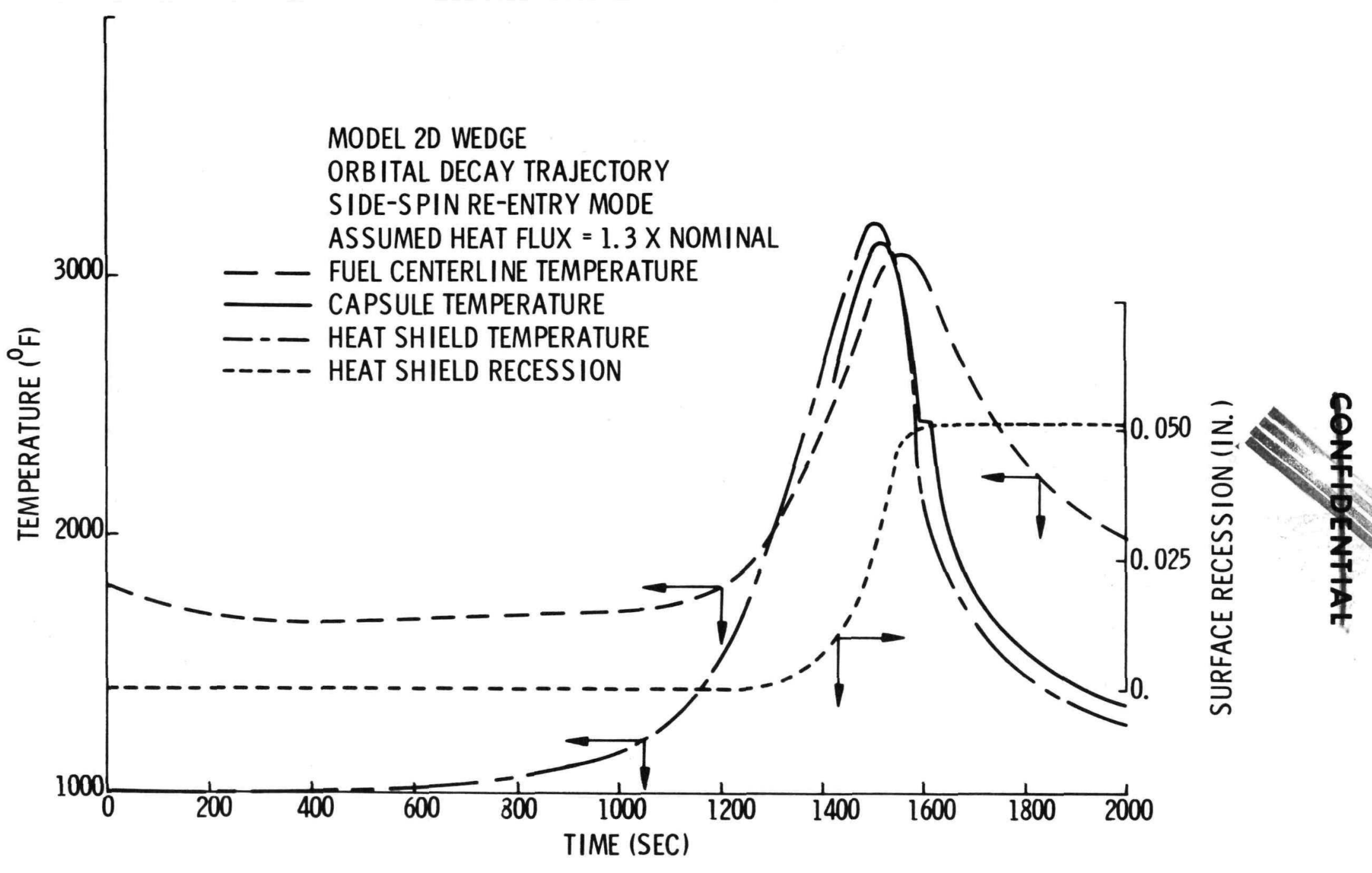

FIG. 6. ANALYTICAL RESULTS FOR DESIGN CASE 

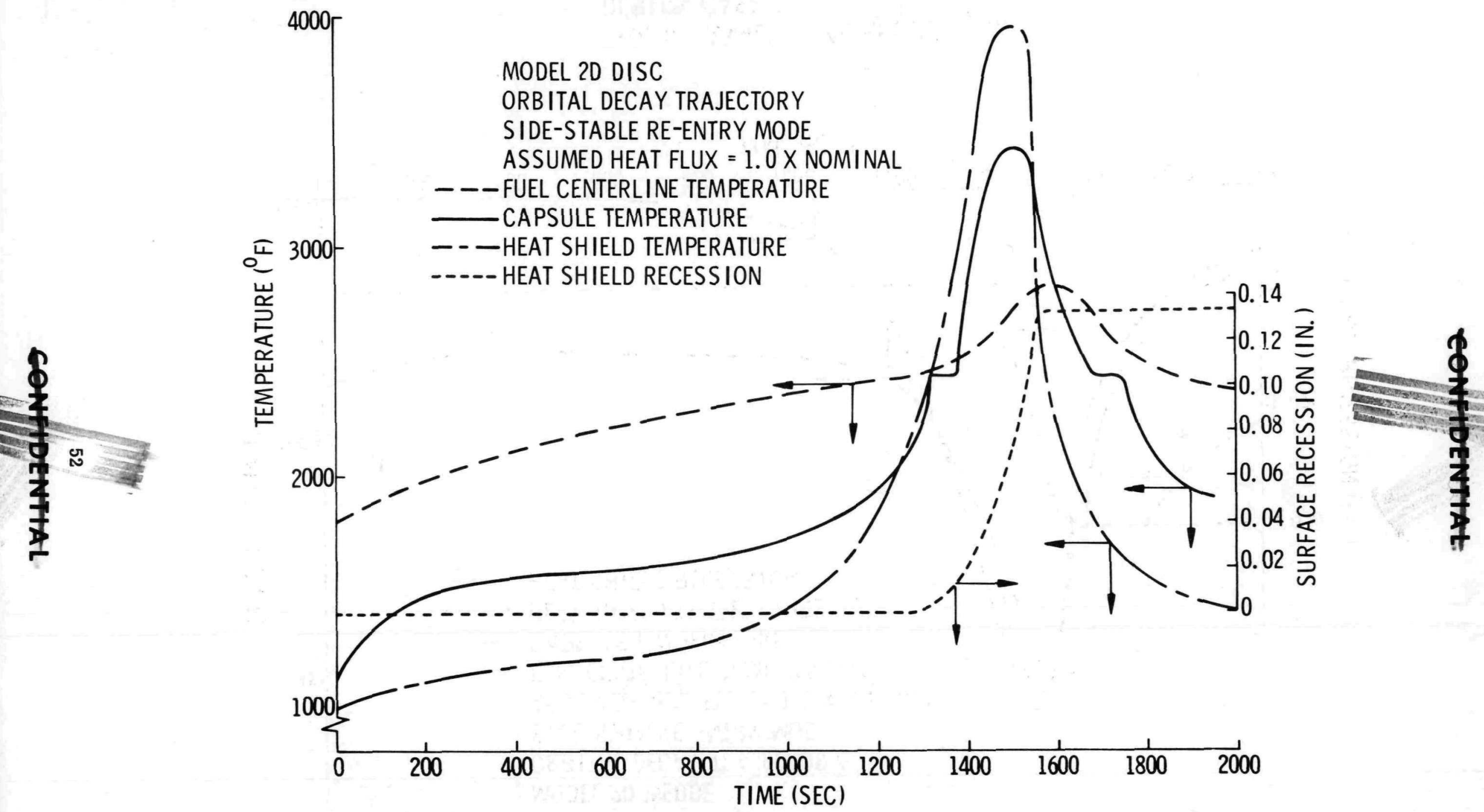

FIG. 7. ANALYTICAL RESULTS FOR SIDE-STABLE CASE 

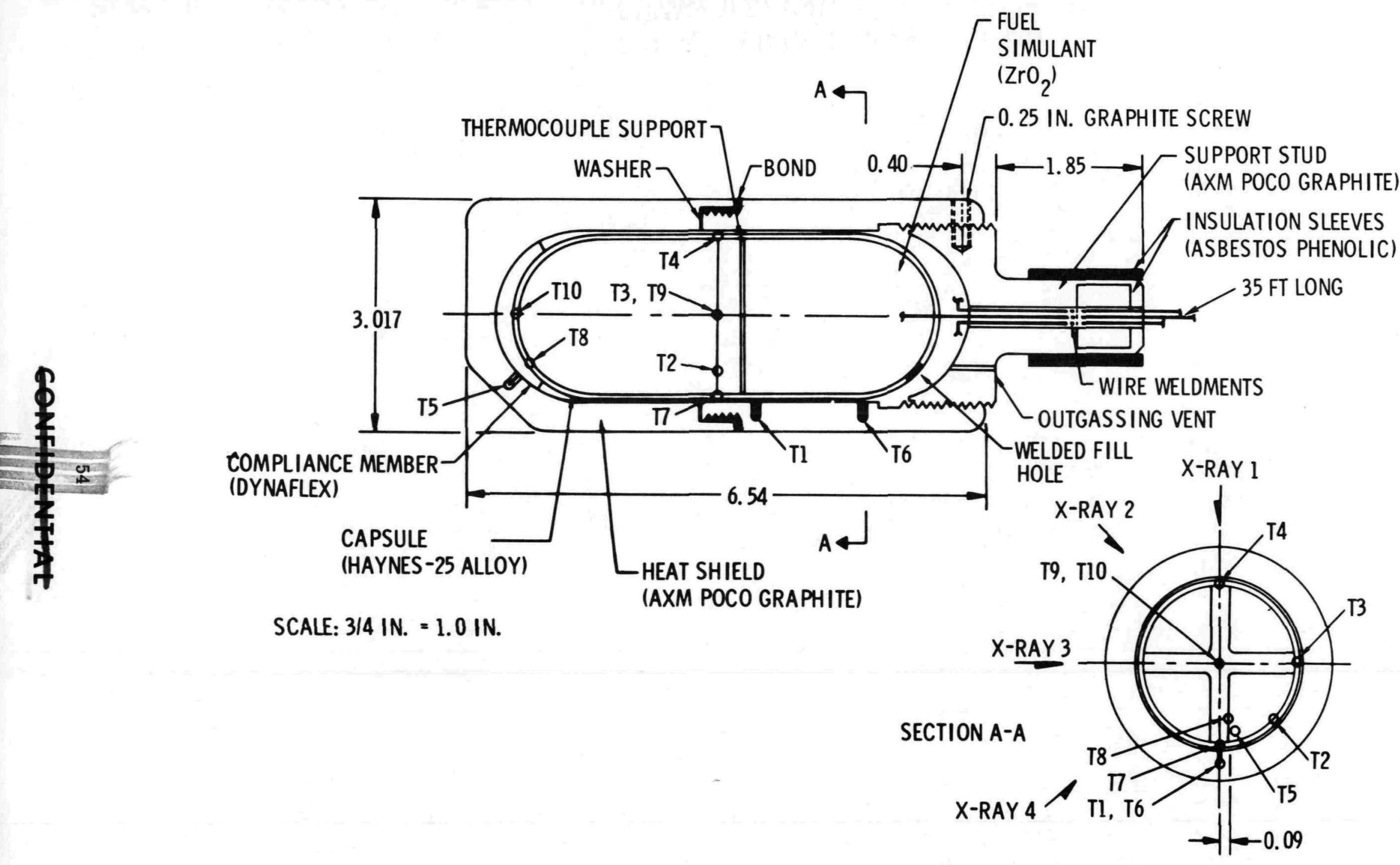

FIG. 9. SIDE-STABLE ASSEMBLY 


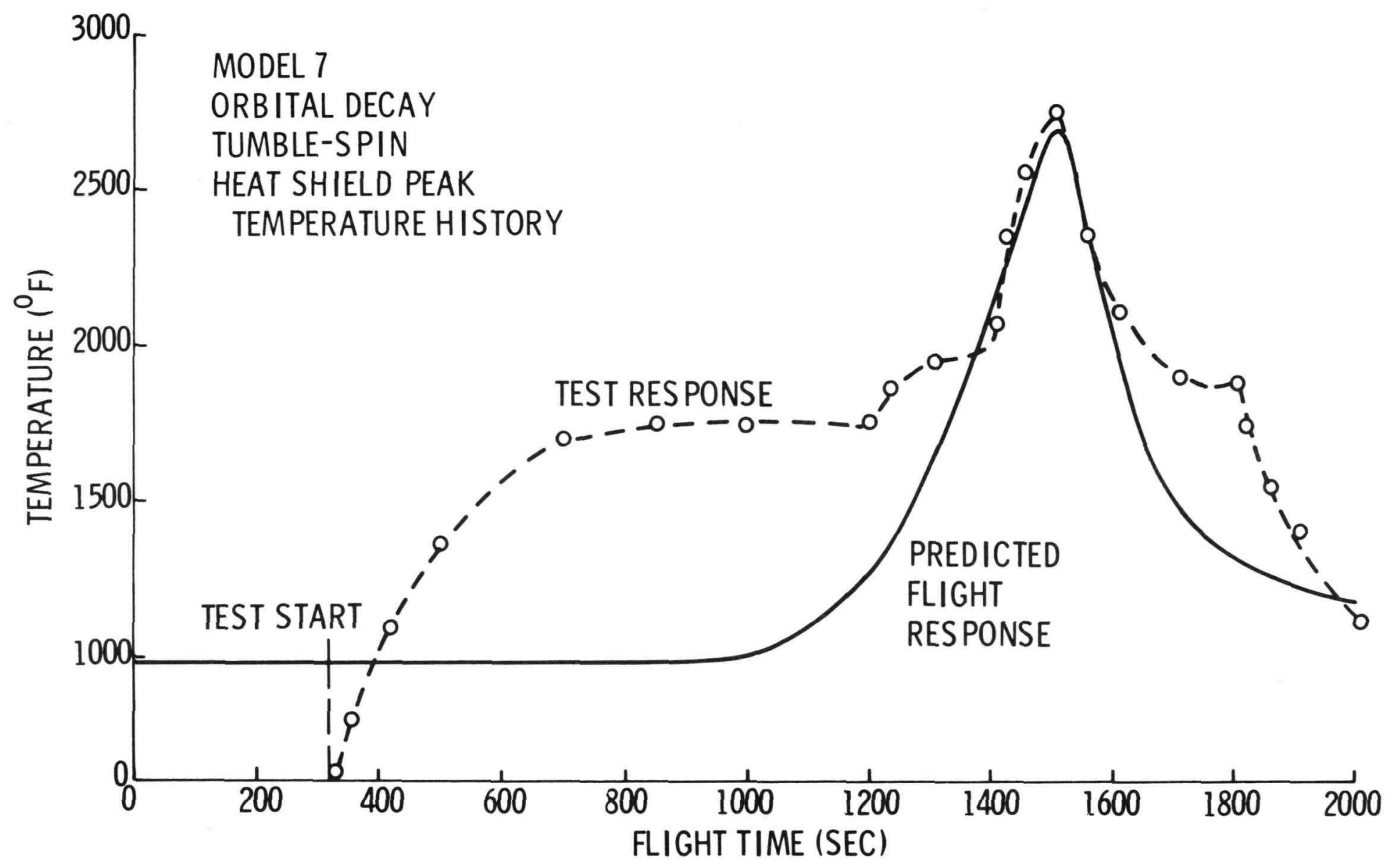

FIG. 10. TEST AND PREDICTED FLIGHT RESULTS 

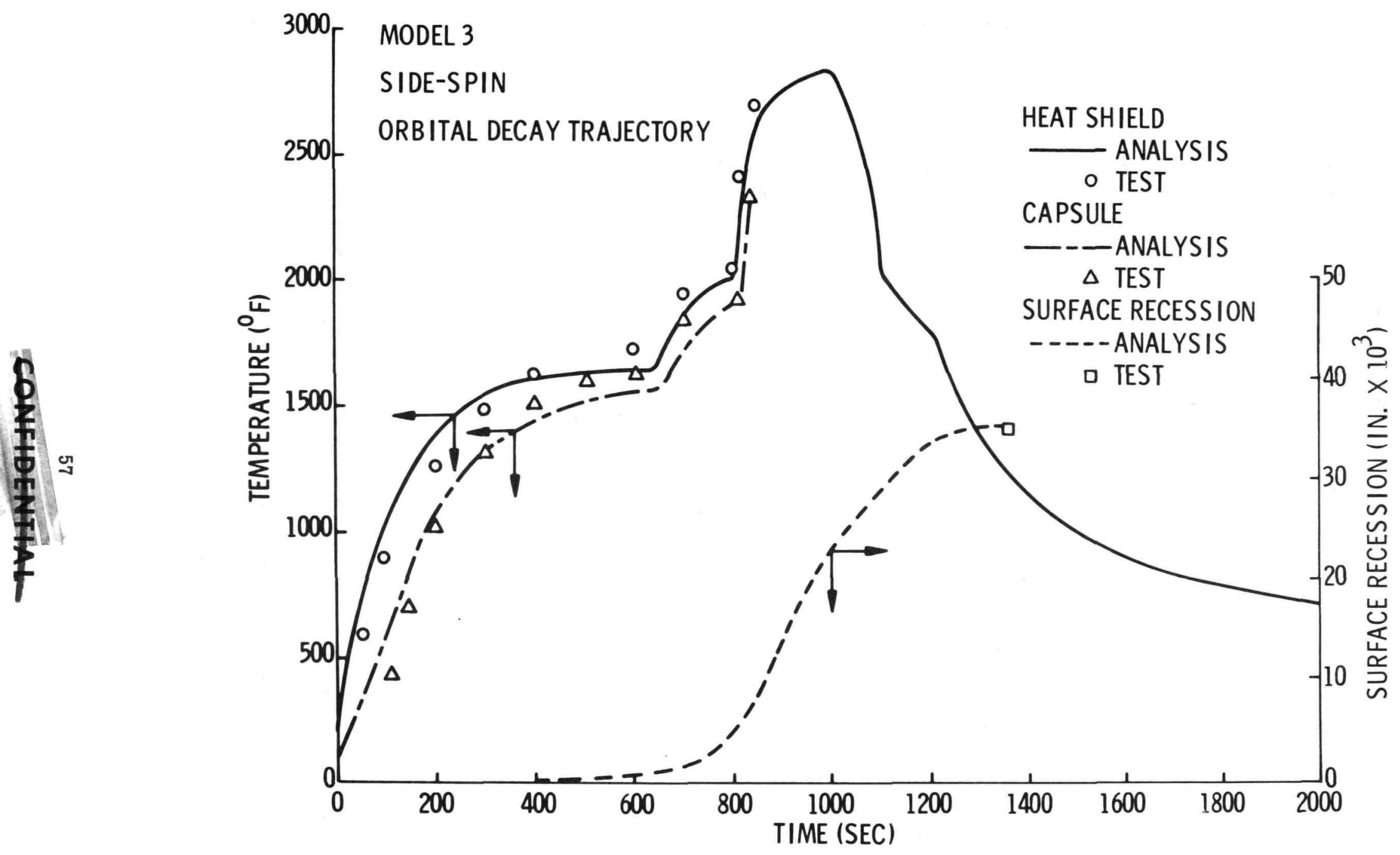

FIG. 12. CORRELATION RESULTS-PEAK TEMPERATURES AND SURFACE RECESSION 


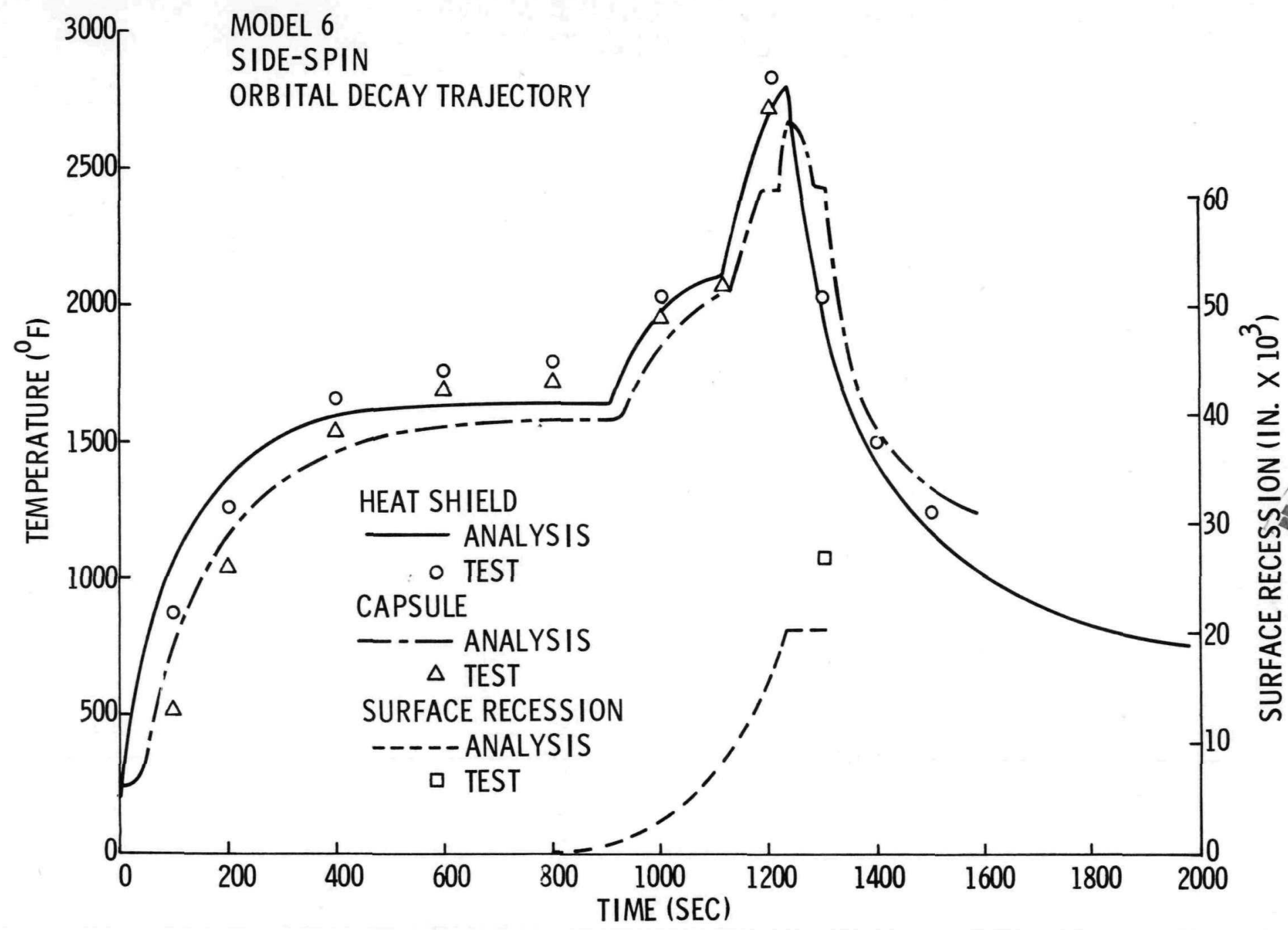

FIG. 13. CORRELATION RESULTS-PEAK TEMPERATURES AND SURFACE RECESSION 


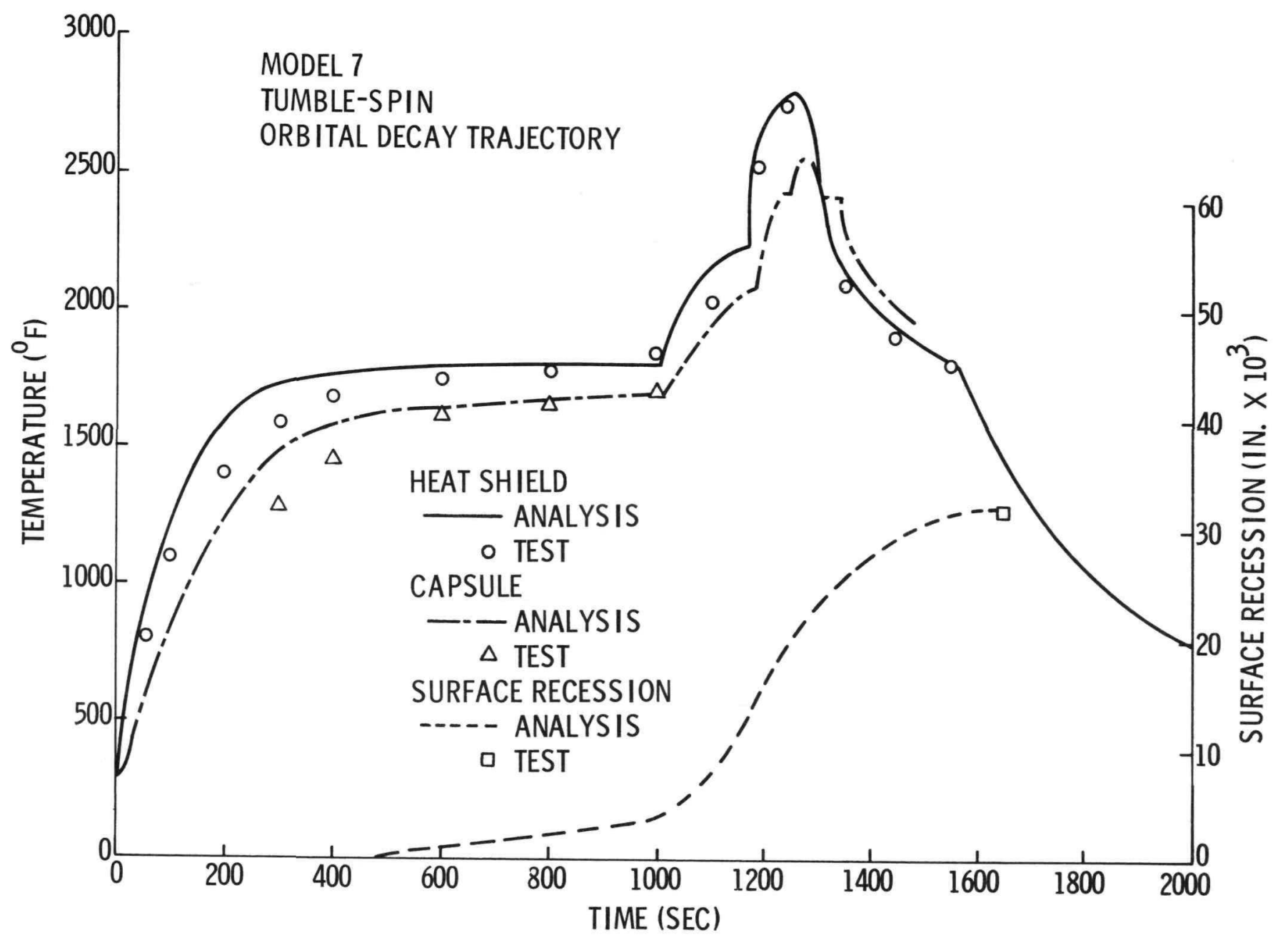

FIG. 14. CORRELATION RESULTS-PEAK TEMPERATURE AND SURFACE RECESSION 

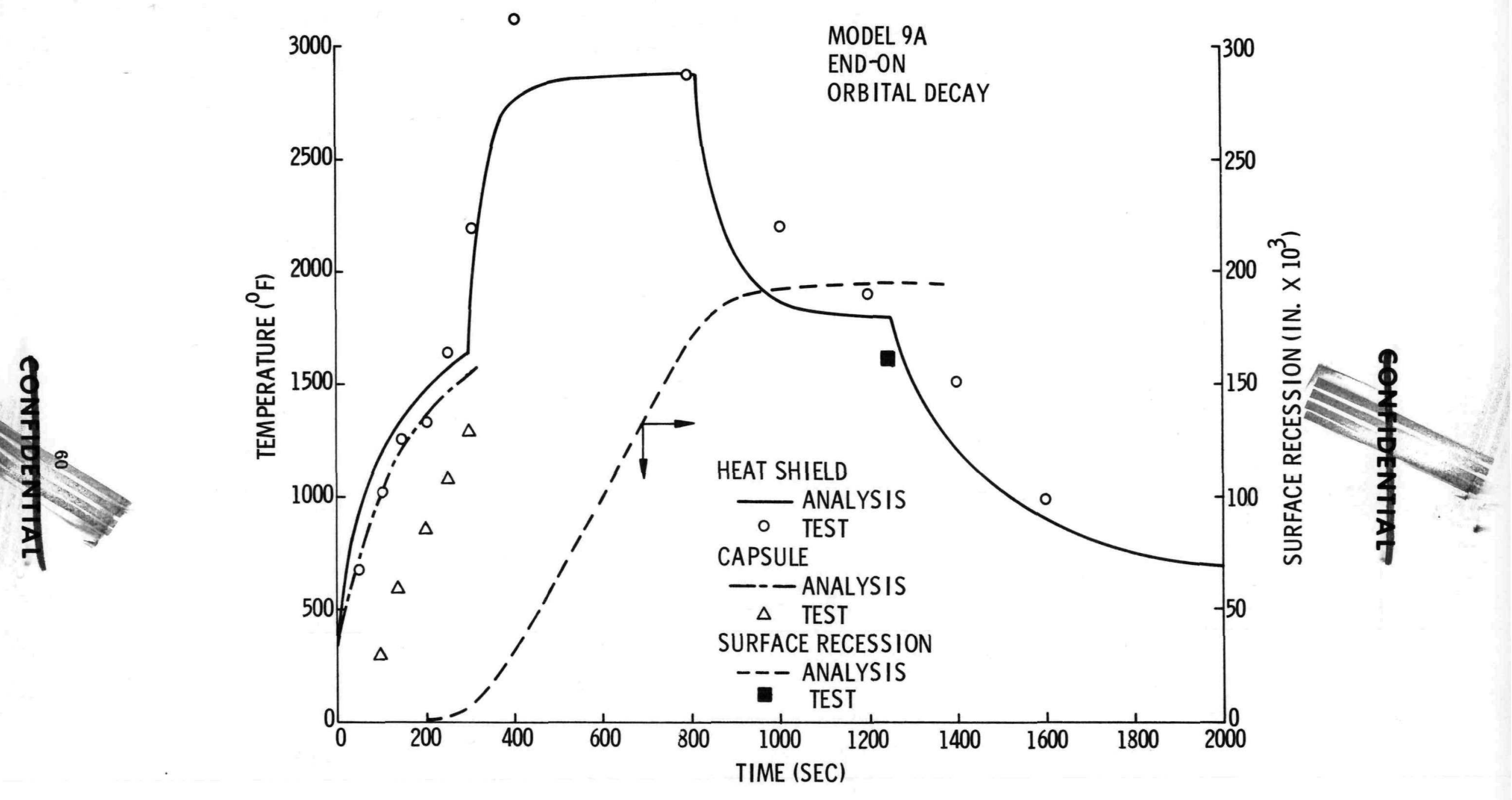

FIG. 15. CORRELATION RESULTS-PEAK TEMPERATURES AND SURFACE RECESSION 


\section{SNAP-27 RADIOISOTOPIC THERMOELECTRIC GENERATORS}

L. Sisler, 3M Company, St. Paul, Minnesota

A. Pitrolo, GE Company, Philadelphia, Pa.

\section{SUMMARY}

This paper presents the design, development, fabrication, and qualification of the SNAP-27 radioisotopic thermoelectric generator system, developed under contract AT(29-2) 2581 for the Atomic Energy Commision, is destined to power the Apollo Lunar Surface Experiment Package (ALSEP). The thermoelectric generator design analysis is presented along with resultant performance data which illustrates that the final output of 63.5 watts (end-of-life) exceeds the design goal of 56 watts.

\section{INTRODUCTION}

The SNAP-2 7 radioisotopic thermoelectric generator (RTG) system was designed and developed as the prime power supply for the NASA Apollo Lunar Surface Experiment Package (ALSEP). System definition was performed by the General Electric Company with the 3M Company as a major subcontractor. The 3M Company was responsible for manufacturing the thermoelectric materials, assembly, and checkout of the thermoelectric converter and assembly and test of modules to provide design support data.

Generator assemblies containing the thermoelectric converter built during the program represented three stages of development:

1) Engineering models instrumented to substantiate the thermopile design (3 units).

2) Qualification models fabricated and processed as specified for flight hardware (2 units).

3) Flight units for operation on lunar surface with ALSEP (5 units).

In addition to the generator assemblies, special test modules containing 10 and 104 thermoelectric couples were constructed and placed on test at 3M and GE. This program was oriented toward obtaining data to verify the design and provide basis for corrective action, if needed. These modules are continuing on test providing the most complete characterization of $\mathrm{PbTe}$ life testing available at this time. Some modules have been on test for over two years.

The SNAP-27 System consists of a complement of subsystems and components interlocked to support the power unit on the ground, during its powered flight to the moon, and on the lunar surface. The key components in the system are shown in Figure 1.

Design features of the system include:

\section{Generator Assembly (GA)}

Contains the thermoelectric conversion elements and the thermal system which receive and reject heat. GA is designed to receive the fuel capsule assembly when power is required - fueling to be performed by an astronaut on the lunar surface. Weight, without the fuel capsule, is less than 28.0 pounds. Power output will not be less than 63.5 watts after one year of lunar operation (initial design was 56.0 watts) providing a minimum conversion efficiency of 4 percent at end-of-life. Generator reliability, with fuel capsule, is 0.995. Generator performance is required after being subjected to loads produced by the Apollo booster system and exposure to one year of lunar day and lunar night cycling.

2. Fuel Capsule Assembly (FCA)

Heat source unit contains $1480 \pm 30$ watts of $\mathrm{Pu}-238$ plutonium dioxide fuel. Capsule weight with attaching backplate is 14.5 pounds. It is designed to contain fuel upon earth impact after free flight when capsule reaches terminal velocity. During earth storage capsule surface temperature is maintained at $500^{\circ} \mathrm{F}$ or lower. Transportation to the lunar surface on the Apollo system is accomplished within the Graphite Lunar Module (LM) Fuel Cask (GLFC) which supports the capsule during the environment.

3. Graphite LM Fuel Cask (GLFC)

A graphite structure designed to support the fuel capsule on the LM descent stage during powered flight. Upon arrival on the lunar surface, the fuel capsule is removed from the GLFC and inserted into the Generator Assembly. The GLFC provides re-entry protection to the fuel capsule (prohibits fuel release) should the LM be aborted during its normal mission.

4. Flight Handling Tool

A torque type jaw mechanism that engages the fuel capsule while in the GLFC such that capsule can be removed from the GLFC for insertion into the generator assembly.

5. Ground Support Equipment

Equipment designed and fabricated to support the system are:

a. Ground Shipping Cask - stores capsule while on earth

b. Test Console - operates and monitors ground testing of generator assembly

c. Ground Handling Tool - handles capsule while on earth

At the initiation of the SNAP -27 program, very little technology was available to commit a generator assembly design, yet schedule restraints required flight hardware deliveries 21 months after start of program. The program defined was therefore based 
on extensive system analysis. A component development activity was undertaken to support the analysis and to provide data for corrective action of potential problems.

This paper presents a summary of the design and development of the generator assembly. Initial systems analysis performed will be discussed followed by results of the thermoelectric test program. Finally, a summary accompanies the original prediction with the results obtained to date.

\section{GENERATOR ASSEMBLY DESCRIPTION}

The SNAP-27 generator assembly is shown in Figure 2. Beginning with the heat source, the thermal energy is radiated from the capsule to the generator hot frame. The heat received by the Inconel $102 *$ hot frame is then conducted through a boron nitride electrical insulator to the thermoelectric couple hot buttons which define the couple hot side temperature interface. Operation of the thermoelectric system was based on $1100^{\circ} \mathrm{F}$ hot junction $\left(\mathrm{T}_{\mathrm{h}}\right)$ and $525^{\circ} \mathrm{F}$ cold junction $\left(\mathrm{T}_{\mathrm{c}}\right)$ temperatures. Couples are arranged in a series parallel connection with each couple laddered to improved reliability. Packed between each leg of the couple is powdered Min-K** insulation to prevent excessive heat leakage between the thermoelectric elements. The cold side of the thermoelectric couple has a stainless steel barrier at each of the legs followed by hemispherical copper button. The spherical seat mates with a female surface of beryllium oxide follower. The sphericity permits axial misalignment to occur without system penalties. Heat flows through the copper into the $\mathrm{BeO}$ follower and then into a massive Be cold frame which minimizes the temperature maldistributions of system. Each leg is spring loaded to provide

150 psi pressure at the hot junction contact at operating temperatures.

Heat from the cold frame is then transferred to an outer case assembly and radiated to space. The outer case assembly has eight fins and is fabricated of beryllium. It is a shrink fit assembly on the beryllium cold frame. On each end of the outer case steel transition rings are brazed to the outer case. End seals are then brazed to the se rings to effect a hermetic seal for the 25 psia (at temperature) argon environment.

Internal wiring and choice of material was selected to minimize the magnetic field produced by the operating unit. Degaussing loops are shown at each end of the generator.

Typical features unique to the thermopile assembly are discussed below:

A preassembled row (series-parallel) of thermoelectric couples is shown in Figure 3 . This assembly consists of the spacer bar, boron nitride insert, hot electrode, hot junction button, and the thermoelectric couple. Also shown are instrumentation wires used in engineering models. Figure 4 shows the row of couples being installed between the hot frame and cold frame.

*Tradename of International Nickel

**Tradename of Johns-Manville
Once a row is installed, the couples are held in the permanent position by installing the followers, springs, shims, and spring retainers. A spring retainer is being positioned in Figure 5 .

The thermopile is complete when all rows of couples are installed and when the end circuit couples are assembled. Figure 6 is a photo of the thermopile assembly. Note the end circuit couples. The thermopile is then shrink fitted (for heat transfer purposes) into the outer case. Both ends of the converter are sealed to form a hermetic enclosure for the thermoelectric hardware.

\section{SYSTEMS ANALYSIS}

Design of the generator assembly was based on the following requirements established in 1965 by the AEC:

$\begin{array}{ll}\text { Electrical } & 56 \text { watts end of two foot } \\ \text { Output: } & \text { cable }\end{array}$

Instrumentation: Six sensors, for diagnostic

Reliability: $\quad 0.995$ for 1 year lunar operation

Design Environments: $\quad+250^{\circ} \mathrm{F}$ (equiv. sink $-280^{\circ} \mathrm{F}$ to $+170^{\circ} \mathrm{F}$ )

Pressure $1 \times 10^{-10} \mathrm{mmHg}$

Storage: $\quad$ Up to two years

Magnetic Field: 1 gamma @ 3 meters

To produce a generator design, the flow of analysis and trade-offs shown in Table I was followed. Each of the more significant items are discussed in detail below.

TABLE I. TRADE-OFF ANALYSIS

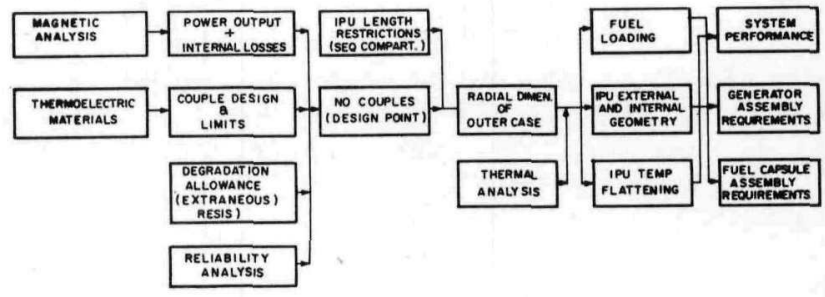

1. Selection of Thermoelectric Materials

a. Thermoelectric Material Selection: These factors were considered in the selection of the optimum $\mathrm{N}$ - and $\mathrm{P}$ materials for the generator. These factors were:

1) Efficiency

2) Chemical stability and compatibility

3) Mechanical compatibility 


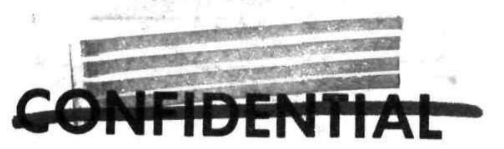

For materials having comparable efficiencies, the material exhibiting the greater Seebeck voltage was preferred, since fewer couples are required to meet electrical power requirements. Fewer parts, less generator weight, fewer contacts, and lower extraneous resistance would result from the use of higher voltage material. It was also desirable, from design and assembly considerations, to select $\mathrm{N}-$ and $\mathrm{P}$-materials for which the length-over-area ratio geometries for optimum performance are similar.

Three $\mathrm{N}$-type materials and two $\mathrm{P}$-type materials were surveyed. These materials were as follows:

$$
\text { N-Type }
$$

*TPM-10 (PbTe) (3N)

TPM-11 (PbTe) (2N)

TPM-108 (PbTe)

At the design temperature of $\mathrm{T}_{\mathrm{h}}=1100^{\circ} \mathrm{F}$ and $\mathrm{T}_{\mathrm{c}}=525^{\circ} \mathrm{F}$, the maximum theoretical leg conversion efficiency was computed. This, along with the load voltage, is shown in Table II.

TABLE II. THERMOELECTRIC MATERIAL COMPARISON

\begin{tabular}{|l|c|c|}
\hline Material & $\begin{array}{c}\text { Max } \\
\text { Efficiency }\end{array}$ & $\begin{array}{c}\text { Load Voltage } \\
\text { at Max } \\
\text { Efficiency }\end{array}$ \\
\hline TPM-108 & 6.33 & $33.2 \mathrm{mv}$ \\
TPM-10 & 5.95 & $38.5 \mathrm{mv}$ \\
TPM-11 & 5.13 & $53.8 \mathrm{mv}$ \\
TPM-19 & 6.40 & $48.8 \mathrm{mv}$ \\
TPM-15 & 6.10 & $37.3 \mathrm{mv}$ \\
\hline
\end{tabular}

In spite of its higher efficiency, TPM-19 was not considered for this application because of insufficient documented evidence to establish stability. Therefore, TPM-15 was selected as the P-leg material for this application. Chemical and mechanical stability and compatibility had been demonstrated for this material used in commercial generators. It has also been used exclusively as the hot end $\mathrm{P}$-material in other SNAP generators. Substantial documented test data demonstrating its performance with time has been accumulated on the se SNAP programs.

Selection of the N-type material was not as clearcut. Several factors were taken into consideration and engineering judgments were made based on past experience.

Table III shows a comparison of the three Ntype materials with the selected $\mathrm{P}$-material and a comparison of the three couple combinations.
The N-type material TPM-11 has a major disadvantage in that its efficiency is significantly lower than the other two types.

The length-to-area ratio of TPM-108 is almost twice as great as that of the P-leg, which is not desirable. It required significantly more couples than the other types. With this material, little fabrication or test experience has been accumulated.

Material TPM-10 yields a couple efficiency slightly lower than that of TPM-108. This is not considered significant, since the difference is within the measured precision of the property values. TPM-10 requires fewer couples than TPM-108 and its length-to-area ratio is sufficiently near that of the P-leg.

On the basis of these considerations, TPM-10 was selected as the N-type thermoelectric material to be used in the SNAP-27 couple.

\section{Couple Design}

a. Leg Size Determination:

1) L/A Ratio - Leg sizes were initially established by determining the optimum length-to-area (L/A) ratio of each leg. In this determination, first cut extraneous resistance associated with leads, electrodes, and contacts were taken into account. The amount of resistance added for each leg was based on results of tests conducted under a SNAP-21A and a SNAP-21B Program. The electrode hardware in these programs is very similar in size and configuration to that being used in the SNAP-2 7 couple design.

Examination of test data (recorded from individually instrumented legs used in

SNAP-21A test modules and prototype generators) shows a range of extraneous resistance associated with the $\mathrm{N}-\mathrm{leg}$ of from less than 1 milliohm to 3 milliohms. The extraneous resistance associated with the P-leg generally exhibits a much wider variation due to the fact that it is inherently more difficult to achieve a low resistance, hot contact.

The variation shown in the SNAP-21A data is typically in the range of 1 to 10 milliohms. Table IV shows a limited amount of data at specific points of time.

Examination of these data shows the relative extraneous resistance values associated with the $\mathrm{N}$ - and $\mathrm{P}$-legs. The values selected for the couple design are 1.7 milliohms for the N-leg and 3.0 milliohms for the P-leg. Requirement for additional margins could be made up by numbers of couples selected. 


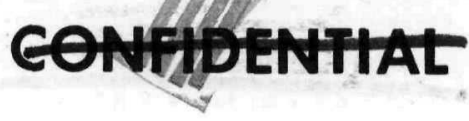

NOTE

Conditions are as follows: a. No extraneous resistance included.

b. Hot junction temperature $=1100^{\circ} \mathrm{F}$

c. Cold junction temperature $=525^{\circ} \mathrm{F}$

TABLE II. COMPARISON OF THERMOELECTRIC MATERIAL THEORETICAL PERFORMANCE CHARACTERISTICS

\begin{tabular}{|c|c|c|c|c|c|}
\hline & $\begin{array}{l}\text { I (L/A) at } \\
\text { Maximum } \\
\text { Efficiency } \\
\text { Amps/Inch }\end{array}$ & $\begin{array}{l}\text { Open } \\
\text { Circuit } \\
\text { Voltage } \\
\text { Millivolts }\end{array}$ & $\begin{array}{c}\text { Load Voltage } \\
\text { at Maximum } \\
\text { Efficiency } \\
\text { Millivolts }\end{array}$ & $\begin{array}{c}\text { Maximum } \\
\text { Theoretical } \\
\text { Efficiency } \\
\%\end{array}$ & $\begin{array}{l}\text { Total Couples } \\
\text { Required } \\
\text { for Two } \\
14-V o l t \\
\text { Circuits* }\end{array}$ \\
\hline $\begin{array}{l}\text { P-Leg } \\
\text { TPM-15 }\end{array}$ & 20.5 & 65.8 & 37.3 & 6.10 & - \\
\hline $\begin{array}{l}\text { N-Leg } \\
\text { TPM-108 }\end{array}$ & 37. 1 & 58.3 & 33.2 & 6.33 & - \\
\hline $\begin{array}{l}\text { Couple } \\
\text { TPM-15/TPM-108 }\end{array}$ & - & 124.1 & 70. 5 & 6. 21 & 397 \\
\hline $\begin{array}{l}\text { N-Leg } \\
\text { TPM-10 }\end{array}$ & 26.4 & 68.4 & 38.5 & 5. 95 & - \\
\hline $\begin{array}{l}\text { Couple } \\
\text { TPM-15/TPM-10 }\end{array}$ & - & 134.2 & 75.8 & 6.04 & 370 \\
\hline $\begin{array}{l}\text { N-Leg } \\
\text { TPM-11 }\end{array}$ & 19.3 & 79.2 & 43.8 & 5. 13 & - \\
\hline $\begin{array}{l}\text { Couple } \\
\text { TPM-15/TPM-11 }\end{array}$ & - & 145.2 & 81. 1 & 5. 52 & 345 \\
\hline
\end{tabular}

*Number of couples indicated here represents ideal conditions, not actual generator.

TABLE IV. SNAP-21A TYPI CAL EXTRANEOUS RESISTANCE $\left(R_{x}\right)$

\begin{tabular}{|l|c|c|c|}
\hline \multicolumn{1}{|c|}{ Device } & $\begin{array}{c}\mathrm{N} \text {-Leg } \mathrm{R} \\
(\mathrm{m} \Omega)\end{array}$ & $\begin{array}{c}\text { P-Leg R } \\
(\mathrm{m} \Omega)\end{array}$ & $\begin{array}{c}\text { Time in } \\
\text { Operation } \\
\text { (hour s) }\end{array}$ \\
\hline \hline Module A1 & 0.2 & 6.1 & 1250 \\
Module A3 & 1.0 & 2.5 & 2700 \\
Module A4 & 1.9 & 2.1 & 2256 \\
Prototype \#3 & 0.7 & 1.1 & 96 \\
Prototype \#3 & 1.2 & 9.4 & 2280 \\
Prototype \#3 & 0.7 & 7.2 & 2280 \\
Prototype \#4 & 2.5 & 2.9 & 24 \\
Prototype \#5 & 1.0 & 5.9 & 24 \\
Prototype \#5 & 2.0 & 9.9 & 24 \\
\hline
\end{tabular}

A computerized analysis was conducted for each leg in order to study the effect of variation in leg geometry (L/A) upon efficiency and load voltage. Figures 7 and 8 show the results of this analysis for the design temperature conditions and for a design load current of 2.0 amperes.

Plotted on the ordinate is the ratio of load current; the abscissa shows the matched load current. With the load current held fixed at 2.0 amperes, the matched load current varies by allowing the L/A ratio to vary.

This variation in L/A ratio is plotted, as well as efficiency and load voltage.

In the selection of the design point, it was desirable to achieve the highest load voltage while maintaining near-maximum efficiency. The efficiency curve is relatively flat over a wide range of the current ratio, while the load voltage decreased linearly with increasing current ratio.

Thus, it was desirable to select the design point at the far left of the flat portion of the efficiency curve. This yields highest load voltage with negligible loss in efficiency from the maximum efficiency point. 
Based on these considerations, the design point conditions were selected. These are summarized in Table V.

TABLE V. LEG DESIGN CHARACTERISTICS

\begin{tabular}{|c|c|c|c|}
\hline Characteristics & $\mathrm{N}$-Leg & P-Leg & Total \\
\hline $\begin{array}{l}\text { Length-to-Area } \\
\text { Ratio (inch-1) }\end{array}$ & 11.88 & 8.40 & \\
\hline Efficiency $(\%)$ & 5. 36 & 5.08 & 5.2 \\
\hline $\begin{array}{l}\text { Load Voltage } \\
\text { (millivolts) }\end{array}$ & 37.8 & 36.2 & 74.0 \\
\hline $\begin{array}{l}\text { Power Output } \\
\text { (watts) }\end{array}$ & 0.076 & 0.072 & 0.148 \\
\hline $\begin{array}{l}\text { Heat Input } \\
\text { (watts) }\end{array}$ & 1. 42 & 1. 43 & 2.85 \\
\hline $\begin{array}{l}\text { Load Current } \\
\text { (amps) }\end{array}$ & 2.0 & 2.0 & 2.0 \\
\hline $\begin{array}{l}\text { Hot Junction } \\
\text { Temperature }\left({ }^{\circ} \mathrm{F}\right)\end{array}$ & 1100 & 1100 & 1100 \\
\hline $\begin{array}{l}\text { Cold Junction } \\
\text { Temperature }\left({ }^{\circ} \mathrm{F}\right)\end{array}$ & 525 & 525 & 525 \\
\hline $\begin{array}{l}\text { Extraneous } \\
\text { Resistance } \\
\text { (milliohms) }\end{array}$ & 1. 7 & 3.0 & 4. 7 \\
\hline
\end{tabular}

Figures 9 through 12 show the predicted performance of each leg with load current variation from open circuit to short circuit conditions.

2) Leg Geometry - The following factors were considered for determination of the actual leg geometry.

a) Previous manufacturing experience had shown that length-over-diameter ratio should not be greater than four.

b) Legs should be of equal length to facilitate bonding.

c) Previous manufacturing experience has shown that the leg diameter should not be less than 0.187 inch.

d) The longer the leg, the less shifting of the cold frame (with respect to the hot frame) would influence the hotside contact.

e) The longer leg is less sensitive to ingradient thermal stresses.

f) A short leg reduces the size and weight of the generator.

g) A short leg is difficult to install into the generator.
These considerations were taken into account to determine the actual leg geometry. Emphasis was on selection of a leg size which would result in a reliable design.

To keep weight to a minimum, the legs would have to be small; but this conflicts with some of the other considerations. A very long leg would help satisfy some of the considerations, but would conflict with the length-over-diameter ratio maximum of four. A length of $0.400 \mathrm{inch}$ was selected for both the $\mathrm{N}$ - and P-legs. This selection was based on judgment from past experience in building thermoelectric generators. From the previously determined length-over-area ratios of the $\mathrm{N}$ - and $\mathrm{P}-\mathrm{leg}$, the diameters were calculated. The diameter of the N-leg was 0.207 inch and the P-leg, 0.247 inch.

3) Systems Degradation Analysis - With couple optimization based on $4.7 \mathrm{~m} \Omega$ extraneous resistance, futher work was performed on a systems basis to arrive at the number of couples necessary to meet performance. Additional unknown factors (expressed as extraneous resistance) would be compensated in the number of couples selected.

One such analysis was the use of a multiple regression technique on the data of two 6-couple modules (modules A2 and A3) and two 252-couple generators (prototypes No. 1 and No. 2). The test duration was approximately 7500 hours for the modules and 4000 hours for the prototypes. The hot and cold junction

temperatures were $1100^{\circ} \mathrm{F}$ and $200^{\circ} \mathrm{F}$, respectively.

The main objectives of the analysis were to:

a) Obtain an estimate of the behavior of system related to the thermoelectric couple as a function of parametric variation over its operating life.

b) Arrive at a method for predicting useful life.

c) Identify those system factors which contribute significantly to performance degradation.

d) Establish whether test results on a small module may be utilized to describe adequately the behavior of a large generator.

The method of multiple regression analysis consists of:

a) Obtaining a least squares curve fit for a dependent variable in terms of independent variables. 
b) Obtaining the linear relationship of the independent variables to each other.

c) Obtaining the linear relationship between the dependent variable'and the independent variables taken individually and as a group.

To perform the analysis, a step-wise multiple regression computer program was utilized. The program performs the least squares curve fit, the evaluation of the linear relationship among variables, and determines the multiple correlation coefficients.

The results of the analysis are as follows:

a) The variation in total resistance is a function of operating time; the module data on a per couple basis may, by appropriate scaling, be used to estimate the total resistance variation of a large generator.

b) The variation of open-circuit voltage and output current was found to be a function of hot and cold junction temperature fluctuations as well as operating time. For this reason, no estimate of the behavior of a large generator based upon the variation exhibited by a module appears feasible.

c) Expressions for resistance, opencircuit voltage and output current for modules and generators as functions of hot and cold junction temperature and operating time were obtained.

Inspection of the systems data generated show s that the performance of a system $(1 \sigma)$ would degrade by $17.5 \%$ in one year.

Since the SNAP-27 would employ many unique features such as full couple laddering (i.e., permit current flow to continue by by-passing the opened couple, increase internal wire size to reduce $\mathrm{I}^{2} \mathrm{R}$ losses), it was determined that a $9.25 \mathrm{~m} \Omega$ extraneous couple resistance would be conservative in sizing the system. Based on the theoretical resistance of the couples of $25.1 \mathrm{~m} \Omega$, an increase of $36.8 \%$ would be permitted. Converted to a power basis, beginning-of-life power (BOL) would be 70 watts, and end-of-life power (EOL) would be 56 watts, allowing for $19 \%$ degradation for nominal case. Therefore, the number of couples was selected on the basis of $9.25 \mathrm{~m} \Omega$ extraneous resistance.

\section{System Performance}

a. Design Point Selection: Using the design values of:

$$
\begin{aligned}
& \mathrm{T}_{\text {hot junction }}=1100^{\circ} \mathrm{F} \\
& \mathrm{T}_{\text {cold junction }}=525^{\circ} \mathrm{F}
\end{aligned}
$$

Extraneous resistance $(\mathrm{EOL})=9.25$ $\mathrm{m} \Omega /$ couple.

A design point selection was made for the SNAP-2 7 thermopile using maximum efficiency as the criterion for selection of the thermal input. Figure 13 summarizes this activity. Thermal input required to the thermopile is 1250 watts.

b. System Performance: EOL power for any system will be determined by the following variables:

1) Operating Mode of the Generator - If excess BOL power is returned to the generator, initial operating temperatures will be reduced by $80^{\circ} \mathrm{F}$ by means of Peltier cooling. This operation reduces degradation rates.

2) Tolerances of Fuel Capsule Loading Plus or minus 50 thermal watts is considered reasonable. Higher side loading increases power output but increases degradation. Converse is true for lower side loading.

3) Storage - Capsule stored on ground for two years will have decayed 37.5 watts by the end of lunar mission.

With the above factors, the SNAP-27 system performance characteristics were determined for:

a) Lunar Day

b) Lunar Night

c) Thermopile Thermal Energy 1250 Watts

d) Extraneous Resistance 0, $9.25 \mathrm{~m} \Omega /$ Couple

Figure 14 gives the lunar day performance for the system under design conditions. Note that two EI and power plots are presented. Zero extraneous resistance per couple represents the system theoretical performance utilizing nominal material characteristics. Traversing from $0 \mathrm{~m} \Omega$ to $9.25 \mathrm{~m} \Omega$ is indicative of a time variable and the control mode for the generator. The upper curves relate the hot and cold junction temperatures as functions of $R_{E}$ and current. 


\section{TEST PROGRAMS}

An extensive thermoelectric testing program was undertaken as part of the SNAP-27 program. It included the following:

1) Isothermal Materials Compatibility Testing

2) Thermoelectric Leg Product Specification Testing

3) 10-Couple Module Testing

4) 104-Couple Module Testing

Through this test program, the materials selected for the generator were evaluated for compatibility to assure that none of the materials in the final system would adversely affect thermoelectric performance. The thermoelectric legs were evaluated independent of other system components, such as contact electrodes, insulation material, and structure to establish firmly the specifications for the legs which would ensure reproducible performance of the key components of the system. Complete thermoelectric couple hardware performance was demonstrated under both design and off-design conditions by $10-$ couple test modules. System performance was demonstrated in the engineering and qualification test generators.

These programs, which progressed through a logical sequence from material selection to final system testing, are discussed as follows:

1. Isothermal Materials Compatibility

The objective of the compatibility test program was to determine the effect of SNAP-2 7 component materials on the chemical and physical properties of the thermoelectric legs in representative environments. The tests were conducted by encapsulating thermoelectric legs with combinations of SNAP-27 component materials in hermetically sealed quartz tubes. The tubes contain the components in an inert atmosphere and spatially arranged to simulate the actual SNAP-27 configuration. Twenty different thermopile materials in various combinations were assembled into 172 test fixtures. The test fixtures were soaked at isothermal conditions of $625^{\circ} \mathrm{F}$ (temperature margin added over design cold junction) or $1100^{\circ} \mathrm{F}$ for periods of time ranging from 25 hours to 4000 hours. Figure 15 shows a typical compatibility test fixture assembly.

The measure of compatibility is obtained by pre- and post-test comparison of:

- Emission spectrographic analysis of thermoelectric material

- Resistance versus length of thermoelectric material

- Gas analysis of inert atmosphere

- Visual examination of SNAP-27 component
The general results of the tests indicate that the components selected will provide a suitably stable, compatible system. The thermoelectric characteristics of the N-legs were stable at both temperature conditions for the entire duration with some sublimation evident under the high temperature long duration tests. The Plegs displayed their characteristic equilibrating in which the Seebeck coefficient and electrical resistivity decreased slightly during the first few hundred hours at high temperature.

2. Thermoelectric Leg Product Specification

The objectives of the Thermoelectric Leg Product Specification Program (TELPS) were to:

- Prepare a thermoelectric leg product specification with all necessary supporting test and process documents that identifies the manufactured properties and parameters of specific SNAP-2 7 thermoelectric materials as consistent with demonstrated performance.

- Prepare documents and develop inspection procedures to permit selection and acceptance of thermoelectric materials within the scope of the above specification.

- Develop and demonstrate a standard performance test for SNAP-27 elements.

The materials characterization was based on the following parameters:

- Seebeck coefficient

- Resistivity

- Shear strength

- Compressive/creep strength

- Thermal conductivity

- Density

- Coefficient of linear expansion

- Surface examination

- Metallographic examination

- Dimensions

- Gross composition

- Trace elements

- Oxygen content

Figure 16 shows the laboratory facilities established to accomplish this program. 
This test program has accomplished the following:

- Product specifications for SNAP-27 Ntype and P-type materials have been developed on the basis of an accumulation of data on a large statistical sample of production SNAP-2 7 legs.

- An ingradient test fixture and test procedure have been developed which have demonstrated capability of making rapid, accurate and precise measurements of ingradient resistance and Seebeck voltage values of SNAP-2 7 thermoelectric legs over extended periods of time and various junction temperatures without the need of special electrical contacts.

- Computerized techniques have been developed which handle the tasks of data reduction, normalization of performance data to specific operating junction temperatures, data sorting, and ultimate data plotting.

- A new rapid technique for the simultaneous determination of the thermoelectric properties, Seebeck coefficient, thermal conductivity, and electrical resistivity of individual test specimens as functions of temperature has been developed and tested. These test results have been used to establish a beginning-of-life specification limits on the thermoelectric properties of SNAP-27 materials.

- An ingradient soak test fixture and testing technique have been developed which have demonstrated the feasibility for largescale ingradient testing of thermoelectric legs.

\section{10-Couple Module Program}

To obtain an early assessment of the SNAP-27 couple performance, flat plate test devices containing 10 SNAP-27 couples were designed, fabricated and placed on test. Early modules contained beryllium components in order to test system compatibility with this material, which had not been previously used within a thermoelectric device. Each of the modules was instrumented such that leg temperatures and electrical characteristics could be readily measured. As the program progressed, additional modules were added so that a detailed evaluation of the thermopile variables could be made. A total of 19 modules was built.

Table VI identifies the modules and the conditions tested.

Figure 17 depicts a typical 10-couple module and Figure 18 shows the 10-couple test stations.

Results of this program are discussed as follows:

a. Hot Junction Temperature $\left(\mathrm{T}_{h}\right)$ : The effects of hot junction temperature on performance stability of SNAP-2 7 10-couple modules is illustrated with plots of normalized power, resistance and Seebeck voltage in Figure 19. Stable power output occurs at a hot junction temperature of approximately $1050^{\circ} \mathrm{F}$. At greater hot junction temperatures, however, the power degrades with time at a rate that increases with hot junction temperature. This power degradation results from a resistance increase caused principally by the $\mathrm{N}-\mathrm{leg}$.

The effects of hot junction temperature on $\mathrm{N}$-leg resistance change with time is shown in Figure 20. The rate of resistance change is extremely sensitive to hot junction temperature at temperatures above $1050^{\circ} \mathrm{F}$. The cause of this degradation has been identified as sublimation of PbTe from the hot end of the thermoelectric leg which reduces the area of contact between the thermoelectric element and the hot button. The reduction in contact area and the reduced leg area results in an increase in effective leg resistance.

The test results indicate that for missions of one year, the generator hot junction temperature is optimum at $1100^{\circ} \mathrm{F}$, but for operational life in excess of one year, the hot junction temperature should be designed for approximately $1050^{\circ} \mathrm{F}$ or less.

b. Cold Junction Temperature: Power output stability is shown in Figure 21 to be insensitive to cold junction temperatures up to $625^{\circ} \mathrm{F}$.

c. Thermal Cycle: Thermal cycling that will occur during operation on the lunar surface was simulated in two 10-couple modules. The performance is compared to modules operating at constant temperatures and shows that no adverse effects from thermal cycling should be expected (Figure 22).

d. Contact Pressure: The effects on performance of contact pressure at the hot junction between the thermoelectric legs and the hot buttons is shown in Figure 23. Increasing the contact pressure from the nominal value of $150 \mathrm{psi}$ to $250 \mathrm{psi}$ increases the stability of power output by reducing variations in the resistance. Examination of the individual leg resistance data indicates the increased contact pressure reduces the resistance variation during the first $2000-$ hour period by effecting an earlier stabilization P-leg resistance. Beyond 4000 hours, the improvement at 250 psi results from a lower N-leg degradation rate.

e. Reduced Gas Pressure: The effects of internal gas pressure on performance stability was measured in modules operating at less than the nominal 25 psia gas pressure in order to establish the effect of hermetic seal leakage in a vacuum environment upon long-term performance. The power output results are shown in Figure 24. Reducing the gas pressure significantly increases the degradation rate. The degradation is caused by a resistance increase of both the $\mathrm{N}$ - and P-legs at the 
TABLE VI. 10-COUPLA MODULE TEST SUMMARY

\begin{tabular}{|c|c|c|c|}
\hline Module & Test Description & $\begin{array}{c}\text { Operating } \\
\text { Time* Hours }\end{array}$ & Comments \\
\hline ST $10 B-1$ & $\begin{array}{l}\text { Design performance/beryllium compatibility } \\
1100 / 525^{\circ} \mathrm{F}\end{array}$ & 2,225 & $\begin{array}{l}\text { Terminated and post-test } \\
\text { analyzed }\end{array}$ \\
\hline ST $10 B-2$ & $\begin{array}{l}\text { Design performance/beryllium compatibility } \\
11009525^{\circ} \mathrm{F}\end{array}$ & 16,655 & Continuing \\
\hline $\mathrm{ST} 10 \mathrm{C}-3$ & Design performance $1100 / 525^{\circ} \mathrm{F}$ & 1,832 & $\begin{array}{l}\text { Terminated and post-test } \\
\text { analyzed }\end{array}$ \\
\hline $\mathrm{ST} 10 \mathrm{C}-4$ & Design performance $1100 / 525^{\circ} \mathrm{F}$ & 16,416 & Continuing \\
\hline LT $10 \mathrm{C}-5$ & $\begin{array}{l}\text { Off-design hot junction temperature } \\
1130 / 525^{\circ} \mathrm{F}\end{array}$ & 14,496 & Continuing \\
\hline LT $10 \mathrm{C}-6$ & $\begin{array}{l}\text { Off-design hot junction temperature } \\
1130 / 525^{\circ} \mathrm{F}\end{array}$ & 14,564 & Continuing \\
\hline LT $10 \mathrm{C}-7$ & $\begin{array}{l}\text { Off-design hot junction temperature } \\
1050 / 525^{\circ} \mathrm{F}\end{array}$ & 13,919 & Continuing \\
\hline $\mathrm{LT} 10 \mathrm{C}-8$ & $\begin{array}{l}\text { Off-design hot junction temperature } \\
1050 / 525^{\circ} \mathrm{F}\end{array}$ & 13,919 & Continuing \\
\hline LT $10 \mathrm{C}-9$ & $\begin{array}{l}\text { Off-design hot junction temperature } \\
1200 / 525^{\circ} \mathrm{F}\end{array}$ & 14,454 & Continuing \\
\hline LT $10 \mathrm{C}-10$ & $\begin{array}{l}\text { Off-design hot junction temperature } \\
1200 / 525^{\circ} \mathrm{F}\end{array}$ & 13,140 & Continuing \\
\hline $\mathrm{LT} 10 \mathrm{C}-11$ & $\begin{array}{l}\text { Reduced internal gas pressure } 16 \text { psia } \\
\text { (nominal design is } 25 \text { psia) }\end{array}$ & 13,415 & Continuing \\
\hline $\mathrm{LT} 10 \mathrm{C}-12$ & Reduced internal gas pressure 0.5 psia & 6,100 & Terminated \\
\hline LT $10 \mathrm{C}-13$ & Thermal cycle $1100 / 525-1060 / 460^{\circ} \mathrm{F}$ & 11,448 & Continuing \\
\hline LT $10 \mathrm{C}-14$ & $\begin{array}{l}\text { Increased leg contact pressure } 250 \text { psi } \\
\text { (nominal design is } 150 \text { psi) }\end{array}$ & 10,504 & Continuing \\
\hline $\operatorname{LT} 10 \mathrm{C}-15$ & Increased leg contact pressure 250 psi & 11,180 & Continuing \\
\hline $\mathrm{LT} 10 \mathrm{C}-16$ & Reduced internal gas pressure 5.0 psia & 5,590 & Continuing \\
\hline $\mathrm{LT} 10 \mathrm{C}-17$ & Thermal cycle $1100 / 525-1060 / 460^{\circ} \mathrm{F}$ & 11,364 & Continuing \\
\hline $\mathrm{LT} 10 \mathrm{C}-18$ & $\begin{array}{l}\text { Elevated cold flunction temperature } \\
1100 / 575^{\circ} \mathrm{F}\end{array}$ & 11,381 & Continuing \\
\hline LT $10 \mathrm{C}-19$ & $\begin{array}{l}\text { Elevated cold junction temperature } \\
1100 / 625^{\circ} \mathrm{F}\end{array}$ & 10,959 & Continuing \\
\hline & Total Module Hours & 213,561 & \\
\hline
\end{tabular}

*As of 26 April 1968.

low gas pressures. As in the case of hot junction temperature, the degradation is the result of sublimation of PbTe from the hot end of the thermoelectric legs which causes a contact resistance increase.
In similar tests, gas constituents were found to affect performance stability. Xenon gas provides a more stable system than one with argon. The reason for this, apparently, is that the larger, less mobile xenon molecules deter sublimation of the thermoelectric materials. 
TABLE VII. 104-COUPLE MODULE TEST SUMMARY

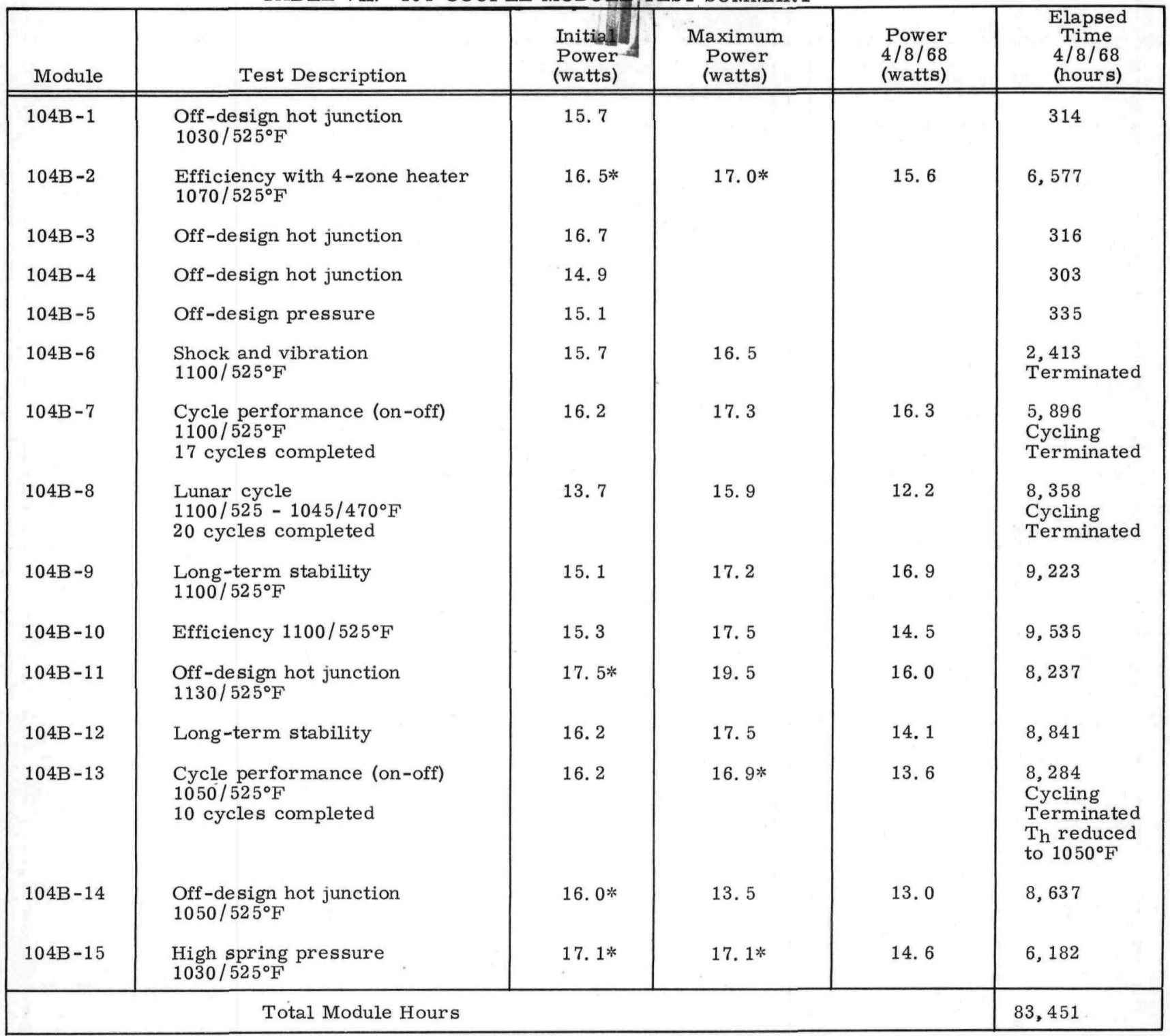

*At $1100 / 525^{\circ} \mathrm{F}$

\section{104-Couple Module Program}

The second major evaluation program for the SNAP -27 thermopile design was conducted by use of "foreshortened" SNAP-27 generator. The module shown in Figure 25 represents a $1 / 4$ length of the system and uses identical materials and design for the thermopile. Extensive instrumentation was employed in order to measure couple, row, system temperature gradients, and electrical performance characteristics. Fifteen modules were built and 12 placed on long-term extensive testing. Table VII summarizes the 104-couple test program.
Results were in agreement with the data presented above for the 10-couple module program.

\section{CONCLUSIONS}

Results to date have shown the program to be extremely successful. The generators have all performed as designed with the exception that the degradation was much less than the design allowed. This resulted in the upgrading of the end-of-life performance from the initial value of 56.0 watts to 63.5 watts.

A total of 25, 000 generator test hours were accumulated by the end of the first quarter of 1968 . One generator has been tested for over 10,000 hours at 
TABLE VII. TEST SUMMARY FOR THF SNAP-2 7 FLIGHT GENERATOR ASSEMBLIES

\begin{tabular}{|c|c|c|c|c|c|c|c|}
\hline \multicolumn{3}{|c|}{ Operating Conditions } & \multirow[b]{2}{*}{$\begin{array}{c}\text { Mod } 13 \\
\text { GA } \\
\text { S/N } 6320006 \\
\end{array}$} & \multirow[b]{2}{*}{\begin{tabular}{|c}
\multicolumn{2}{c}{$\begin{array}{c}\text { Mod } 19 \\
\text { GA }\end{array}$} \\
S/N 6320009 \\
\end{tabular}} & \multirow[b]{2}{*}{$\begin{array}{c}\begin{array}{c}\text { Mod 21 } \\
\text { GA }\end{array} \\
\text { S/N 6320011 } \\
\end{array}$} & \multirow[b]{2}{*}{$\begin{array}{c}\text { Mod 22 } \\
\text { GA } \\
\text { S/N } 6320012 \\
\end{array}$} & \multirow[b]{2}{*}{$\begin{array}{c}\text { Mod 23 } \\
\text { GA } \\
\text { S/N } 6320013 \\
\end{array}$} \\
\hline $\begin{array}{l}\text { Power } \\
\text { Input }\end{array}$ & $\begin{array}{l}\text { Eqv. } \\
\text { Load }\end{array}$ & $\begin{array}{c}\text { Sink } \\
\text { Temp. } \\
\left({ }^{\circ} \mathrm{F}\right)\end{array}$ & & & & & \\
\hline $1505 W$ & $16 \mathrm{~V}$ & +170 & $69.8 \mathrm{~W}$ & $69.1 \mathrm{~W}$ & $68.2 \mathrm{~W}$ & $68.3 \mathrm{~W}$ & $70.7 \mathrm{~W}$ \\
\hline $1455 \mathrm{~W}$ & $16 \mathrm{~V}$ & +170 & $67.1 \mathrm{~W}$ & $67.5 \mathrm{~W}$ & 66. $0 \mathrm{~W}$ & $66.2 \mathrm{~W}$ & $67.9 \mathrm{~W}$ \\
\hline $1415 W$ & $16 \mathrm{~V}$ & +170 & $63.4 \mathrm{~W}$ & $64.7 \mathrm{~W}$ & $63.2 \mathrm{~W}$ & $63.2 \mathrm{~W}$ & $65.0 \mathrm{~W}$ \\
\hline $1505 W$ & $16 \mathrm{~V}$ & -280 & $72.5 \mathrm{~W}$ & $72.9 \mathrm{~W}$ & 71. 3W & 71. $3 \mathrm{~W}$ & $72.9 \mathrm{~W}$ \\
\hline $1455 \mathrm{~W}$ & $16 \mathrm{~V}$ & -280 & 68. $8 \mathrm{~W}$ & $68.8 \mathrm{~W}$ & $66.7 \mathrm{~W}$ & 67. 3W & $68.9 \mathrm{~W}$ \\
\hline $1415 W$ & $16 \mathrm{~V}$ & -280 & $65.3 \mathrm{~W}$ & $65.3 \mathrm{~W}$ & $64.0 \mathrm{~W}$ & $64.1 \mathrm{~W}$ & $65.1 \mathrm{~W}$ \\
\hline 1450W & $\begin{array}{l}4.7 \\
\text { ohms }\end{array}$ & Ambient & $69.6 \mathrm{~W}$ & $69.7 \mathrm{~W}$ & $67.8 \mathrm{~W}$ & $69.1 \mathrm{~W}$ & $70.2 \mathrm{~W}$ \\
\hline \multicolumn{3}{|c|}{$\begin{array}{l}\text { Total Accumulated Operational } \\
\text { Time (air and vacuum) (hours) }\end{array}$} & 550 & 593 & 581 & 640 & 571 \\
\hline \multicolumn{3}{|c|}{$\begin{array}{l}\text { Total Weight in Pounds } \\
\text { (less protective cable sleeving) }\end{array}$} & 27.83 & 27. 77 & 27. 96 & 27. 36 & 27. 80 \\
\hline
\end{tabular}

lunar cycle condition, and another (qualification model) for over 6000 hours. The systems have been successfully integrated by Bendix in the ALSEP program. Figures 26 and 27 relate the actual measured performance compared to the original predicted data.

Flight generators, built and acceptance tested, have shown an exceptional degree of repeatability both on performance and in weight. Table VIII presents the data for the five flight units. Note that the maximum power variation is 2.5 watts and that the maximum weight spread is less than 0.2 pound.

The operation of the test modules and generators has accumulated approximately 20 million couple hours of operating time without a failure. This information, summarized in Table IX, illustrates the high degree of confidence and reliability that can be placed in power systems of this type.

The technology developed by the 10- and 104-couple module has clearly shown that significant gains can be made to future systems with respect to long-term, stable operation. These factors are:

1) Leg contact pressure should be increased at least to $250 \mathrm{psi}$.

2) Hot junction temperature can be tailored either for maximum power short-life systems, or for maximum power long-life systems. Optimum $\mathrm{T}_{\mathrm{h}}$ for the latter case is $1050^{\circ} \mathrm{F}$.

3) Increasing gas pressure enhances couple stability. Pressures of 35 to 50 psia should be considered.

4) Use of xenon, or perhaps mixtures of xenon and helium, should improve stability.
The success of this program, the information obtained for further product improvement, and the increasing need for long-lived, reliable power sources will undoubtedly result in the increased use of thermoelectric power supplies of this type.

TABLE IX, RELIABILITY OF SNAP-27 THERMOELECTRIC COUPLES

\begin{tabular}{|c|c|c|c|c|}
\hline \multirow[b]{2}{*}{ Device } & \multirow{2}{*}{$\begin{array}{c}\text { Quan- } \\
\text { tity }\end{array}$} & \multicolumn{2}{|c|}{ Operating Time } & \multirow{2}{*}{$\begin{array}{l}\text { Fail- } \\
\text { ures }\end{array}$} \\
\hline & & Devices & Couple & \\
\hline 10-Couple & 19 & 213,561 & $2,135,610 *$ & 0 \\
\hline 104-Couple & 15 & 83,451 & $8,678,904$ 冰 & 0 \\
\hline $\begin{array}{l}\text { Engineering } \\
\text { Generators }\end{array}$ & 2 & - & $6,728,124 * * * *$ & 0 \\
\hline $\begin{array}{l}\text { Qualification } \\
\text { Generators }\end{array}$ & 2 & - & $2,468,570 * * *$ & 0 \\
\hline TOTAL & 37 & - & $20,011,208$ & 0 \\
\hline
\end{tabular}

*As of April 27, 1968

**As of April 8, 1968

***As of March 31, 1968 
SNAP-27 PRIME HARDWARE MONTAGE

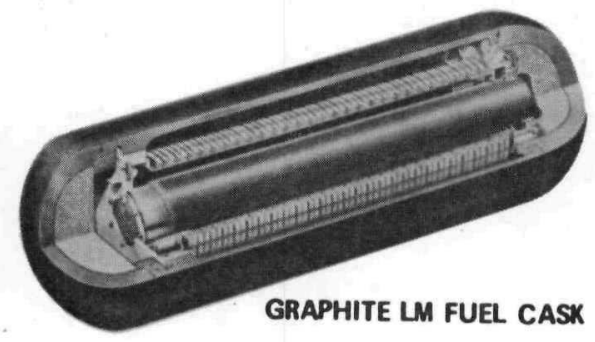

GRAPHITE LM FUEL CASK

FUE CAPSULE ASSEMBLY

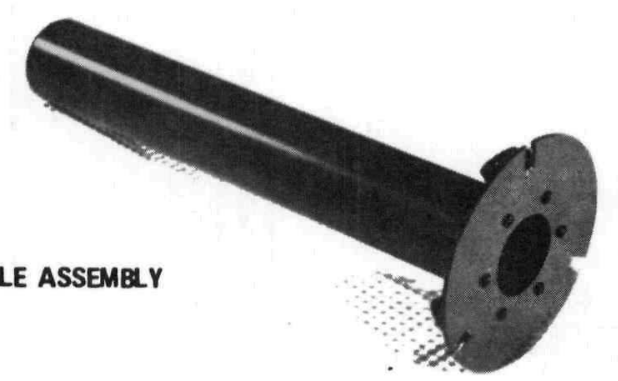

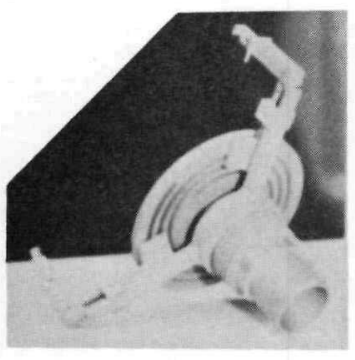

FLIGHT HANDLING TOOL
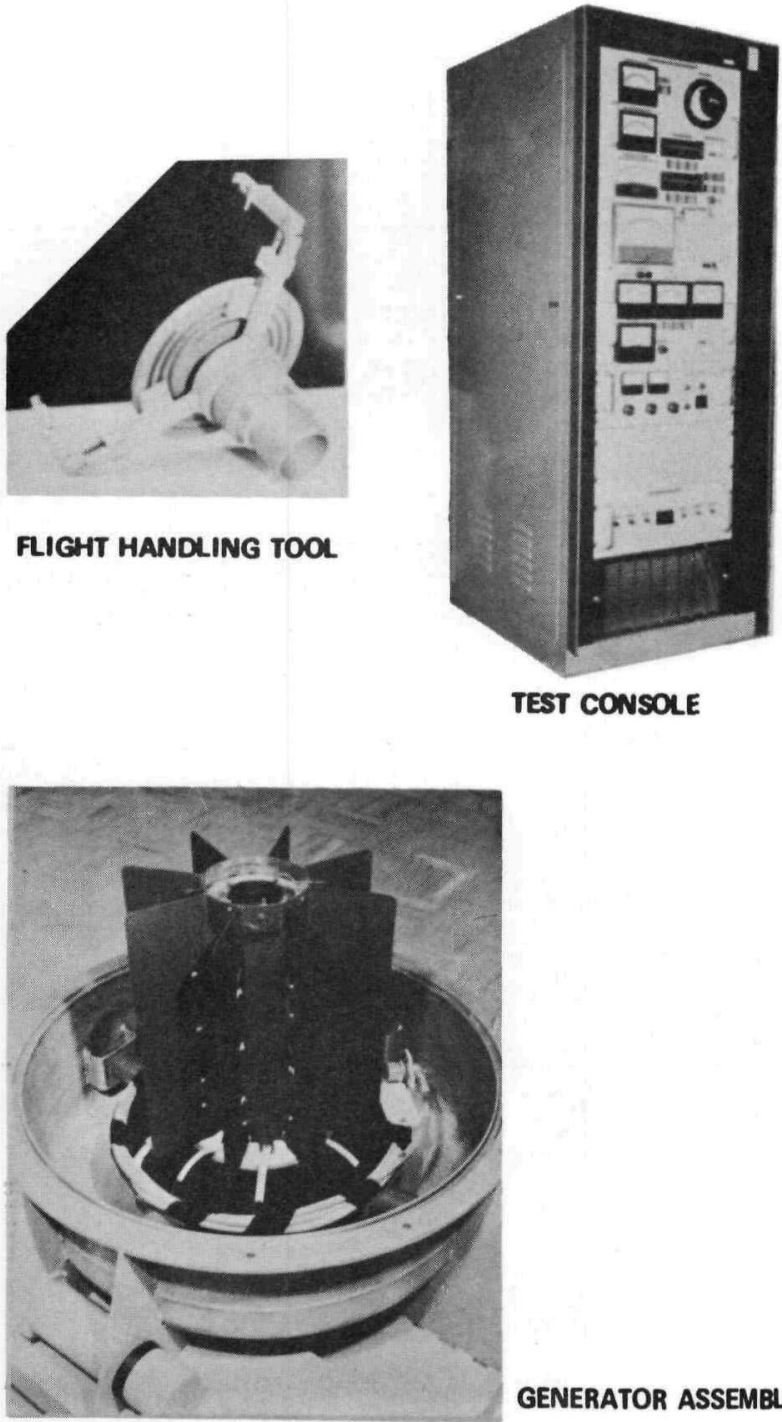

GENERATOR ASSEMBLY W/SHIPPING CONTAINER

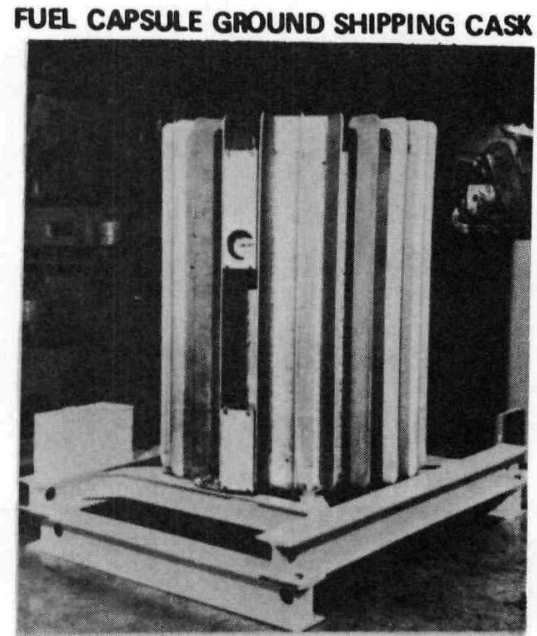

Figure 1. SNAP-27 Prime Hardware Montage 


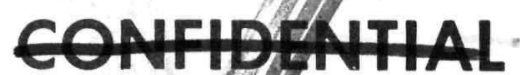
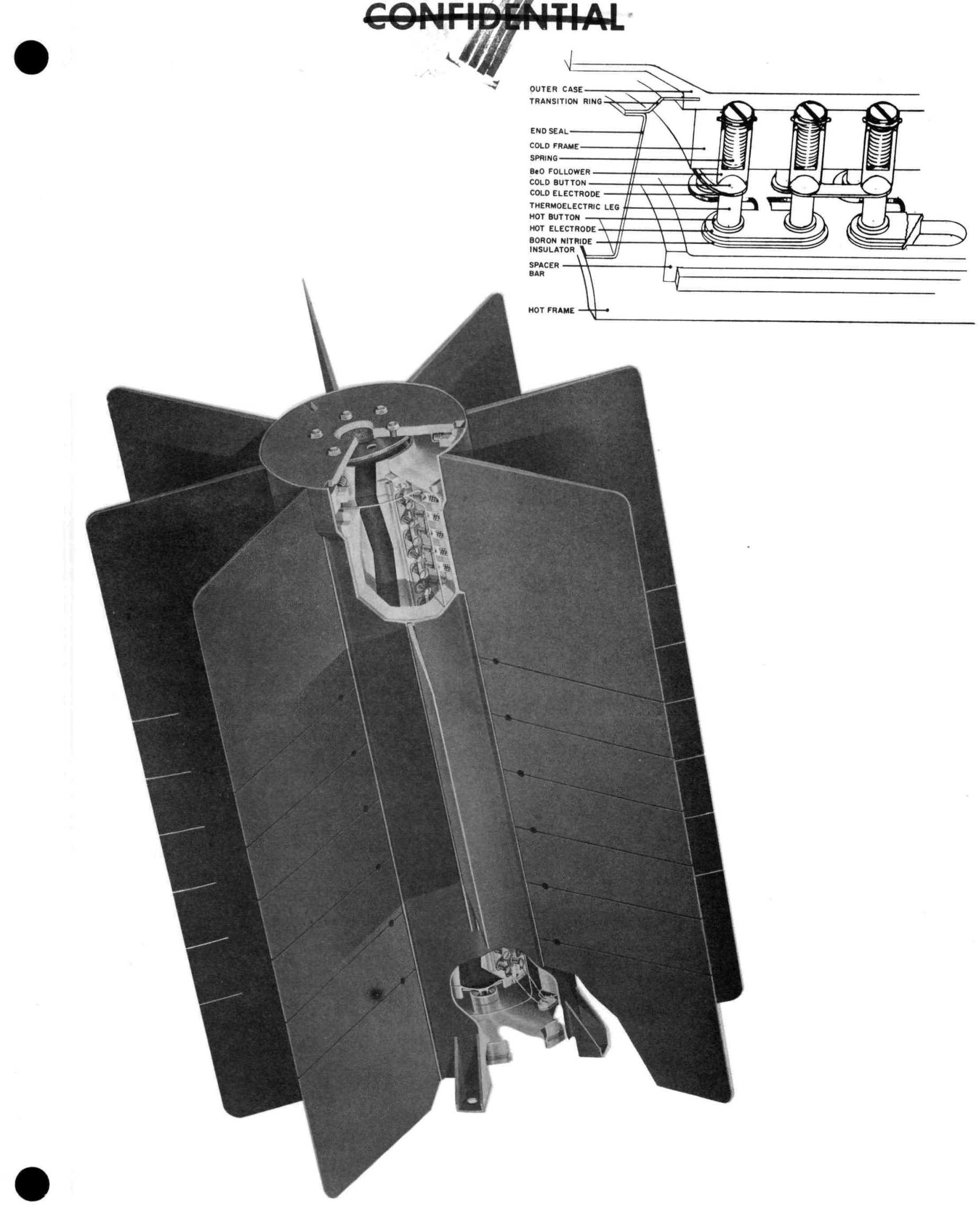

Figure 2. SNAP-2 7 Generator Assembly 

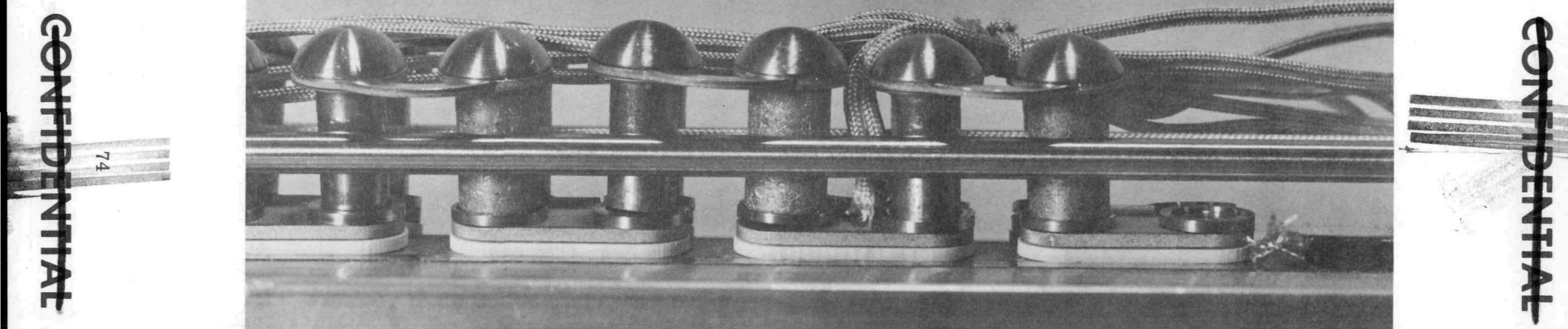

Figure 3. Preassembled Row of Couples 
$\frac{8}{4}$

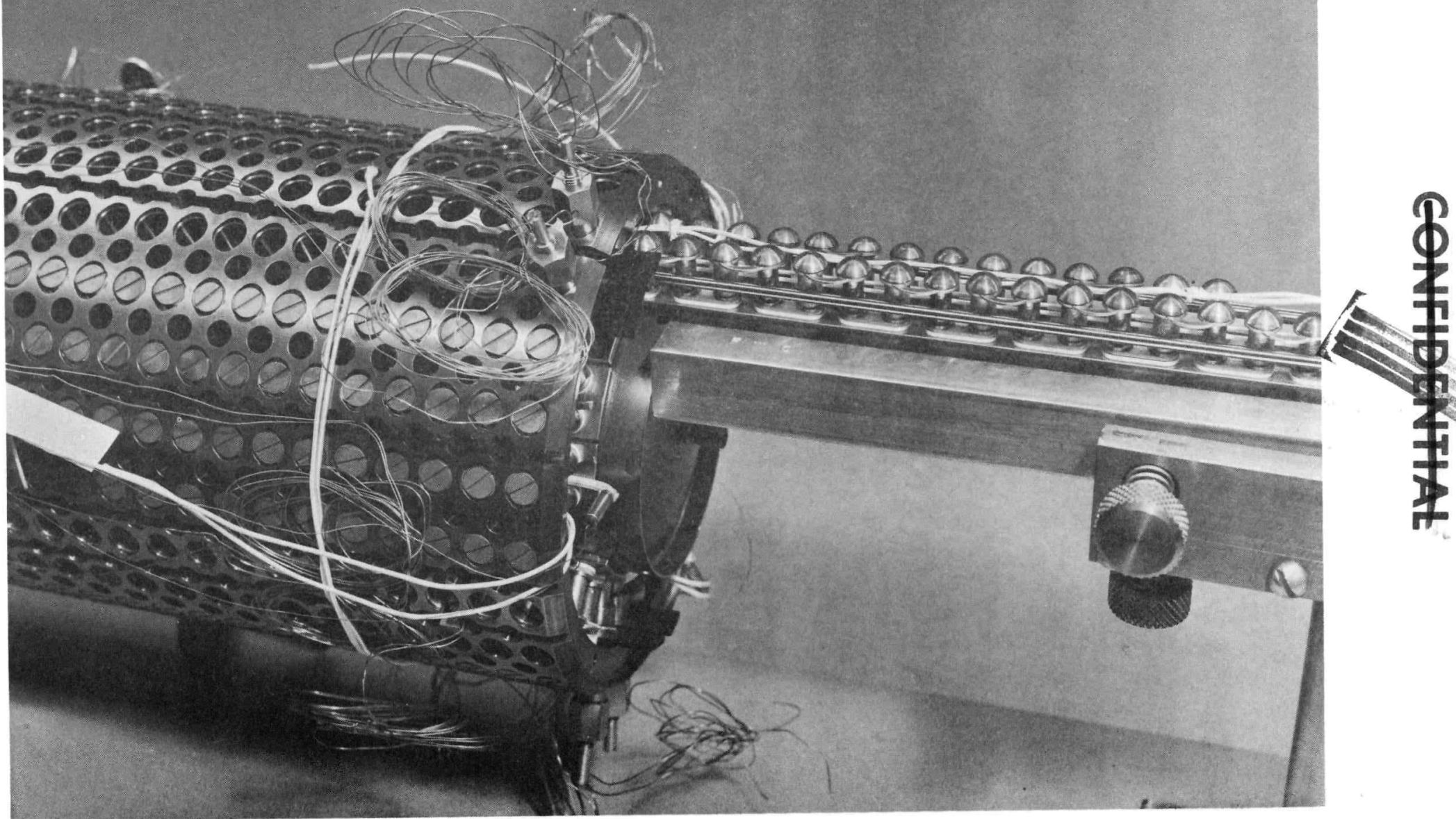




$\frac{\$}{\$}$

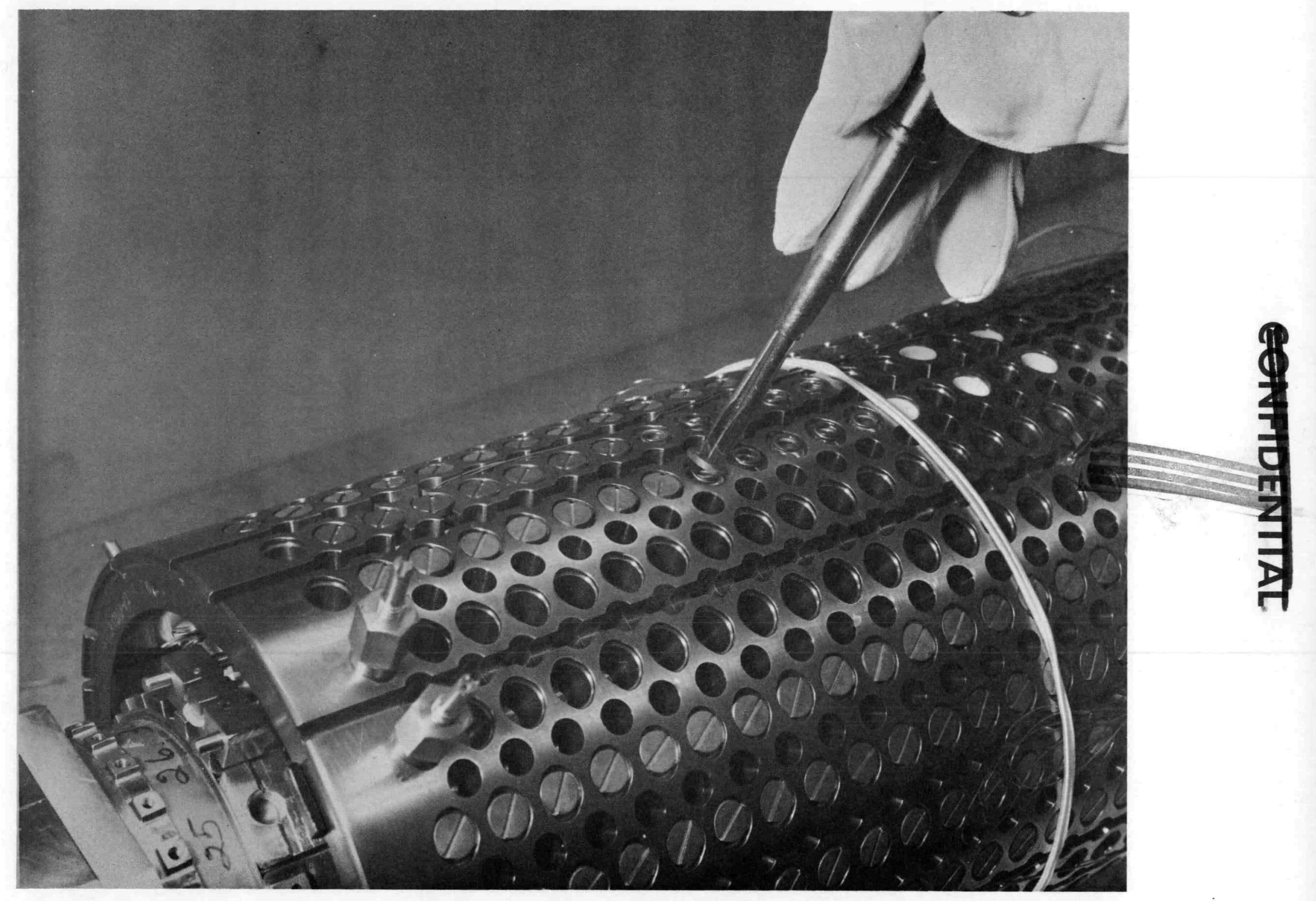

Figure 5. Spring Retainer Installation 


\section{○}
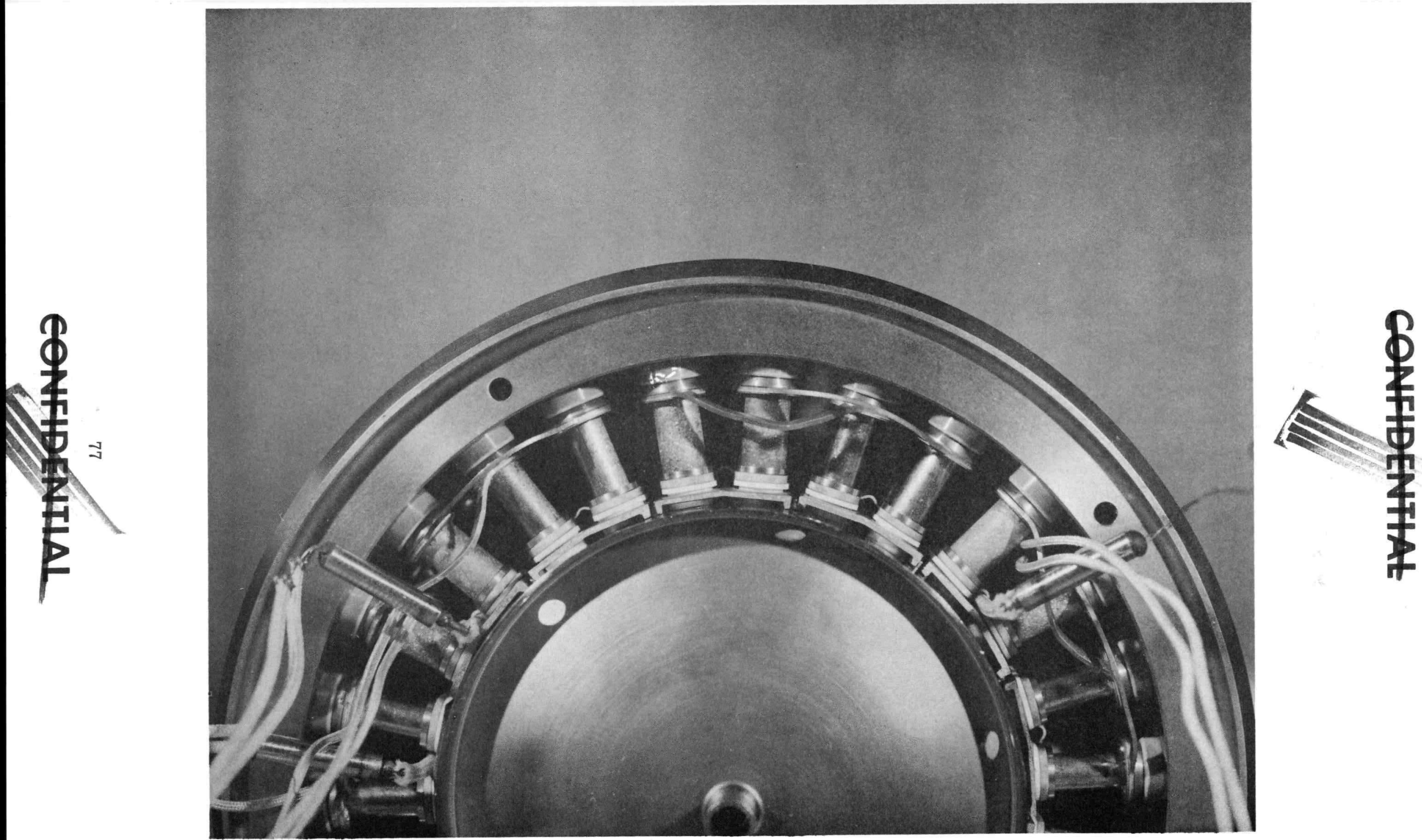

Figure 6. Thermopile End View 


\section{EONFTDENTTAL}
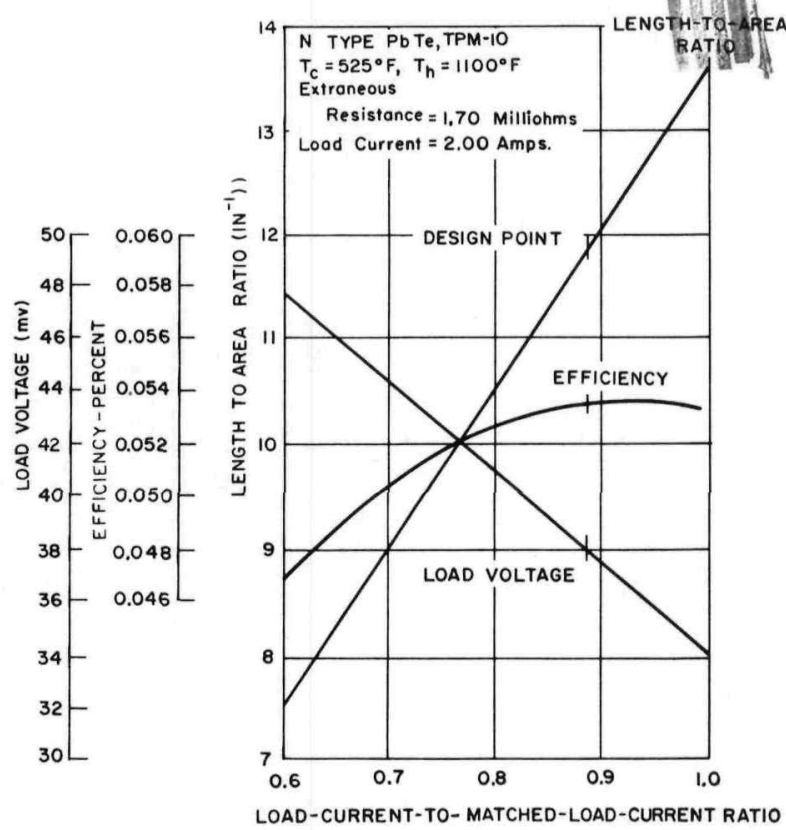

Figure 7. N-Leg Geometry Analysis

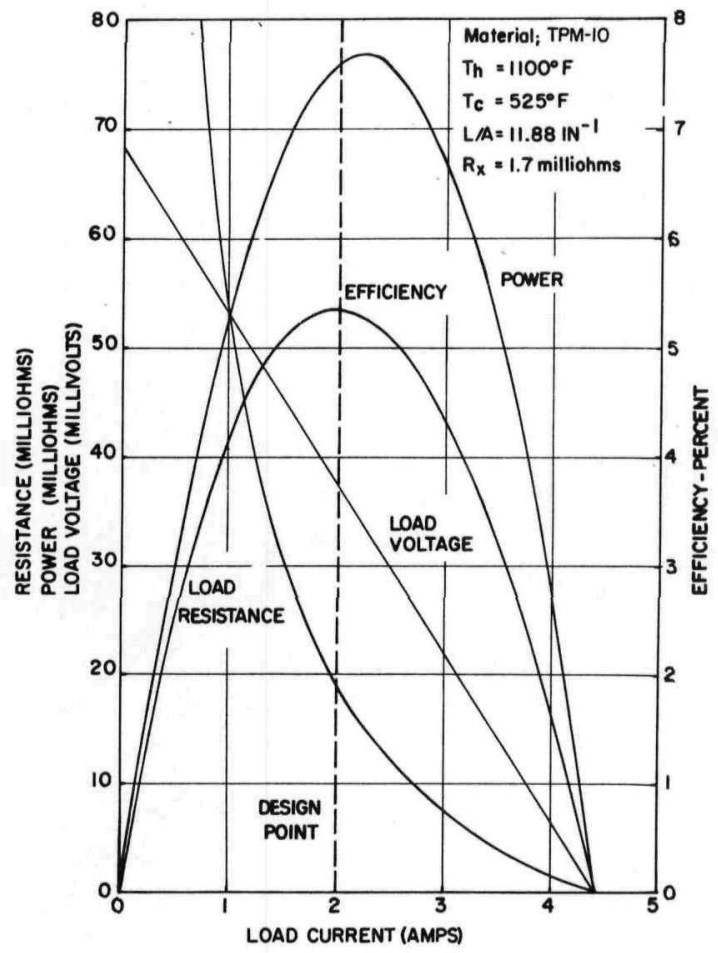

Figure 9. N-Leg Performance Characteristics

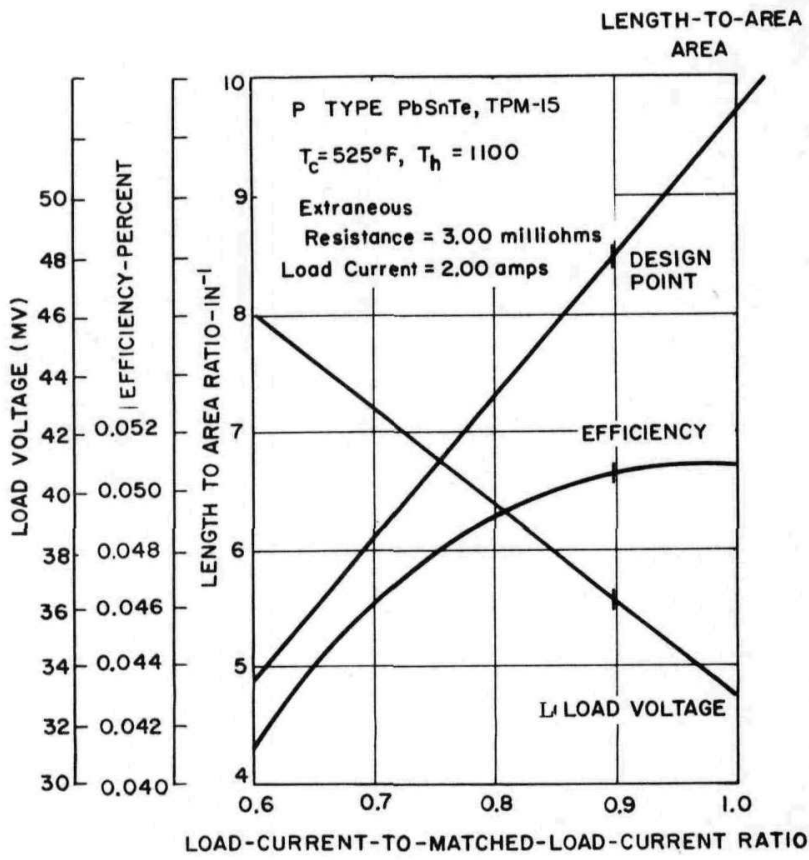

Figure 8. P-Leg Geometry Analysis

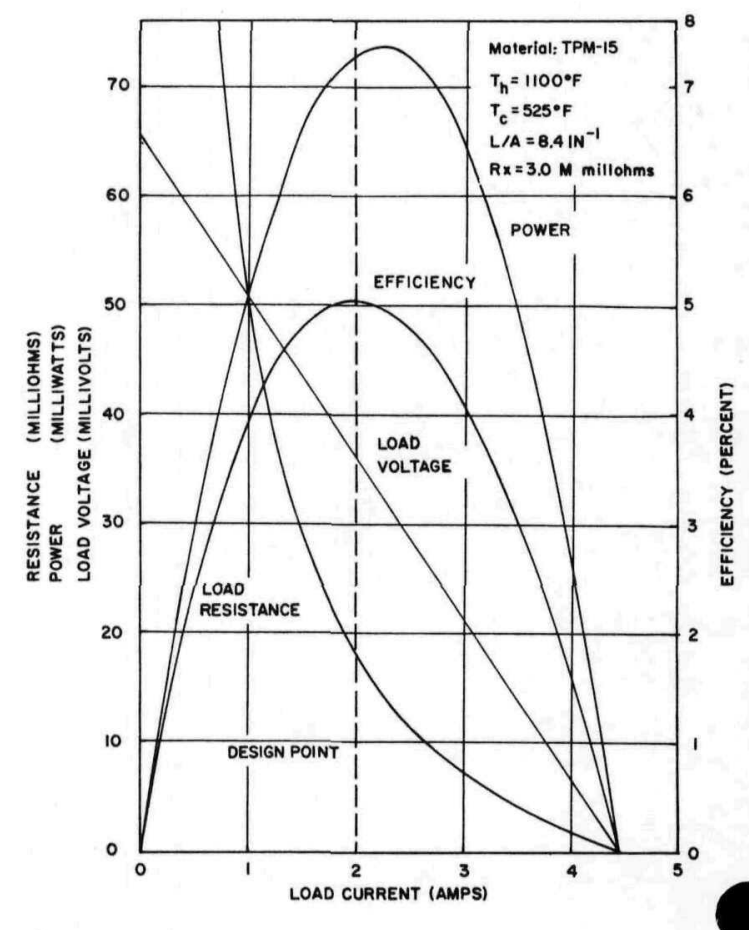

Figure 10. P-Leg Performance Characteristics 


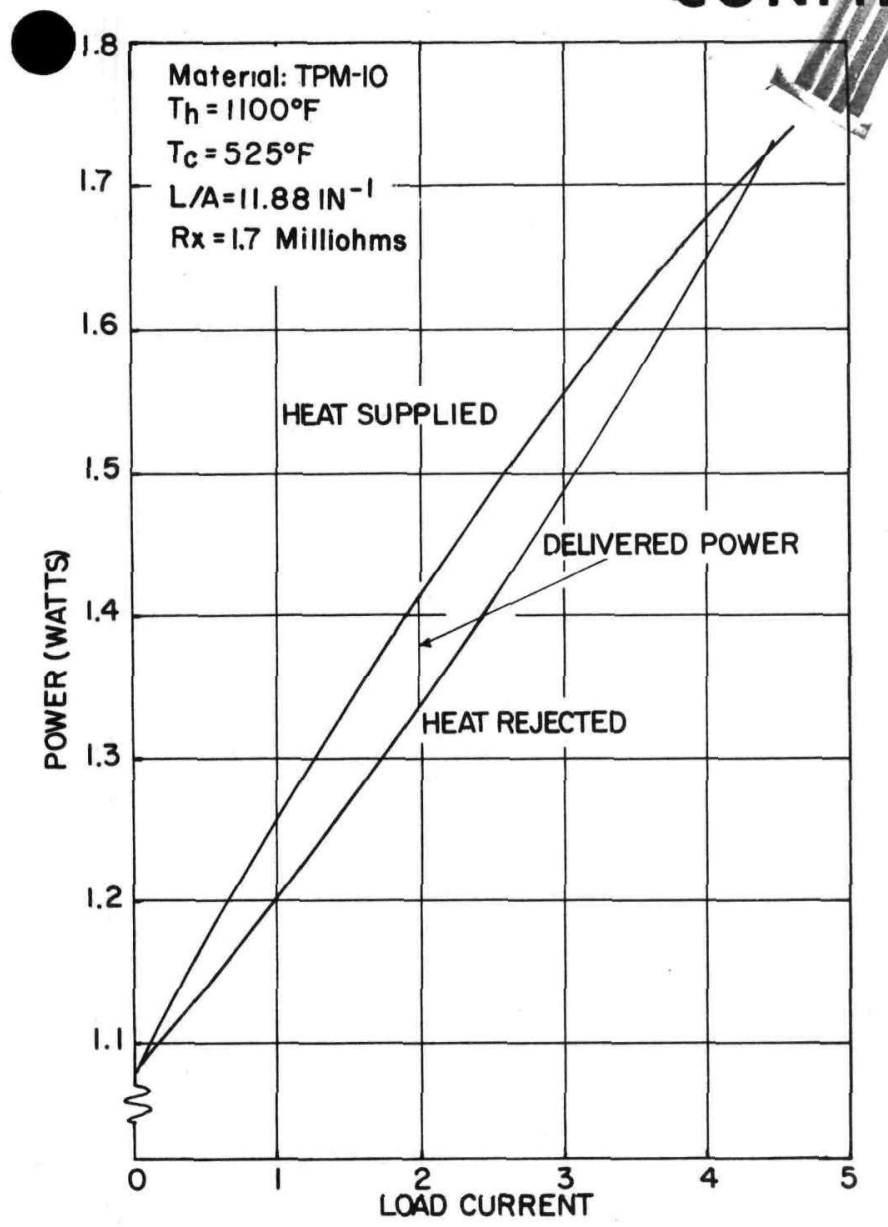

Figure 11. N-Leg Predicted Thermal Performance Characteristics

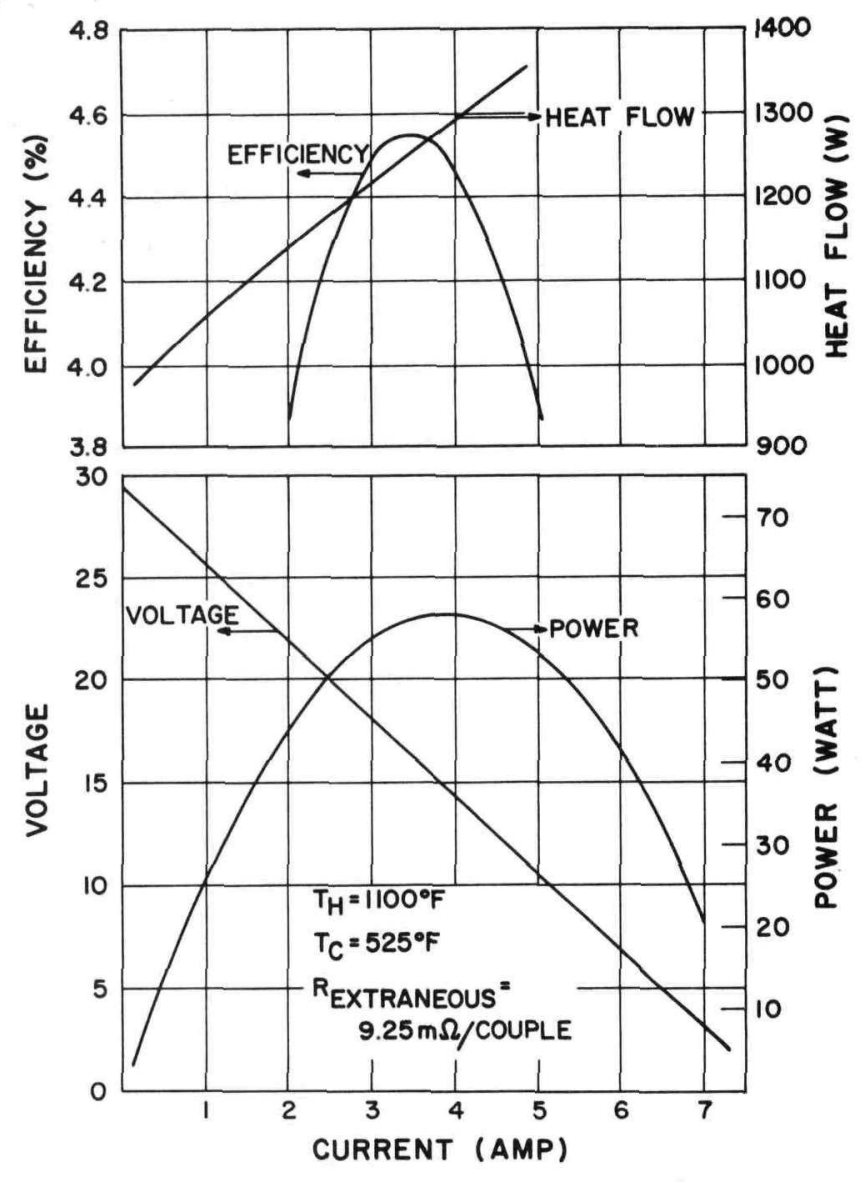

Figure 13. Design Point Selection

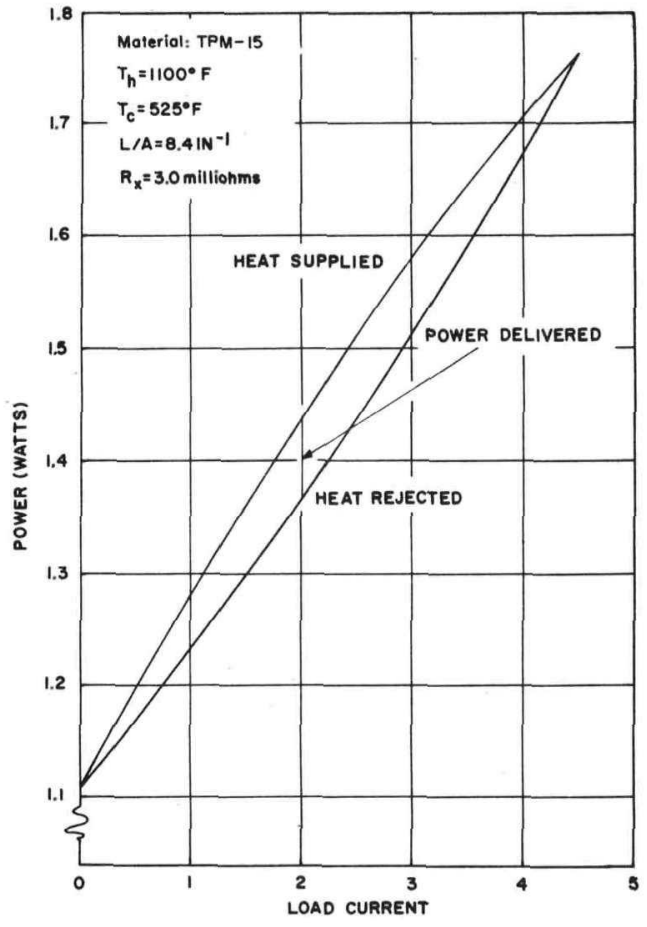

Figure 12. P-Leg Predicted Thermal Performance Characteristics 


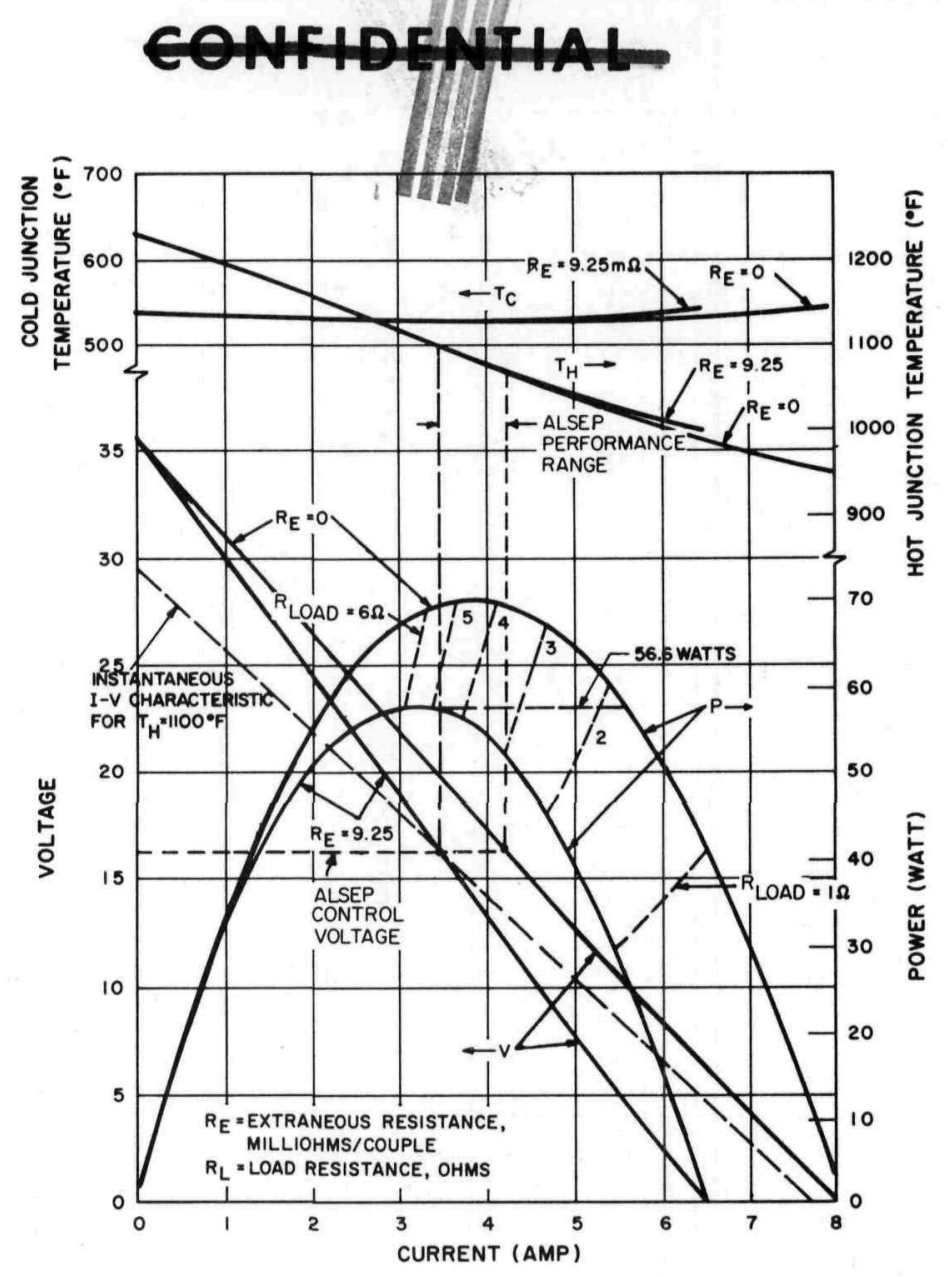

Figure 14. Generator Design Performance Characteristics

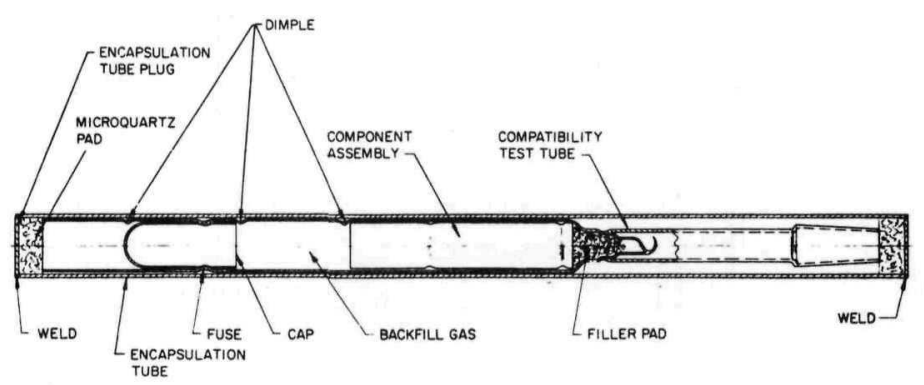

TYPICAL COMPONENT ASSEMBLY

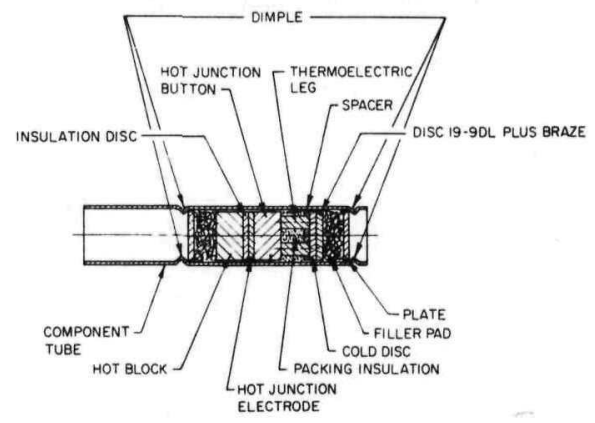

Figure 15. Isothermal Compatibility Test Fixture 80 

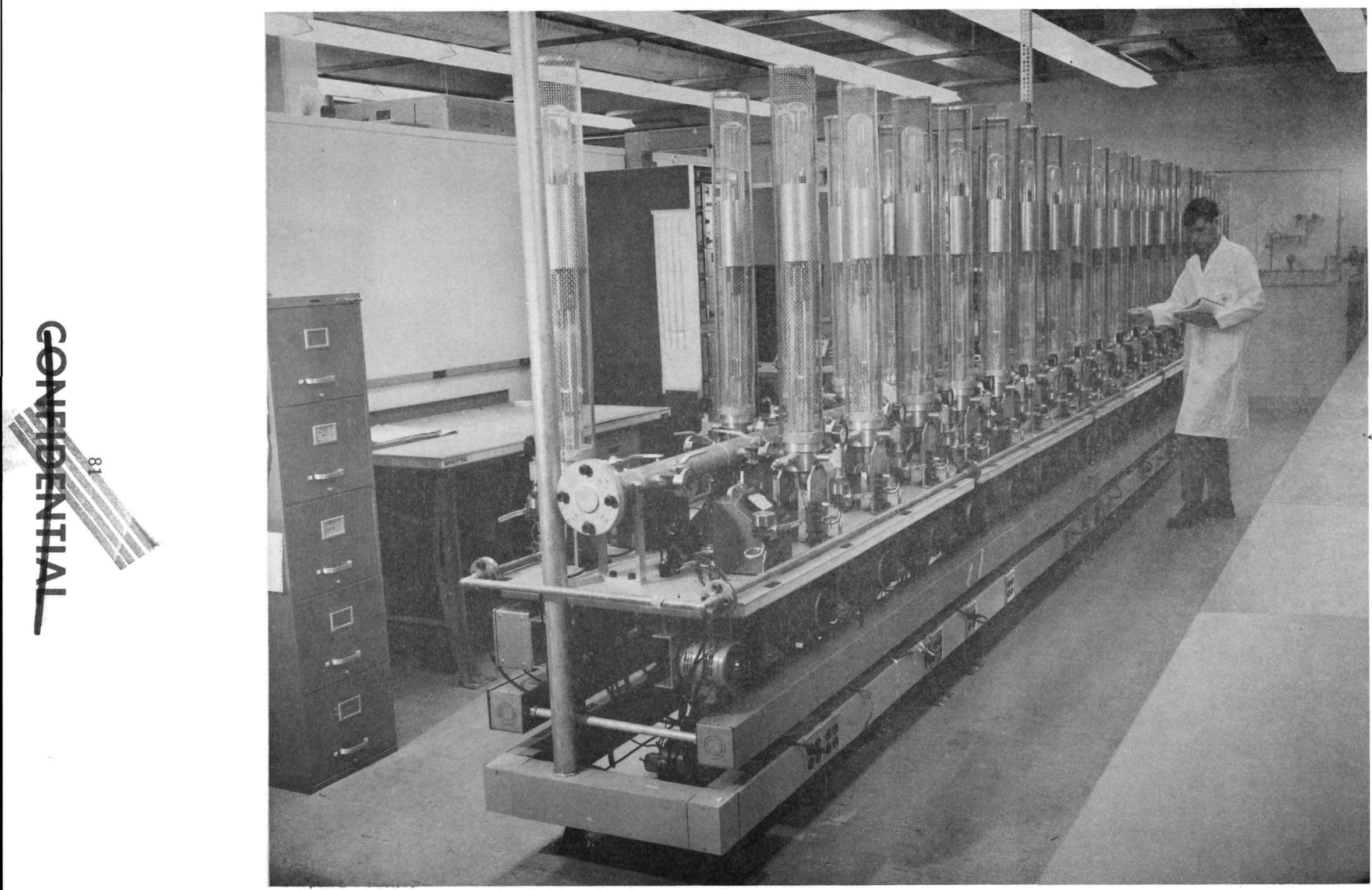

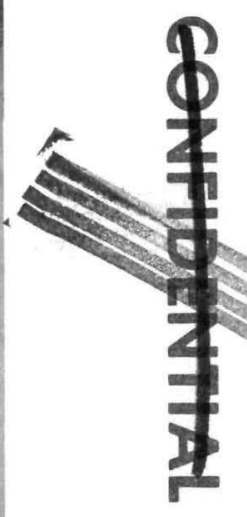

Figure 16. TELPS Laboratory 
CONFIDENTHAL iil

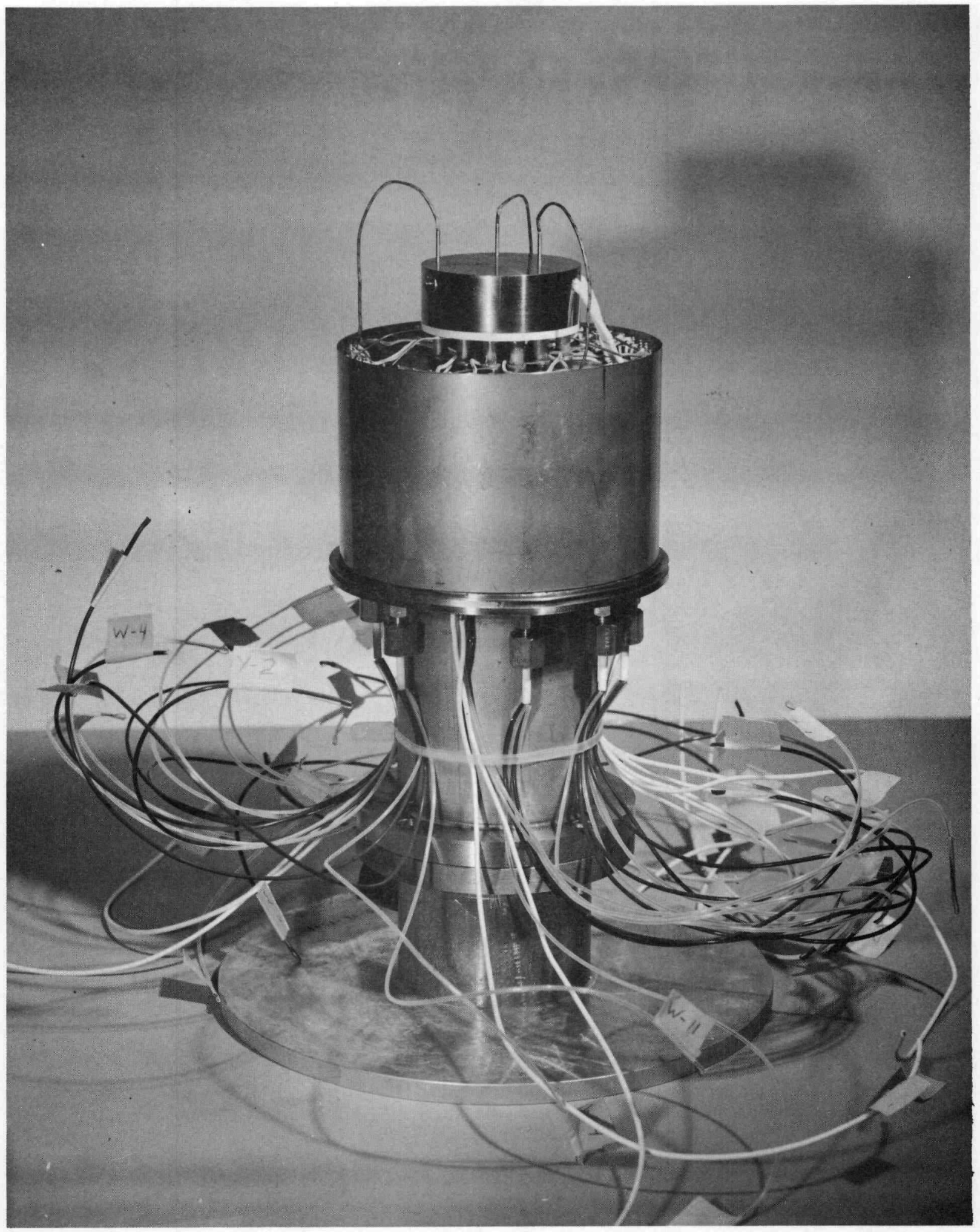

Figure 17. 10-Couple Module Partially Assembled

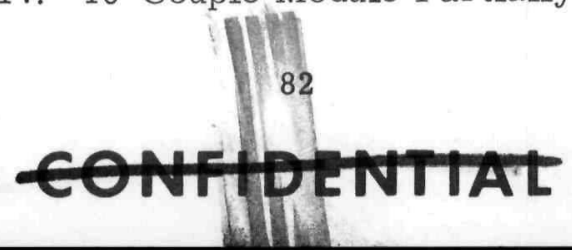


$\frac{\$}{\ddagger}$

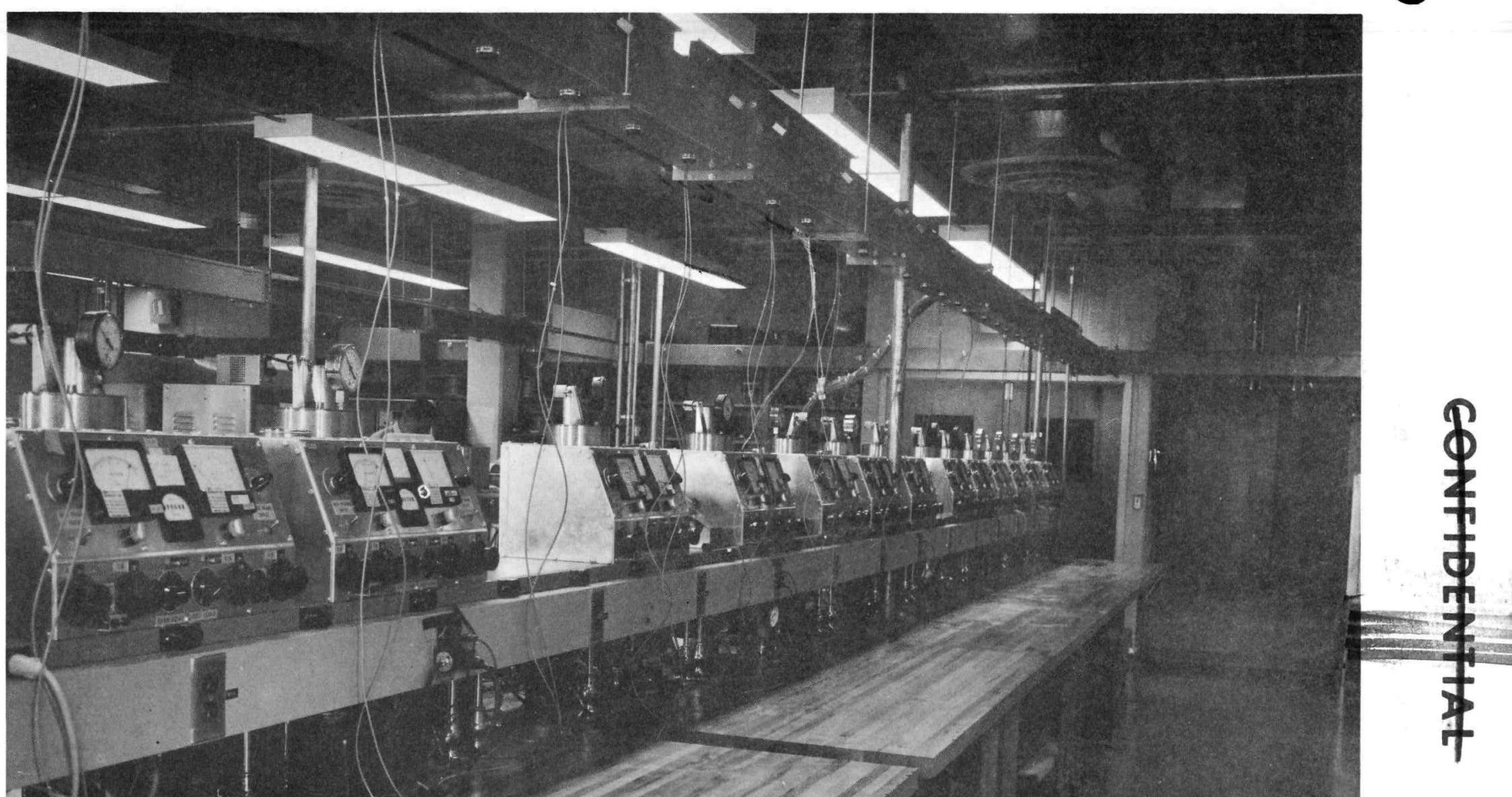




\section{GONFTDENTTAL}

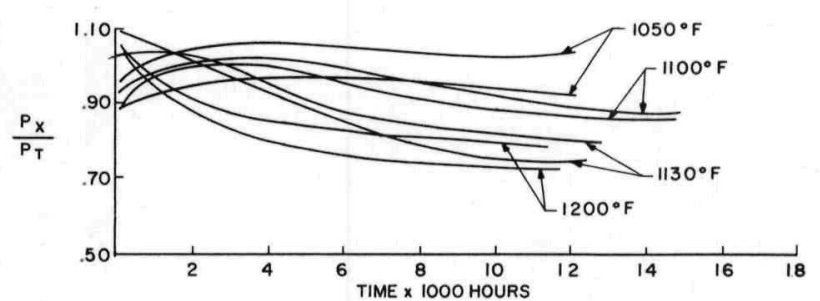

Figure 19. Standard Design/Varying $T_{h}$

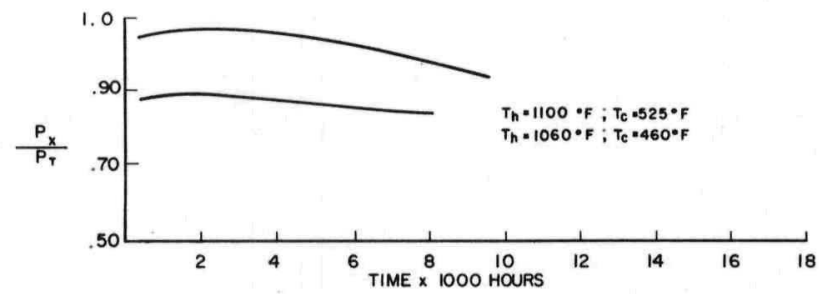

Figure 22. Thermal Cycle Tests

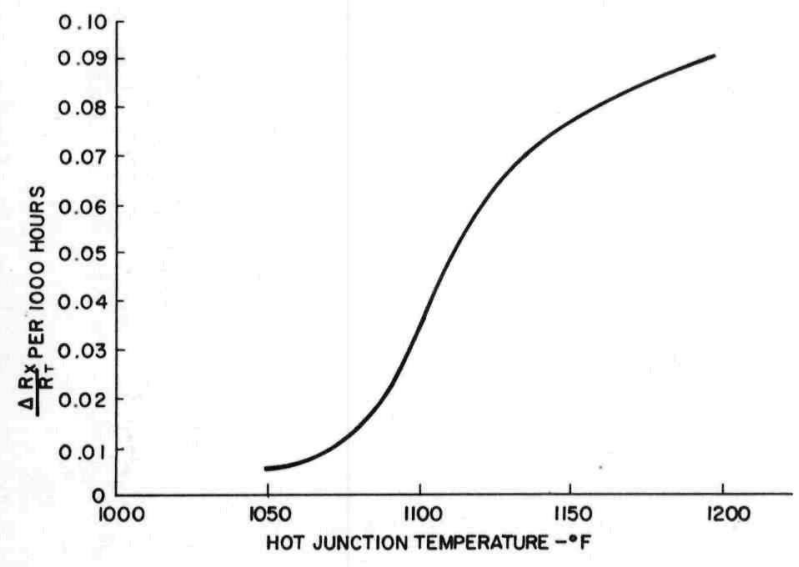

Figure 20. N-Leg Degradation Rate

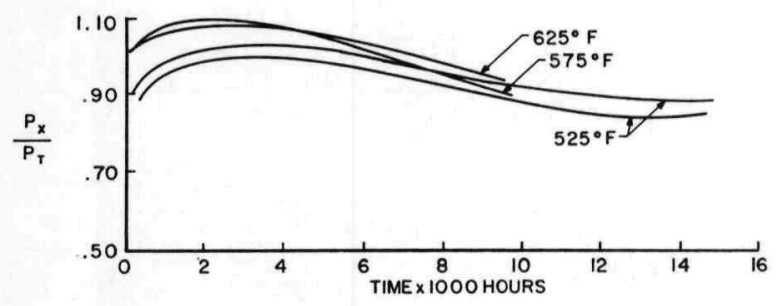

Figure 21. Varying Cold Junction Temperature

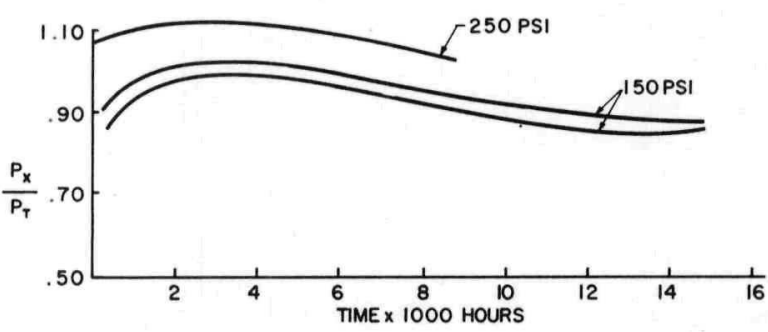

Figure 23. Varying Contact Pressure Tests

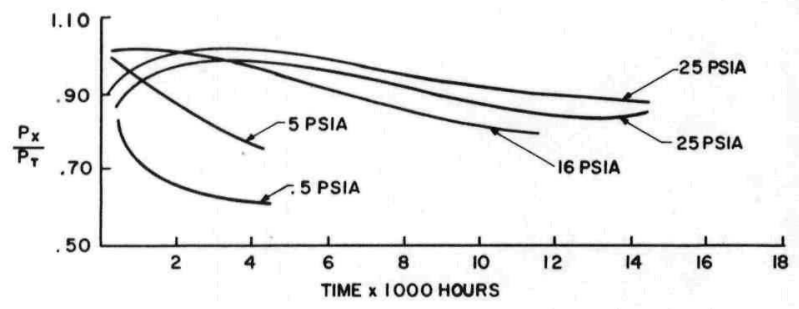

Figure 24. Varying Internal Gas Pressure Tests 


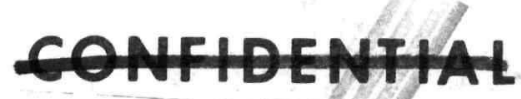

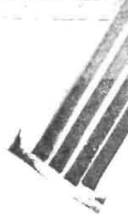

-

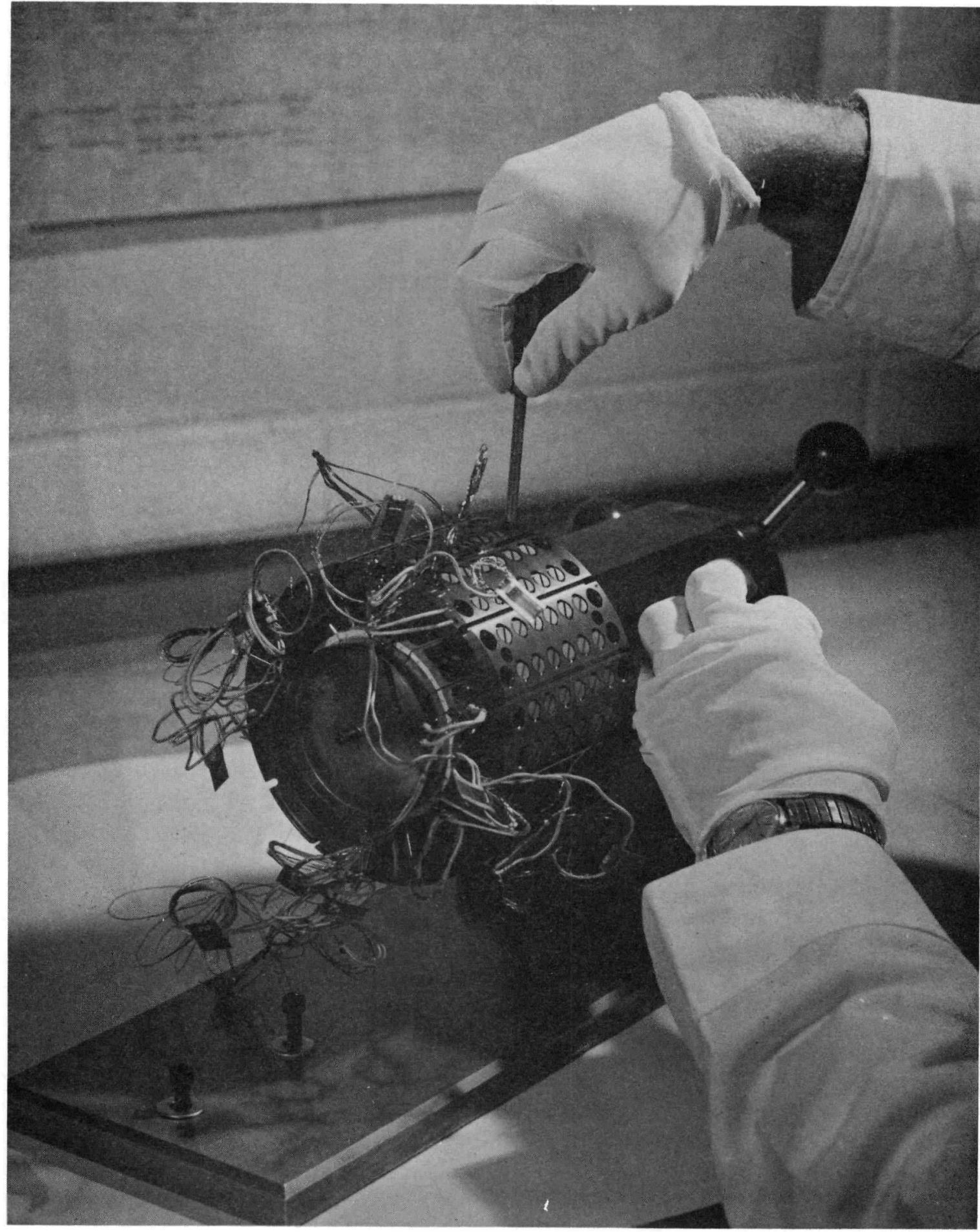

Figure 25. 104-Couple Modules 


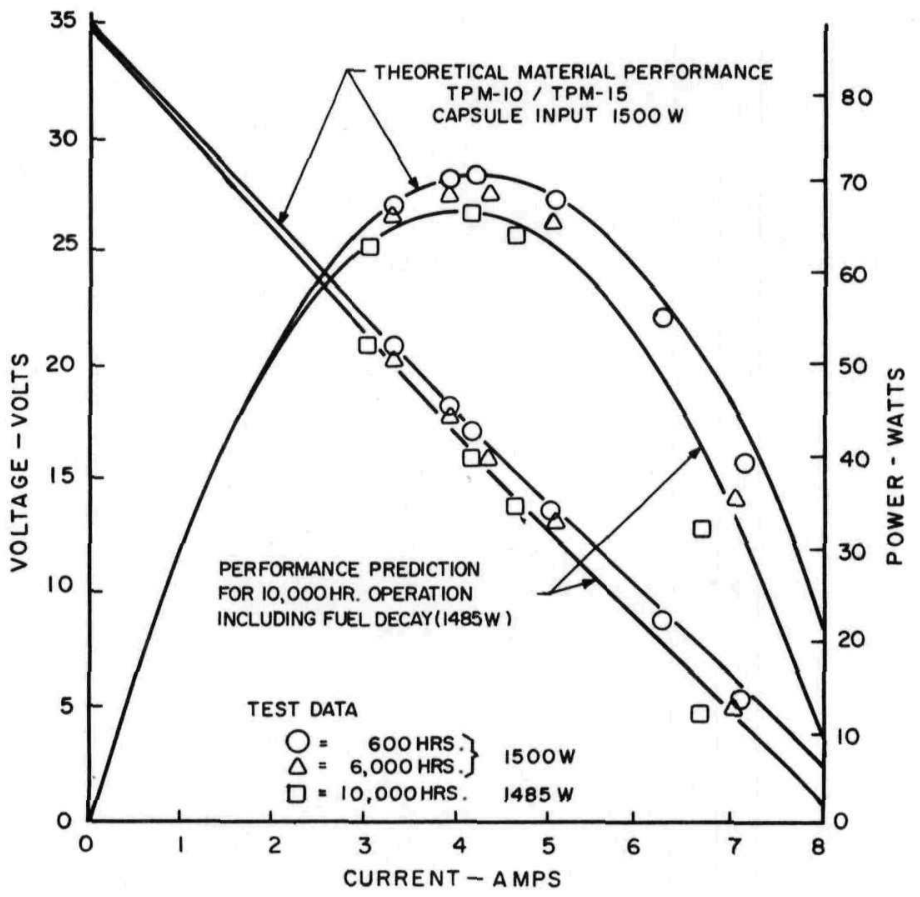

Figure 26. Engineering Test Generator Mod 5 Performance

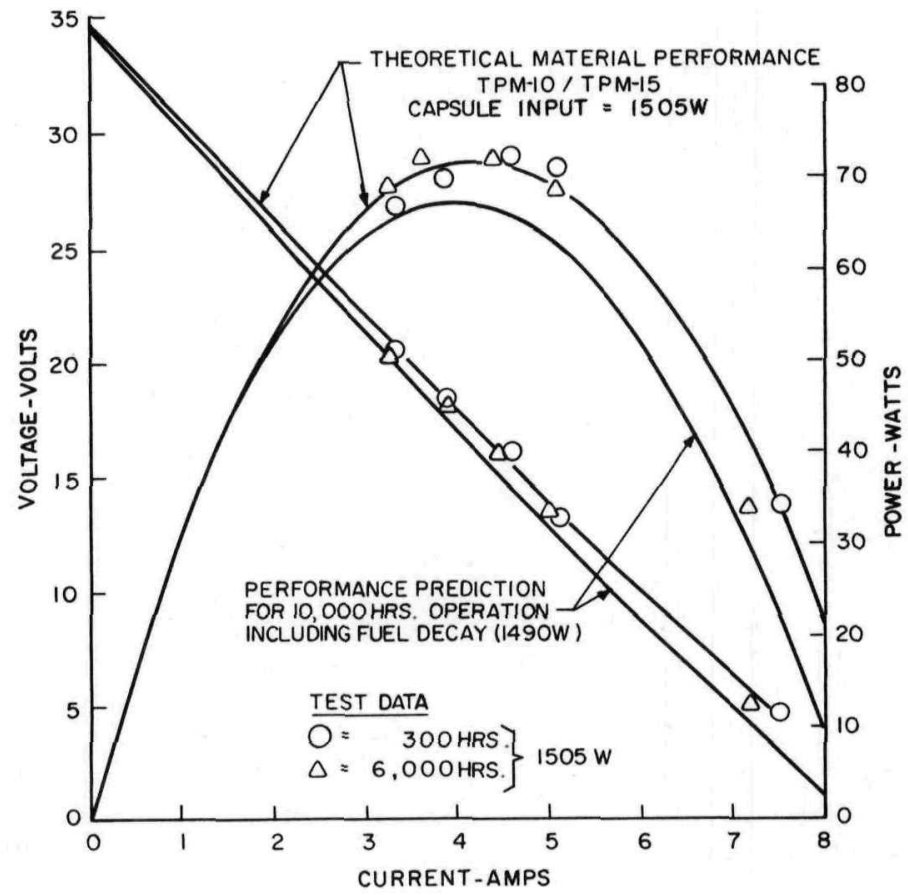

Figure 27. Qualification Generator Mod 10 Performance 


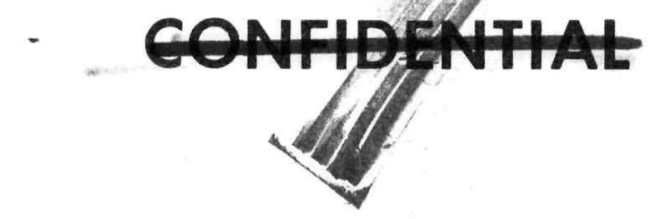

\title{
COMPACT THERMOELECTRIC CONVERTER PROGRAM
}

\author{
J. Kenney \\ Westinghouse Electric Corporation \\ Astronuclear Laboratory \\ Pittsburgh, Pennsylvania
}

\section{SUMMARY}

The fundamental objective of the Compact Thermoelectric Converter Program, being conducted by Westinghouse for the Atomic Energy Commission under Contract AT(29-2)-2638, is the development of a tubular thermoelectric module of good performance, long life and high reliability.

The tubular thermoelectric module being developed encapsulates lead telluride in a unique voidfree design without the requirement of bonded joints within the curcuit. The design of the tubular module is described and the advantages of the selected materials and design features are discussed. Performance data, including data illustrating improvements resulting from solutions to several key problems, are presented to illustrate progress being made toward achieving the goals of the program.

The application of the tubular module in reactor and RTG systems is discussed to illustrate the unique advantages of the tubular module in thermoelectric systems.

\section{INTRODUCTION}

For the past three years the Westinghouse Astronuclear Laboratory has been engaged in the development of a tubular thermoelectric module, under contract to the Atomic Energy Commission, in what is called the Compact Thermoelectric Converter Program. The goals of this technology development program are to design, fabricate, and demonstrate, through test, a tubular thermoelectric module having good performance, long life, and high reliability.

As a result of the general success achieved to date in the development of the tubular module, the program has been expanded to include the application of the tubular module to a prototype $25 \mathrm{Kw}(\mathrm{e})$ reactor power system. In addition, several proto- type RTG systems, using the tubular module being developed under the Compact Converfer Program, have been fabricated and are being tested.

To provide you with an overall view of the program, the state-of-the-art of the tubular thermoelectric module technology program will be reviewed and several typical applications will be discussed in order to illustrate the unique advantages of the tubular module.

\section{TUBULAR THERMOELECTRIC MODULE}

The tubular thermoelectric module being developed to satisfy the goals of the Compact Converter Program is shown in Figure 1. It consists of alternate washers of $n-$ and $p$-type lead telluride, separated by thin mica washers. The elctrical connection is accomplished by cylindrical conductor rings located at the I.D. and O.D. of the lead telluride washers. The conductor rings are also separated by the same mica washers which electrically isolate the lead telluride washers. The result is a radially serpentine current path along the length of the module. The complete circuit is electrically isolated from the structural claddings by thin sleeves of boron nitride, which has reasonably high thermal conductivity to promote radial heat flow, while still exhibiting good properties as an electrical insulator. The thermoelectric circuit and boron nitride sleeves are completely encapsulated between the end structure and the inner and outer claddings, which serve as the structural members of the module and as flow boundaries and heat transfer surfaces.

Figure 2, which shows a longitudinal section of the tubular module, illustrates the basically simple geometrical arrangement of the component parts, which are in the form of washers, rings, and sleeves. After assembly, the module is axially compressed and welded, and is compacted in a room temperature autoclave to remove the remaining assembly voids. 
Final compaction and essentially complete densification of internal parts, especially the lead telluride, is achieved by a hot autoclaving cycle. As a result of this processing, the module becomes a fully densified, void-free unit that is extremely rugged. This unique design concept enables the use of lead telluride, with its high figure of merit, to be operated at high temperature for long periods of time in any environment. Similarly, and of equal importance, good radial heat transfer from the inner clad to the outer clad and good electrical contact between elements of the thermoelectric circuit is achieved through high internal pressures, thus eliminating any need for bonded joints. The high pressures are assured by the processing conditions, which leave the circuit components and the inner clad in compression and the outer clad in tension. In addition, under operating conditions, the radial temperature gradient assures increased interface pressures.

The processing techniques, designed to achieve complete densification and high internal pressure, result in lead telluride characteristics significantly different than those found in the literature. As a result of achieving full densification, the thermal conductivity of the as-processed material is about 10 percent greater and the electrical resistance is about 10 percent less than the corresponding values normally associated with lead telluride. Accordingly, new materials property data have been determined for the as-processed lead telluride used in the tubular modules.

In parallel with developing these materials property data, several key materials problems have been identified and solutions demonstrated. A brief discussion of two problems, one involving n-type and the other p-type lead telluride, will serve to illustrate the types of problems that have been solved.

Modules fabricated in 1965 and early in 1966 showed a common characteristic of low electrical resistance, typically $1 \mathrm{ohm}$ or so, between the circuit and the cladding after processing or shortly after initiation of testing. Because the calculated resistance of the boron nitride sleeve is about $10^{6}$ ohms at test temperature, it seemed likely that the integrity of the boron nitride insulation was being compromised during processing. Destructive examination of several modules established that the boron nitride was becoming impregnated with lead, which caused the low resistance path. A series of laboratory experiments demonstrated that lead was being squeezed out of the thermoelectric washers during the hot autoclaving cycle, when the module was under high pressure at elevated temperature. The free lead followed the path between the mica washers and the conductor rings, where it impregnated the boron nitride sleeves. This phenomenon continued during the early period of module operation, with a resultant reduction of power output, as will be shown later when performance is discussed. The solution to this problem was partially resolved by processing at more closely controlled temperatures. However, this solution limited operation to a hot side temperature of $1100^{\circ} \mathrm{F}$, otherwise the low resistance to clad would occur as a result of module operation. The ultimate solution was finally identified to be the use of stoichiometric lead telluride which, of course, doesn' t have any free lead. Modules fabricated with stoichiometric n-type material have been operated at temperatures above $1300^{\circ} \mathrm{F}$ for extended periods without exhibiting low resistance to clad, thus verifying the solution to this problem.

Another problem solved in a similar manner was that associated with p-type material. This problem manifested itself as a rapid increase in circuit resistance during the first 500 to 1000 hours of operation, thereby causing a significant decrease in module performance. As in the case of the free lead problem, a series of experiments were devised in the materials laboratory to identify the source of the problem and to develop solutions. From these experiments it became evident that the mechan ism was one of a TEGS-2P/iron conductor ring reaction, principally at the interface with the hot inner conductor. Several solutions were postulated and the most promising, the use of tungsten in place of iron for the inner conductor rings, has eliminated the short-term performance degradation previously experienced.

The effects of these and other technology developments may be seen in Figure 3, which illustrates the continuing progress being made toward achieving the program goals. These curves of circuit efficiency represent the state of technology for the years noted. Circuit efficiency is defined as the ratio of module electrical power output to the thermal power calculated to pass through the circuit. The use of circuit efficiency enables a direct comparison of module thermoelectric performance, thus eliminating a need to account for different module lengths, end designs, or test configurations. Modules fabricated with 1965 technology had the low resistance to clad problem caused by free lead impregnating the boron nitride sleeves, which resulted in a reduced level of performance. The difference in the long term performance of 1965 and 1966 modules illustrates the effect of the solution to the low resistance to clad problem. Having solved the low resistance to clad problem, it became evident that another mechanism had contributed significantly to 
the short term degradation. The solution to the TEGS-2P/iron reaction problem is illustrated by the 1967 modules, which have tungsten inner conductor rings. Continuing progress is being made towards achieving a degradation-free module operating over extended periods at higher operating temperatures, as illustrated by the testing at $11000 \mathrm{~F}$ and $1200^{\circ} \mathrm{F}$ initiated in 1968. It is anticipated that circuit efficiencies of over 8 percent can be achieved by combining demonstrated improvements into an improved module design.

Table I illustrates the cumulative time on modules tested at various hot side temperatures, and indicates the maximum time achieved on a single tubular module for each temperature condition. As noted, total time achieved to date exceeds 271,000 hours, with maximum time on one module exceeding 25,000 hours. On the basis of these test results, some limited in nature and some quite extensive, it is believed that the technology base through which the program goals can be achieved has been demonstrated.

\section{APPLICATIONS}

The technology oriented Compact Converter Program has concentrated on the development of the fubular thermoelectric module. The basis for this approach is that the tubular module is itself a power conversion system. Large systems require only hydraulic and electrical manifolding of modules to achieve the desired power range, which can be accomplished with the requirement of additional tubular module development effort. Small systems, on the other hand, would use single modules. To illustrate the adaptability of the tubular module, three systems currently being developed have been selected for discussion.

\section{Two Loop Reactor Heated System}

A preliminary design of a thermoelectric converter assembly for application with a reactor heat source has been completed. This converter assembly consists of twenty-four tubular modules arranged into six subassemblies of four tubular modules each. As shown in Figure 4, each subassembly is enclosed in a single metal jacket that provides containment for NaK coolant flowing around the four modules. As shown, the primary NaK flows through the inner bore of the four tubular modules similar to a counterflow heat exchanger. At the design operating conditions each tubular module produces 262 watts at 14 volts matched load. The four tubular modules in a subassembly are connected in series electrically, yielding a matched load voltage of 56 volts.
A cutaway of the converter assembly is shown in Figure 5. The orientation of the converter assembly and the location of the manifolds can be modified to satisfy the requirements of a particular application.

The hot loop NaK enters one end of each longitudinal manifold at the top and flows to the other end. A portion of the flow exits downward from the manifold through each tubular module to the lower longitudinal manifold where it is collected and returned to the reactor. The cold loop NaK enters the bottom of the divided outer can which clusters each transverse group of modules into a four-pack. Cold NaK then flows into annuli that surround each tubular module, removes the waste heat from the modules and is then collected in an exit manifold and pumped to the radiator.

A summary of the design and performance characteristics is given in Table 2. For the selected system operating temperatures, the converter assembly produces $6.3 \mathrm{KWE}$. Because the six subassemblies are connected electrically in parallel, the output voltage of the converter assembly is 56 volts.

At the present time, prototype tubular modules, designed for application in the converter assembly described above, are being assembled and processed. Testing of these tubular modules will be initiated early in September 1968. The detailed design, fabrication, and test of a converter subassembly will be accomplished during 1959.

\section{Direct Coupling RTG System}

Another interesting concept for application of the tubular module is shown in Figure 6. In this instance, the module inside diameter has been increased in size to enable insertion of a radioisotope, such as $\mathrm{Co}-60$, for the heat source. Because the module is a fully densified unit, the shielded assembly is readily adaptable to underseas application where, in fact, the increased external pressure and low sink temperature would combine to improve performance. A unit such as that shown using available Co-60 at 350 curies/gram would have an end-oflife power of about 80 watts for a 2 year lifetime rating ( 125 watts $\mathrm{BOL})$. By proper selection of module length and shielding, the power output of a system such as this may be varied from approximately 5 watts to 250 watts. The design shown uses a 1-1/2 inch I.D. tubular module with $3 / 4$ inch diameter cobalt-60 wafers surrounded by a $3 / 8$ inch thick tungsten cylinder inserted in the bore of the module. The unit, which is surrounded by a steel shield for gamma radiation attenuation, could either be used terrestrially or underseas, the primary differences 
being the sealing methods required for underseas application.

Integrated Heat Pipe/Tubular Module RTG System

The application of the tubular module as the energy conversion unir for a space or remote terrestrial power supply system requires coupling of the module to the heat source. The advent of high power density isotopes permits the heat source to be inserted directly within the inner clad of the tubular modules, as represented by the directly-coupled RTG system previously discussed. An alternate approach to direct coupling is the use of a heat pipe, which provides the means for thermally coupling the heat source and the tubular module. The use of the heat pipe to couple the heat source to the module is particularly attractive from the standpoint of isotope handling, and increases the number of useful isotopes since the radioisotope capsule size is no longer limited 'oy the dimensions of the tubular module.

The Westinghouse Astronuclear Laboratory has designed, fabricated, and tested an integrated heat pipe/tubular module power supply having a unidirectional radiator. This electrically heated unit was designed to provide a means of evaluating the application of tubular modules and heat pipes for use in systems requiring up to several hundred watts of electrical power. The systems that have been fabricated and tested are based on state -of-theart components. The design modifications required for an actual space system would include the replacement of the electrical heater with an isotope source of a similar configuration and a weight optimized radiator tailored to space vehicle integration constraints.

The basic components of the system are an electrical heater, the heat pipe, the tubular module, and a unidirectional radiator. The electrical heat source consists of 10 heaters inserted into a split stainless steel cylindrical block, which is mechanically attached to the heat pipe. A flame-sprayed copper coating was applied to the heat pipe to assure good thermal contact with the stainless steel block.

A 1-inch diameter by 18-inch long sodium heat pipe is used to transport thermal energy from the heat source to the inner clad of the tubular module. The heat pipe working fluid and geometry were selected by mating the operating characteristics of the heat pipe to the thermal requirements of the tubular module. The outer wall of the heat pipe is fabricated from 304 Stainless Steel. The heat pipe wick consists of five layers of 60-mesh 304 Stainless Steel screen held against the outer wall by a 304 Stainless Steel restrainer having a 50 percent porosity. Good heat transfer from the heat pipe to the inner clad of the tubular module is attained by inserting a split boron nitride sleeve in this annulus. Differential thermal expansion between the heat pipe and the tubular module assures good interface conditions during operation.

The tubular module selected for this application has a 1.1-inch inner diameter, a 2.6inch outer diameter, and an active thermoelectric length of 7.2 inches. This module was representative of the state-of-the-art of tubular module development at the time of selection.

The radiator is constructed from six sections of 6061 Aluminum, which are clamped to the outer clad of the tabular module. The radiator design is based on unidirectional heat transfer in a space environment, i.e., 85 percent of the heat is rejected in the direction of the heat source with back-side heat loss limited to 15 percent or less. The unidirectional nature of the, radiator was selected to simplify the integration of the power supply with other space vehicle components, such as electronic gear. The unidirectionality was achieved by coating one face of the radiator with SICON black paint while the back face was highly polished to reduce the emissivity.

A photograph of a test system, with typical test results, is shown in Figure 7. One unit has been tested for 625 hours without any noticeable change in performance. Testing of a second unit has recently been initiated and its performance duplicates that of the first unit tested. 


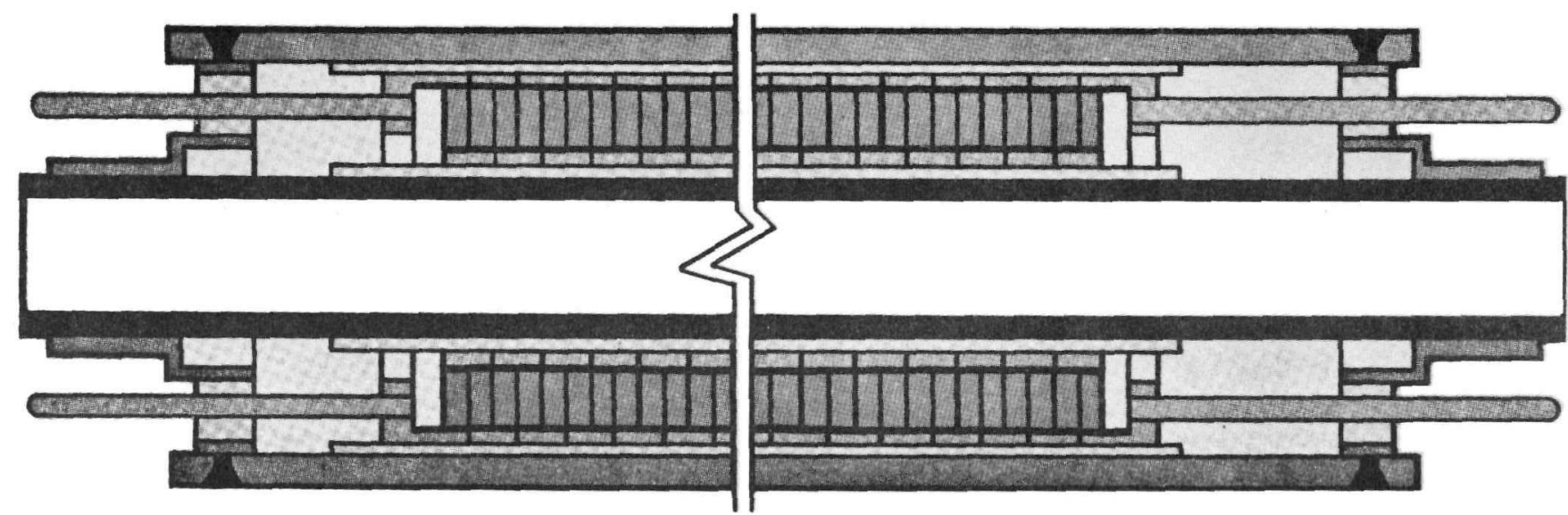

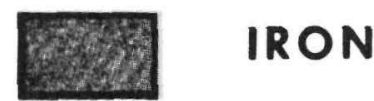

STAINLESS

STEEL

INCONEL 718

LEAD

TELLURIDE

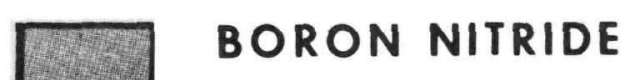

MICA: ELECTRICAL

INSULATION

ALSIMAG-22 2:

THERMAL INSULATION 


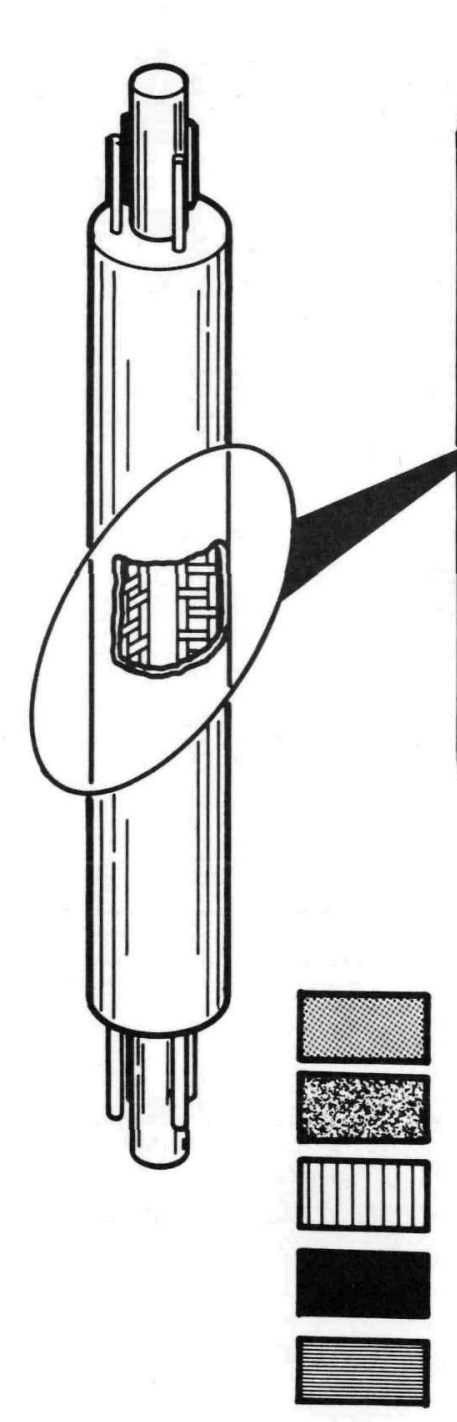

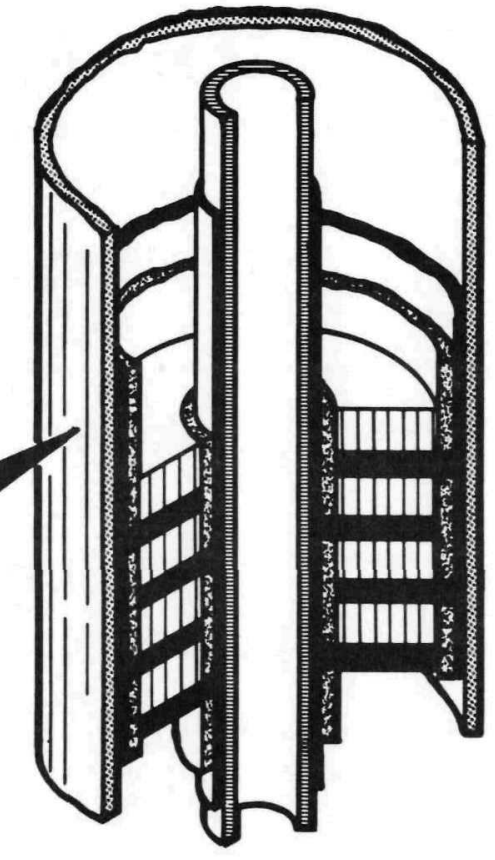

\section{DESIGN FEATURES}

- FUlly encapsulated

- fully compacted-Void free

- structurally rugged

- NO BONDED JOINTS

- USES PbTe at hIgh temperature

- meCHANICALLY AND ELECTRICALLY ADAPTABLE

- LONGEVITY- SHELF AND OPERATING

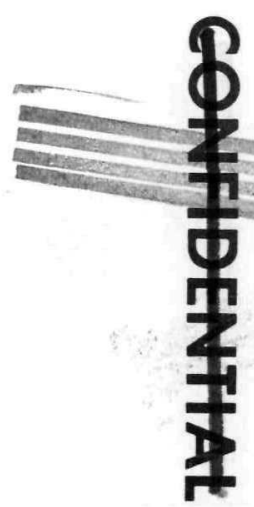

OUTER CLADDING

INNER CLADDING

THERMOELECTRIC MATERIAL

ELECTRICAL INSULATION

ELECTRICAL CONDUCTOR

Figure 2. Tubular Thermoelectric Module 


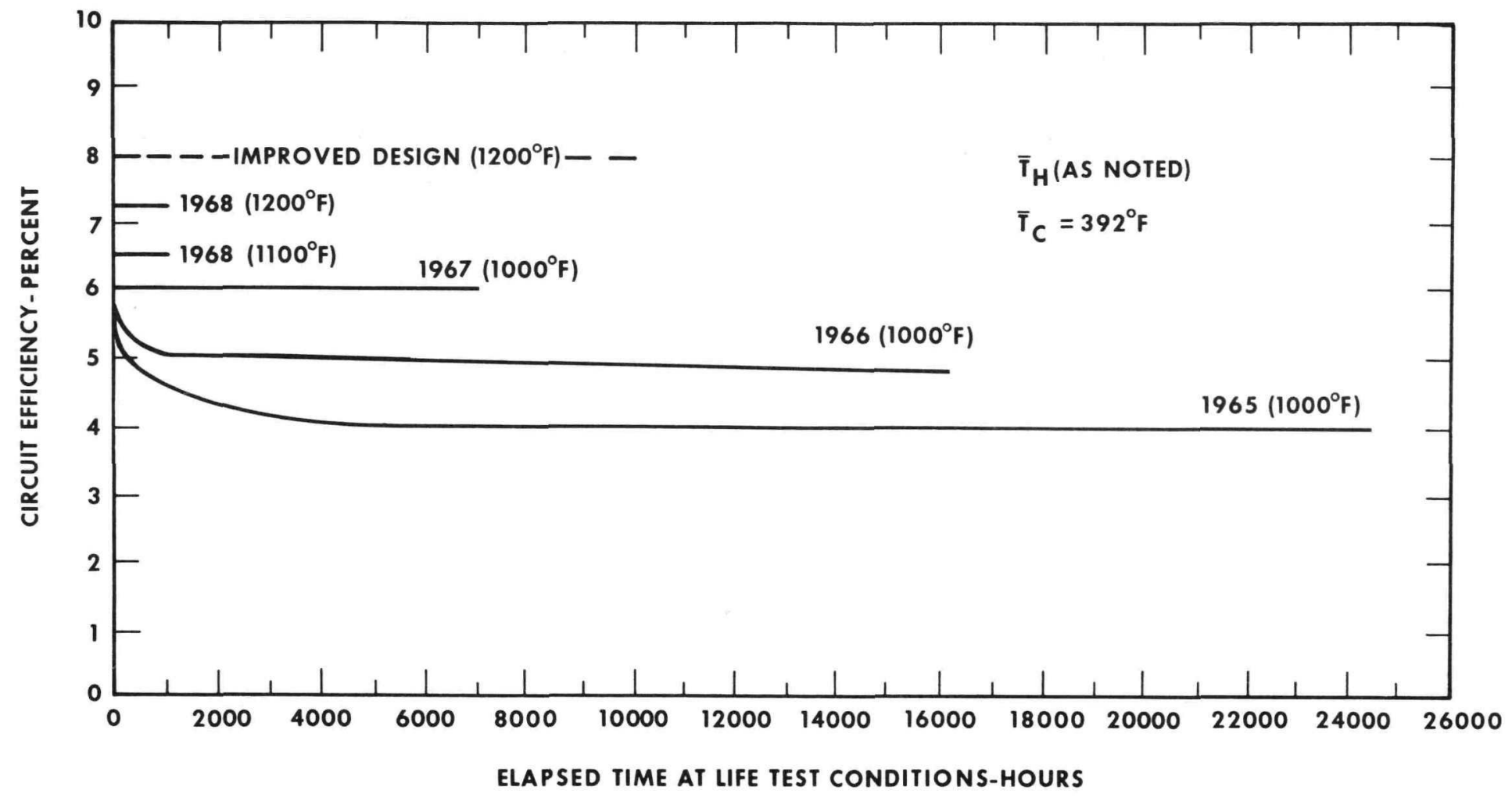

Figure 3. Tubular Module Test Results 


\section{TUBULAR MODULE TEST EXPERIENCE}

\begin{tabular}{|c|c|c|r|r|}
\hline $\begin{array}{c}\overline{\mathrm{T}}_{\mathrm{H}} \\
\left({ }^{\circ} \mathrm{F}\right)\end{array}$ & $\begin{array}{c}\mathrm{T}_{\text {MAX. }} \\
\left({ }^{\circ} \mathrm{F}\right)\end{array}$ & $\begin{array}{c}\text { NO. } \\
\text { MODULES }\end{array}$ & $\begin{array}{c}\text { TOTAL TIME } \\
\text { (HOURS) }\end{array}$ & \multicolumn{1}{c|}{$\begin{array}{c}\text { MAX. TIME } \\
\text { (HOURS) }\end{array}$} \\
\hline 1000 & 1050 & 58 & 217,100 & 24,600 \\
1100 & 1150 & 9 & 25,800 & 9,500 \\
1125 & 1175 & 4 & 5,500 & 2,000 \\
1150 & 1200 & 2 & 6,000 & 4,000 \\
1200 & 1270 & 12 & 10,300 & 1,700 \\
1250 & 1340 & 1 & 1,200 & 1,200 \\
1300 & 1350 & 2 & 5,900 & 4,200 \\
& & & 271,200 & \\
\hline
\end{tabular}




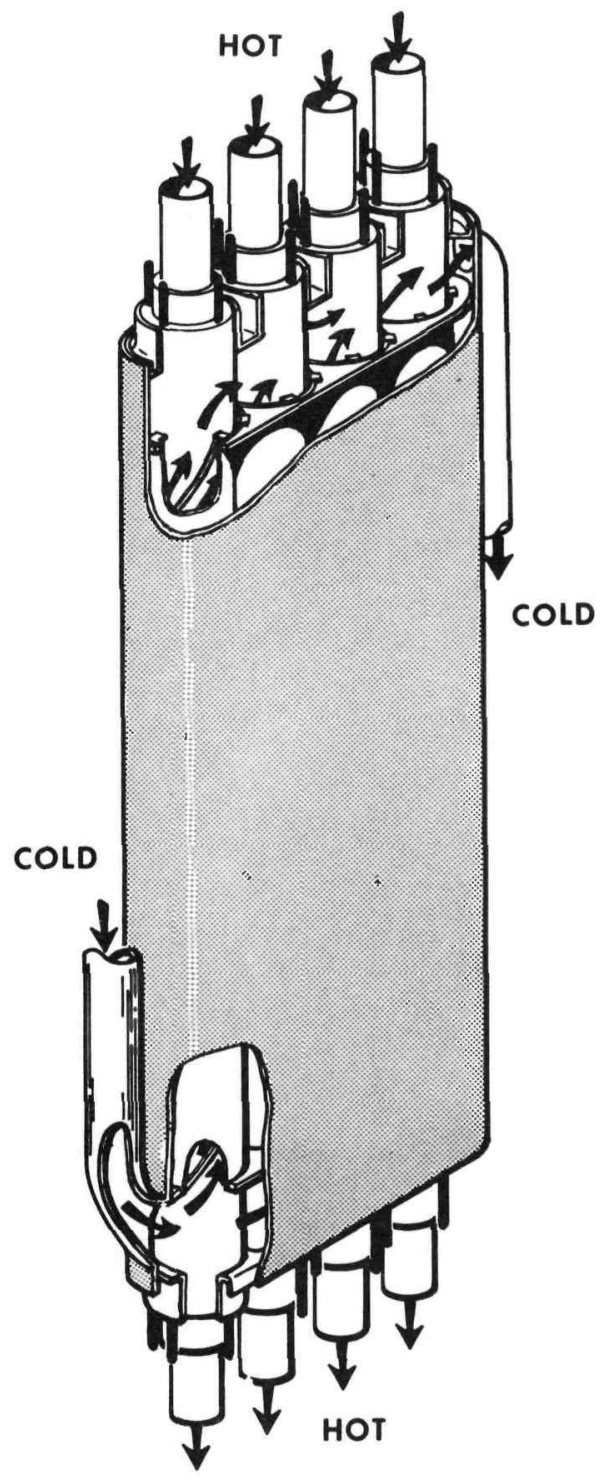

TABLE OF DATA

TUBULAR MODULES-4

262 WATTS

$14 \mathrm{VML}$

18.7 AMPS

SUBASSEMBLY

1048 WATTS

$56 \mathrm{VML}$

18.7 AMPS

TEMPERATURES

$\overline{\mathrm{T}}_{\mathrm{H}} 1125^{\circ} \mathrm{F}$

$\overline{\mathrm{T}}_{\mathrm{C}} 570^{\circ} \mathrm{F}$

$\Delta T_{A} 200^{\circ} \mathrm{F}$

Figure 4. Converter Subassembly 


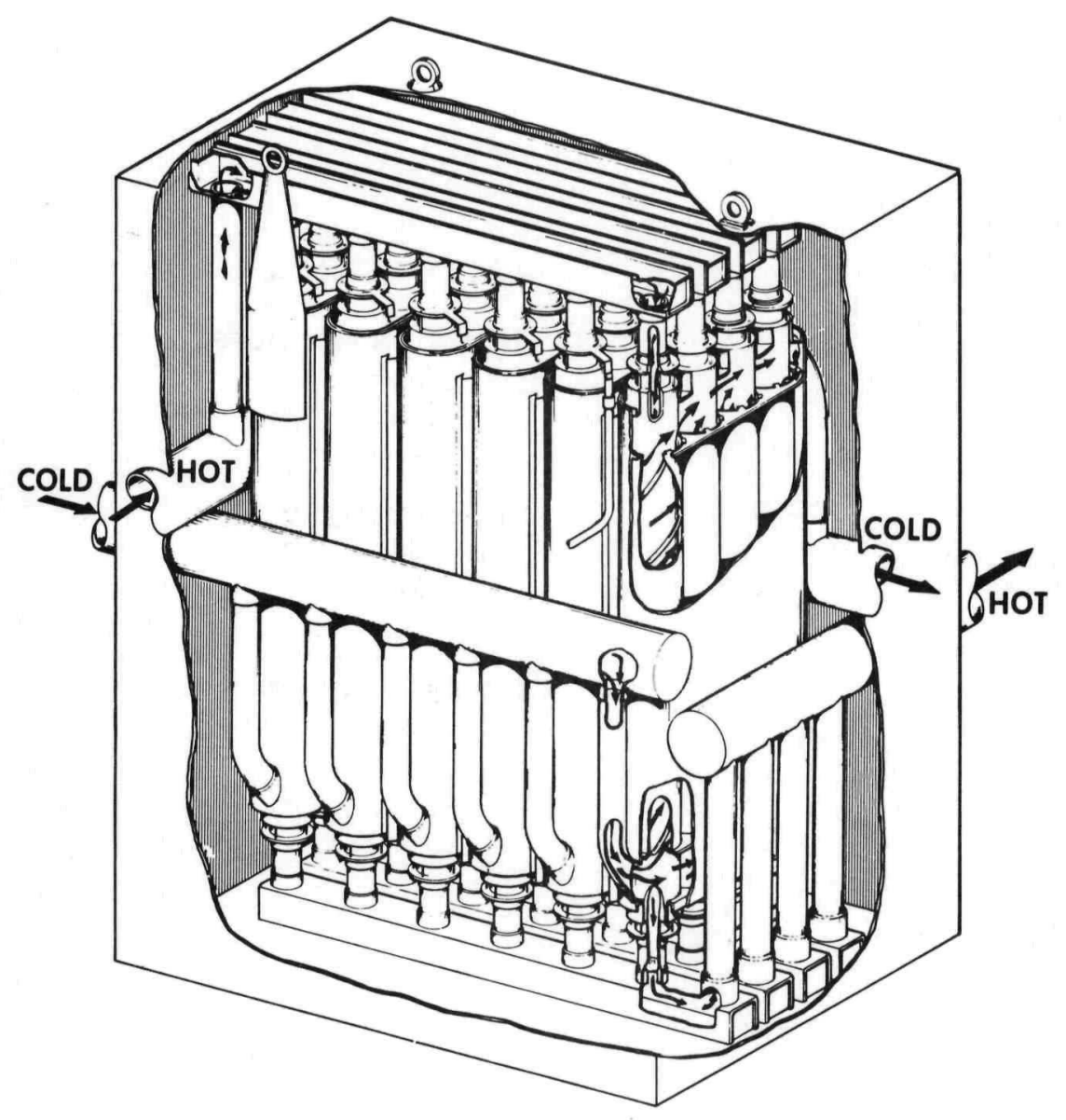

POWER

6.3 KW AT56 $V_{M L}$

WEIGHT

284 LBS.

\section{DIMENSIONS}

$12 \times 19 \times 24$ IN.

TEMPERATURE

$\overline{\mathrm{T}}_{\mathrm{H}} 1125^{\circ} \mathrm{F}$

$\overline{\mathrm{T}}_{\mathrm{C}} 570^{\circ} \mathrm{F}$

Figure 5. Converter Assembly (Converter Subassemblies - 6) 
TABLE 2. CONVERTER ASSEMBLY CHARACTERISTICS

\begin{tabular}{|c|c|c|c|}
\hline $\begin{array}{l}\text { Power Output (KWE) } \\
\text { Efficienty (\%) } \\
\text { Matched Load Voltage } \\
\text { Number of Tubular Modules } \\
\text { Number of Modules Electricall } \\
\text { Current Per Subassembly (ampe } \\
\text { Wet Weight (pounds) } \\
\text { Volume (ft } 3 \text { ) } \\
\text { Envelope Dimensions (inches) }\end{array}$ & in Series & & $\begin{array}{l}6.3 \\
4.6 \\
56.0 \\
24 \\
4 \\
18.7 \\
284 \\
3.4 \\
12 \times 19 \times 24\end{array}$ \\
\hline Temperature $\left({ }^{\circ} \mathrm{F}\right)$ & Hot Loop & & Cold Loop \\
\hline $\begin{array}{l}\text { Inlet Fluid } \\
\text { Outlet Fluid } \\
\text { Mean Fluid } \\
\text { Mean Clad }\end{array}$ & $\begin{array}{l}1246 \\
1046 \\
1146 \\
1125\end{array}$ & & $\begin{array}{l}463 \\
663 \\
563 \\
570\end{array}$ \\
\hline $\begin{array}{l}\text { NaK Flow Rate (pounds/sec) } \\
\text { Pressure Drop (psi) } \\
\text { Tubular Modules }\end{array}$ & $\begin{array}{l}3.03 \\
0.28\end{array}$ & & $\begin{array}{l}2.88 \\
0.26\end{array}$ \\
\hline $\begin{array}{l}\text { Power/Module } \\
\text { Open Circuit Voltage/Module } \\
\text { Inner Diameter (inches) } \\
\text { Outer Diameter (inches) } \\
\text { Active Length (inches) } \\
\text { Dry Weight (pounds) }\end{array}$ & & $\begin{array}{l}262 \text { watts } \\
28.0 \\
0.75 \\
1.50 \\
15.0 \\
5.75\end{array}$ & \\
\hline
\end{tabular}




\section{SONFHEENFTAL}

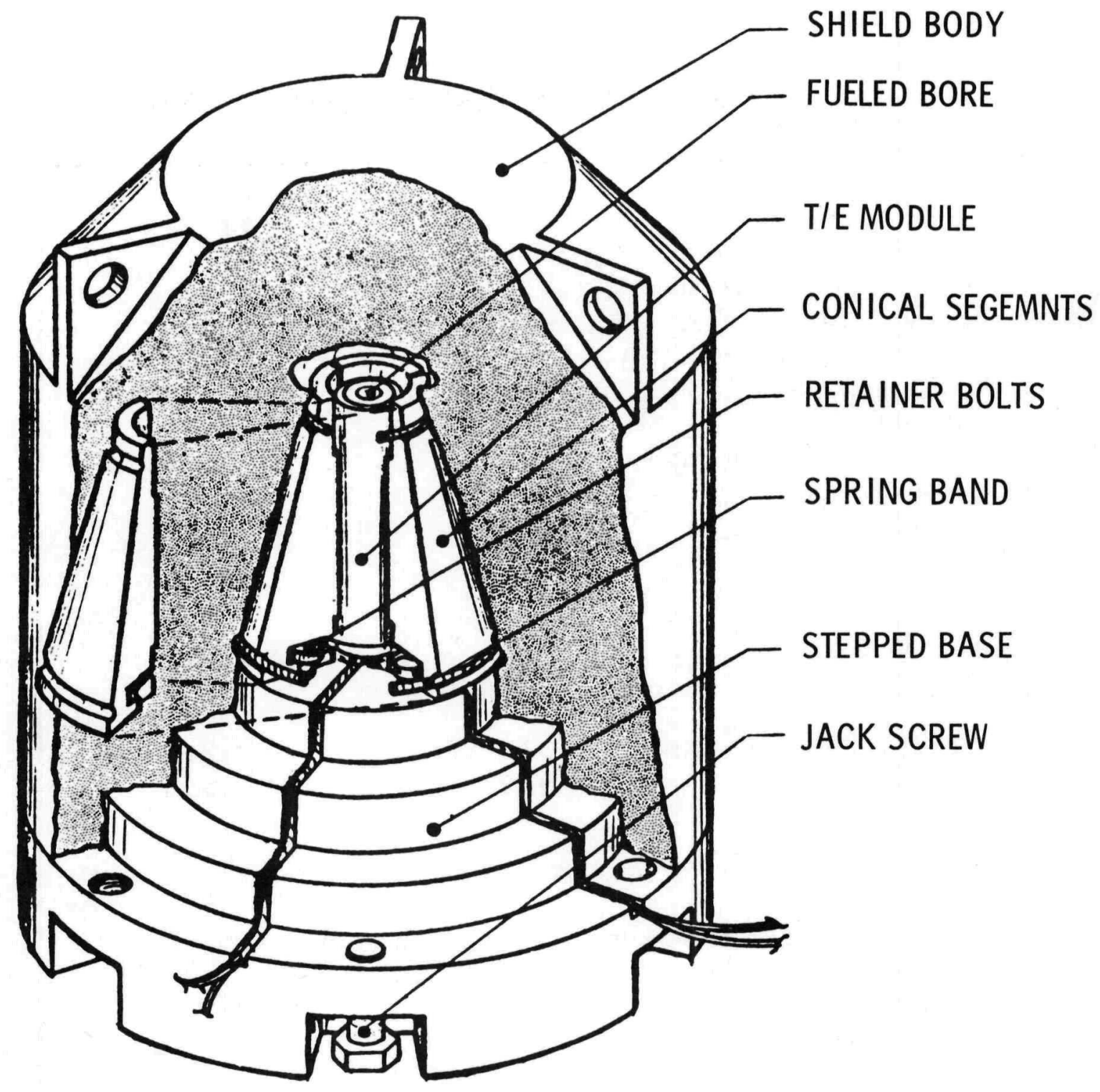

Figure 6. Co-60 Fueled RTG-125 Watts (e) 


\section{(1)}

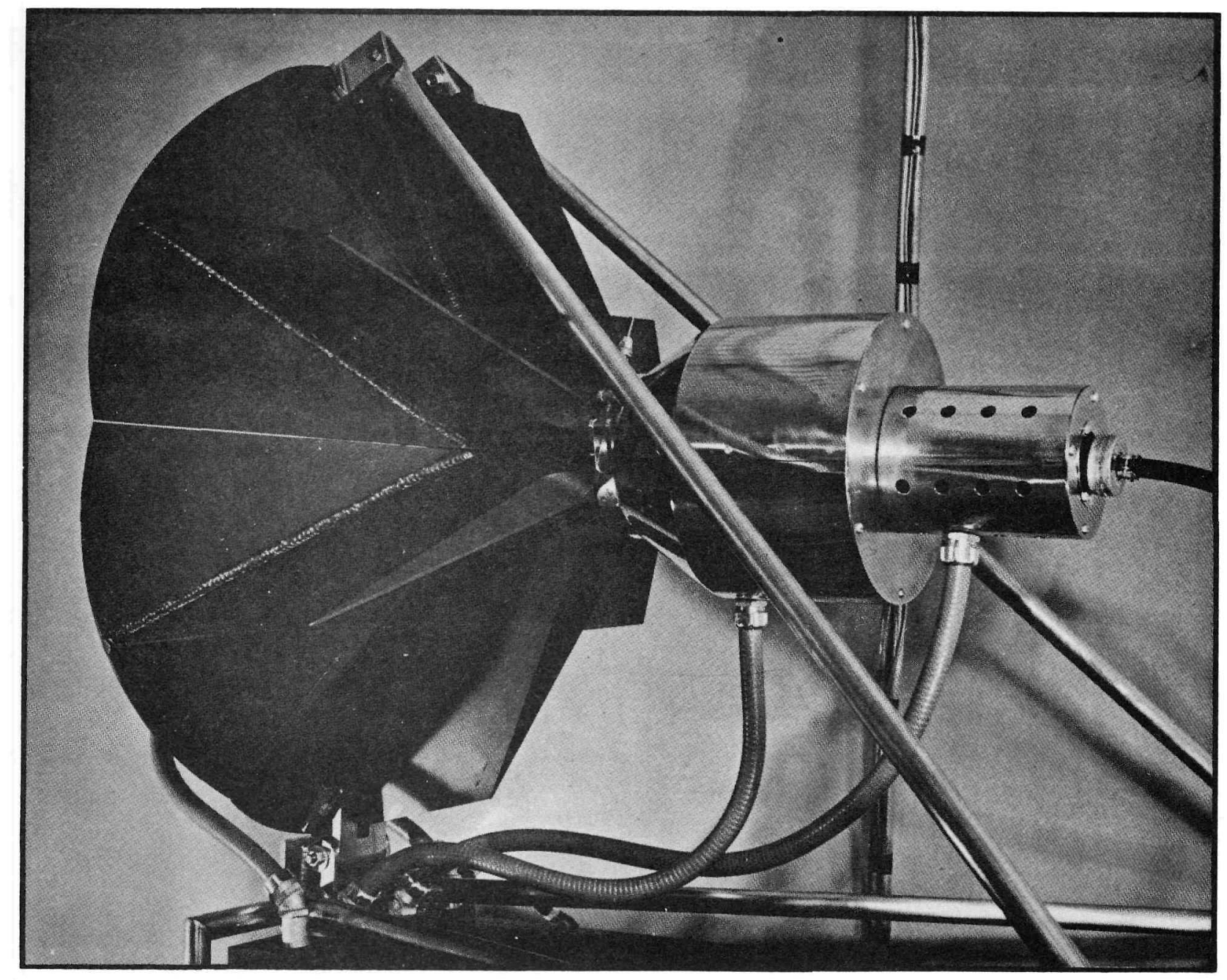

- power 120 Watts(e)

- MOdule EFFICIENCY $7.2 \%$

- temperature $1000 / 400^{\circ} \mathrm{F}$

- overall efficiency

$5.4 \%$

Figure 7. Integrated Heat Pipe Tubular Module System 
If the reservoir volume is made large with respect to the heat pipe volume, then the temperature of the heat pipe will remain nearly constant regardless of power input. In this mode of operation, power changes will cause a change in heat rejection area, but not temperature. The interface between the hot and cold zones will move with power changes. The temperature of operation of this type of heat pipe is pre-set at the time of processing when the desired amount of inert gas is admitted to the device.

When used in connection with a radioisotope heat source, the constant temperature heat pipe system is designed so that at the beginning of life the hot zone of the heat pipe extends completely to the end of the excess power rejection zone. As the isotope decays, the zone will shorten and the temperature interface will move back toward the conversion zone. The converters will remain at constant temperature and electrical output will be uniform until the interface reaches the conversion zone when power output will drop. This is considered to be the end of life of the mission. Systems have been designed which have the capability of producing uniform electrical power output over an eight to one change in the power input; i. e. a period of three half lives in the isotope decay cycle. The heat which passes out through the excess power rejection system can be used for other purposes, recognizing that it has a constantly changing value.

This paper presents the results of a program which was carried out by RCA for the AEC with three primary objectives.

1. Establish the design criteria for a constant temperature heat pipe.

2. Determine the operating characteristics of the device under both steady state conditions and over a four to one change in power input.

3. Determine the capability of the constant temperature heat pipe to perform for long periods of time.

The results of the work in each of these areas are reported in the following paragraphs.

\section{Heat Pipe Design}

The heat pipe thermal design was accomplished using an RCA computer program which makes use of the heat pipe working equation:

$\Delta P_{c} \geq \Delta P_{l}+\Delta P_{v}+\Delta P_{g}+\Delta P_{e}$

where

$\Delta P_{c}=$ Liquid driving force in the capillary structure

$\Delta P_{l}=$ Pressure drop in the liquid due to viscous drag

$\Delta P_{V}=$ Pressure drop in vapor space

$\Delta \mathrm{P}_{\mathrm{g}}^{\mathrm{V}}=$ Pressure drop (or gain) due to gravity

$\Delta \mathrm{P}_{\mathrm{e}}=$ Pressure drop due to evaporation and condensation

The derivation of the heat pipe equation and the expressions which describe the various pressure drops have been presented elsewhere ${ }^{2}$.

Based on the results of the computer program, a heat pipe was designed having the characteristics tabulated in Table I.

TABLE I

Operating temperature $600^{\circ} \quad \mathrm{C}$

Maximum theoretical power

$4000 \quad W$

Wick thickness

0.100 In.

Pore radius

0.007 In.

Total pressure drop

6 Torr

Equilibrium vapor pressure of potassium

Operating length 140 Torr

Outside diameter

Inside diameter

Vapor diameter

19 In.

Ratio of initial to final reservoir volume

1. 45 In.

1. 25 In.

1.05 In.

.909

The heat pipe which was designed, is shown in cross section in Figure 3 . The heat pipe body consists of two main sections, the evaporator-load section and the inert gas reservoir section. The main body of the heat pipe is 270 grade ultra high purity nickel. The capillary wick structure consists of five wraps of $45 \times 45$ "A" nickel mesh which has been compressed and sintered to the inside wall of the heat pipe. 
In the testing program conducted at RCA, electrical heating was used to simulate the radioisotope input. The heater that was used consisted of a heavy wall nickel cylinder containing eight calrod im mersion heaters in a "gattling gun" arrangement. The annular heater assembly was brazed to the outside of the heat pipe with nickel-palladium solder.

The load section of the heat pipe is the four inch length adjacent to the heater. A water cooled heat sink was used to duplicate the load of a typical thermoelectric converter. The power throughput was measured by calorimetry.

The excess power rejection zone extends from the load zone to the end of the heat pipe and employs four water cooled heat sinks to remove the heat. These sinks are spaced one inch apart. Calorimetry was also used to measure the excess power which was removed.

The inert gas reservoir consists of a larger diameter stainless steel cylinder connected to the heat pipe at one end by a conical stainless steel transition member. The reservoir is completely lined with wick in order to return any working fluid which finds its way into this section. The wick consists of one layer of $20 \%$ dense nickel matrix with 0.010 inch pore size in the cone and two layers of $45 \times 45$ stainless steel mesh in the cylinder. Provision was made for both heating and cooling the reservoir during the tests.

The heat pipes were fabricated by inserting the wick, brazing on the heater block and heat sinks and then joining the various segments by electron beam welding. Care was taken to be sure that the separate wicks meshed together properly.

Processing of the heat pipes was done on an ultra high vacuum system with an auxiliary system for injecting argon into the reservoir to achieve the correct operating pressure. The heat pipe assembly was heated to a temperature above the normal operating range in order to outgas all of the components parts while still connected to the vacuum system. After suitable outgassing, potassium was admitted to the heat pipe in a quantity just slightly more than required to operate the heat pipe. The potassium filled tube was then sealed off and árgon was admitted to the heat pipe in the correct amount to give 140 Torr of pressure when the heat pipe was up to full operating temperature. The heat pipe was then removed from the exhaust system by a nickel pinch-off.

\section{$\underline{\text { Performance Testing }}$}

Five heat pipes were fabricated and processed as part of the test program. four heat pipes had inert gas reservoirs as described above and the fifth was built without a reservoir as a control sample to determine whether any difference in operating characteristics could be caused by the presence of the reservoir. For instance, there was some initial concern that the non-condensible reservoir gas would gradually mix with the working fluid vapor when they existed together for long periods of time.

The first heat pipe was used to check out the design and short term performance characteristics. Tests on this pipe showed that the heat pipe performance was satisfactory. However, this assembly employed a coiled calrod heater which was found to have poor heat transfer characteristics. Modifications to the heater design were made and all other heat pipes employed the immersion heater block described above. To prevent undue thermal stress and possible heater runaway, the temperature difference between the heater block and heat pipe was limited to $35^{\circ} \mathrm{C}$. Under this constraint the maximum power through the heat pipe was determined to be 1750 watts. This value was then used as the $100 \%$ power point in all future heat pipe tests.

Heat pipes No. 2 and 3 were tested in a similar manner for performance: their lifetimes, however, were different. The history of these two pipes is shown in Figure 4. As can be seen in this figure, both heat pipes were brought up to $100 \%$ power and held for 1000 hours. At the end of this period the power input was reduced in a programmed manner to 
simulate the decay of a radioisotope The power was reduced to $25 \%$ of the initial power over the period of 3000 hours. At the end of this two half-life decay period the power was maintained at the low value for several hundred hours after which it was increased back to the $100 \%$ level. Heat pipe No. 3 was removed from life test after 6000 hours of undegraded performance. Heat pipe No. 2 was continued on life test until it had completed 10,000 hours of undegraded performance. No change in any of the operating characteristics of these two heat pipes was observed during the test.

The temperature profiles of heat pipe No. 2, before and at the end of the exponential decay period, are shown in Figure 5. It can be seen from this figure that the load zone of the heat pipe only dropped $25^{\circ} \mathrm{C}$ during this 4 to 1 power input change. At the conclusion of the exponential decay test the $100 \%$ power profile was almost identical to that before test.

Heat pipe No. 5, which had no reservoir, was operated at the $100 \%$ power level for 6000 hours. This heat pipe was also operating normally at the end of this period when it was removed for analysis.

Heat pipe No. 4, which had an inert gas reservoir, was tested at a constant input, and it transmitted 1750 watts at $600^{\circ} \mathrm{C}$ for its entire lifetime. This heat pipe has remained on test under these conditions. The lifetime currently has exceeded 17, 000 hours and the test is continuing.

In all of the tests the heat pipe performance remained stable. There was no change in temperature distribution or power throughput with life other than that imposed on the heat pipes during the exponential decay tests.

\section{Post Test Analysis}

A detailed analysis of heat pipes No. 2, 3 , and 5 was performed by the Metals and Ceramics Division of Oak Ridge National Laboratory. Procedures were developed for removing both the working fluid and the inert gas for analysis without contaminating the samples. The heat pipe body was cut into several sections and methods were developed for removing the wick structure from these segments without deforming it. All of the metal parts were given a detailed metallurgical and chemical examination. In areas of special interest electron diffraction and electron microprobe techniques were used to study the surfaces.

The results of this examination showed that the entire condensing section of the heat pipe and the reservoir section were unaffected by the long time of operation. There was no erosion or deposits and no gross contaminating materials were found in the working fluid or inert gas. In the evaporator section of all three heat pipes there was a small area in the center of the evaporator where the wick structure was eroded and this area was surrounded by a black deposit. The eroded area in each case was at the top of the evaporator as the heat pipe was operated horizontally. Heat pipe No. 5, which did not have a reservoir, had the largest eroded region. The area was approximately $2^{\prime \prime} \mathrm{x} .125^{\prime \prime}$ and the erosion occurred at the wick-vapor interface. A photograph of this eroded region is shown in Figure 6 .

The two constant temperature heat pipes which had inert gas reservoirs showed much less erosion and deposit. The eroded area of the wick structure was only approximately. 25 inches in diameter and it was located at the wickwall interface. The black material surrounding the erosion looked similar. It is interesting to note that the magnitude of the eroded area and the amount of deposit were no greater in the 10,000 hour heat pipe (No. 2) than in the 6,000 hour heat pipe (No. 3). Since the erosion does not appear to be a function of life, it is believed that a contaminating agent was present early in life and that most of the erosion occurred at that time. An analysis of the black material indicated it to be a mixture of nickel and potassium carbonate. Since the carbonate will form from the oxide in air, it is believed that oxygen was the original contaminating agent and that the material, as deposited, 
was a compound of nickel, potassium/and oxygen. The source of oxygen is not yet known. An evaluation of the oxygen content of the original heat pipe materials show that a very low level was present after the cleaning and vacuum firing operations. It is possible that the residual surface oxygen was sufficient for erosion or that additional oxygen was introduced with the potassium. The investigation is currently continuing.

\section{CONCLUSIONS}

The results of this experimental program have confirmed that the temperature of a heat pipe can be held with in close limits by the use of an inert gas reservoir to establish the vapor pressure within the pipe. The reservoir volume need not be exhorbitant to accomplish this function. A ratio of 10/11 of initial reservoir volume to final volume was found satisfactory for holding the temperature of a $600^{\circ} \mathrm{C}$ pipe within $25^{\circ} \mathrm{C}$. This constant temperature feature can be used to maintain a thermal to electrical conversion device at nearly constant temperature and consequently, at uniform electrical output even though the heat source is a radioisotope which is decaying exponentially with time. The constant temperature heat pipe was found to be an inherent long life device. In the four heat pipes tested, accumulated life of over 39, 000 hours was obtained without a failure or change in heat transfer capability. . The longest life pipe is still operating at over 17, 000 hours of life and the other three were removed at $6,000,6,000$, and 10,000 hours while still operating with undegraded performance.

Some erosion and redeposit of material was observed in the evaporator section of the analyzed heat pipes. While this situation did not cause a change in performance, additional work should be done to determine and eliminate the cause of the reaction.

The constant temperature mode of operation of the heat pipe has been demonstrated to be a powerful tool for obtaining uniform electrical output from a radioisotope heated thermoelectric converter. Uniform thermionic conversion has also been demonstrated using this device. Designs and experiments have also shown this feature to be valuable in other areas. Constant temperature furnaces can be made which will hold semiconductor materials at extremely uniform temperature. Samples can be heated in a nuclear reactor to obtain neutron bombardment data at constant temperature. RCA has made a semiconductor heat sink employing this design so that the temperature sensitive semiconductor remains at a uniform tempera ture even though its dissipation is changing.

The constant temperature heat pipe can also serve as an overload device. In fact the isotope heated tenerator described in the paper can benefit from this function. If for any reason the load is removed from the conversion device, the radioisotope temperature will be held to a constant value and the additional power will be dissipated by using more of the excess power radiator. The fact that the heat pipe will run at constant temperature even though the thermal load changes, opens up other application possibilities. In one proposed application the constant temperature heat pipe would be used to conduct heat out of a nuclear reactor to thermionic conversion units. If the reactor power changes, the converter temperatures will remain constant. If the converter load is reduced, the excess power will be directed into the heat pipe which extends beyond the converter units where it can be safely dissipated without causing a temperature excursion of the reactor core. This same system has been considered for a flame fired Brayton power generator to prevent overheating of the heat exchanger.

The constant temperature heat pipe is indeed a unique device for transferring and controlling thermal power. Several applications of this device have been described. Undoubtedly a great many more applications will come to light as the engineer becomes more familiar with its capabilities. 


\section{GONFTEENTAE}

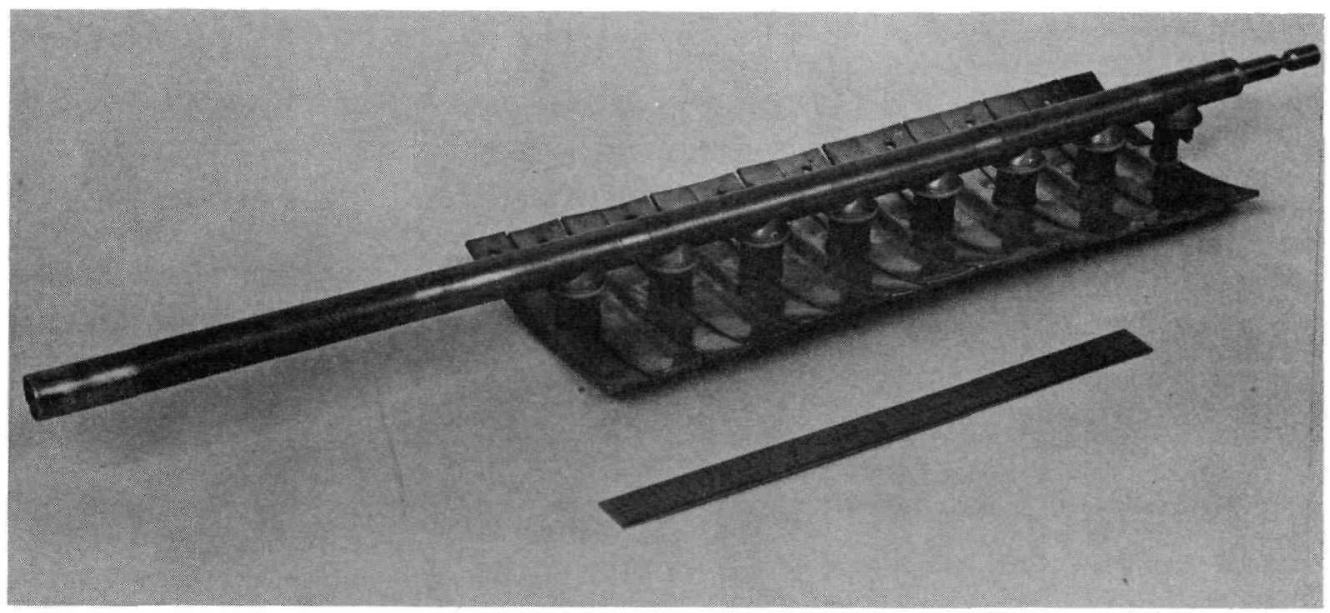

FIGURE 1 HEAT PIPE-THERMOELECTRIC CONVERSION SYSTEM

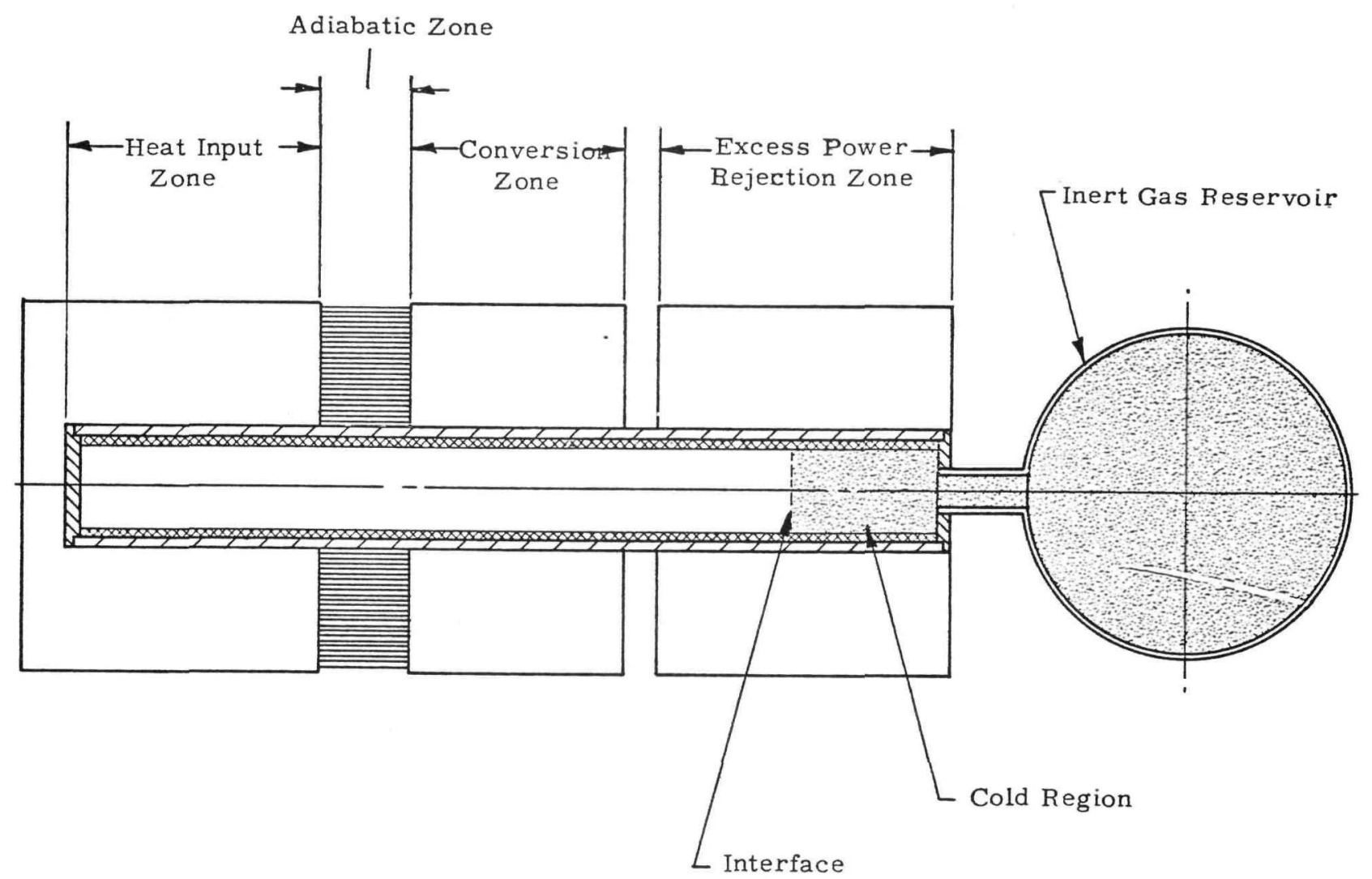

FIGURE 2 DIAGRAM OF A CONSTANT TEMPERATURE HEAT PIPE 

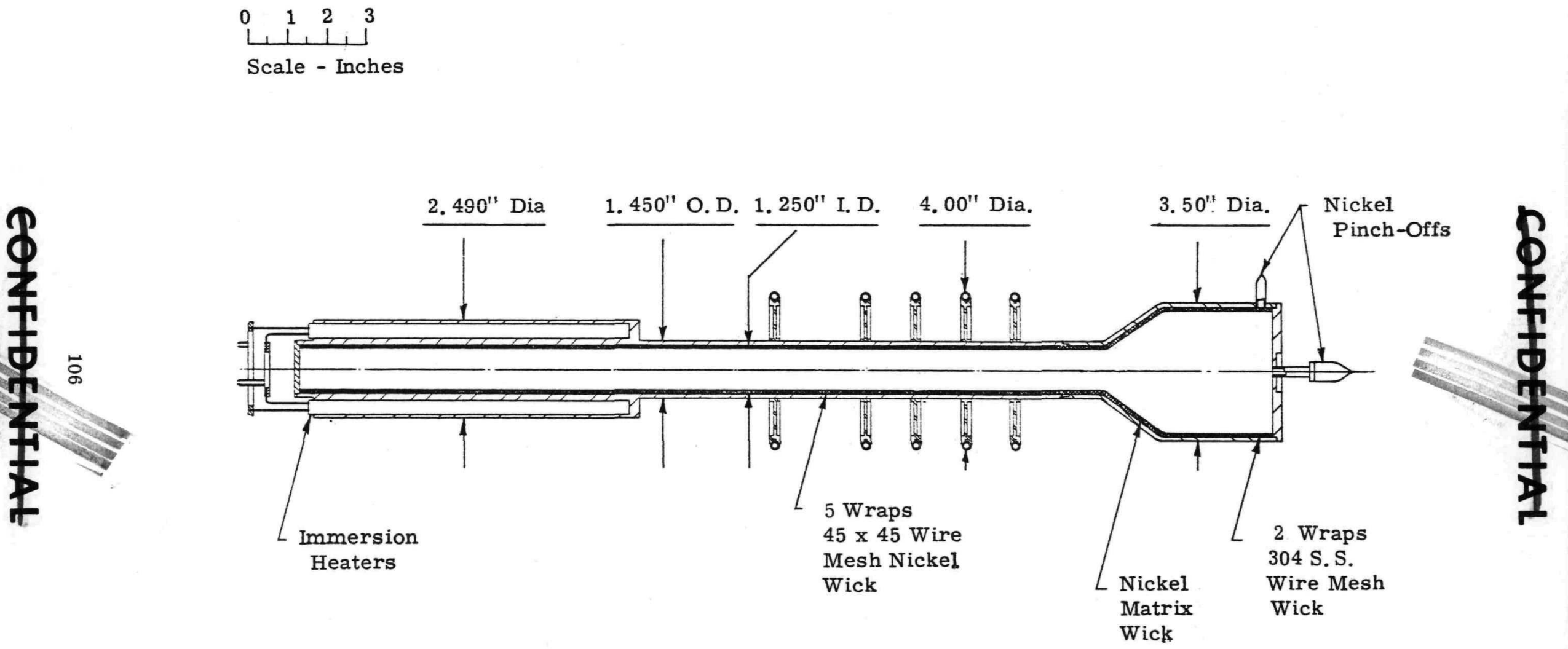

FIGURE 3 CROSS-SECTIONAL DRAWING OF HEAT PIPE 


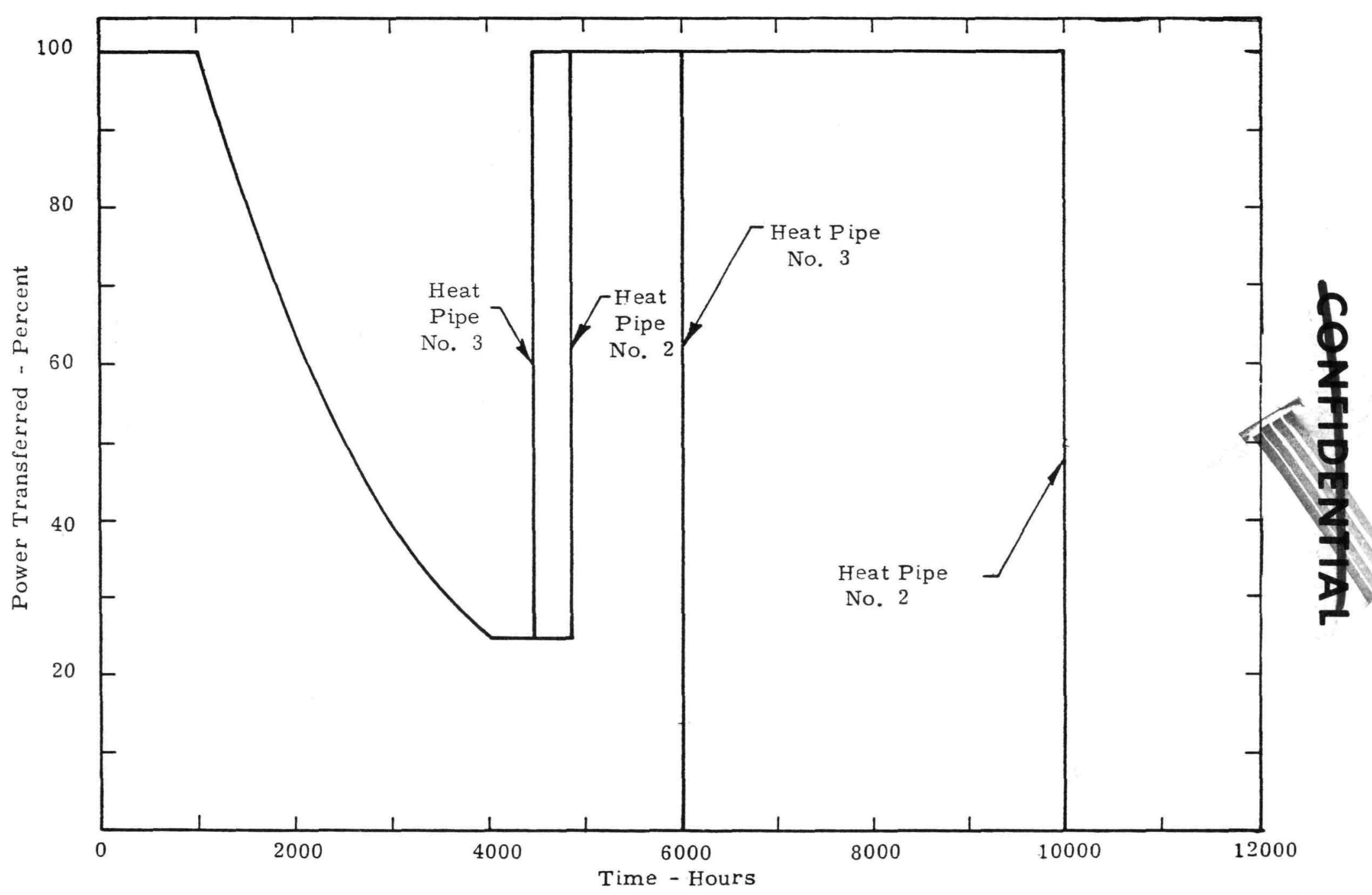

FIGURE 4 PERCENT OF POWER TRANSFERRED VERSUS TIME FOR HEAT PIPES No. 2 \& No. 3 

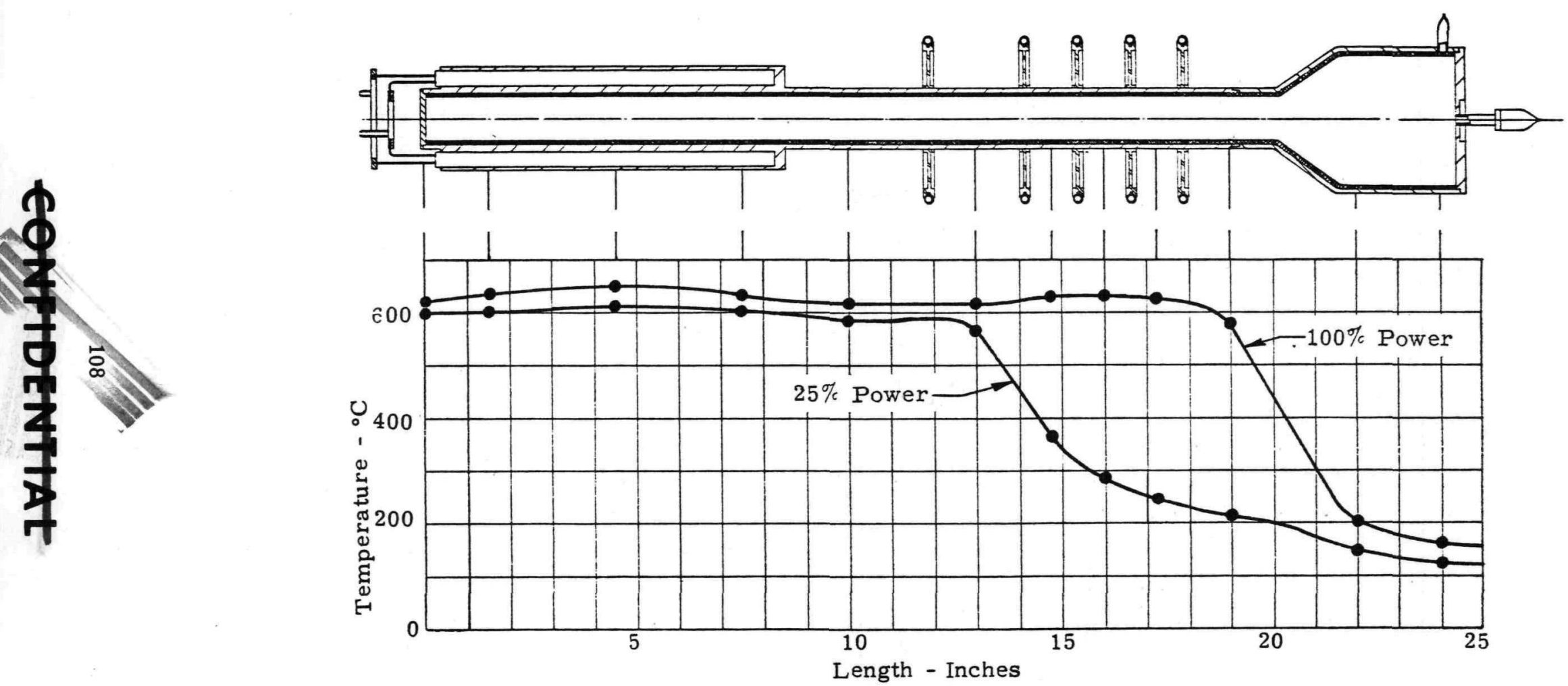

FIGURE 5 TEMPERATURE PROFILE OF HEAT PIPE No. 2 AT BEGINNING AND END OF TWO HALF LIFE DECAY PERIOD 


\section{GOnfHEnthe

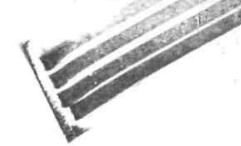

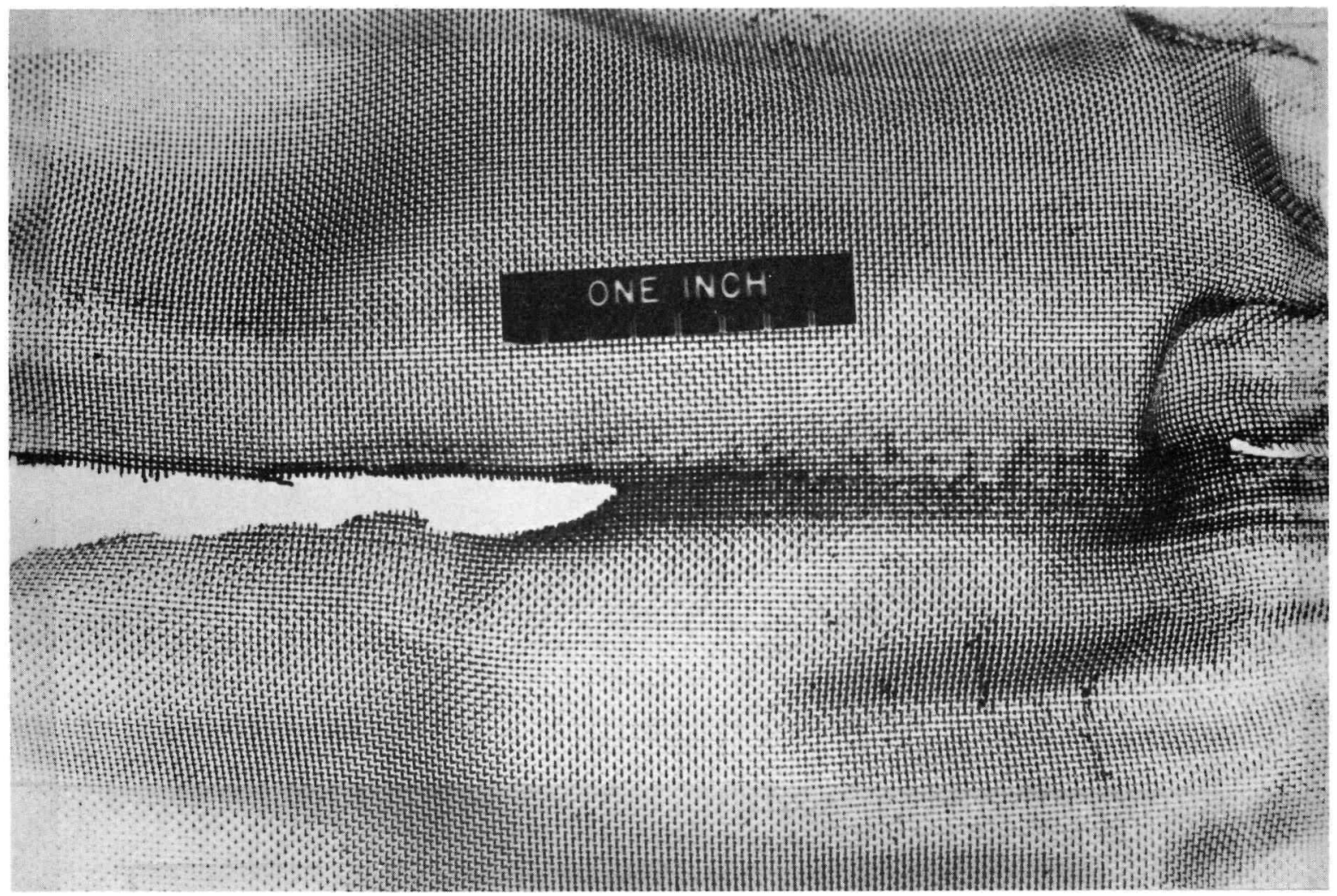

FIGURE 6 ERODED AREA IN THE WICK STRUCTURE OF HEAT PIPE No. 5 


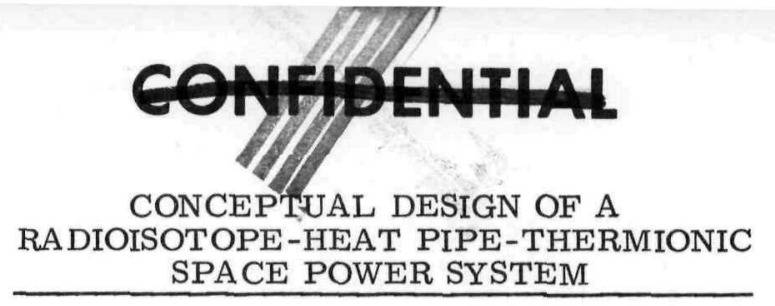

Frank D. Altieri and Andrew J. Parker, Jr. Hittman Associates, Inc. Columbia, Maryland

and

Willis E. Harbaugh

Radio Corporation of America

Lancaster, Pennsylvania

\section{SUMMARY}

A detailed design study was performed to determine the feasibility of developing a 250 watt(e) space power supply which incorporates polonium-210 fuel capsules, thermionic diodes, a heat pipe and a unique thermal power flattening device as its basic components. The objective of the generator design was to develop a safe, reliable, durable and lightweight system. The results of the study, as described herein, have proven conclusively that such a design is feasible. The major development areas associated with the design exist in the materials, fuel capsule, and fuel form areas.

\section{INTRODUCTION}

The power system which is presented in this paper is the result of two years of systems analysis and component fabrication and testing efforts. The program was performed for NASA and was technically monitored by the Jet Propulsion Laboratory. The systems analysis tasks were performed by Hittman Associates, Inc. under subcontract to the Radio Corporation of America (RCA). (1) All component fabrication and testing tasks were performed by the prime contractor, RCA. (2)

The systems analysis tasks were performed for two aerospace nuclear safety philosophies:

${ }^{(1)}$ RCA P. O. 9-168441-H16, Phase I RCA P. O. 9-A 276090-H14, Phase II

(2)

NASA Contract NASw-1254, Phase I NASA Contract NAS7-100 - P. O. 951754 , Phase II
(1) High altitude burnup of the generator system and dispersion of the radioactive fuel

\section{(2). Random intact reentry}

(RIR) and complete containment of the nuclear fuel under all situations of abort

Obviously, these criteria are diametrically opposite and will have a significant effect on the system power density (output electrical power in watts per pound of generator system weight). The generator system was to deliver 250 watts of electrical power to the spacecraft bus at the end of a one year space mission. One of the primary objectives of the system's study was to verify analytically the operation of a power flattening device which utilized a heat pipe in conjunction with a gas reservoir controller. A short-lived radioisotope, polonium-210 (Po-210), was purposely selected as the system heat source to validate the power flattening technique. The electrical power converter consisted of two RCA developed thermionic diodes. Thus briefly stated, the power system consists of two thermionic converters coupled to an isotopic heat source through a heat pipe which is also used to dump waste heat to space. The waste heat dumped includes excess heat from the heat source early in life or nonconverted heat during periods of spacecraft off maximum electrical demand. The heat pipe utilizes lithium as the working fluid. The heat pipe heat rejection area is controlled by the application of a unique method which positively controls the active or working section of the heat pipe under varying 
system operating conditions. This is a complished by the use of a close coupled helium gas reservoir which relocates the active heat rejection area based on overall system requirements. Two system concepts were designed to satisfy the following design goals.

$\begin{array}{lcc}\text { Parameter } & \text { Burnup System } & \text { RIR System } \\ \begin{array}{l}\text { Net electrical } \\ \text { power, watts } \\ \text { (end-of-life) }\end{array} & 250 & 250\end{array}$

Fuel

$\mathrm{Po}-210$

$\mathrm{Po}-210$

Operating life-

time, years

1

1
Operational environment

vacuum and air

13

System ef-

ficiency, $\%$

Specific weight, watts/pound

Integrated neutron flux

limit, $\mathrm{n} / \mathrm{cm}^{2}$

Maximum photon energy deposition, $\mathrm{erg} / \mathrm{gm}$

Planetary impact capability (generator operational after impact) a table which presents the analysis results for each case will be given. In addition, a description of the system test facility for both the hoat pipes, heat pipes and converters, and the converters will be presented. Appropriate component and facility photographs are included.

\section{SYSTEMI DESCRIPTION}

The two generator systems that are presented in this paper are shown schematically in Figure 1. Each system is composed of several basic components including:

11

$10^{12}$

Heat pipe

\section{Helium reservoir}

Heat source section (fuel capsules)

\section{Thermionic diodes}

Control radiator

Drag plate

The heat pipe is the central component to which the fuel capsules, thermionic diodes and inert gas reservoir are attached. The fuel capsules, annular in shape, are mounted to one end and circumscribe the heat pipe. Two thermionic diodes are mounted to the pipe adjacent to the fuel section. The heat pipe extends well beyond the diodes to provide excess heat rejection area. This region is called the control radiator. Attached to the end of the heat pipe, opposite to the fuel, and adjacent to the control radiator

The component fabrication and test effort section, is a helium reservoir. The entire includes the development of the thermionic converters, the heat pipe, the heat pipe wick structure (including the selection of the working fluid), the gas reservoir and the effect its location has on system operation, and the attachment (welding, bonding, etc.) method for the various systems components. The test work includes component vacuum operation for selected periods of time and component life tests for the major systems components. No nuclear fuel capsules were developed. Input power (heat) is provided by electrical resistance heaters during the test programs.

This paper presents a description of the basic system and each generator component. Certain system components will change as a function of the nuclear safety philosophy that is selected. The resulting selections will be discussed in parallel to present the reader with a clear design comparison for each case postulated. Finally, heat pipe assembly is housed within four fuel, diode, control radiator, and reservoir sections.

The fuel capsules provide the thermal energy which is subsequently converted to electrical power. (A portion of the energy generated by the fuel is transported by the heat pipe to the emitter of the thermionic diodes where this heat is converted to electrical energy. ) The excess thermal energy is transferred to the control radiator section, where it is dissipated. Developed RTG systems incorporate either a passive or an active thermal control system. The passive system is designed to reject the maximum quantity of waste heat, usually by a finned radiator, and no rejection area control is available to the system. The active system will generally incorporate a mechanically operated shutter to vary the heat rejection area with time or will incorporate hermetically sealed outer cans enclosing the 
a secondary cooling loop (e.g., a tube ty fluid) to obtain the desired system control. The method that is utilized in the device which is described herein is different than either of the above described techniques. It is a self-contained active system. However, it is inherently simpler than the more conventional active systems and its reliability is close to that of a passive system. The helium reservoir is coupled to the heat pipe to reduce the effective radiating surface of the control radiator as the isotope decays. The generator is designed and calibrated so that the interface between the lithium vapor (the heat pipe working fluid) and the helium occurs at the interface between the control radiator and the reservoir sections at the beginning of system life. At this time the partial pressure of the lithium vapor and the pressure in the helium reservoir are equal. As the isotope decays, less excess heat is available and too much radiating area momentarily exists. Thus, the temperature of the system tends to drop slightly. This slight drop in temperature decreases the partial pressure of the lithium vapor. Since the reservoir volume is relatively large (a minimum of $2: 1$ to the control radiator volume exclusive of the diode section) and is designed to control the system pressure, the helium expands into the control radiator, reducing the effective length of the heat pipe while maintaining a relatively constant temperature.

A description of the basic components of each of the systems follows. If the description is applicable to both systems, a single paragraph is presented. For those components that are a function of the system design philosophy, specific descriptions are provided. Paragraph "a" will always refer to the burnup system design criterion while paragraph "b" will always refer to the RIR system.

Heat Pipe

The heat pipe, shown schematically in Figure 2 and used as the basis for the analytical model, is the heart of the generator design and is used as both a structural and thermal transport member. It has multiple supports along its length and is embedded in insulation at the fuel capsule end. The multiple supports distribute the load and minimize bending. The heat pipe is 31.1 inches long and has a nominal outer diameter of 1 inch. The pipe is madefrom TZM tubing, with a thickness of 0.060 inch. A molybdenum wick covers the internal cylindrical surface of the pipe. The proposed wick consists of molybdenum screen rolled into a multilayer tube. These screens are inserted into the pipe and can be held to the inner surface of the pipe by a helical molybdenum spring. Other more optimum wick structures exist and were investigated experimentally. However, this particular wick structure eases fabrication and assembly operations. A 0.25 inch diameter TZM tube is welded to the end of the main heat pipe and provides a transition zone to the helium reservoir. This small pipe is also a heat pipe since a wick is provided. Its small diameter helps to thermally isolate the reservoir from the heat pipe and insures a relatively constant reservoir temperature throughout the mission life.

\section{Helium Reservoir Section}

The helium reservoir is a conically shaped TZM container with a maximum diameter of 6.6 inches and a length of 2.85 inches. Its thickness is 0.030 inch and it is mounted directly to the cylindrically shaped Haynes - 25 container which houses the entire reservoir section. The reservoir is designed to operate at $500^{\circ} \mathrm{R}$. The helium reservoir to heat pipe volume ratio is $7: 1$.

The helium reservoir is a conically shaped TZM container with a maximum diameter of 5.2 inches and a length of 2.6 inches. Its thickness, mounting provision and operating temperature are similar to that described in the previous paragraph. A parametric analysis in reservoir to heat pipe (less diode section) volume, was performed to determine the minimum reservoir size which would satisfy system operating design criteria. The results of the analysis indicated that a helium reservoir to heat pipe volume ratio of $2: 1$ is acceptable. Table 1 presents the analytical results. Figures 3 and 4 present the effect that the reservoir size has on system operating parameters. The beginning-of-life system design point that must be maintained corresponds to a lithium temperature of $2850^{\circ} \mathrm{F}$ and a system pressure of $63 \mathrm{psia}$.

Heat Source Section

The heat source is composed of an annular shaped $\mathrm{Ta}-10 \mathrm{~W}$ capsule shown schematically in Figure 5. The overall outer diameter is 4.0 inches and the inner diameter is 1 inch. The fuel is doubly encapsulated. The fuel capsule assembly is made up of five annular capsules (doughnut shaped) which are fueled separately. Each of these capsules has an outer diameter of 3.6 inches, a length of 1.7 inches and is fueled with 3176 thermal watts of polonium. The polonium fuel form selected was a porous Ta-DyPo matrix formed into an annular ring by cold pressing tantalum and dysprosium powder. The annular Ta-Dy rings are fueled in a sealed steel container 
by introducing polonium deposited platinum screens into the container and allowing the polonium to react in situ with dysprosium. The wall thickness for each of these capsules is $20 \mathrm{mils}$ and the material selected is Ta-10W based upon corrosion and compatibility considerations. Each of these smaller capsules is then assembled into a single annular shaped Ta-10 W pressure vessel with an outer wall thickness of 0.2 inch, an outer diameter of 4 inches, and inner diameter of approximately 1 inch, and an overall length of 8.6 inches. A large void volume is provided to reduce the helium pressure generated and reduce the associated stresses. The fuel capsule assembly is completely embedded in a tantalum multifoil insulation.

The entire fuel capsule with its insulation is surrounded by a cylindrically shaped 30 mil thick Haynes-25 can, which,together with the outer housing of the diode, control radiator and reservoir sections, provides a vacuum environment to prevent the refractory metals in the system from oxidizing when the generator is operating in an air environment. The fuel section housing is 5.2 inches in diameter and 10.2 inches long. The fuel capsule is designed to (1) contain fuel for five years in an air environment, (2) survive a terminal velocity impact of $333 \mathrm{ft} /$ sec, (3) leak He at a controlled rate, and (4) operate at a temperature of $1500^{\circ} \mathrm{C}$. The results of the study are summarized below.

(1) Fuel Matrix and Inner Fuel Capsules. The isotope is formed into a fuel compound with dysprosium. The compound is then dispersed into a platinum-rhodium matrix. For ease of handling and greater integrity, the fuel $(15,879$ watts $(t))$ is assumed to be evenly distributed among five inner capsules which have a 3.8 inch outer diameter, and 1.65 inches length and are separated by spacers. The fuel loading is 3176 watts/ inner capsule. Since the outer capsule provides the impact strength for the overall container, the inner capsule wall thicknesses can be a minimum of 20 mils. The spacers are $90 \mathrm{mils}$ thick. The fuel power density is assumed to be 100 watts/cubic centimeter, thus the fuel matrix volume per inner capsule is 1.95 cubic inches. The fuel thickness is 0.283 inches. The inner capsule configuration is shown schematically in Figure 5. All capsule materials are Pt-40Rh.
(2)

Helium Leakage. Each of the inner capsulesprovides a helium leak path out of one end. This is accomplished by selectively orienting $\mathrm{Al}_{2} \mathrm{O}_{3}$ fibers in a pattern which is parallel to the capsule centerline and located adjacent to the void volume space. Thus, helium gas will tend to migrate toward the end of the outer capsule which contains a vent port by way of the annular area that is formed between the inner and outer capsules. This is the capsule end away from the diode section. A plenum and a porous $\mathrm{Al}_{2} \mathrm{O}_{3}$ plug are built into this portion of the outer capsule to control the leakage rate. A helium vent port is fabricated into the outer capsule wall to direct the flow of gas into the adjacent generator housing void space.

The possibility of allowing the helium gas to fill the voids in the crushable honeycomb structure and the forward generator housing is feasible. A preliminary calculation of the available void space indicates at least 1200 cubic inches of void. With this void and a helium generation rate of $3.07 \times 10^{-8} \mathrm{gm}$-moles/ second, it would take over one year to build up a pressure of approximately two and one-half atmospheres in the honeycomb and void.

The advantage that this design presents is that the structural integrity of the generator outer housing is not compromised. The effective fiber area that is required to vent the helium from the inner capsules to the plenum area was determined using Figure 6. The area determination was based on a wall thickness of 0.100 inches and a pressure differential of three atmo spheres.

Outer Fuel Capsules. The outer fuel capsule was designed to meet the generator impact criterion (impact velocity of 333 $\mathrm{ft} / \mathrm{sec}$ ) and to withstand oxidation loss under ambient conditions. Platinum- 40 rhodium was selected as the capsule fabrication material to meet the above criteria and to 
reduce compatibility problems. length of the section is 8.2 inches. Flanges To improve the material strength are provided at each end to mate with adcharacteristics, a matrix con- djoining sections. The diameter of the cylinsisting of the $\mathrm{Pt}-40 \mathrm{Rh}$ and $\mathrm{Al}_{2} \mathrm{O}_{3}$ drieal portion of the housing is eight inches. fibers, which are randomly oriented, was selected. Figures Control Radiator Section 7 and 8 are used to determine the capsule wall thickness, required material tensile stress, and the percent fiber volume that is required in the fabrication material matrix. For a capsule wall thickness of 0.100 inches, the fabrication material must have a tensile strength of at least 75,000 psi. The matrix that is postulated is required to have a minimum fiber volume of 22 percent. The outer capsule configuration is shown schematically in Figure 5: It is four inches in diameter by nine inches long.

\section{Thermionic Diode Section}

Two RCA type A1279A cylindrical thermionic diodes are attached to the heat pipe adjacent to the fuel section. The design emitter and collector temperatures of these diodes are $1450^{\circ} \mathrm{C}$ and $650^{\circ} \mathrm{C}$, respectively. Both the emitter and collector of the diodes are made from molybdenum.

Four copper fins 3.2 inches in width and 76 mils thick are attached to each diode to dissipate waste heat from the diodes and to maintain the collector temperature at $650^{\circ} \mathrm{C}$. Copper fins, though heavy, exhibit a high thermal conductivity and can be readily attached to the molybdenum collector. They were selected for these reasons.

As previously indicated, an outer can is provided in the diode section to maintain a vacuum environment. Beryllium was selected as the housing material, since it has a low density and a high thermal conductivity. In addition, it has good reentry characteristics, especially for the RIR system. The housing actually serves three functions. It provides the internal environment indicated above, it acts as a structural support member and it provides sufficient radiating area so that the waste heat from the diodes can be rejected to space. The diode section housing is basically a right circular cylinder with three longitudinal triangular fins. The shell is rugged and durable and is capable of resisting over 500 psi of external overblast pressures (which may be generated by a launch explosion).

The shell is designed to operate at approximately $650^{\circ} \mathrm{F}$. Each of its three fins is approximately 0.2 inch thick at the base and 3.86 inches in width. The overall
The control radiator section is provided to dissipate beginning of life waste heat and to control automatically the available radiator area during spacecraft offdesign power modes. It is composed of two basic components, the heat pipe in that region and the outer housing. The effective length of the heat pipe, for beginning of life operation, is 13 inches. The outer shell mates with the diode housing and is a right circular beryllium section, 0.10 inch thick and approximately 15 inches long. Six longitudinally oriented, triangular shaped fins are provided to dissipate all of the waste heat at a maximum temperature of $1200^{\circ} \mathrm{F}$. Each fin has a base thickness of 0.217 inch and a width of 3.86 inches. Since reliable welding and brazing of beryllium sections can present significant problems, the beryllium section, as well as the diode housing will be machined out of a solid beryllium block to achieve the desired finned shape. (If beryllium welding techniques become more fully developed, the se can be used. )

\section{Drag Plate and Impact Abort Can}

A drag plate and impact abort can have been provided so that the integrity of the generator housing, and the internal components, can be maintained in the event of a low altitude abort (below 100, 000 feet). The drag plate, 28 inches in diameter and web shaped, reduces the terminal velocity of the generator to $100 \mathrm{ft} /$ second and the abort can, will absorb a significant portion of the impact load.

Impact Structure (RIR Generator Design)

The nose or forward structure of the generator housing was extended to a total length of 28. 40 inches. This was required to satisfy the planetary impact criterion imposed on the system design (i.e., survive a planetary impact equivalent to $500 \mathrm{~g}$ 's and remain operational). It is assumed that the generator is integrated within a spacecraft and impact absorbing system. The generator orientation is vertical with reference to the spacecraft and the spacecraft impact direction is nearly along the generator vertical axis. The $500 \mathrm{~g}$ impact criterion is interpreted to apply to the entire spacecraft and generator complex and this complex must survive and be operational under specified loading. The impact loading as experienced by the generator can be significantly reduced by allowing a relative motion of the generator with 
respect to the primary system during im pact. Thus, the design solution, which can provide reduced shock loading to the generator, is a stopping distance.

Velocities of typical spacecraft planetary approaches are approximately 19,000 to 27,000 feet per second. To survive impact and to reduce spacecraft impact loads to within a $500 \mathrm{~g}$ criterion, these velocities must be reduced either by aerodynamic drag or retro rockets. The velocity reduction is required as a shock absorbing system cannot practically reduce velocities higher than about 400 feet per second. At greater velocities, the required "stopping distance" becomes prohibitive (Figure 9 ).

An interpretation of the $500 \mathrm{~g}$ impact criterion is as follows:

(1) The generator is part of a larger but undefined spacecraft.

(2) The spacecraft velocity is reduced to the regime of 200-400 feet per second before impact.

(3) A shock absorbing system reduces the spacecraft impact load to an average long duration $500 \mathrm{~g}$ load.

(4) The $500 \mathrm{~g}$ load is at the generator to spacecraft interface and is oriented in the direction of the generator vertical axis.

The selected design consists of a 28.40 inch piston and a mating female crushable structure which is integrated into the spacecraft structure.

The nose or forward heat shield of the generator is a hemispherical cap of pyrolytic graphite which fits over the Haynes-25 structural impact member. Some of the reasons for using pyrolytic graphite are as follows:

Due to the low thermal conductivity normal to the laminations, the surface temperature becomes high enough to radiate away much of the aerodynamic heating during reentry.
Due to the low normal thermal conductivity, the temperatures at the back of the heat shield remain reasonably low.
(3)

Pyrolytic graphite is definitely within existing technology and has been used successfully as a reentry heat shield.

The thickness requirement for the nose heat shield ( 0.51 inch) was established with the aid of a TAP- 4 digital computer code. The heat shield is sized to withstand an orbital decay reentry from 400, 000 feet. The peak temperature of the heat shield reaches $5000^{\circ} R$. Some oxidation and sublimation of the graphite is expected at this temperature; however, net mass transfer is neglected for calculational convenience as the resulting vapor efflux should tend to lower the convective heating rates. A peak temperature of $1640^{\circ} \mathrm{F}$ will be reached in the impact structure. The temperatures obtained indicate that a nose heat shield thickness of about 0.5 inch is acceptable. The pyrolytic graphite material required for the nominal thickness presented weighs 4. 3 pounds.

Drag Plate and Heat Shield Structure (RIR Generator Design)

To meet the generator intact reentry criterion, the drag plate must be retained to limit the generator velocity during the entire reentry heating phase. Pyrolytic graphite is attached to the drag plate to provide the required thermal protection. Since the drag plate is subject to aerodynamic loading and has a large diameter, the structural properties of the plate have an important effect on overall generator weight. During reentry the low thermal conductivity of the graphite (as compared to an ablator) is used to advantage to lower the operating temperature of the metal structural member. There is no doubt that an optimum combination of drag plate structure and heat shield configuration exists for which overall generator weight can be minimized. The analysis required to obtain this optimum weight was not performed. If pursued, however, it would consider the following:

(1) Drag plate structure drag plate materials must be lightweight metals with good strength at high temperatures.
(a) Lightweight honey- comb - steel, Hastelloy-C or Haynes-25

(b) Single reinforced plate of similar materials 
(a) Pyrolytic graphite

Low thermal conductivity ablative materials

(c) that the thermionic diode emitter and collector are designed to operate at are $1450^{\circ} \mathrm{C}$ and $650^{\circ} \mathrm{C}$, respectively. A complete performance and design summary is presented in Table 2.

\section{Component Fabrication and Test}

The heat pipe-thermionic converter power system described in the foregoing theoretical analysis was fabricated in all important aspects. A photograph of the heat pipe-converter system which was constructed is shown in Figure 13. The photograph includes the central core heat pipe, the two thermionic converters, the six excess power radiators and the argon gas reservoir. Several modifications were made from the theoretical system. The gas reservoir was modified to attach to the heat pipe by a 0.625

Fuel containment following reentry of the generator is partially dependent upon the impact capability of the structure and hence impact velocity. Impact analyses show that the fuel capsule alone can survive impact velocities up to $333 \mathrm{ft} / \mathrm{sec}$. The terminal velocity of the complete stabilized generator, including the drag plate, is calculated to be $106 \mathrm{ft} / \mathrm{sec}$.

Thus, the generator terminal velocity is well below the limiting capsule constraint of $333 \mathrm{ft} / \mathrm{sec}$. Even without accounting for the energy absorption capability of the generator forebody structure, the integrity of the fuel capsule should be assured at impact.

The 36 inch diameter drag plate was not sized to meet the terminal velocity constraint. The present plate size was selected to reduce aerodynamic heating to critical components during reentry. The qualitative effect of drag plate diameter upon reentry heating is shown in Figure 10. The transient heat transfer equations were solved using the TAP-4 code. A honeycomb structural member was selected to provide the backup structure to the heat shield because of its high stiffness per unit weight. Shape optimization of the graphite was not attempted and its nominal thickness is a strong function of the choice of honeycomb material. Hastelloy-C honeycomb was selected for this design. During reentry, the maximum temperature attained at the interface between the heat shield and the honeycomb is $2080^{\circ} \mathrm{F}$. This temperature is attained using a 0.31 inch, nominal thickness, of pyrolytic graphite. This results in a 24 pound weight penalty.

The configurations of the two systems that were described are presented by Figures 11 and 12.

\section{System Performance}

The generator is designed to provide 250 watts of electrical power for one year. The total end of life thermal losses are 298 watts and the overall efficiency is approximately 11 percent. The temperature inch diameter, three inch long molybdenum section which contained a molybdenum valve, seat and a tungsten spring. No capillary wicking was required in the gas reservoir and connecting section since the valve served to isolate the lithium vapor from the evacuated gas reservoir during processing stages of the heat pipe. The dimensions of the excess gas reservoir were modified to .present a reservoir to heat pipe volume ratio of 16.5:1. The reservoir dimensions were of a right circular cylinder 5.125 inches long and 3.000 inches in diameter. The larger ratio was selected since the prototype system would not be surrounded by a re-radiating shell as indicated in the theoretical analysis. The heat pipe-thermionic system contained two RCA/NASA Type A $1279 \mathrm{~A}$ converter s connected in parallel. One of the thermionic converters built for the power system is shown in Figure 14.

The cylindrical converter employs a molybdenum emitter and molybdenum collector. The unconverted heat is rejected from the collector by copper fins. The cesium pressure is controlled by the temperature of the appendage arm projecting from the sapphire window as sembly shown. The sapphire window allows optical measurement of the emitter temperature during operation. Figure 15 shows in graphical form the performance of an RCA/NASA A-1279A thermionic converter. The data for this display were taken while the A-1279 was operating on a lithium-T ZM heat pipe at $1500^{\circ} \mathrm{C}$. Values of voltage versus current were obtained from an ac sweep of the converter electrodes.

The values obtained were broken into incremental bits and used as input data to RCA computer program 780DS ${ }^{\prime}$ Thermionic Converter Performance Data Analysis." The computer program analyzed the data and computed power output and efficiency versus 
converter output voltage. The data is presented in tabular form in Figure 16.

The facility used to process and test the power system is shown in photograph Figure 17. The vacuum bell is three feet in diameter by three and one-half feet long. The heat pipe and reservoir were placed in a horizontal position in the bell during processing and test.

An independent vacuum system was connected to the opposite end of the argon gas reservoir by a vacuum line passing through the wall of the vacuum bell. Processing of the heat pipe consisted of heating the lithium working fluid to operating temperatures and forcing out all residual gases through a small orifice at the condenser end of the heat pipe. The orifice was later sealed-off under vacuum. The valve section between the heat pipe and reservoir was chilled with cooling water, thus preventing lithium vapor from escaping into the gas reservoir. After completion of the heat pipe processing, the heat pipe was cooled to room temperature and the condensed lithium in the valve melted. Argon gas was introduced to the reservoir through the external vacuum system. The argon gas was set at a computed cold pressure which established the heat pipe operating temperature of $1500^{\circ} \mathrm{C}$. After final testing, the line to the external vacuum system was welded off. The converters were then placed on the tapered section located on the heat pipe which were designed to accept the matching taper of the emitter. Evaluation of the system could be performed by adjusting the ac power input to the evaporator section which in time adjusted the gas vapor interface position along the heat pipe.

A table of the temperature profile of the heat pipe under operation appears in Table 3. Condition A lists the heat pipe profile at the start of mission, that is, the full length of the heat pipe is active. Condition B lists the heat pipe profile at the end of mission, that is, the heat zone just beyond the second converter. It should be noted that the temperature flattening feature of the argon gas loaded heat pipe permits a decrease in pipe temperature of only $29^{\circ} \mathrm{C}$ from start of mission gas interface position to end of life gas interface position.

The heat source for the prototype power system was supplied by passing current through the input section of heat pipe. The magnetic pressure exerted by the ac current flow on the working fluid apparently created "hot spots" which appeared in the area of $\mathrm{T}_{1}$, Figure 18. Thus, the full power capabilities of the heat pipe could not be explored.

\section{CONCLUSIONS}

The generator configurations that are postulated are feasible. The most promising system and the one which should be considered for further hardware and system's analysis is the RIR design. The automatic power flattening capability of the heat pipe has been demonstrated both experimentally and by analysis. To establish smaller and more optimum system configurations, further designs should consider a longer halflife isotope (e.g., curium-244). The following conclusions can be summarized from the analyses and design effort performed for the burnup configuration:

$$
\begin{aligned}
& \text { The conceptual burnup } \\
& \text { design presented is } \\
& \text { basically feasible. }
\end{aligned}
$$

The major problem areas requiring development lie in the fuel capsule and fuel form areas. The compatibility of the various structural materials used (at temperature) must also be studied in detail.

$$
\begin{aligned}
& \text { The use of Po- } 210 \text { for ex- } \\
& \text { tended periods of time } \\
& \text { approaching three half- } \\
& \text { lives of the isotope has } \\
& \text { been demonstrated analyti- } \\
& \text { cally. It is apparent that } \\
& \text { the use of longer half-life } \\
& \text { isotopes or shorter opera- } \\
& \text { tional lifetimes for the } \\
& \text { selected fuel would result } \\
& \text { in more favorable genera- } \\
& \text { tor configurations. }
\end{aligned}
$$

(4) The nuclear safety analyses performed indicate that the burnup generator will meet prelaunch, ground handling and launch hazards.

The following additional conclusion can be summarized from the analyses and design effort performed for the RIR configuration:

\section{(1) Aerospace nuclear safety}

(a) A pyrolytic graphite nose heat shield thickness of 0.51 inch is sufficient to keep the back face (interior) temperatures reasonably low. 
(b) A drag plate heat shield thickness of 0.31 inch is probably sufficient to maintain the strength of the drag plate material during reentry.

(c) Deep water burial of the generator system with ultimate release of the fuel inventory is not a serious nuclear safety problem.

(d) Earth burial of the generator system can present a nuclear safety problem since the inevitable consequence of a complete burial at even shallow depths will result in fuel release. This situation can be avoided by the use of procedural constraints prior to the actual aerospace applications, i. e., in the prelaunch mode.

\section{(2) Nuclear radiation}

(a) The integrated neutron flux of $10^{12}$ $\mathrm{n} / \mathrm{cm}^{2}$ and the photon energy deposition of $10^{8} \mathrm{erg} / \mathrm{gm}$ over a one year period were determined to be reasonable design criteria for most spacecraft components.

(b) The use of sensitive component and/or generator placement ("booming") within the spacecraft must be used to utilize the inherent shielding benefits from the $1 / r^{2}$ reduction factor. In addition, the use of patch or partial radiation shields is to be used.
(3)

Generator/Spacecraft Component Temperatures.

The surface temperature of components located near the generator will be approximately $520^{\circ}$ $F$ (maximum) for a normal space operating mode and approximately $495^{\circ} \mathrm{F}$ for a typical prelaunch (on the pad) operating mode.

(4)

Impact

(a) The linear velocity attenuating device (mandrel and housing) postulated can reduce the $500 \mathrm{~g}$ impact load to a reasonable component design value.

(b) The generator components, with the exception of the diodes, can be designed to survive the $500 \mathrm{~g}$ impact.

(c) Initial observations of the diodes lead to the conclusion that they are the pacing (or limiting) factor with reference to the impact criteria. In particular, the ceramic seals appear fragile and will probably not survive generator longitudinal motion.

(d) The drag plate as presently designed imposes an undue hardship with regard to meeting the impact criteria due to its massive structure.

(e) Spacecraft attenuation from 500 to $300 \mathrm{~g}$ impact is feasible and can provide a potentially lighter weight system. 
TABLE 1. RESERVOIR VOLUME PARAMETRIC

Reservoir-Heat Pipe ${ }^{(1)}$ Volume Ratio, $\mathrm{V}_{\mathrm{R}} / \mathrm{V}_{\mathrm{HP}}$

Reservoir Volume, $\mathrm{V}_{\mathrm{R}}$, in ${ }^{3}$

Total end of life gas Volume, $\mathrm{V}_{\mathrm{T}}$, in ${ }^{3}$

End of life pressure, $\mathrm{Pe}, \mathrm{psia}$

Average end of life gas 653.7 temperature,

Moles of inert gas in system

Average beginning of

0. $5: 1$

3.074

$1: 1$

$2: 1^{(2)}$

$2: 1$

$5: 1^{(2)}$

12.4

12.4

30.8

$7: 1$

$16: 1^{(2)}$

6. 148

18. 6

18.6

36.95

32

451

$3.56 \times 10^{-5}$

8. $57 \times 10^{-5}$

809.4

688.7

2832

2853

2827

Beginning of life
lithium temperature, ${ }^{\circ} \mathrm{F}$

Beginning of life

11.51

12.25

13. 21

13.05

13.54

13. 21

13. 64

measured from last

diode, in.

Reservoir-Heat Pipe (1)

$0.5: 1$

$1: 1$

$2: 1^{(2)}$

$2: 1$

$5: 1^{(2)}$

12.98

31.16

1. 433

1.186

1. 393

1. 544

1. 364

perature

1. 311

1. 335

1. 748 end of life $\left({ }^{O}\right)$

(1) Heat pipe volume is defined as the control radiator section excluding the diode section.

(2) These cases used the heat rejection areas for the $7: 1$ case, and the correct system volumes. 
TABLE 2. RADIOISOTOPE THERMIONIC HEAT PIPE GENERATOR SYSTEM DESIGN SUMMARY

\section{$\underline{\text { Performance }}$}

Net Electrical Power, watts

Power Lead Loss, watts

Dc-dc Conversion Efficiency, \%

Gross Electrical Power, watts

Thermionic Diode Efficiency, \%

Parasitic Heat Losses, watts

Gross Thermal Power, watts

Overall System Efficiency, \%

Beginning of Life Fuel Inventory, watts

Design Life, days

Prelaunch Processing Period, days

Total Life, days

Radioisotope Fuel

\section{Burn-Up and RIR}

250

85

300

$15^{*}$

298

2298

11

15879

365

20

385

Po-210

\section{Thermal Characteristics}

Diode Emitter Temperature, ${ }^{\circ} \mathrm{C}$

$1450\left(2642^{\circ} \mathrm{F}\right)$

Diode Collector Temperature, ${ }^{\circ} \mathrm{C}$

$650\left(1202^{\circ} \mathrm{F}\right)$

Cesium Reservoir Temperature, ${ }^{\circ} \mathrm{C}$

$325\left(617^{\circ} \mathrm{F}\right)$

Maximum Fuel Temperature, Beginning of Life, ${ }^{\circ} \mathrm{F} \quad 3320$

Maximum Fuel Temperature, End of Life, ${ }^{\circ} \mathrm{F}$

Diode Housing Temperature, ${ }^{\circ} \mathrm{F}$

650

Fuel Capsule Housing Temperature, ${ }^{\circ} \mathrm{F}$ 200

Control Radiator Temperature, ${ }^{\mathrm{O}} \mathrm{F}$

* 14 is the best value that has been achieved in laboratory tests to date. 
TABLE 2. (CONT.)

Thermal Characteristics (Continued)

Helium Reservoir Temperature, ${ }^{\mathrm{O}} \mathrm{F}$

Diode Inner Fin Effectiveness

Diode Housing Fin Effectiveness

Control Section Fin Effectiveness
Burn-Up and RIR

60

0.39

0.5

0.45
Weight Summary

Fuel Section

Capsule, lbs

Insulation, lbs

Housing, lbs

Sub-total

Diode Section

Diodes, lbs

Diode Fins, lbs

Housing Fins

Hou sing, lbs

Sub-total, lbs
Helium Containment Capsule (Burn-Up)

16. 8

1. 0

4. 2

22.0

2.8

2. 8

0.7

0.2

2.5

6. 2

8.1

2.4

0.4

10.9

Sub-total, lbs

Reservoir Section

Reservoir, lbs

Housing and Support, lbs

Drag Plate

Sub-total, lbs
0.6

0.6

4.1

3. 6

3. 0

24.0

7. 7

28.2 
TABLE 2. (CONT.)

$\begin{array}{ccr}\text { Heat Pipe, lbs } & \text { Burn Up } & \frac{\text { RIR }}{2.0} \\ \text { Impact Abort Can, lbs } & 5.0 & 5.0 \\ \text { DC-DC Power Conditioner } & 12.0 & 12.0 \\ \text { Total Generator Weight } & 65.8 & 88.8\end{array}$

\section{Generator Geometry}

General

Heat Pipe, O. D., in.

1.0

1.0

Heat Pipe Length, in.

31.10

31.10

Reservoir Section Length, in.

6. 10

2. 60

Reservoir Diameter, in.

6. 60

5. 20

Reservoir Housing Diameter, in.

8. 0

8. 0

Reservoir Housing Thickness, in.

0.040

0.040

Fuel Section

Capsule Overall Diameter, in.

4. 0

4. 0

Capsule Outer Wall Thickness

0.20

0.10

Inner Liner Thickness, in.

0.020

0.020

Fuel Matrix Layer Thickness, in.

0.210

0.238

Fuel Section Length, in.

8. 70

9.0

Fuel Hou sing Section Length, in.

10.20

28. 40

Diameter of Housing, in.

5.20

8. 0

Diode Section

Outer Radius of Diode, in.

0.75

0.750

Number of Diode Fins

Diode Fin Root Thickness, in.

4

0.076
4

0.076 


\section{TABLE 2. (CONT.)}

Diode Fin Width, in.

Diameter of Diode Housing, in.

Number of Diode Housing Fins

Diode Housing Fin Root Thickness

Control Radiator Section

Housing Diameter, in.

Number of Fins

Fin Root Thickness, in.

Fin Width, in.

Control Section Length, in.
Burn-Up

RIR

3.20

8. 0

3

0.20

8. 0

8. 0

6

0.217

3. 860

15. 0

15. 40

\section{$\underline{\text { Materials }}$}

Fuel

Fuel Form

Capsule

Capsule Liner

Fuel Housing

Impact Absorber

Heat Pipe

Wick

Drag Plate

Diode Emitter

Diode Collector

Diode Fins

Diode Housing and Fins

Control Radiator and Fins

Reservoir

Reservoir Housing
Po-210

Ta-DyPo

Ta-10W

Ta-10W

Haynes -25

Al Honeycomb

TZMI

Molybdenum

Screen

Molybdenum

Molybdenum

Copper

Beryllium

Beryllium

TZM

Haynes-25
Po-210

PtRh-DyPo

$\mathrm{Pt}-40 \mathrm{Rh}+$ $\mathrm{Al}_{2} \mathrm{O}_{3}$ fibers

$\mathrm{Pt}-40 \mathrm{Rh}+$ $\mathrm{Al}_{2} \mathrm{O}_{3}$ fibers

Haynes-25

Haynes-25

TZM

Not Defined

Titanium + Hastelloy-C Honeycomb + Pyrolytic Graphite

Molybdenum

Molybdenum

Copper

Beryllium

Beryllium

TZM

Haynes-25 


\section{b. RIR CONCEPT}

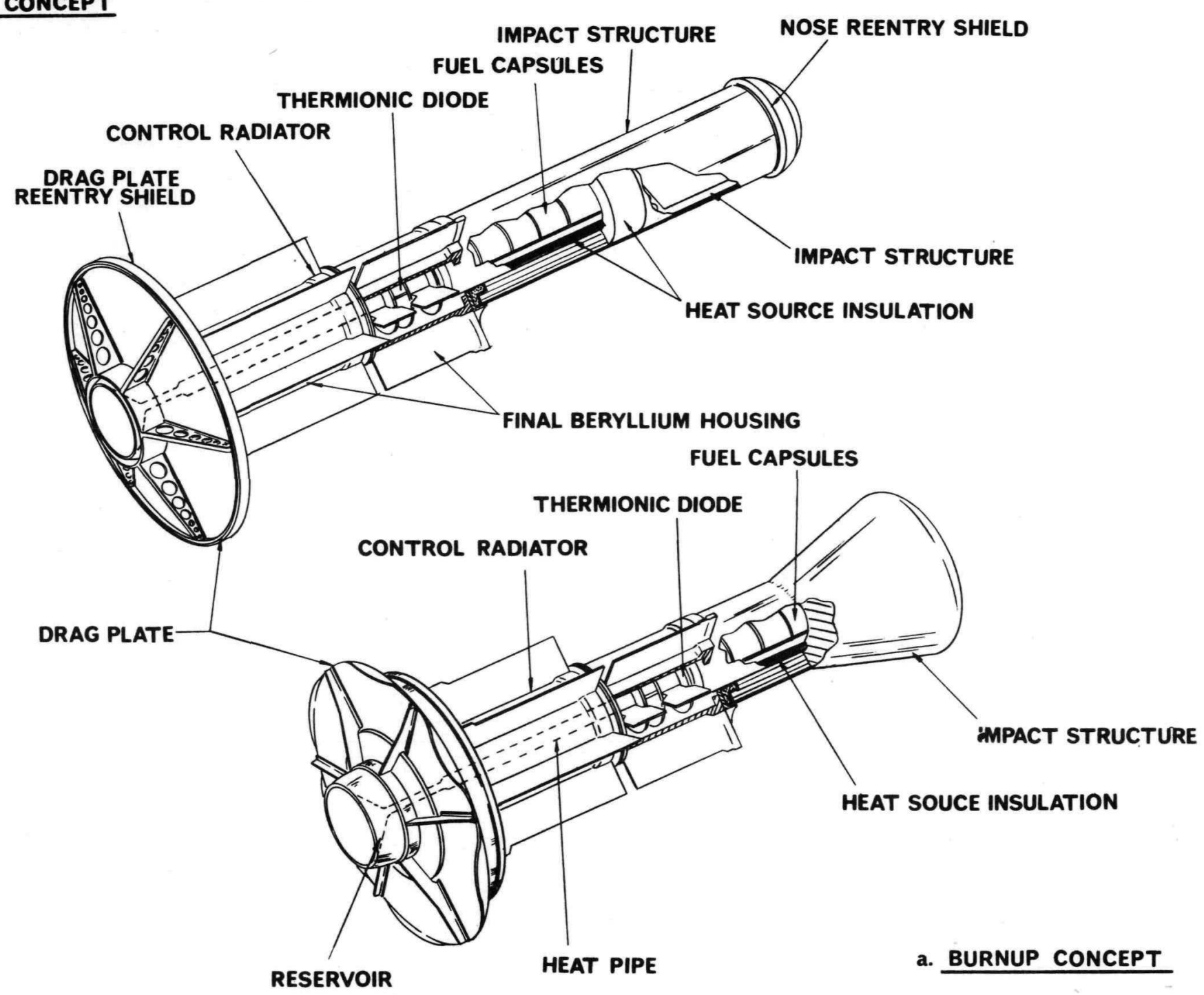

Figure 1. Thermionic Heat Pipe Generator System Concepts 


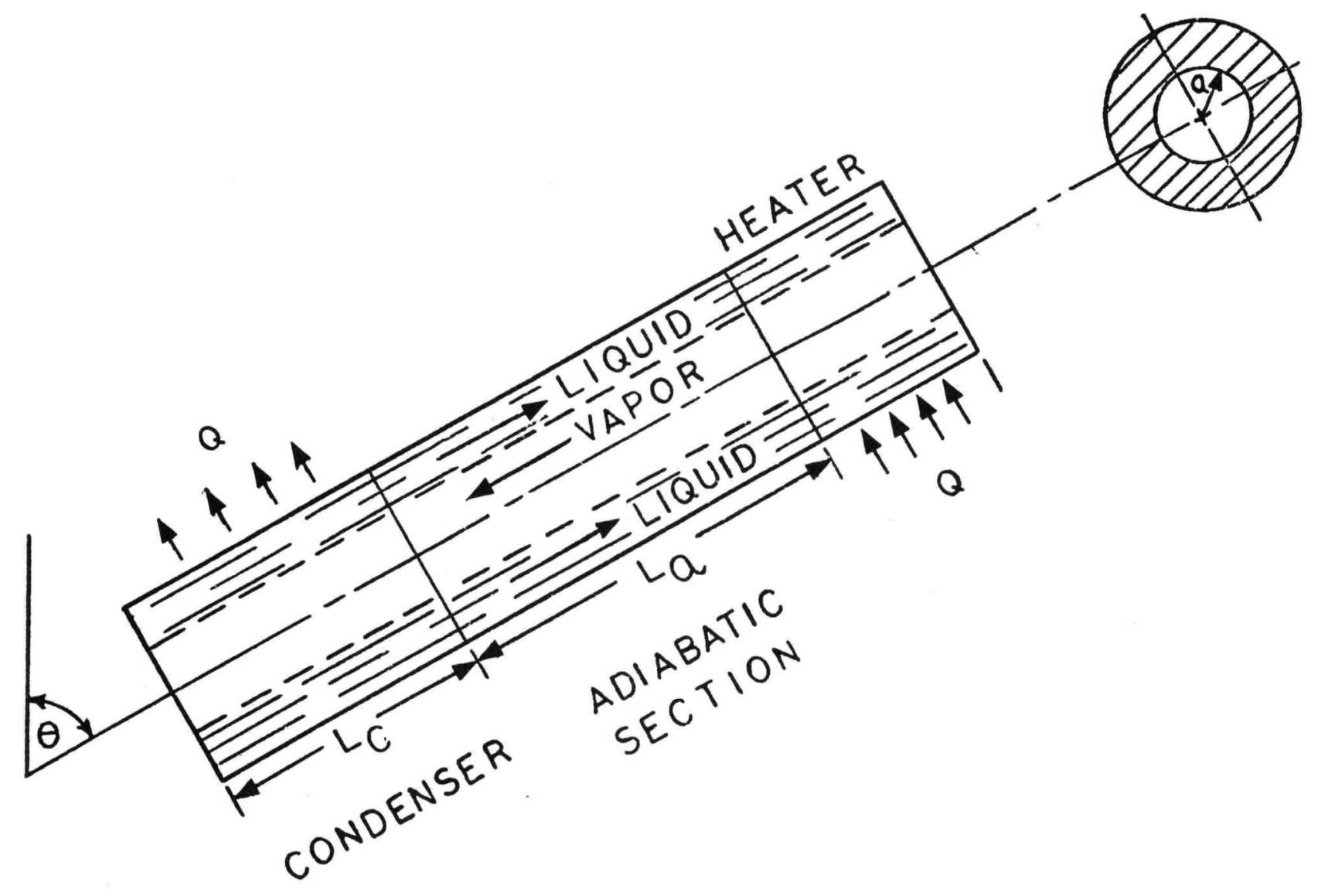

Figure 2. Idealized Heat.Pipe Configuration 

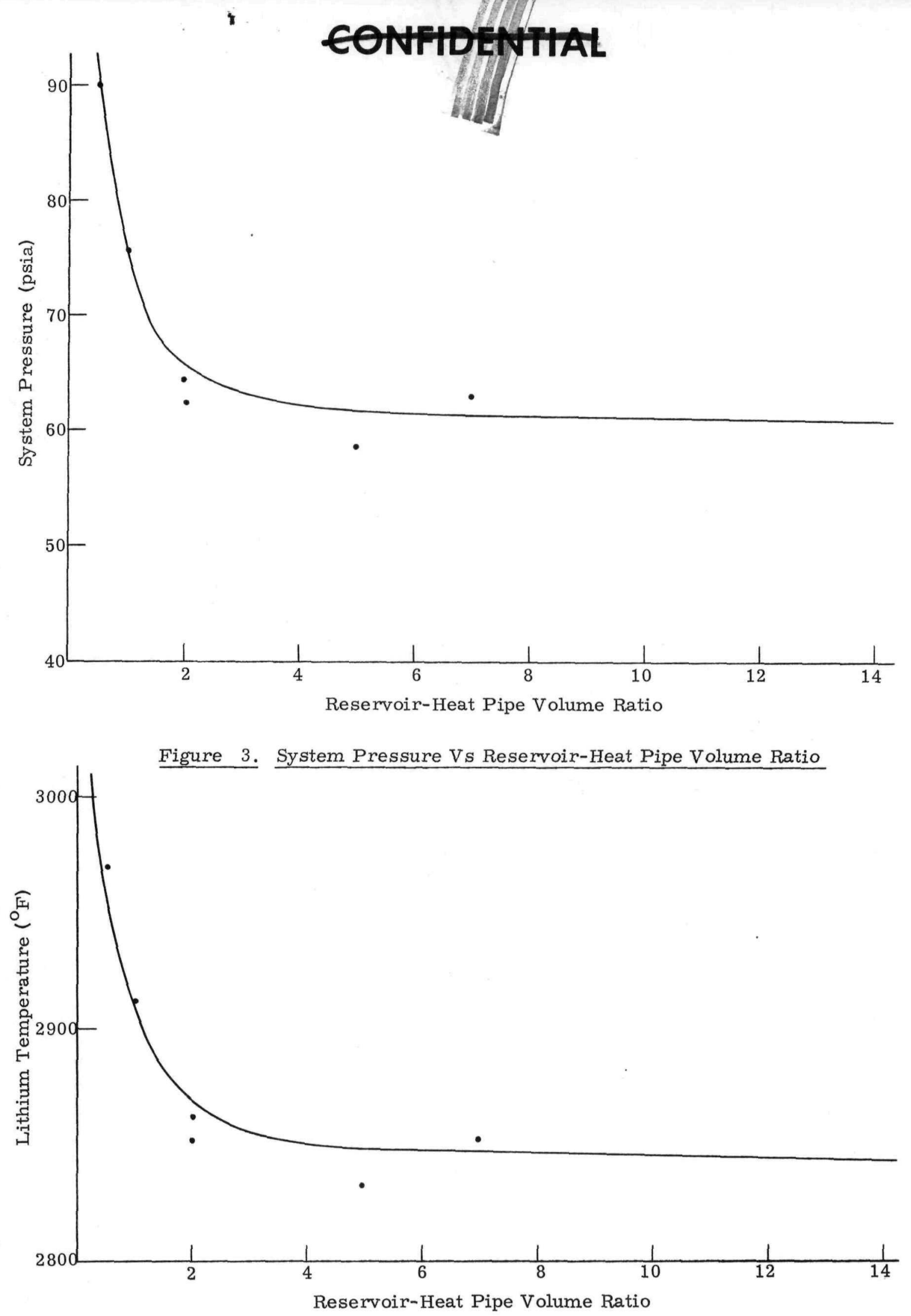

Figure 4. Lithium Temperature Vs Reservoir-Heat Pipe Volume Ratio 


\section{-}
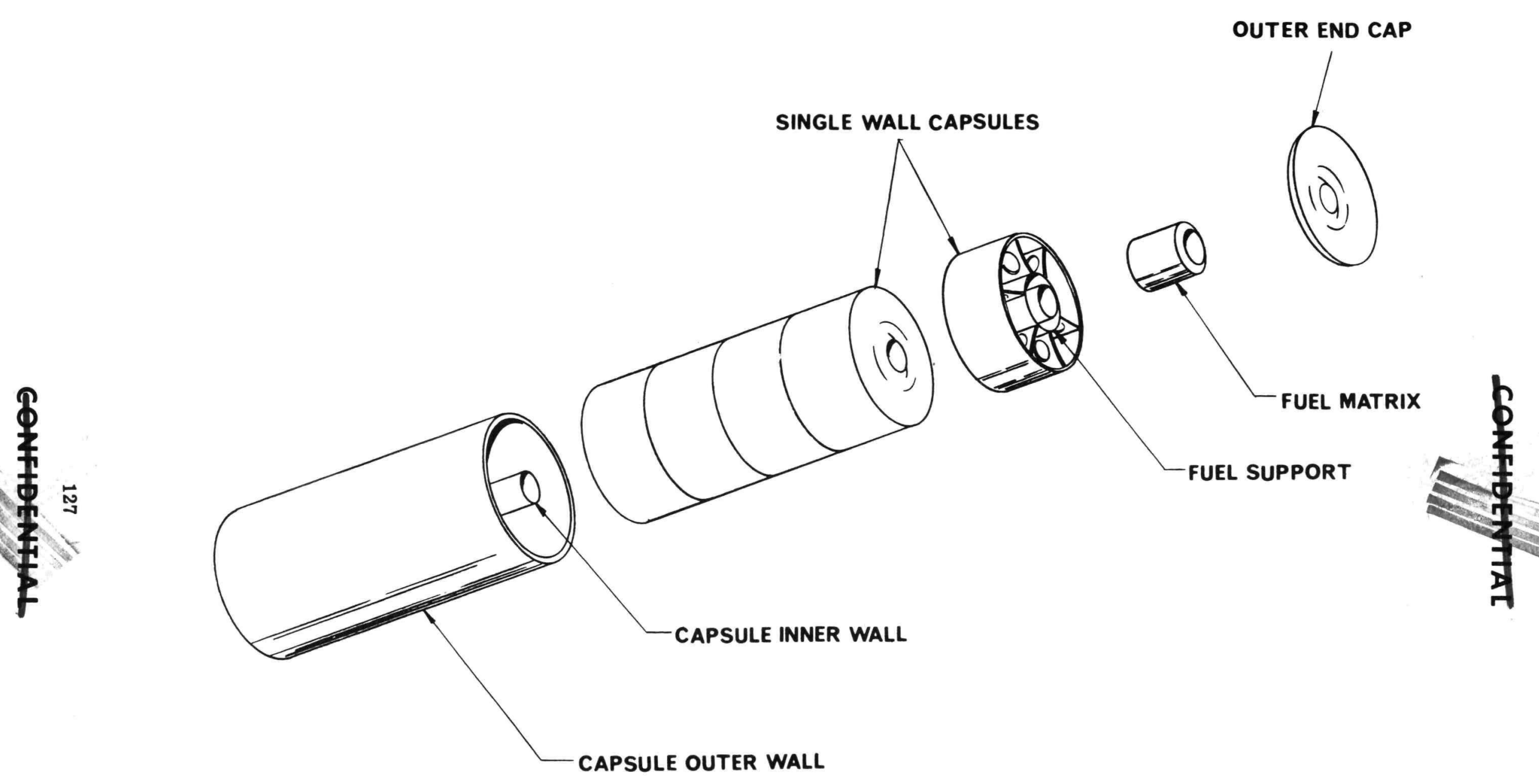

Figure 5. Exploded View of Fuel Capsule 
cONFIP ENTTAL

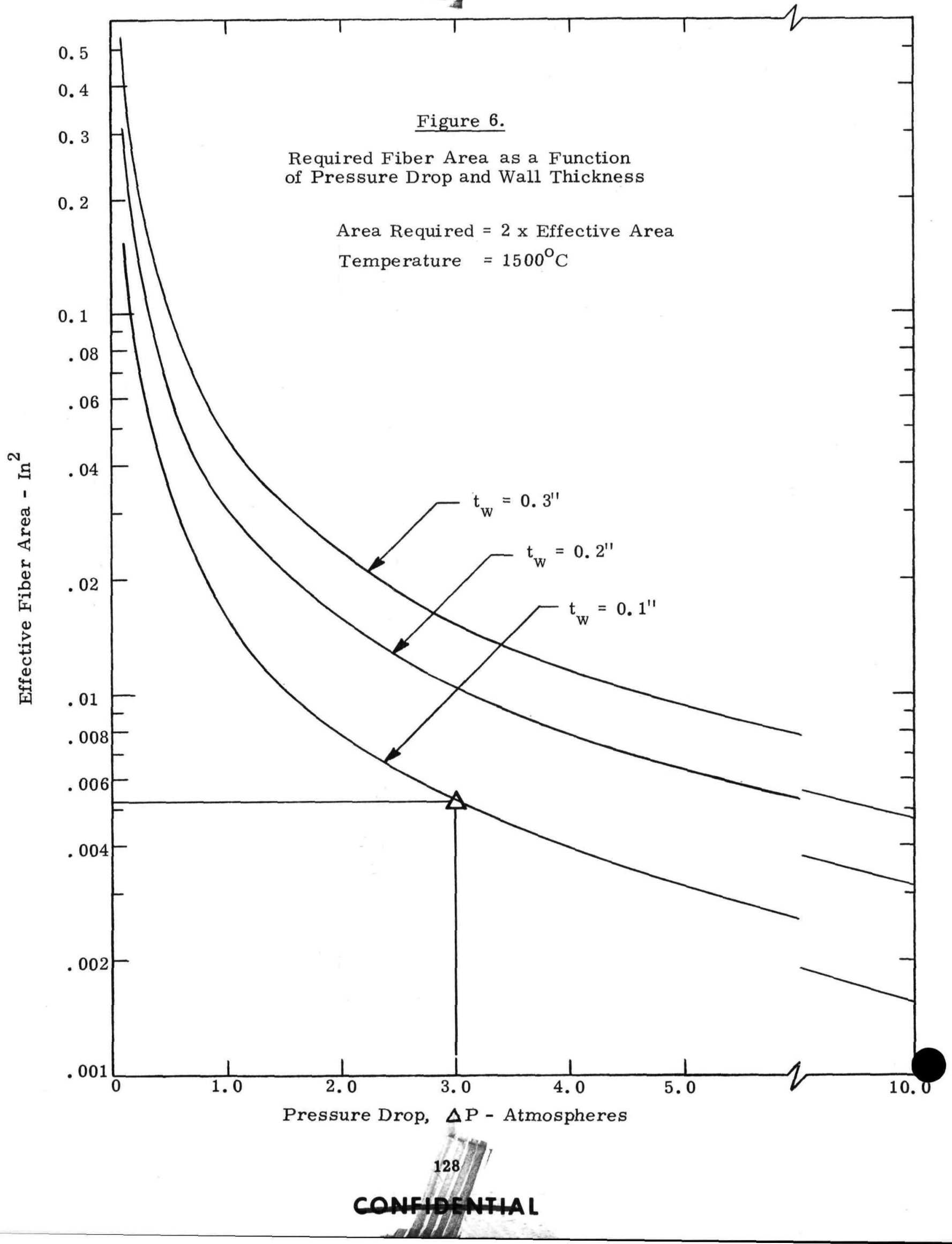




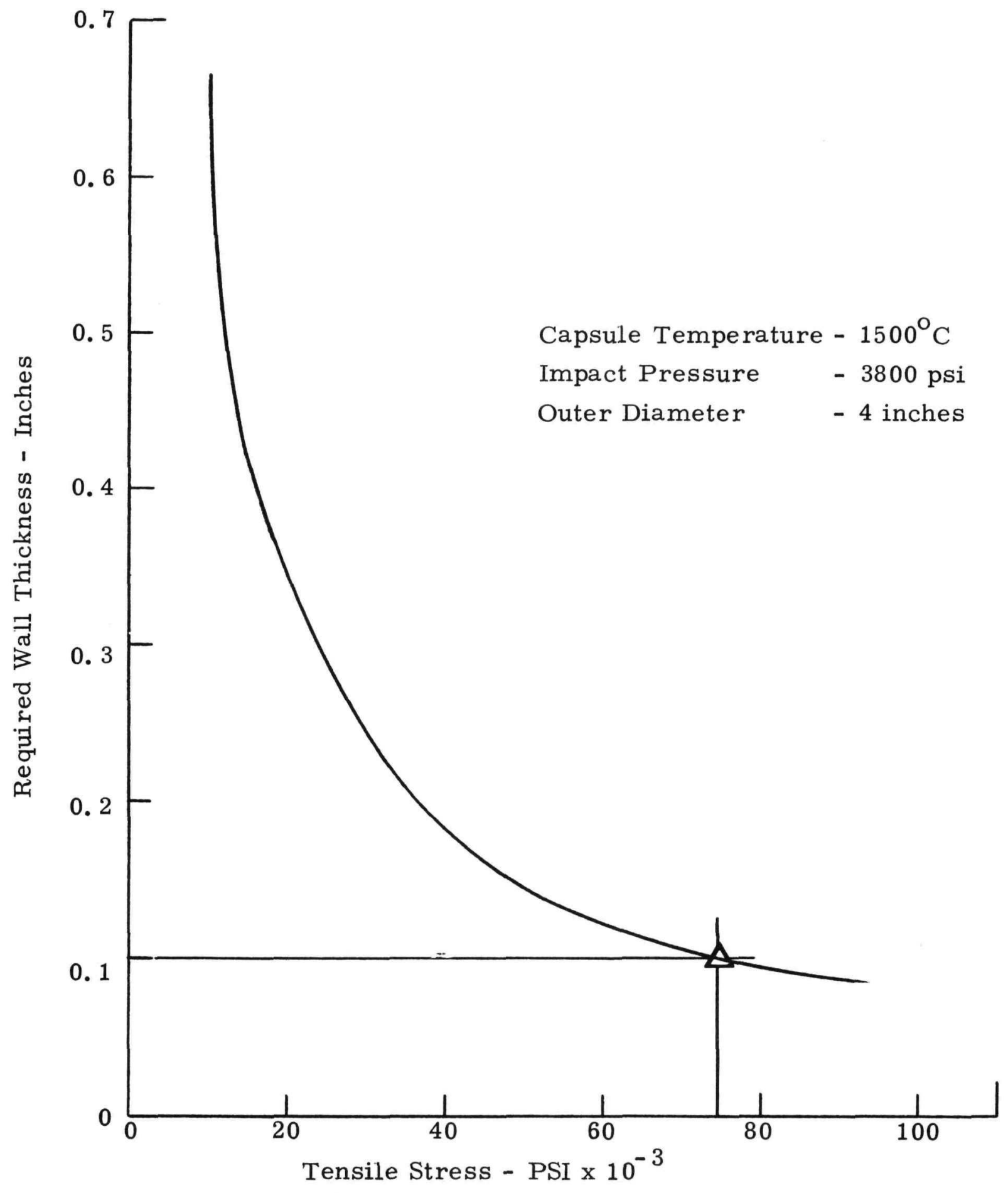

Figure 7. Capsule Wall Thickness Versus Tensile Stress 


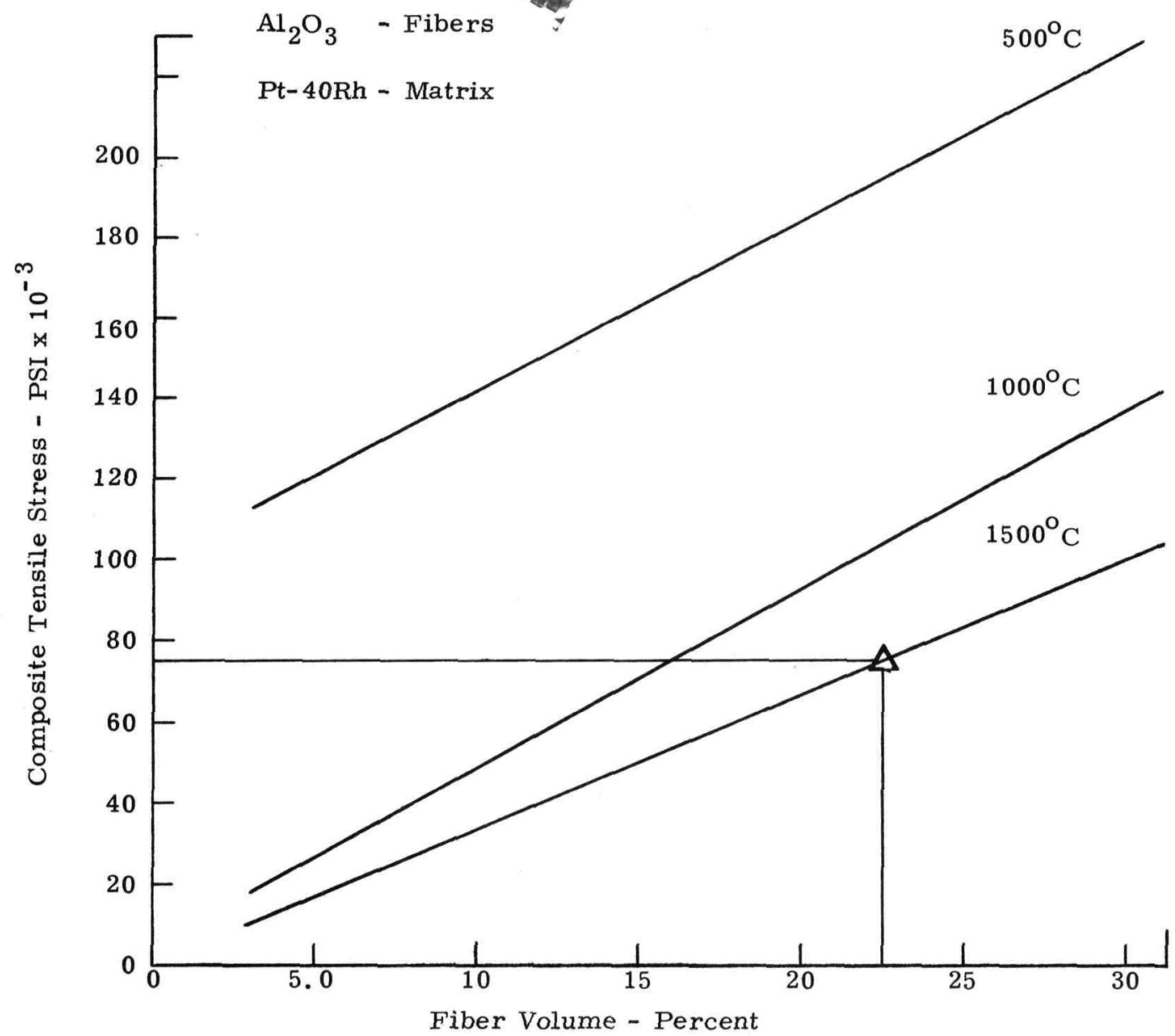

Figure 8. Capsule Material Composite Stress as a Function of Fiber Volume and Capsule Temperature

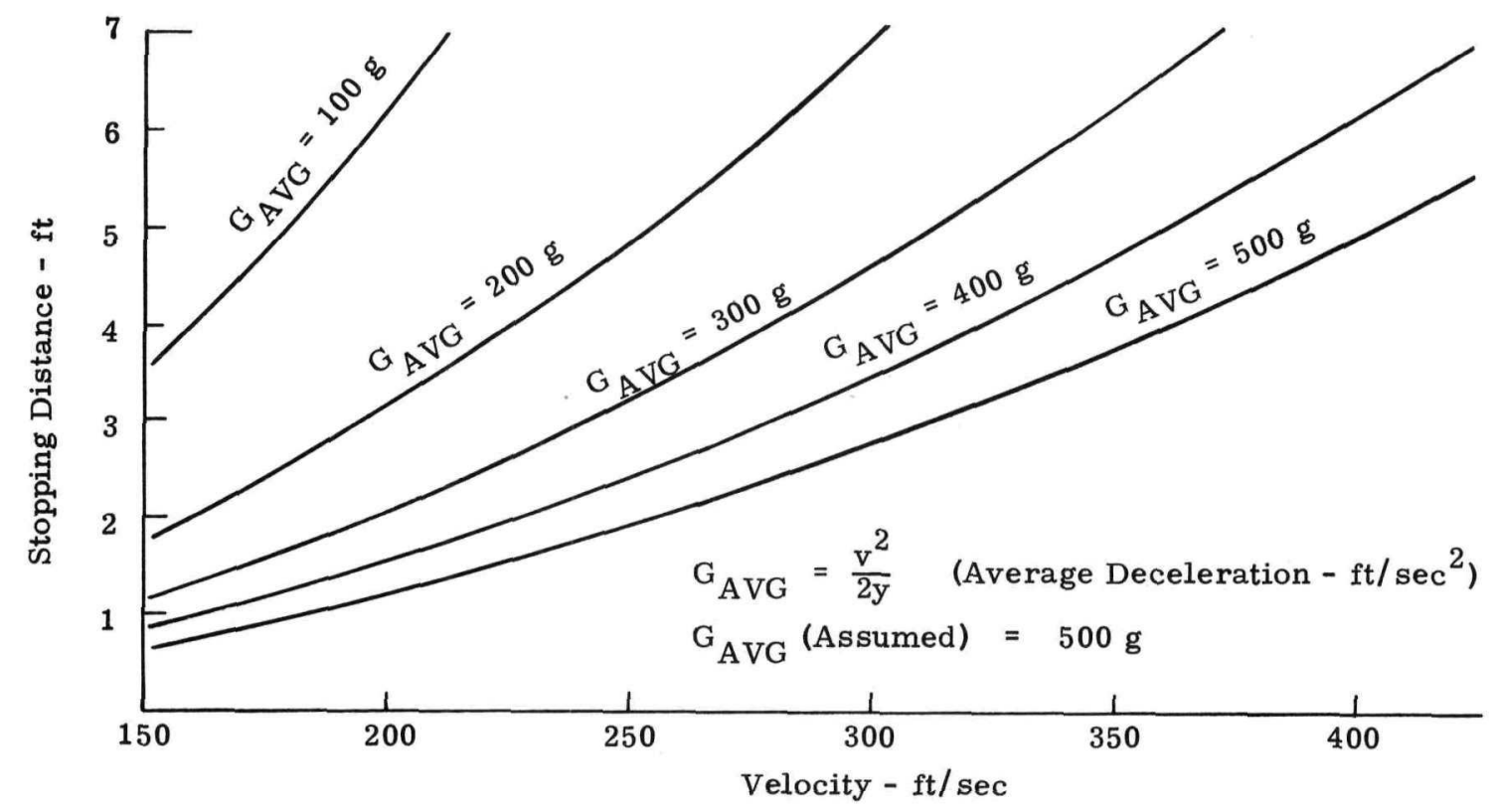

Figure 9. Average G Load Versus Stopping Distance 


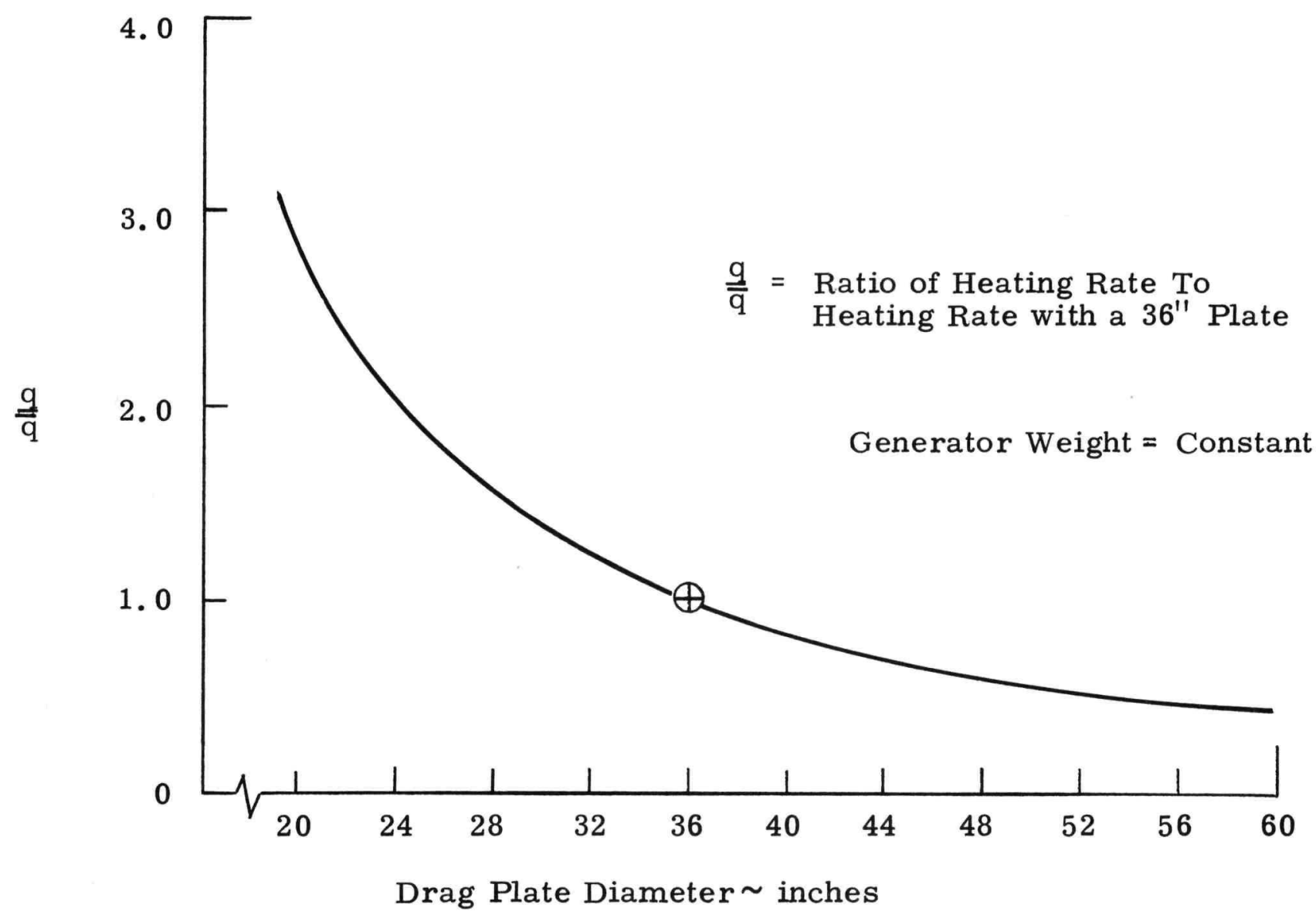

Figure 10. Variation of Heating Rate With Drag Plate Diameter 


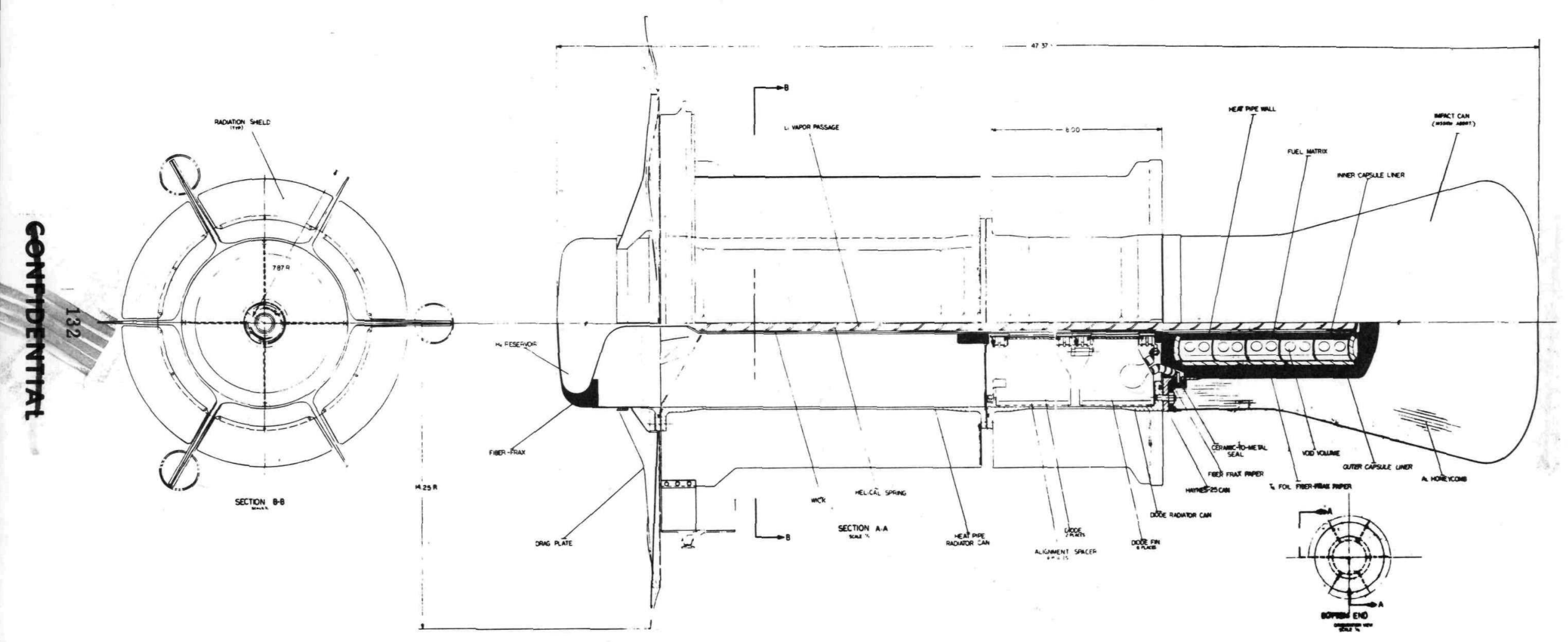

Figure 11. Radioisotope Thermionic Heat Pipe Generator System Burnup Design 


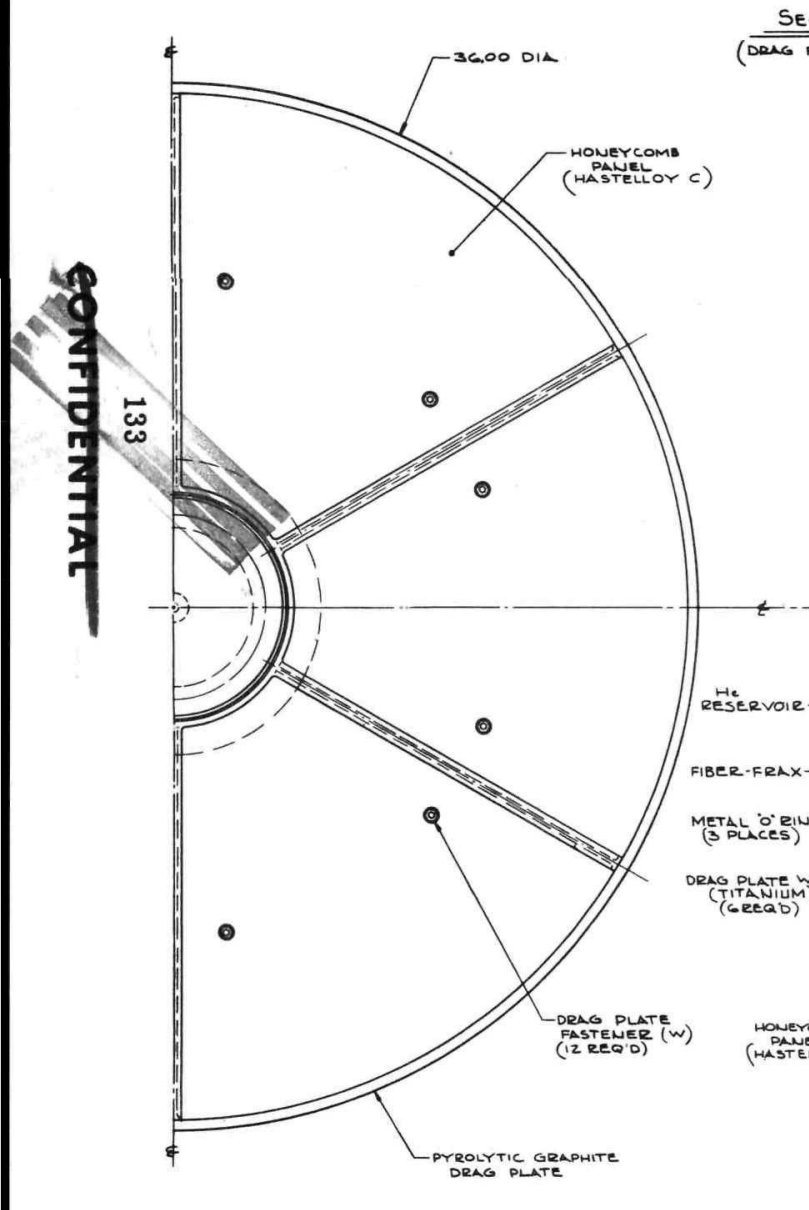

$\underset{\text { (TYP) }}{\text { RADIATION (HEAT) SHIELD }}$
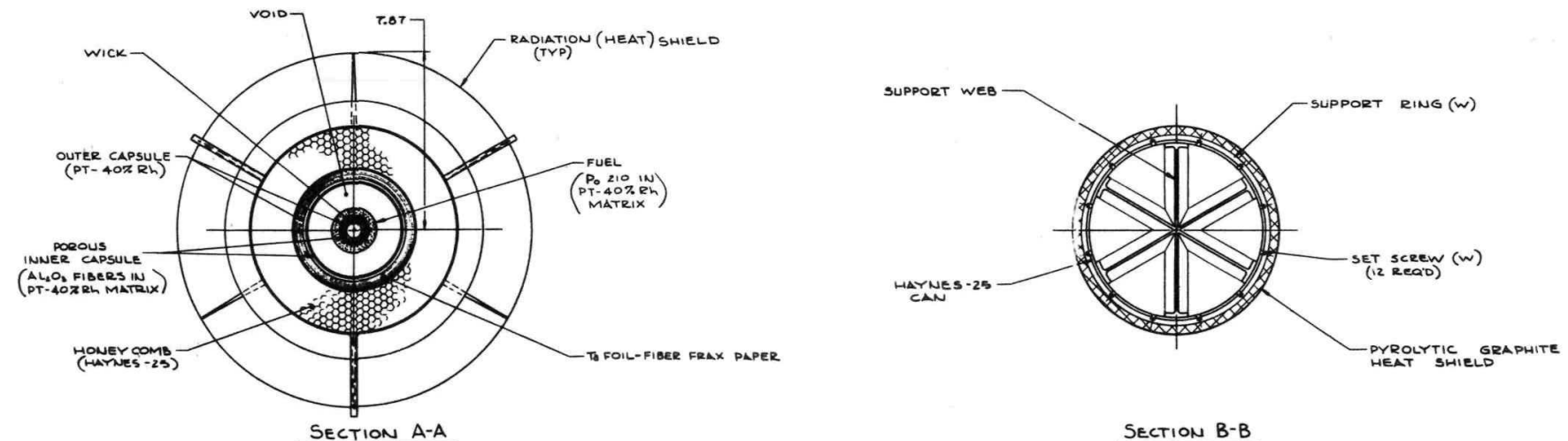

SECTION B-B 


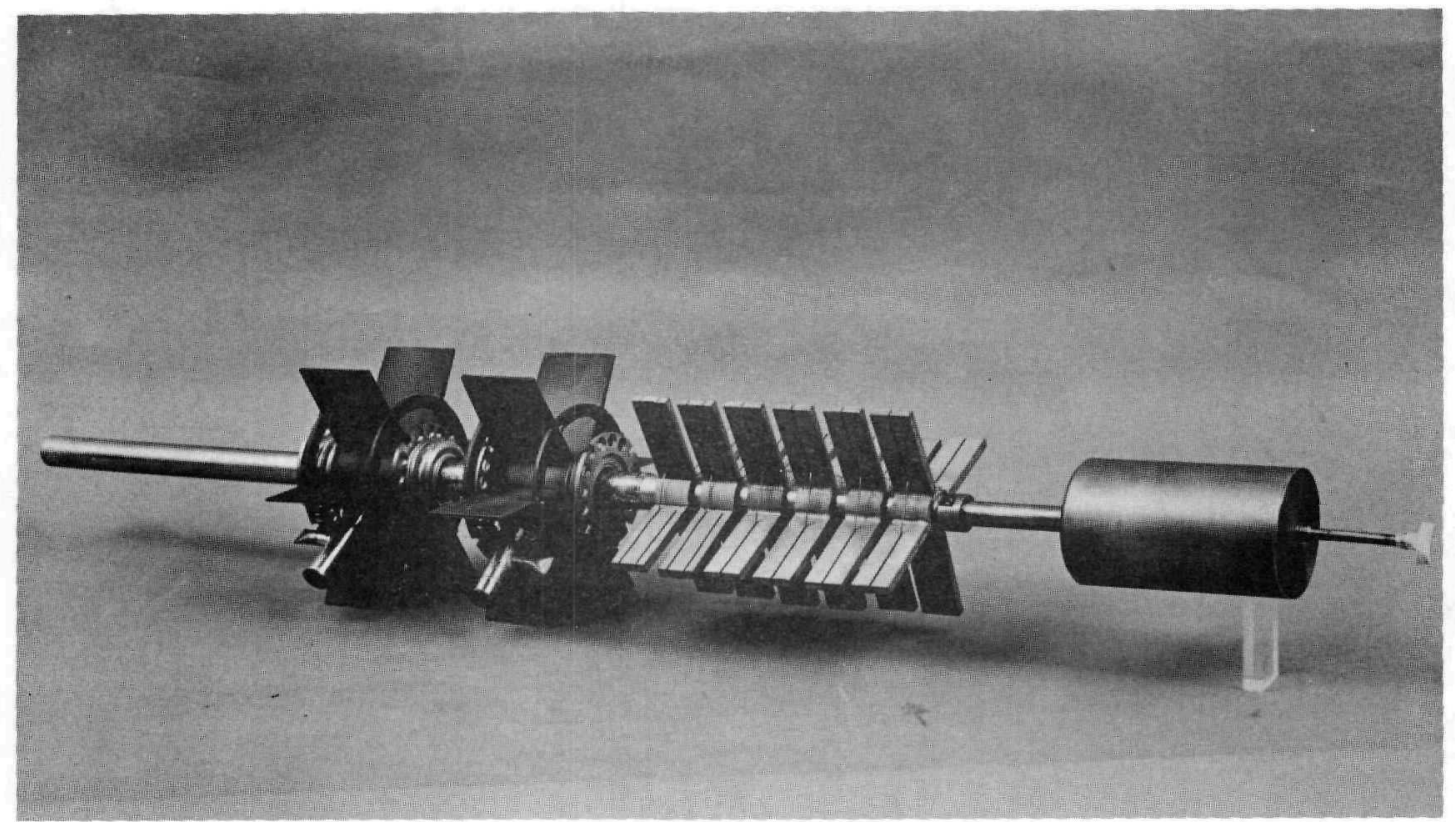

FIGURE 13 HEAT PIPE THERMIONIC CONVERTER POWER SYSTEM

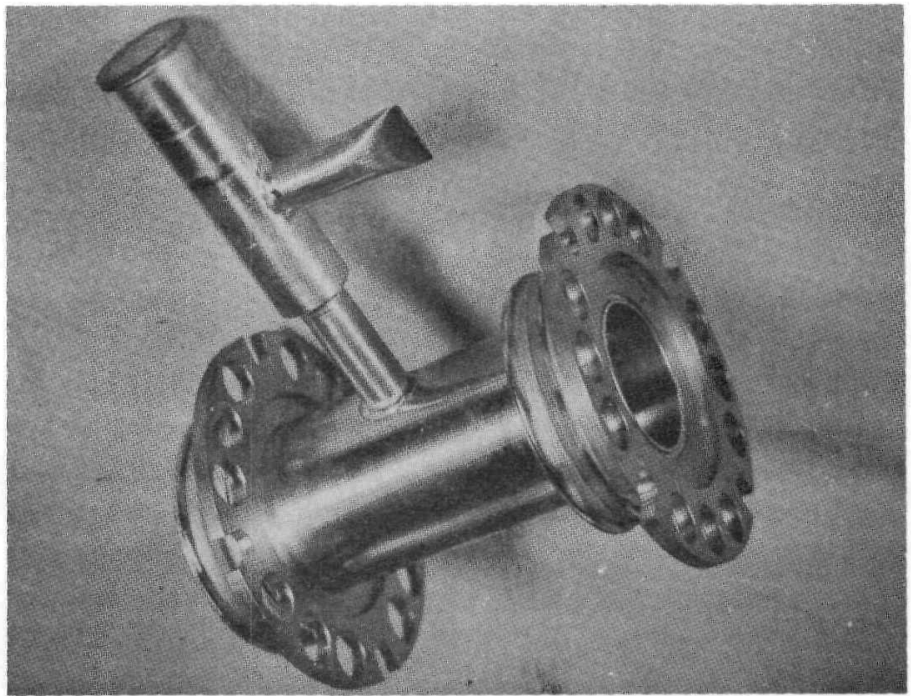

FIGURE 14 NASA/RCA A-1279A THERMIONIC CONVERTER 


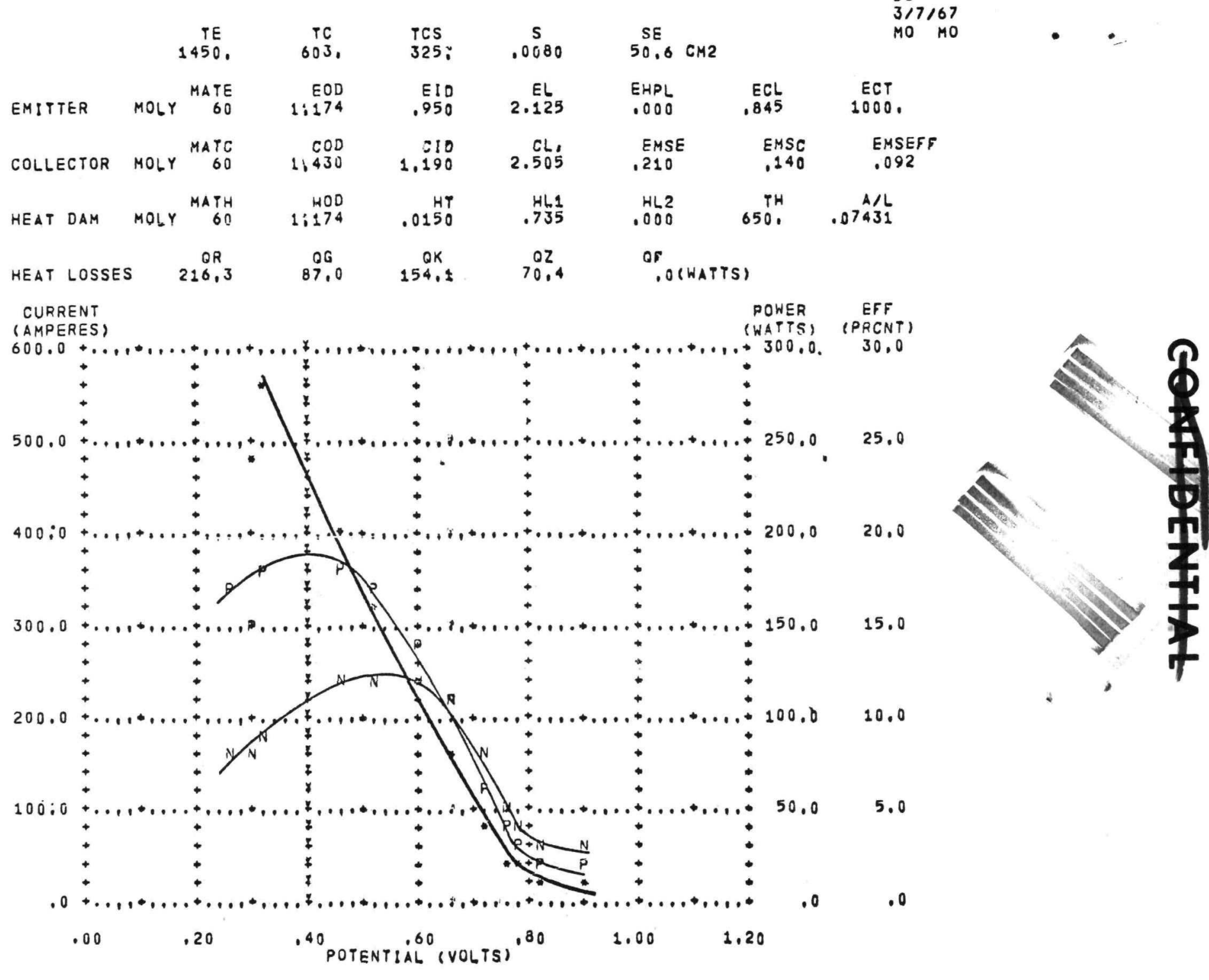

* - volt-a yp ERe curve

$P P P P$ - POWER JUTPUT CURVE

FIGURE 15

NN N $N$ - EFFICIINEYY CURVE 
RCA TYPE AI279A THERMIONIC CONVERTER PERFORMANCE DATA ANALYSIS

$03 / 20 / 67 \quad I-V$ CURVE

RAF/RJB A1279C71

\section{6}

$3 / 7 / 67$

$\begin{array}{ccccc}T E & T C & T C S & S & S E \\ 1450, & 603, & 325, & .0080 & 50.6 \quad C_{142}\end{array}$

\begin{tabular}{|c|c|c|c|c|c|c|c|c|}
\hline EMITTER & MOLY & $\begin{array}{r}\text { MATEE } \\
60\end{array}$ & $\begin{array}{r}\text { EOD } \\
1.174\end{array}$ & $\begin{array}{r}\text { EID } \\
.950\end{array}$ & $\begin{array}{c}E L \\
2.125\end{array}$ & $\begin{array}{l}\text { EHPL } \\
.0 O 0\end{array}$ & $\begin{array}{r}E C L \\
.845\end{array}$ & $\begin{array}{c}\text { ECT } \\
1000 .\end{array}$ \\
\hline COLLECTOR & MOLY & $\begin{array}{r}\text { MATC } \\
60\end{array}$ & $\begin{array}{r}C O D \\
1.430\end{array}$ & $\begin{array}{r}\text { CID } \\
1.190\end{array}$ & $\begin{array}{r}C L_{1} \\
2.505\end{array}$ & $\begin{array}{l}\text { EMSE } \\
.210\end{array}$ & $\begin{array}{l}\text { EMSC } \\
.140\end{array}$ & $\begin{array}{l}\text { EMSEFF } \\
.092\end{array}$ \\
\hline HEAT DAM & MOLY & $\begin{array}{r}\text { MATH } \\
\text { OO }\end{array}$ & $\begin{array}{r}400 \\
1.274\end{array}$ & $\begin{array}{r}H T \\
.0150\end{array}$ & $\begin{array}{l}\text { HL1 } \\
.735\end{array}$ & $\begin{array}{r}\text { HL? } \\
.000\end{array}$ & $\begin{array}{r}\text { TH } \\
650^{\circ},\end{array}$ & $\begin{array}{r}A / L \\
.07431\end{array}$ \\
\hline
\end{tabular}

HEAT LOSSES 216,3

$\begin{array}{ccc}O G & O K & 0 Z \\ 87.0 & 154.1 & 70.4\end{array}$

$D F$

. O WATTS

$\begin{array}{cr}\text { I } & F \\ \text { (AMPS) } & \text { (VOLTS) } \\ 647 . ? & .260 \\ 566.3 & .325 \\ 405.4 & .305 \\ 404.5 & .455 \\ 323.6 & .525 \\ 242.7 & .590 \\ 161.8 & .660 \\ 80.9 & .720 \\ 48.5 & .750 \\ 32.4 & .730 \\ 24.3 & .820 \\ 20.2 & .900\end{array}$

(WA WE

2.546

2.566

2.539

2.616

2.649

2.691

2.752

2.855

2.930

2.991

3.033

3.060

DE
(WATTS.)
1647.7
1453.7
1756.5
1058.1
857.2
$653 . ?$
$445 . ?$
230.9
$142 . ?$
96.8
73.6
61.9

QHJ
(WATTS)
73,9
56.6
41.6
28.9
18,5
10.4
4.6
1.2
.4
.2
.1
.1

$E F F$
(PCNT)
7.87
9.43
0.40
11.71
12.35
12.18
11.00
7.68
5.44
4.04
3.31
3.09

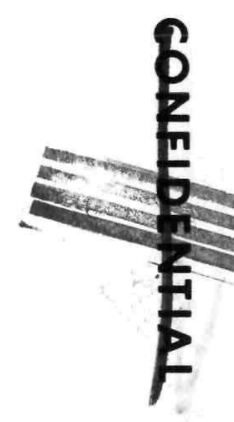

FIGURE 16 


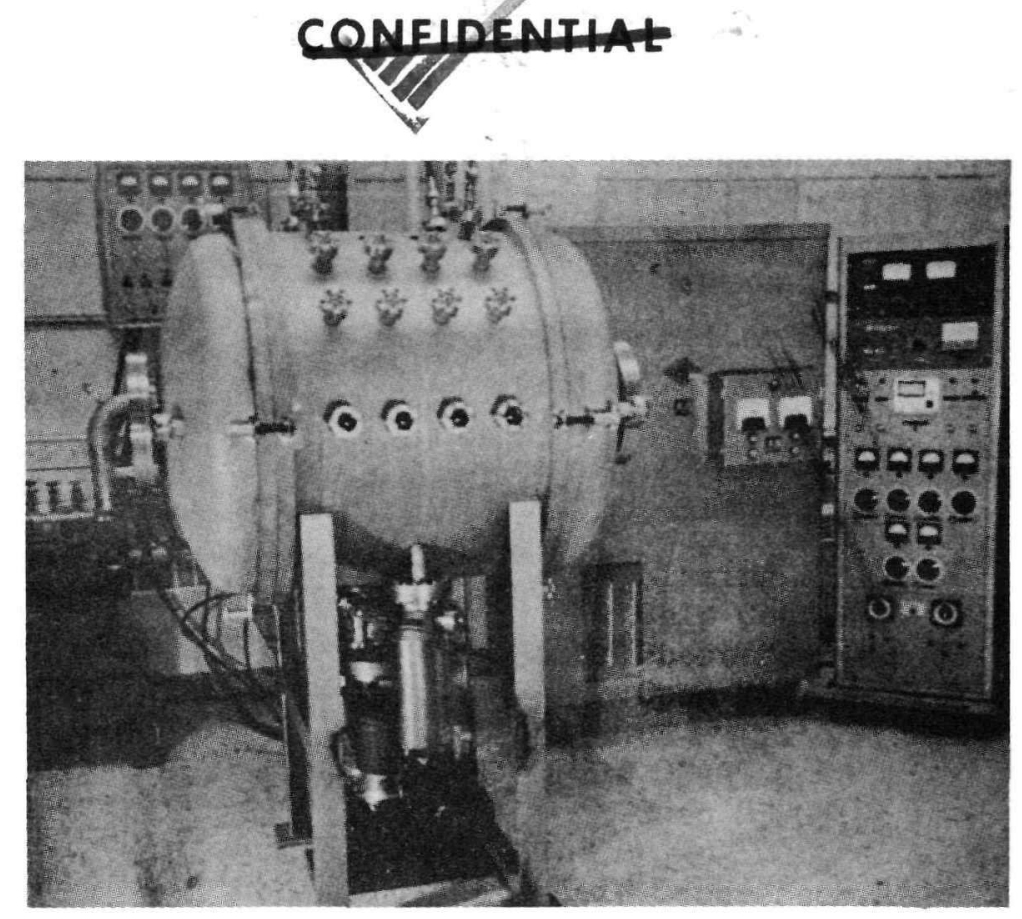

VACUUM TEST CHAMBER

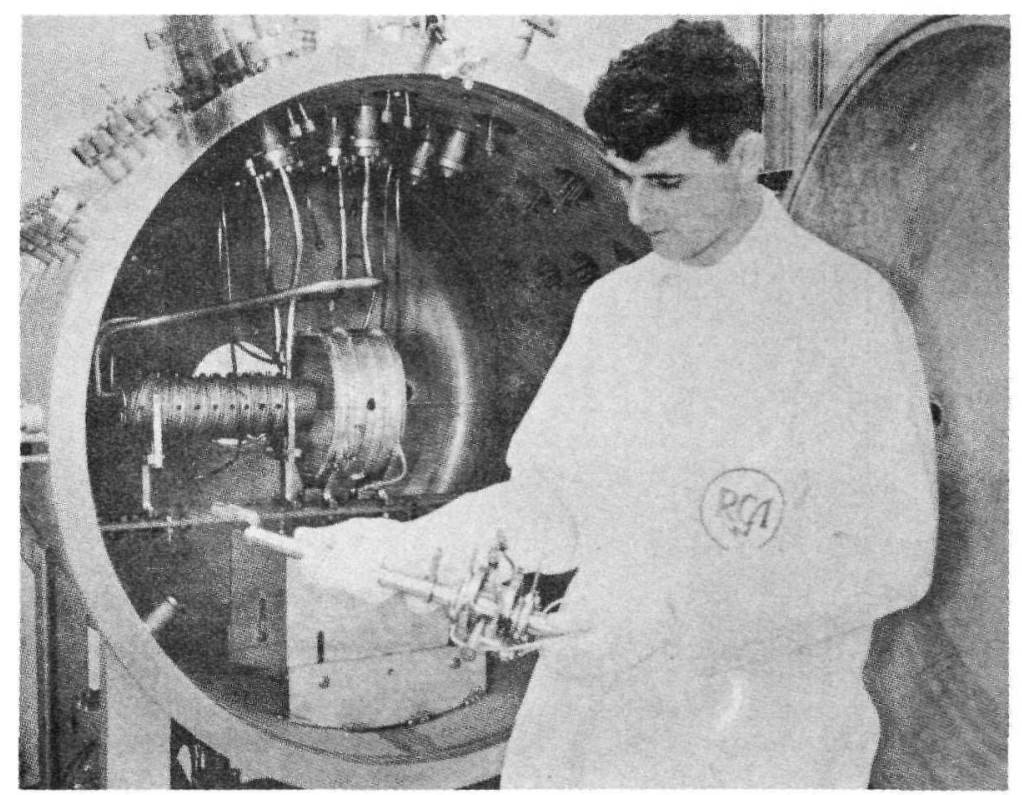

CONVERTER-HEAT PIPE SYSTEM BEING INSTALLED IN TEST CHAMBER 
FIGURE 18. HEAT PIPE THUY MIONIC CONVERTER

PROTO YPE SYSTEM

PERFORMANCE

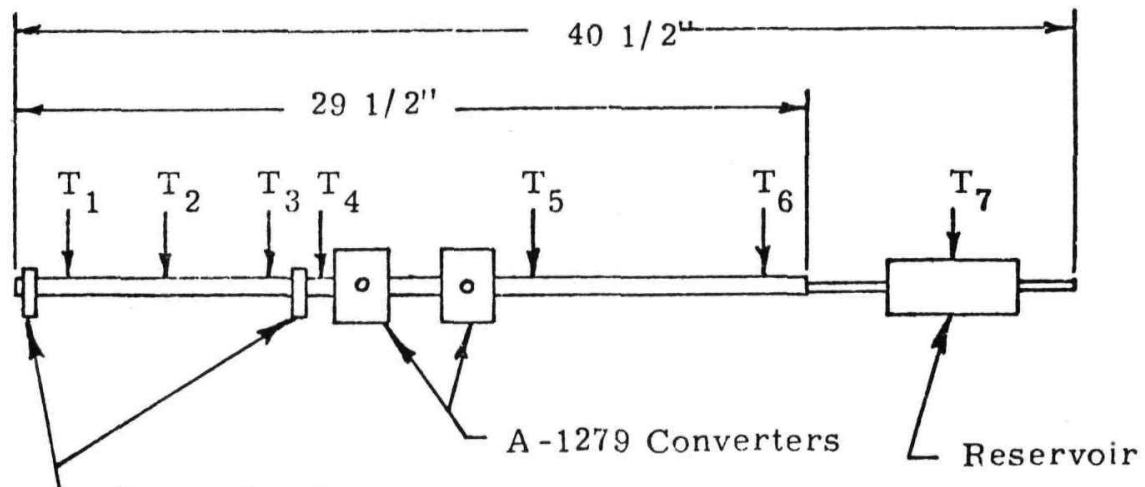

Power Leads

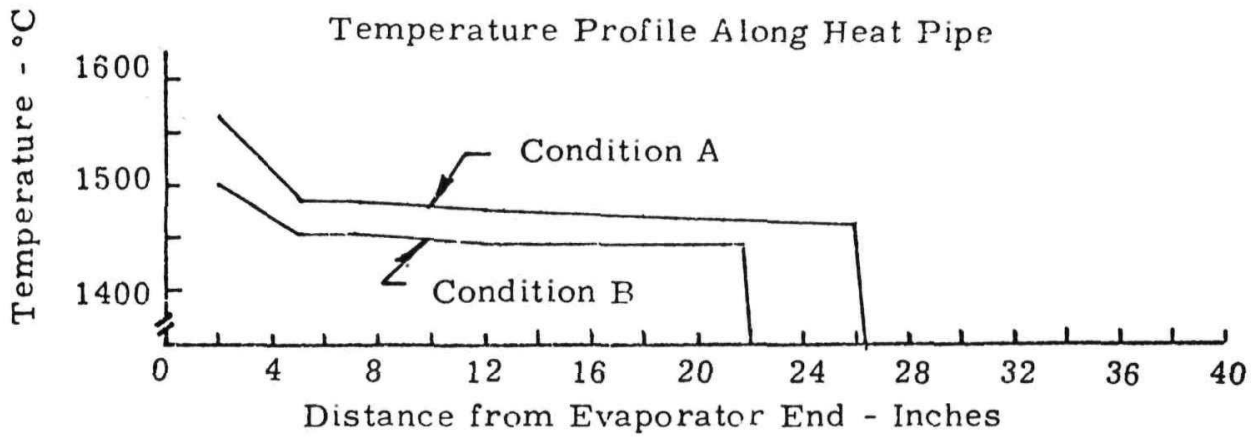

TABLE 3

\begin{tabular}{|c|c|c|c|c|c|c|c|}
\hline \multirow[t]{3}{*}{ Condition } & \multicolumn{6}{|c|}{ Temperature $-{ }^{\circ} \mathrm{C}$} & \multirow[b]{2}{*}{ Reservoir } \\
\hline & \multicolumn{3}{|c|}{ Fvapcrator } & \multicolumn{3}{|c|}{ Condenser } & \\
\hline & $\mathrm{T}_{1}$ & $\Gamma_{2}$ & $\mathrm{I}_{3}$ & $\mathrm{~T}_{4}$ & $\mathrm{~T}_{5}$ & $\mathrm{~T}_{6}$ & $\mathrm{~T}_{7}$ \\
\hline A & 1565 & 1482 & 1482 & 1475 & 1465 & 1053 & 299 \\
\hline $\mathrm{L}$ & 1500 & 1453 & 1453 & 1446 & 1443 & NC & 233 \\
\hline $\begin{array}{l}\text { Distance from } \\
\text { Evaporator } \\
\text { End - Inch }\end{array}$ & 2 & 5 & 7 & 12 & 21 & 27 & 34 \\
\hline
\end{tabular}




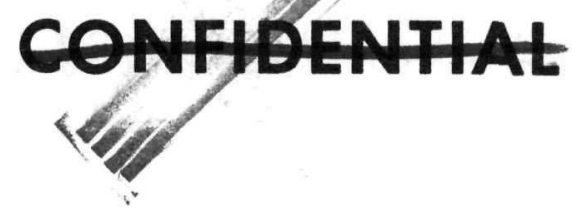

FAST REACTOR SYSTEMS FOR SECONDARY SPACE POWER*

W. N. Podney, E. Garelis, B. L. Koponen, and J. P. Layton ${ }^{\dagger}$
Lawrence Radiation Laboratory, University of California

Livermore, California

\section{ABSTRACT}

This paper presents a concept of a fast reactor that can provide the long-lived, versatile, high-temperature $\left(1500^{\circ} \mathrm{K}\right)$ heat source required for space applications in the $1980^{\prime} \mathrm{s}$, which will need secondary electrical power of $100 \mathrm{kWe}$ or more. The concept is based on a core composed of uranium mononitride fuel elements enriched in either $U^{235}$ or $U^{233}$, clad with a ductile tungsten alloy, and cooled with lithium either by convective flow of the liquid or by vaporization of lithium in heat pipes made of the same tungsten alloy. A $250-\mathrm{kg}$ cylindrical core, $26 \mathrm{~cm}$ in both diameter and length and fueled with $\mathrm{U}^{235}$, can produce $7 \mathrm{MW}$-years of thermal energy; a $\mathrm{U}^{233}$ fueled core having a mass of $80 \mathrm{~kg}$ and a diameter and length of $18 \mathrm{~cm}$ can produce $2 \mathrm{MW}$-years of thermal energy.

A preliminary comparative study has been made on four advanced systems, all using a fast reactor for the heat source but differing in the method by which the heat energy is converted to electrical power: (1) an alkali-metal Rankine cycle, (2) an inert-gas Brayton cycle, (3) silicongermanium thermoelectric elements, (4) out-of-core thermionic diodes. Below a power level of $100 \mathrm{kWe}$ these systems show little difference in performance. However, only the Rankine-cycle and thermionic systems can provide the very high performance required at power levels approaching $1 \mathrm{MWe}$.

\footnotetext{
${ }^{*}$ Work performed under the auspices of the U.S. Atomic Energy Commission.

${ }^{\dagger}$ Senior Research Engineer, Department of Aerospace and Mechanical Sciences, Princeton University. On leave at Lawrence Radiation Laboratory, Livermore, until 31 August 1968.
}

\section{INTRODUCTION}

Nuclear reactor systems based on zirconium-hydride-moderated reactors and using either a thermoelectric converter, a mercury or organic Rankine cycle, or an inert-gas Brayton cycle as a means of energy conversion have widely been considered for secondary power applications in space that require up to $70 \mathrm{~kW}$ of electrical power. These systems are limited to reactor outlet temperatures of about $1000^{\circ} \mathrm{K}$ and lifetimes of about two years, and have specific masses well above $100 \mathrm{~g} / \mathrm{We}$. The applications foreseen in the $1970^{\prime}$ s include direct-broadcast television satellites, manned earth-orbiting space stations, and lunar bases - all with power requirements between 10 and $30 \mathrm{kWe} .1-9$

A projection into the $1980^{\prime}$ s of power requirements for a variety of earth-orbiting space stations and for possible extended lunar operations has been made at this Laboratory (see Fig. 1). An interesting configuration for a semipermanent type of earth-orbiting space station studied in the Space Science Laboratory, NASA Marshall Space Flight Center, is shown in Fig. 2; these NASA scientists have projected in a general way the overall requirements for the decade. 10

As projected in Fig. 1, an active Space Program will require secondary power levels ranging up to $100 \mathrm{kWe}$ by 1980 and possibly up to $1 \mathrm{MWe}$ within the decade. Lifetimes of at least five years would be needed. Since present systems cannot meet the performance desired at these higher power levels and longer lifetimes, and since the overall development time for advanced reactor systems is from eight to ten years, it is necessary to characterize the applicable systems and to proceed with the development of the basic technology without undue delay. 
Operational and performance requirements of a power system designed to meet the needs of such missions must be defined in coordination with spacecraft studies. As a first step in this direction, tentative and necessarily incomplete specifications are listed in Table I. The requirements for dependability and safety can be stated only in the most general terms at this time. A statement of operational characteristics such as the duty-cycle of the powerplant and maintenance, and the method of integrating the powerplant with the spacecraft-must await further definition of the missions.

\section{TABLE I}

Tentative Requirements of Nuclear Reactor Secondary Space Power Systems for Manned Missions in the Early 1980's

Power level

Lifetime

Specific mass

Radiation dose $\mathrm{e}^{*}$

Dependability

\section{0 to $300 \mathrm{kWe}$ \\ 5 years \\ $\sim 50 \mathrm{~g} / \mathrm{W}$ or less \\ $<5 \mathrm{Rem} / \mathrm{yr}$}

Assured against any credible failure or accident during system lifetime that removes it from further use despite serviceability (includes maintenance, replacement, and repair) provisions.

Safety Provided against any unexpected excursion during handling, launch, operation, or disposal.

\footnotetext{
* At a dose plane of specified diameter (typically $50 \mathrm{~m}$ ) and distance (typically 30 to $50 \mathrm{~m}$ ) from reactor.

It seems clear, however, that the present technology of zirconium-hydride-moderated reactors cannot provide power sources having a low enough specific mass at power levels exceeding $100 \mathrm{kWe}$. Heat source temperatures of $1500^{\circ} \mathrm{K}\left(\sim 2250^{\circ} \mathrm{F}\right)$ or greater are required to increase both the efficiency at which the power conversion system operates and the radiator temperature, thereby reducing the mass of the system. Above about $1100^{\circ} \mathrm{K}\left(\sim 1500^{\circ} \mathrm{F}\right)$, there are no neutronmoderating materials that can provide a compact, high-power-density, epithermal reactor. Consequently, the next generation of space power reactors must necessarily be fast spectrum reactors based on ceramic fuels, refractory structural materials, and alkali metal coolants.
}

After considerable study, the materials selected at the Lawrence Radiation Laboratory for space reactors with an outlet temperature of $1500^{\circ} \mathrm{K}$ or greater are uranium mononitride (UN) as fuel, tungsten or a

ductile tungsten alloy (particularly one alloyed with rhenium or possibly molybdenum, such as W-25Re-30Mo) as cladding and structure, and lithium (Li) as coolant. Selected physical properties of uranium mononitride, the alloy W-25Re-30Mo, and lithium are listed in Table II.

\section{TABLE II}

Selected Properties of Advanced Reactor Materials from LRL Liquid-Metal-Cooled Reactor Program

(Typical Values for Around $1500^{\circ} \mathrm{K}$ )

Uranium Mononitride, UN

Melting point

Density, theoretical

Thermal conductivity

Thermal expansion, linear
$3125^{\circ} \mathrm{K}$
$14.32 \mathrm{~g} \mathrm{~cm}^{-3}$
$0.25 \mathrm{~W} \mathrm{~cm}^{-1}{ }^{\circ} \mathrm{C}^{-1}$
$9.9 \times 10^{-6}{ }^{\circ} \mathrm{C}^{-1}$

Tungsten Alloy, W-25Re-30Mo (a/o)
Melting point

Density

Thermal conductivity

Thermal expansion, linear

Tensile strength

Creep rate@1000 N $\mathrm{cm}^{-2}$ stress

Modulus of elasticity

Electrical resistivity

$3225^{\circ} \mathrm{K}$

$(0.65) \mathrm{W} \mathrm{cm}^{-1}{ }^{\circ} \mathrm{C}^{-1}$

$5.0 \times 10^{-6}{ }^{\circ} \mathrm{C}^{-1}$ $48.6 \times 10^{3} \mathrm{~N} \mathrm{~cm}^{-2}$

$\left(4 \times 10^{-8}\right) \mathrm{hr}^{-1}$

$45.5 \times 10^{6} \mathrm{~N} \mathrm{~cm}^{-2}$

$5.8 \mu \mathrm{ohm} \mathrm{cm}$

\section{Lithium, Li}

Melting point

Vapor pressure (a) $1500^{\circ} \mathrm{K}$

Boiling point@1 atm

Density

Viscosity

Thermal conductivity

Heat capacity

Heat of fusion

Heat of vaporization

Electrical resistivity

$455^{\circ} \mathrm{K}$

$4.4 \mathrm{~N} \mathrm{~cm}^{-2}$

$1600^{\circ} \mathrm{K}$

$0.41 \mathrm{~g} \mathrm{~cm}^{-3}$

0.14 centipoise

$0.71 \mathrm{~W} \mathrm{~cm}^{-1}{ }^{\circ} \mathrm{C}^{-1}$

$717 \mathrm{cal} / \mathrm{mole}$

$35,403( \pm 400)$

$\mathrm{cal} / \mathrm{mole}$

$54 \mu \mathrm{ohm} \mathrm{cm}$
$16.9 \mathrm{~g} \mathrm{~cm}^{-3}$

$0.98 \mathrm{cal} \mathrm{g}^{-1}{ }^{\circ} \mathrm{C}^{-1}$

Based on preliminary test results, these materials are believed to be mutually compatible around $1500^{\circ} \mathrm{K}$; additional data on corrosion at $1500^{\circ} \mathrm{K}$ will be available from both capsule and loop tests in the LRL materials program and elsewhere within the next year. 11,12 The acquisition of data at $1800^{\circ} \mathrm{K}$ and above is being planned. Much data is needed at all temperatures - particularly the very highest - on fuels with various microstructures, as well as on the effects of the large number of reactor fuel element design variables. 
This paper first describes a fast reactor concept, based on the above materials, that would provide a nominal $1500^{\circ} \mathrm{K}$ heat source for advanced secondary space power systems with the potential for later increases in temperature. It then presents a preliminary comparative study of space power systems using this heat source with either a Rankine cycle, a Brayton cycle, thermoelectric elements, or out-of-core thermionic diodes to produce electric power.

\section{FAST REACTOR CONCEPT}

The reactor concept is based on a cylindrical core composed of UN fuel elements clad with the tungsten-based alloy W-25Re$30 \mathrm{Mo}$ and cooled with lithium. The elements may be cooled either by convective flow of liquid lithium or by vaporization of lithium within heat pipes made of the same tungsten alloy. Control is provided during operation by varying the neutron leakage from the lateral surface of the core. This is accomplished by moving beryllia ( $\mathrm{BeO}$ ) side reflectors, for shadow-shielded reactors, or by rotating tungsten drums that are backed with a boron-10 ( ${ }^{10}$ ) compound, for $4 \pi$-shielded reactors.

\section{Core Size and Mass}

The internal structure of the core, such as fuel element radius and thickness of the cladding, is largely determined by material stress limits and maximum heat transfer rates. For the purposes of determining the critical size of the core and its control characteristics, this information is transcribed into a specification of the material composition of the core in terms of the volume fractions of the constituents. Based on previous detailed designs 13 for fast reactor cores containing these materials, a representative composition is a fuel volume fraction of 0.65 , a clad volume fraction of 0.20 , and a coolant volume fraction of 0.15 .

The radius ${ }^{*}$ required to attain a critical state for a cylindrical core of this composition and having a length-to-diameter ratio of unity is $13.2 \mathrm{~cm}(\sim 5.2 \mathrm{in})$, with the fuel enriched in $\mathrm{U}^{2} 35$ to $95 \%$ by weight. For a pure $\mathrm{U}^{23} 3$ fuel, ${ }^{\dagger}$ the critical radius is $9.02 \mathrm{~cm}$

\footnotetext{
*These results were obtained using a DTF one-dimensional transport theory code with eight-group cross sections based on the Howerton Evaluated Library.

${ }^{\dagger}$ Since $\mathrm{U}^{233}$ is produced from thorium, there is little difficulty in obtaining pure $\mathrm{U}^{23} 3$ via the PUREX separation process. The pure material is readily obtainable from Hanford and/or Savannah River. Uranium enriched to 95 weight percent in $\mathrm{U}^{235}$ is available commercially from NUMEC.
}

( 3.55 in). The reactor masses, which include a $0.6-\mathrm{cm}$-thick pressure vessel of the molybdenum alloy Mo-50Re and a 3-cmthick side reflector of $\mathrm{BeO}$, are approximately $250 \mathrm{~kg}$ for the $\mathrm{U}^{2} 35$-fueled core and $80 \mathrm{~kg}$ for the U233-fueled core. These cores are representative, respectively, of the minimum size and mass for a fast reactor fueled with $\mathrm{U}^{235}$ and $\mathrm{U}^{2} 33$.

The energy content of the cores is determined by the relation

$$
V \mathrm{X}_{f}=\left(8.46 \times 10^{-5}\right) \mathrm{PT} / \mathrm{b},
$$

where $\mathrm{V}$ is the volume of the core in liters, $\mathrm{X}_{\mathrm{f}}$ the volume fraction of fuel, PT the MWdays of thermal energy, and $\mathrm{b}$ the average fuel burnup. For a maximum burnup of $2 \%$ the $\mathrm{U}^{2} 35$-fueled core can produce $2.41 \times 10^{3}$ MW-days of thermal energy, or operate at a maximum thermal power level of $1.4 \mathrm{MW}$ throughout an intended lifetime of five years. Similarly, the $\mathrm{U}^{233}$-fueled core can produce $0.706 \times 10^{3} \mathrm{MW}$-days of thermal energy, or operate at a maximum thermal power level of $0.41 \mathrm{MW}$ for five years.

For energy requirements that exceed these limits, the volume of fuel required, and hence the mass of the reactor, increases in proportion to the energy required, as is evident from Eq. (1), since the fuel burnup is limited. Based on a 5-year lifetime, then, the minimum mass per unit thermal power of the reactor is approximately $0.2 \mathrm{~g} / \mathrm{W}$. This minimum is attained at a thermal power level of 1.4 MW for the U235-fueled reactor and at $0.41 \mathrm{MW}$ for the $\mathrm{U}^{233}$-fueled reactor. Consequently, at thermal power levels above 1.4 MW, the two cores have the same size and mass. Since electrical power levels exceeding $100 \mathrm{kWe}$ require thermal power levels of the order of $1 \mathrm{MW}$ or greater, a $\mathrm{U}^{23} 3$-fueled core presents no appreciable advantage in performance, and we restrict further consideration to $\mathrm{U}^{2} 35$-fueled reactors.

\section{Control Characteristics}

Further definition of the reactor requires consideration of the control requirements and the reactivity effects produced by the control mechanisms. The control requirements are specified according to the reactivity margins needed (1) to assure a subcritical state during launching operations prior to orbital startup of the reactor (ground shutdown), (2) to shut down the reactor during operation (operational shutdown), (3) to compensate for fuel depletion and temperature effects during operation (operational losses), and $(4)$ to provide control at the nominal endof-life conditions (operational reserve). 
For the ground shutdown requirement, we specify that the reactor be $2 \%$ subcritical. under the conditions of the maximum ciedible reactivity insertion, which is taken to be submersion of the reactor in sea water due to an abortive launch.* The operationalshutdown margin is likewise specified to be $2 \%$. A margin of about $2 \%$ is required to compensate for operational losses, and a $1 \%$ margin is specified to provide for operational reserve.

Two independent means of control are proposed to fulfill these requirements. First, the lithium coolant in the core, which is in a solid state before operation, is enriched with enough of the strongly absorbing isotope $\mathrm{Li}^{6}$ to assure that the reactor is $2 \%$ subcritical when completely reflected with water. After a stable orbit has been achieved, the coolant is diluted during reactor startup with the isotope $\mathrm{Li}^{7}$ to attain an appropriate operating enrichment. Second, movable reflectors are provided to vary the neutron leakage from the lateral surface of the core. The reflectors provide the reactivity margins required during startup, operation, and shutdown, which amount to a total of about $5 \%$. For $4 \pi$-shielded reactors, the reflectors are replaced by rotatable tungsten drums that are backed with a boron-10 compound.

The reactivity changes produced by the control mechanisms and their influence on core size were computed using a onedimensional diffusion theory code with 16group cross sections based on the Howerton Evaluated Library.14 As before, the cylindrical core is taken to have a length-todiameter ratio of unity, and its composition is $65 \%$ by volume of UN fuel enriched in $\mathrm{U}^{235}$ to $95 \%$ by weight, $20 \mathrm{vol} \%$ of clad, and 15 vol $\%$ of coolant.

The $\mathrm{Li}^{7}$ enrichment of the coolant required to provide the ground-shutdown and operational-shutdown and operationalshutdown reactivity margins of $2 \%$ is shown as a function of core radius in Fig. 3. For core radii less than $13.2 \mathrm{~cm}$, a critical state cannot be attained for a $\mathrm{Li}^{7}$ enrichment less than $100 \%$. Similarly, for core radii exceeding $14.5 \mathrm{~cm}$, the reactivity margin required for ground shutdown cannot be achieved by the use of the $\mathrm{Li}^{6}$ isotope. At a radius of $13.4 \mathrm{~cm}$, for example, a $\mathrm{Li}^{7}$ enrichment of $60 \%$ in the solid coolant contained in the core prior to startup would provide the specified $2 \%$ margin under the conditions of water submersion. During startup, the coolant is diluted to a $\mathrm{Li}^{7}$ enrichment of $86 \%$, which provides the $2 \%$ margin required for operational shutdown.

\footnotetext{
*It is assumed that water does not penetrate the reactor pressure vessel.
}

Because of the strong poisoning effect of $\mathrm{Li}^{6}$ in the coolant, a loss of coolant from the core during operation may result in a large increase in reactivity. This effect can be precluded, however, by selecting a $\mathrm{Li}^{7}$ enrichment greater than $75 \%$ for the operational shutdown condition. Consequently, the radius of the core must not exceed $13.6 \mathrm{~cm}$ in order to provide safety both during operation in orbit and during launching operations prior to orbital startup of the reactor.

The change in reactivity or worth associated with reflectors made of $\mathrm{BeO}$ is shown in Fig. 4 as a function of the $\mathrm{Li}^{7}$ enrichment of the coolant and the thickness of the reflector material, for core radii of 13 and $14 \mathrm{~cm}$. As is evident from Fig. 4, a 2-cm-thick BeO reflector would provide a $6.5 \%$ reactivity margin for a $13-\mathrm{cm}$-radius core with a $\mathrm{Li}^{7}$ enrichment of $75 \%$ in the operational shutdown condition. The $5 \%$ margin required, then, can be readily provided by rather thin reflectors of $\mathrm{BeO}$.

Although thin, movable reflectors could also provide adequate control for $4 \pi$-shielded reactors, the space required between the core and shield for reflector movement results in a substantial increase in the mass of the shield. This can be obviated by using rotating drums made of a shielding material which also acts as a fast-neutron reflector, such as tungsten, backed with a strong neutron absorbing material, such as a boron-10 compound. Then, in effect, the shield abuts the core.

An estimate of the range of reactivity worth that can be obtained by rotation of control drums $11.7 \mathrm{~cm}$ in diametert is shown in Fig. 5 as a function of the thickness of the absorbing material, for three material combinations. At the extremes of drums made of one or the other of the materials, rotation of the drums, of course, produces no effect. In each case, the maximum worth is attained for an absorber thickness of approximately $3 \mathrm{~cm}$. Although the material combination $\mathrm{BeO}-\mathrm{B}^{10}$ is the most effective because of the superior neutron reflecting properties of $\mathrm{BeO}$, more than adequate control can be provided with tungsten-based drums, which are superior as a shielding material.

\section{SHIELDING}

The radiation shield required for protection of the crew is the most massive component of a secondary space power system. It is also the most difficult to design precisely

${ }^{\dagger}$ A diameter of $11.7 \mathrm{~cm}$ corresponds to 12 drums placed circumferentially about a 13.2-cm-radius core. 
because of inadequately defined criteria, experimental uncertainties, and computational complexity. Nevertheless, for the purpose of making a preliminary, comparative study of secondary space power systems, the shield mass is estimated based on a laminated design that consists of three tungsten layers sandwiching two layers of lithium-6 hydride, $\mathrm{Li}^{6} \mathrm{H}$. The thickness of the layers is chosen to obtain a minimum mass with the constraint that the dose rate at a distance of 50 meters not exceed $0.6 \mathrm{mRem} / \mathrm{hr}$, which is approximately equivalent to the AEC dose rate criterion of $5 \mathrm{Rem} /$ year.

The results shown in Figs. 6 and 7 are based on a simple calculational model in which the radiation is considered to emanate from a point source located at the center of the reactor core. The neutron source strength is taken to be equal to one-half the fission neutrons born in the core, and their dose rate is determined by using a modified Albert-Welton kernel to account for neutron removal by lithium and tungsten. Gamma rays produced by fission and prompt decay in the core are assumed to escape with a probability given by the expression for a purely absorbing sphere, 15 and their dose rate is determined from a simple exponential buildup factor, in which secondary gamma rays are considered to be produced only in the tungsten layers.

The results, then, represent no more than a crude estimate of a minimum shield mass; they are, however, comparable with those reported by Gylfe. ${ }^{2}$ Although sculpturing the shield to conform with a spatial variation in the dose rate allowed (particularly in the case of a $4 \pi$-shield) would reduce its mass, such precision in the design cannot yet be predicted with adequate confidence. Moreover, sufficient information on the geometry of the spacecraft and mission objectives to warrant a precise design is not available. Nevertheless, as we show later (Fig. 11), moderate uncertainties in the mass of a massive shield do not appreciably change the minimum specific mass of a system at high power levels.

\section{COMPARATIVE SYSTEM STUDY}

As noted in the Introduction, criteria for the advanced missions are not defined precisely enough to serve as a basis for appraising the merits of different system concepts in detail. As a result, the system concepts themselves can only be defined in general terms and the comparison of systems based on a Rankine cycle, a Brayton cycle, thermoelectric effects, and thermionic emission is necessarily preliminary in nature.
Since one of the more important and often quoted indexes of the performance of a space power system is its specific mass, we choose this quantity as the focal point for comparison. Other considerations such as reliability, versatility, growth potential, and fundamental development problems are discussed individually for each system since an objective basis for comparison is not possible at present.

Although the specific mass of a welldefined system can be determined to any desired accuracy, enough information to warrant the detailed calculations required is seldom available and the calculational effort is often prohibitive. Moreover, detailed calculations tend to obscure the effect of significant parameters and do not provide a simple and uniform basis for comparison. This contributes to the continuing controversy encountered in appraising the merits of conceptual systems. It is desirable, then, to have a simple, uniform, and more important, a reasonably accurate means of estimating and comparing the minimum specific mass of conceptual systems.

To establish a uniform basis for comparison, we first present a simple analytic description of a system, which is in the spirit of the analysis reported by Pitkin, 16 and point out its limitations. On this basis, we show that the minimum specific masses of different system concepts can be uniformly compared in terms of three parameters: first, the mass of the radiator per unit radiated power, for a uniform radiating temperature equal to the heat source temperature; second, the mass of the heat source per unit thermal power, at the power level above which the mass of fuel becomes proportional to power; and third, the fraction of Carnot efficiency at which the power conversion device operates. These three parameters characterize the radiator, heat source, and power conversion device, respectively.

It is understood, however, that such a simple description only provides a framework for comparison for the values of the parameters considered. The appropriate parametric values must be determined by physical and design analysis of the system components for the appropriate range of power levels and the projected state of the art.

\section{System Description}

For this purpose, the mass of a system is considered to be the sum of the mass of a radiator and reactor heat source, which includes a reactor core, reflector, and a shadow shield. The mass of the power 
conversion device and other components cap ordinarily be neglected in determining the conditions at which the minimum specific mass of a system is attained. Furthermore, for systems with a massive shield (as usually prevails for secondary power applications) the mass of these components does not significantly change the value of the minimum specific mass of the system. Thus, the results based on this model are expected to be reasonably accurate for systems in which the mass of the shield is the greatest fraction of the system mass.

Radiator specific mass: The mass of the radiator per unit electrical power, $\alpha_{r}$, is independent of electrical power and is described by the relation ${ }^{*}$

$$
\alpha_{\mathrm{r}}(\mathrm{x}, \mathrm{y})=\left[\frac{\mathrm{gh}(\mathrm{y})}{\mathrm{x}}\right]\left[\frac{1}{\eta(\mathrm{x}, \mathrm{y})}-1\right],
$$

where $\mathrm{x}$ is the ratio of the minimum radiating temperature to the temperature, $\mathrm{T}_{\mathrm{h}}$, of the heat source; $y$ is the ratio of the minimum to maximum radiating temperatures; and $\eta(x, y)$ is the efficiency of the power conversion device. The function $\mathrm{h}(\mathrm{y})$ accounts for a nonuniform temperature distribution over the radiating surface, with $h=1$ for a uniform distribution. The quantity $\mathrm{g}$, which is the mass per unit power radiated at a uniform radiating temperature equal to the heat source temperature, is given by

$$
\mathrm{g}=\rho_{\mathrm{e}} /\left(\sigma \mathrm{T}_{\mathrm{h}}{ }^{4}\right),
$$

where $\rho_{\mathrm{e}}$ represents an effective mass per unit radiating area, and $\sigma$ is the StefanBoltzmann constant.

The effective mass per unit radiating area includes such factors as the emissivity of the radiating surface, radiator geometry, redundant radiator area required to assure reliability, and so forth. In brief, the engineering design of the radiator is characterized by $\rho_{\mathrm{e}}$. We note, however, that the effective mass per unit radiating area may itself depend on the radiating temperature because of material stress limits. Although this is significant from an engineering point of view, the inclusion of such detail is not

\footnotetext{
${ }^{*}$ The effect of a finite sink temperature is negligible, provided the fourth power of the ratio of the sink temperature to the minimum radiating temperature is much less than unity. This is a good approximation for heat source temperatures of the order of $1500^{\circ} \mathrm{K}$.

$\dagger_{T}$ introduced here so that the Brayton cycle can be included within the same formulation.
}

onsistent with our aim. Hence, we consider $\rho_{\mathrm{e}}$ to be sensibly constant with the caution that abrupt changes can occur when a dense, refractory alloy is required to maintain structural integrity at high radiating temperatures.

Heat source mass: The mass of a reactor heat source with a core of given material composition depends directly on the thermal power level of the reactor. For reactors in which the size of the core is not limited by heat transfer rates, ${ }^{*}$ the mass of the heat source is independent of power for all thermal power levels, $P_{t h}$, below some maximum value, $\mathrm{P}_{t h}{ }^{*}$, above which the mass of fuel required increases in proportion to the thermal power level. The value of $\mathrm{P}_{\text {th }}$ * is determined by the maximum energy that can be obtained from the minimum critical mass of fuel. As can be inferred from Eq. (1), then, the value of $\mathrm{P}_{\text {th }}$ * is inversely proportional to the design lifetime and directly proportional to the maximum burnup of the fuel that can be allowed. The constant of proportionality is determined by the material composition of the reactor core.

The mass of a shadow shield varies with the thermal power of the reactor for two reasons: first, the thickness of the shield changes to maintain a tolerable dose rate, and second, the solid angle of the shadow depends on the reactor dimensions. To a first approximation, the thickness of the shield is proportional to the logarithm of the power, so that large variations in power are necessary to change the shield mass appreciably. The change is shield mass with reactor dimensions depends on the dose plane radius and its distance from the reactor as well as on the manner in which the reactor dimensions are varied. For a dose plane radius and distance that are large compared to the reactor dimensions for secondary power systems, the mass of the shield is at most proportional to the thermal power of the reactor for $\mathrm{P}_{\text {th }}>\mathrm{P}_{\text {th }}$. For $\mathrm{P}_{\text {th }} \leq \mathrm{P}_{\text {th }}$, the mass of the shield is effectively independent of power.

Consequently, we describe the dependence of the mass of the heat source on thermal power by the function

$$
\mathrm{M}\left(\mathrm{P}_{\mathrm{th}}\right)=\mathrm{M}^{*} \text {, for } \mathrm{P}_{\mathrm{th}} \leq \mathrm{P}_{\mathrm{th}}^{*}
$$

and

$$
\mathrm{M}\left(\mathrm{P}_{\mathrm{th}}\right)=\mathrm{M}^{*}\left(\mathrm{P}_{\mathrm{th}} / \mathrm{P}_{\mathrm{th}}{ }^{*}\right) \text {, for } \mathrm{P}_{\mathrm{th}} \geq \mathrm{P}_{\mathrm{th}}^{*} \text {, }
$$

where $M^{*}$ is the minimum mass of the reactor heat source and corresponds to the minimum critical mass of fuel. For power levels

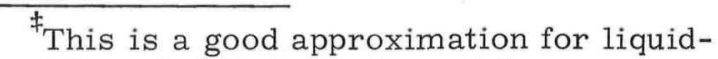
metal-cooled fast reactors at the power levels considered herein. 
below $\mathrm{P}_{\text {th }}$ * the description is precise, and for power levels above $\mathrm{P}_{\text {th }}$ * the description represents a reasonable upper limit for the mass of the heat source.

\section{Minimum Specific Mass of a System}

The specific mass $\alpha$ of a system, then, is represented as a function of electrical power $\mathrm{P}$ by the expression

$\alpha(\mathrm{P})=\frac{\mathrm{M}^{*}}{\mathrm{P}}+\alpha_{\mathrm{r}}(\mathrm{x}, \mathrm{y})$, for $\mathrm{P} \leq \mathrm{P}_{\mathrm{th}}{ }^{*} \eta(\mathrm{x}, \mathrm{y})$,

and by

$$
\begin{aligned}
& \alpha(\mathrm{P})=\frac{\mathrm{G}}{\eta(\mathrm{x}, \mathrm{y})}+\alpha_{\mathrm{r}}(\mathrm{x}, \mathrm{y}), \\
& \quad \text { for } \mathrm{P} \geq \mathrm{P}_{\text {th }}{ }^{*} \eta(\mathrm{x}, \mathrm{y}),
\end{aligned}
$$

where $\alpha_{r}(\mathrm{x}, \mathrm{y})$ is given by Eq. (2) and $\mathrm{G}=\mathrm{M}^{* * / \mathrm{P}_{\mathrm{th}}}{ }^{*}$ is the mass of the heat source per unit thermal power at the power level above which the mass of fuel required becomes proportional to power. For a given design of the heat source and radiator, which are characterized by the quantities $\mathrm{G}$ and $\mathrm{g}$, the specific mass at each electrical power level has a minimum value, $\alpha_{m}(\mathrm{P})$, which corresponds to the largest value of $\mathrm{x}$, denoted by $\mathrm{x}_{0}(\mathrm{P})$, that can be attained without suffering an intolerable loss in efficiency. ${ }^{\dagger}$

The overall character of the minimum specific mass of a system as a function of electrical power is shown schematically in Fig. 8. At electrical power levels less than some value $P_{1}$, which correspond to thermal power levels less than $\mathrm{P}_{t h}{ }^{*}$, the specific mass of the heat source is independent of efficiency, so that the optimum temperature ratio $x_{01}$ and the corresponding efficiency $n_{01}$ are determined from Eq. (2) by requiring a minimum specific mass of the radiator alone. Since the specific mass of the radiator is independent of power, the values are constants for all electrical power levels less than $\mathrm{P}_{1}$, and $\mathrm{P}_{1}=\mathrm{P}_{\text {th }}{ }^{*} \eta_{01}$.

At electrical power levels greater than some value $\mathrm{P}_{2}$, which correspond to thermal power levels exceeding $\mathrm{P}_{\mathrm{th}}{ }^{*}$, the specific mass of the heat source is inversely proportional to efficiency. Consequently, an efficiency $\eta_{02}$ greater than $\eta_{01}$ gives a minimum specific mass of a system because the mass of the heat source is then reduced at the

${ }^{t}$ The specific mass, however, does not exhibit a relative minimum with respect to the temperature ratio y but decreases monotonically as y ranges from zero to unity. The monotonicity results because the thermodynamic cycle more closely approximates a Carnot cycle as y approaches unity. expense of a lesser increase in radiator mass. Since the specific mass of a system is independent of power for $\mathrm{P}>\mathrm{P}_{2}$, the values $\eta_{02}$ and $x_{02}$ are also constants, and $\mathrm{P}_{2}=\mathrm{P}_{\text {th }}{ }^{*} \eta_{02}$ so that $\mathrm{P}_{2}>\mathrm{P}_{1}$.

At electrical power levels between $\mathrm{P}_{1}$ and $\mathrm{P}_{2}$, the minimum specific mass of a system is attained at efficiencies between $\eta_{01}$ and $n_{02}$ with the heat source operating at the maximum thermal power level $\mathrm{P}_{\mathrm{th}}{ }^{*}$. (It can be shown that the function $\alpha_{m}(P)$ is smooth at both $\mathrm{P}_{1}$ and $\mathrm{P}_{2}$.)

The mass of the heat source, then, is equal to $M^{*}$ for all electrical power levels less than $\mathrm{P}_{2}$ and increases in proportion to electrical power for power levels exceeding $\mathrm{P}_{2}$. The specific mass of the radiator, however, has the constant minimum value $\alpha_{\mathrm{r} 1}=\alpha_{\mathrm{r}}\left(\mathrm{x}_{01}, \mathrm{y}\right)$ for $\mathrm{P} \leq \mathrm{P}_{1}$ and increases to the constant value $\alpha_{r 2}=\alpha_{r}\left(x_{02}, y\right)$ for $\mathrm{P} \geq \mathrm{P}_{2}$, as $\mathrm{P}$ increases from $\mathrm{P}_{1}$ to $\mathrm{P}_{2}$.

For the purpose of comparison, we first consider the minimum specific mass at the power level $\mathrm{P}_{2}$ at which it becomes constant with power. The optimum value $\mathrm{x}_{02}$ is determined by the relation

$$
G / g=\frac{h(y)}{x_{02}^{4}}\left[\frac{-4 n_{02}\left(1-\eta_{02}\right)}{x_{02} \eta_{02}^{\prime}}-1\right],
$$

where $\eta_{02}=\left(x_{02}, y\right)$ and $\eta_{02}^{\prime}=\partial \eta /\left.\partial x\right|_{x=x_{02}}$. This relation is obtained by setting the derivative with respect to $\mathrm{x}$ of Eq. (5b) equal to zero.

By using Eq. (6a) to eliminate the quantity $\mathrm{G}$ in Eq. (5b), we obtain the expression

$$
\alpha_{\mathrm{m} 2}=\frac{g h(y)}{x_{02}^{4}}\left[\frac{-4\left(1-\eta_{02}\right)}{x_{02} \eta_{02}^{\prime}}-1\right]
$$

for the minimum specific mass of a system at electrical power levels exceeding $\mathrm{P}_{2}$.

\section{Specific Mass Comparison}

The efficiency of a system may depend not only on ratios of operating temperatures but also on electrical power level, as is the case for turbomachinery; on the absolute value of the heat source temperature, as with thermionic emission; or on material properties, as for thermoelectric conversion. To isolate the dependence on such factors and to characterize the method of power conversion by a single quantity, we write the efficiency as the product $a(x, y)(1-x)$, where the factor $(1-x)$ is the Carnot efficiency, and consequently, $a(x, y) \leq 1$. The attainable fraction of Carnot efficiency, $a(x, y)$, then, is taken as a measure of the merit of a power conversion device. 
For devices based on a Rankine cycle 0 thermoelectric effects, the fraction of Carno efficiency is effectively independent of $x$, and, to a good approximation, waste heat is rejected at a uniform radiating temperature, so that $\mathrm{y}$ and $\mathrm{h}(\mathrm{y})$ are equal to unity. For these systems, then, Eqs. (6a) and (6b) take the form

$$
\mathrm{G} / \mathrm{g}=\frac{4}{\mathrm{x}_{02}^{5}}\left[1-\frac{5 \mathrm{x}_{02}}{4}-\mathrm{a}\left(1-\mathrm{x}_{02}\right)^{2}\right]
$$

and

$$
\alpha_{\mathrm{m} 2}=\frac{4 \mathrm{~g}}{\mathrm{ax}_{02}^{5}}\left[1-\mathrm{a}\left(1-\frac{3 \mathrm{x}_{02}}{4}\right)\right] .
$$

The value of the optimum temperature ratio, $x_{02}$, determined by Eq. (7a) is plotted in Fig. 9 as a function of the ratio G/g for several values of the fraction of Carnot efficiency, a. At $\mathrm{G} / \mathrm{g}=0$, the values of $\mathrm{x}_{02}$ are those that correspond to a minimum specific mass of the radiator; that is, $x_{02}=x_{01}$, at $\mathrm{G} / \mathrm{g}=0$. As the ratio $\mathrm{G} / \mathrm{g}$ increases, which implies that the mass of the heat source becomes an increasingly larger fraction of the system mass, the optimum temperature ratio decreases in order to attain a larger Carnot efficiency, which in turn acts to reduce the mass of the heat source at the expense of a lesser increase in radiator mass.

For thermionic conversion, however, the diode efficiency for a given emitter, or heat source, temperature does not decrease monotonically as the collector, or radiator, temperature increases. Rather, the efficiency increases to a maximum value $\mathrm{C}$ at some collector-to-emitter temperature ratio $x_{m}$ and then, to a first approximation, decreases linearly to zero as the collectorto-emitter temperature ratio approaches unity. ${ }^{*}$ Thus, the fraction of Carnot efficiency is effectively constant for $\mathrm{x} \geq \mathrm{x}_{\mathrm{m}}$ and is given by $a=C /\left(1-x_{m}\right)$. Consequently, the optimum temperature ratio for a thermionic system cannot be less than $x_{m}$, and Eqs. (7a) and $(7 \mathrm{~b})$ do not apply for $\mathrm{x}_{02}<\mathrm{x}_{\mathrm{m}}$. In this instance, the minimum specific mass $\alpha_{\mathrm{m} 2}$ for a thermionic system is determined from Eq. (5b) with $x=x_{m}, y=1$, and $\eta=C$.

For an ideal ${ }^{\dagger}$ Brayton cycle, the fraction of Carnot efficiency is given by

${ }^{*} \mathrm{~A}$ value of $\mathrm{x}_{\mathrm{m}}=0.55$ is consistent with the experimental date of Blue and Ingold 17 and Wilson and Lawrence, 18 whereas a value of $x_{m}=0.67$ is inferred from the data of Leonard. 19

${ }^{+}$For simplicity, we consider here only an ideal cycle, in which case regenerative heating has no influence on specific mass.

$$
a(x, y)=\frac{1-x / y}{1-x} \text {, with } x / y<1,
$$

where $\mathrm{y}$ is the ratio of the compressor inlet temperature to the turbine outlet temperature, and $\mathrm{x}$ is the ratio of the compressor inlet temperature to the turbine inlet, or heat source, temperature. Equations (6a) and $(6 \mathrm{~b})$ then take the form

$$
G / g=\frac{4 g h(y)}{x_{02}^{4}}\left(\frac{3}{4}-\frac{x_{02}}{y}\right)
$$

and

$$
\alpha_{\mathrm{m} 2}=\frac{3 \mathrm{gh}(\mathrm{y})}{\mathrm{x}_{02}^{4}}
$$

where $h(y)=(y / 3)\left(1+y+y^{2}\right)$ for a two-loop system in which waste heat is radiated directly from the gaseous working fluid at a nonuniform temperature, and $h(y)=1$ for a three-loop system in which an intermediate heat exchanger is used to transfer the waste heat from the gaseous working fluid to a condensing radiator that radiates at a nearly uniform temperature.

The value of $\mathrm{x}_{02} / \mathrm{y}$ as determined by Eq. (9a) is shown in Fig. 10 as a function of the ratio $\mathrm{G} / \mathrm{g}$, for several values of $\mathrm{y}$. The dashed curves correspond to a two-loop system, the solid curves to a three-loop system. In both cases, a minimum specific mass of the radiator is attained for $\mathrm{x}_{02} / \mathrm{y}=3 / 4$, which corresponds to an efficiency of $25 \%$. For $\mathrm{G} / \mathrm{g}>0$, the ratio $\mathrm{x}_{02} / \mathrm{y}$ is always less than $3 / 4$ and approaches the value $3 / 4$ as y becomes small. Consequently, the fraction of Carnot efficiency for an ideal cycle, as given by Eq. (8), always exceeds $1 / 4$ at the conditions for a minimum specific mass.

Equations (7) and (9), then, provide a basis for uniform comparison of the minimum specific mass of the four system concepts. The minimum specific mass of Rankine-cycle and thermoelectric systems, as determined by Eq. (7), is shown (in units of the quantity g) as a function of the fraction of Carnot efficiency by the solid curves in Fig. 11, for three values of the ratio $\mathrm{G} / \mathrm{g}$. The two groups of dashed curves in Fig. 11 delineate the minimum specific mass, as determined by Eq. (9), for a two-loop and a three-loop Brayton-cycle system. The minimum specific mass of a thermionic system is given by the solid curves in Fig. 11 provided the optimum value $\mathrm{x}_{02}$ given in Fig. 9 is greater than $\mathrm{x}_{\mathrm{m}}$.

As is evident in Fig. 11, the minimum specific mass of a system is most sensitive to variations in the fraction of Carnot efficiency. For a heat source requiring a 
massive shield, which corresponds to a large value of $\mathrm{G}$ and hence of the ratio $\mathrm{G} / \mathrm{g}$, mode ate variations in shield mass do not appk ciably change the minimum specific mass. Similarly, as the heat source temperature increases, which decreases the value of $g$ and hence increases the ratio G/g, the minimum specific mass approaches a limiting value given by G/a. Even for a massive heat source, however, temperatures of the order of $2000^{\circ} \mathrm{K}$ are required to approach this limit.

To make a specific comparison of the four system concepts, we consider the heat source of each system to consist of a $U^{235}$. fueled fast reactor, as described earlier under REACTOR CONCEPT, and a shadow shield, of the design described in the section SHIELDING, with a half-angle of $18^{\circ}$-which corresponds approximately to that used in the MORL study. 2 For a five-year lifetime and a thermal power level less than 1.4 MW, then, the mass of the reactor is approximately $250 \mathrm{~kg}$, and the mass of the shadow shield is about $2550 \mathrm{~kg}$, as determined from Fig. 7. Thus, the quantity $\mathrm{G}$ that characterizes the heat source is equal to $2 \mathrm{~g} / \mathrm{W}$. We further suppose that the radiator of each system has an effective mass per unit area of $2 \mathrm{~g} / \mathrm{cm}^{2}$, which is a representative value. 20

On this basis, a comparison of the minimum specific masses and associated radiator specific masses $\alpha_{\mathrm{r} 2}$ is made in Table III for a low and a high value of the fraction of Carnot efficiency of each system. A heat source temperature of $1500^{\circ} \mathrm{K}$ is taken for thermionic conversion and the Rankine and Brayton cycles, and $1200^{\circ} \mathrm{K}$ is considered to be the maximum operating temperature for proven thermoelectric materials - in particular, silicon-germanium. A temperature of $1800^{\circ} \mathrm{K}$ is also considered for thermionic conversion to indicate its potential at higher temperatures.

Systems based on a Rankine cycle potentially can achieve the greatest fraction of Carnot efficiency. For an alkali metal working fluid operating in a Rankine cycle at heat source temperatures of the order of $1500^{\circ} \mathrm{K}$, approximately $95 \%$ of Carnot efficiency can be achieved.21 Because of entropy increases in the turbine, pump, and piping, however, the actual efficiency of a Rankine-cycle system is limited to about $60 \%$ of Carnot efficiency in the power range of 100 to $500 \mathrm{kWe} .22$

The fraction of Carnot efficiency of an ideal Brayton cycle depends directly on the temperature ratio $\mathrm{y}$, which is related to the electrical power level, $P$, and the mass flow rate of the gaseous working fluid, $\dot{m}$, by

$$
\mathrm{y}=1-\mathrm{P} / \eta \dot{\mathrm{m}} \mathrm{c}_{\mathrm{p}} \mathrm{T}_{\mathrm{h}},
$$

where $c_{p}$ is the isobaric specific heat of the working fluid. For a three-loop system values of $\mathrm{y}$ between 0.4 and 0.5 are consistent with the studies of AiResearch, ${ }^{6,2} 3$ so that for a two-loop system values of 0.2 to 0.3 are appropriate because the added pressure drop associated with a gas radiator further limits the mass flow rate. The corresponding values of the fraction of Carnot efficiency, in each case, are given in Table III.

\section{TABLE III}

Comparison of Minimum Specific Masses for $\mathrm{G}-2 \mathrm{~g} / \mathrm{W}$ and $\rho_{\mathrm{e}}=2 \mathrm{~g} / \mathrm{cm}^{2}$.

\begin{tabular}{|c|c|c|c|c|c|c|c|c|c|}
\hline $\begin{array}{l}\text { Conversion } \\
\text { Method }\end{array}$ & $\begin{array}{c}\mathrm{T}_{\mathrm{h}} \\
\left({ }^{\circ} \mathrm{K}\right)\end{array}$ & $\begin{array}{c}g \\
(g / W)\end{array}$ & $\begin{array}{l}\mathrm{G} / \mathrm{g} \\
\text { ratio }\end{array}$ & $\mathrm{a}$ & $\mathrm{x}_{02}$ & $n_{02}$ & $\underset{(\mathrm{g} / \mathrm{W})}{\alpha_{\mathrm{r} 2}}$ & $\frac{\operatorname{m}_{\mathrm{m} 2}}{(\mathrm{~g} / \mathrm{W})}$ & $\begin{array}{c}\mathrm{P}_{2} \\
(\mathrm{kWe})\end{array}$ \\
\hline Carnot cycle & 1500 & 0.07 & 29 & 1.0 & 0.453 & 0.547 & 1.4 & 5 & 765 \\
\hline Rankine cycle & 1500 & 0.07 & 29 & $\begin{array}{l}0.4 \\
0.6\end{array}$ & $\begin{array}{l}0.512 \\
0.50\end{array}$ & $\begin{array}{l}0.195 \\
0.30\end{array}$ & $\begin{array}{l}4 \\
3\end{array}$ & $\begin{array}{l}14 \\
19\end{array}$ & $\begin{array}{l}270 \\
420\end{array}$ \\
\hline $\begin{array}{l}\text { Brayton cycle: } \\
\text { two-loop } \\
\text { three-loop }\end{array}$ & $\begin{array}{l}1500 \\
1500\end{array}$ & $\begin{array}{l}0.07 \\
0.07\end{array}$ & $\begin{array}{l}29 \\
29\end{array}$ & $\begin{array}{l}0.333 \\
0.40 \\
0.410 \\
0.510\end{array}$ & $\begin{array}{l}0.143 \\
0.204 \\
0.282 \\
0.331\end{array}$ & $\begin{array}{l}0.285 \\
0.32 \\
0.295 \\
0.337\end{array}$ & $\begin{array}{l}35 \\
12 \\
26 \\
11\end{array}$ & $\begin{array}{l}42 \\
18 \\
33 \\
17\end{array}$ & $\begin{array}{l}400 \\
448 \\
413 \\
472\end{array}$ \\
\hline Thermoelectric & 1200 & 0.17 & 12 & $\begin{array}{l}0.1 \\
0.2\end{array}$ & $\begin{array}{l}0.603 \\
0.597 \\
\mathrm{x}_{\mathrm{m}}\end{array}$ & $\begin{array}{c}0.04 \\
0.08 \\
\mathrm{C}\end{array}$ & $\begin{array}{l}30 \\
14\end{array}$ & $\begin{array}{l}80 \\
39\end{array}$ & $\begin{array}{r}56 \\
113\end{array}$ \\
\hline Thermionic & $\begin{array}{l}1500 \\
1800\end{array}$ & $\begin{array}{l}0.07 \\
0.034\end{array}$ & $\begin{array}{l}29 \\
60\end{array}$ & $\begin{array}{l}0.067 \\
0.240 \\
0.25 \\
0.48\end{array}$ & $\begin{array}{l}0.55 \\
0.67 \\
0.55 \\
0.67\end{array}$ & $\begin{array}{l}0.03 \\
0.08 \\
0.11 \\
0.16\end{array}$ & $\begin{array}{r}24 \\
4 \\
3 \\
0.5\end{array}$ & $\begin{array}{l}91 \\
29 \\
21 \\
13\end{array}$ & $\begin{array}{r}42 \\
112 \\
155 \\
224\end{array}$ \\
\hline
\end{tabular}


The product of the figure-of-merit and operating temperature of known thermoelectric materials has a maximum value of about one, based on present experimental evidence. 24 Consequently, fractions of Carnot efficiency greater than about 0.2 cannot be achieved.

Estimates of the effect of the collector temperature on the efficiency of a thermionic diode vary widely, and the efficiency increases rapidly with the temperature of the emitter. As reported in Ref. 19, a maximum efficiency is attained at a collector temperature 0.667 of the emitter temperature and is about $8 \%$ at $1500^{\circ} \mathrm{K}$ and $16 \%$ at $1800^{\circ} \mathrm{K}$. Similarly, as reported in Ref. 17, a maximum efficiency is attained at a collector temperature 0.55 of the emitter temperature and is about $3 \%$ at $1500^{\circ} \mathrm{K}$ and $11 \%$ at $1800^{\circ} \mathrm{K}$. Because the ratio $\mathrm{G} / \mathrm{g}$ is large in each case in Table III, $\mathrm{x}_{02}<\mathrm{x}_{\mathrm{m}}$ and the optimum temperature ratios are equal to $\mathrm{x}_{\mathrm{m}}$; that is, 0.55 or 0.67 .

A comparison of the minimum specific masses throughout the power range of 50 to $1000 \mathrm{kWe}$ is made in Fig. 12 for the larger values of the fraction of Carnot efficiency of each conversion method given in Table III. As is evident in Fig. 12, the specific masses do not differ appreciably for power levels less than $100 \mathrm{kWe}$, although those corresponding to thermoelectric and Brayton-cycle systems are somewhat higher because of their larger radiator mass. Along the sloping portions of the curves, the difference in specific mass between systems is due to a difference in radiator mass alone. Because of the massive shield, then, a sharp distinction in specific mass is not evident until the power levels at which the mass of the heat source becomes inversely proportional to efficiency are attained.

\section{Other Considerations}

The results shown in Fig. 12 indicate that each of the four system concepts can potentially provide a specific mass less than $50 \mathrm{~g} / \mathrm{W}$ at power levels above $100 \mathrm{kWe}$. The ability to achieve this potential, however, is contingent upon the solution of fundamental development problems associated with each concept. Furthermore, other important requirements such as reliability, the potential to achieve higher efficiencies and temperatures, and the ability to serve as a power source for a variety of missions must be considered in appraising the merits of a space power system. Since enough information is not yet available to make an unequivocal evaluation, we briefly recount the characteristics of each concept and suggest a tentative path for development.

Rankine-cycle systems: Perhaps the most severe limitation on the performance
Rankine-cycle systems is that of moisture rmation in the turbine. Liquid entrained in vapor not only degrades turbine efficiency but also adversely affects mechanical reliability because it erodes the turbine blades. The turbine materials must also withstand the dynamic stress levels at high temperatures for long periods of time and resist the corrosive effect of the working fluid. Furthermore, dependable bearing lubrication must be developed. Although such problems are not insurmountable, their solution requires the development of suitable alloys, precise design and fabrication, extensive testing facilities, and time. Thus, although the potential performance of Ranking-cycle systems is great, the extent to which it can be realized is not yet clear.

Brayton-cycle systems: Although the use of an inert gaseous working fluid greatly reduces the problem of turbine development, the development of superior alloys to withstand the dynamic loads for long times at high temperatures is still required. The extensive experience gained in manufacturing high-temperature gas turbines for aircraft, however, provides reasonable assurance that high-temperature, reliable, long-lived gas turbines could be developed within a decade. ${ }^{23}$ The initial success in the development of gas bearings further supports this contention. Nevertheless, reliable operation of a closedcycle gas turbine at temperatures of the order of $1500^{\circ} \mathrm{K}$ for extended periods $(10,000-$ $20,000 \mathrm{hr}$ ) without maintenance has yet to be demonstrated.

The use of a gaseous working fluid, however, does present two disadvantages in terms of system performance. First, the low compressor-inlet temperature required to attain a high efficiency results in a large radiator area. Second, a large fraction of the turbine work is needed to drive the compressor so that the cycle efficiency is sensitive to pressure losses.

Because pressure losses limit the mass flow rate, the temperature differentials over which heat is absorbed and rejected must increase at high power levels. Consequently, the ratio of the compressor inlet to turbine outlet temperature, $y$, must decrease for a given temperature of the heat source. Therefore, the fraction of Carnot efficiency also decreases, and the radiator specific mass increases very rapidly at high power levels. Pressure losses, then, limit the performance of Brayton-cycle systems at high power levels.

Thermoelectric systems: At present, thermoelectric conversion appears to be in the most advanced state of development. Thermoelectric elements of silicon-germanium 
have been operated at the RCA Laboratory in Harrison, New Jersey without failure or appreciable degradation for periods up to five years at temperatures of $700^{\circ} \mathrm{K}$, and for extended periods at $1200^{\circ} \mathrm{K}$. Fabrication techniques are well developed, and a space power system, SNAP 10A, using SiGe thermoelements as a means of energy conversion has operated in earth orbit for 43 days and in ground tests for 1 year.

Unfortunately, however, the figures-ofmerit $Z$ of known materials have values such that the product $Z \mathrm{~T}_{\mathrm{h}}$ is invariably less than 1.5. Consequently, the fraction of Carnot efficiency that can be attained is limited to $\sim 20 \%$. This places a fundamental limit on the performance of thermoelectric systems.

The highest operating temperature yet attained for a thermoelectric device is $1500^{\circ} \mathrm{K}$. A p-type boron-carbide material ${ }^{*}$ was used in a device that operated at a hot junction temperature of $1500^{\circ} \mathrm{K}$ and a cold junction temperature of $1000^{\circ} \mathrm{K}$ for 2556 hours at the Dayton Laboratory of the Monsanto Research Corporation. 25 An n-type material capable of operating at this temperature, however, was not successfully developed, so that thermal conduction losses through the metallic n-leg of the thermocouple resulted in unacceptably low efficiencies.

Presently, the practical limit on the hot junction temperature is $\sim 1200^{\circ} \mathrm{K}$. At this temperature, efficiencies approaching $20 \%$ of Carnot efficiency can be attained with SiGe thermoelements developed by RCA. Other proven materials such as PbTe are limited to temperatures below $900^{\circ} \mathrm{K}$, which is too low to be considered with a fast reactor heat source.

Thermionic systems: Because the development of thermionic diodes for the purpose of energy conversion is still in its beginning stages, their performance limits are not yet established. Although the need for high emitter temperature that can be allowed without an unacceptable degradation in performance has not yet been ascertained. From the results of Table III, however, it appears that emitter temperatures of $1800^{\circ} \mathrm{K}$ or greater are required to assure an acceptable performance.

The emphasis in diode development is currently directed toward a thermionic system in which the diodes form an integral part of the nuclear fuel elements in the core. The successful development of the in-core concept requires, first of all, that precise

This material is designated as MCC50 in Ref. 25. dimensional stability of the diodes be maintained at high temperatures $\left(2000^{\circ} \mathrm{K}\right)$ under the stresses produced by fuel swelling. Second, the effects produced by the nuclear radiation environment, such as contamination of the interelectrode plasma and embrittlement of the emitter or collector materials, must be ascertained and taken into account. Finally, the large number of diodes required must be carefully assembled and interconnected in such a way that the conditions required both for operation of the diodes and for a critical reactor are met. Again, the solution of such fundamental development problems requires extensive testing facilities and time.

Little attention has yet been given to a system in which the diodes are located outside the core and heat is transferred from the core to the emitter surfaces by heatpipes. 26 This concept, in effect, substitutes the development of a heat-pipe-cooled reactor for the more difficult development problems associated with placing the diodes in the core. In this way the diodes and reactor can be developed and tested independently and simultaneously. First comparisons indicate little difference in performance between the two concepts, although no detailed studies for secondary power applications have been made.

Because dynamic stresses are not coupled with high temperatures in a thermionic system, in contrast to a Rankine- or Braytoncycle system, high temperatures can be more readily achieved, so that it is thought that the highest performance can be realized for a thermionic system.

\section{CONCLUSION}

On the basis of the preceding comparative study, we suggest a tentative path for the development of fast reactor systems for secondary space power. First, thermoelectric and Brayton-cycle systems show the most promise for successful development within the next decade. Below a power level of $100 \mathrm{kWe}$, the specific mass and radiator area required per unit electrical power of each system are, for all practical purposes, equivalent, as is evident in Fig. 12. At power levels exceeding $100 \mathrm{kWe}$, however, Brayton-cycle systems have superior performance because of their greater efficiency, Nevertheless, reliable operation throughout a five-year lifetime would require a replacement schedule for the turbomachinery, whereas thermoelectric systems can potentially be developed to operate reliably for five years without replacement or maintenance. For missions in the early $1980^{\prime} \mathrm{s}$, then, emphasis should be placed on the development of thermoelectric and Brayton-cycle systems. More 
detailed and extensive studies with resp to specific mission requirements and po system design are required, however, belde a final appraisal and choice between them can be made.

Second, Rankine-cycle and thermionic systems alone have the potential for the very high performance required at power levels approaching $1 \mathrm{MWe}$, which may be required in the mid to late $1980^{\prime} \mathrm{s}$. Thermoelectric systems are limited because no more than about $20 \%$ of Carnot efficiency can be attained with known semiconductor materials. Braytoncycle systems are limited by the large radiating surface area required because of limitations imposed on the mass flow rate of the working fluid by pressure losses.

The difference in specific mass and radiator area between Rankine-cycle and thermionic systems is negligible, although the latter requires a higher operating temperature $\left(1800^{\circ} \mathrm{K}\right)$ for equivalent performance. Because dynamic stresses are not coupled with the higher temperatures in thermionic systems, however, their potential for realizing reliable operation over an extended lifetime is considered to be greater than that for Rankine-cycle systems. Thus, in light of the fundamental development problems associated with these two systems, their development is more appropriately directed toward missions planned for the late $1980^{\prime} \mathrm{s}$ and beyond that required high power levels and very high performance. Again, more extensive studies and component tests are necessary to make a final evaluation.

Nonetheless, the reactor concept described herein is largely independent of the method of power conversion, and initial design studies can proceed on the basis of defining the smallest cores and highest power densities attainable. In this respect, an appraisal of the relative merits of convectively cooled and heat-pipe cooled reactors is required. Although both concepts are compatible with each of the four methods of power conversion, the heat pipe has the remarkable property of being able to transport large heat fluxes at nearly constant temperature, which is a decided advantage particularly for out-of-core thermionic systems.

Finally, we conclude that very small, precisely designed, fast reactors based on UN fuel, W-25Re-30Mo structural material, and lithium coolant can provide the hightemperature, long-lived, versatile heat source required for secondary power requirements in the $1980^{\prime} \mathrm{s}$. A cylindrical core $26 \mathrm{~cm}$ in both diameter and length and fueled with $\mathrm{U}^{2} 35$ can provide 1.4 MW of thermal power for five years. Control can be provided by movable $\mathrm{BeO}$ reflectors having a thickness of 2 to $3 \mathrm{~cm}$ for a shadowshielded reactor, or by rotatable tungsten drums backed with $3 \mathrm{~cm}$ of a boron-10 compound for a $4 \pi$-shielded reactor. Proper enrichment of the lithium coolant with the strongly absorbing isotope $\mathrm{Li}^{6}$ affords a unique means of assuring a subcritical state prior to orbital startup of the reactor.

\section{REFERENCES}

${ }^{1}$ Joint Committee on Atomic Energy, Congress of the United States, AEC Authorizing Legislation FY 1968, Pt. 3, Feb.-Mar. 1967, p. 1651 .

${ }^{2}$ J. D. Gylfe, "Reactor and shield subsystems for MORL and lunar base power plants," IECEC Conf. Proc., pp. 699-609, August 1967.

${ }^{3}$ B. J. Tharpe and A. J. Aiker, "Nuclear electric power for manned space stations," AIAA Paper No. 64-713, September 1964.

${ }^{4}$ W. N. Gardner, "MORL design studies the significant results," Astronautics and Aeronautics, pp. 34-46, March 1967.

${ }^{5}$ R. L. Gervais and V. D. Kirkland, "Reactor power systems for manned earth orbital applications," IECEC Conf. Proc., pp. 727738, August 1967.

${ }^{6}$ A. Pietsch, "Reactor-powered Brayton cycle for large space stations," IECEC Conf. Proc., pp. 65-75, August 1967.

${ }^{7}$ R. L. Gervais and T. F. Plunkett, "Power system design requirements for manned earth orbital commercial applications," Douglas MSSD Paper No. 4406, October 1967.

8 MI. Rosenblum, "Design requirements of a reactor-Rankine power system for a lunarbase mission," IECEC Conf. Proc., pp. 689697, August 1967.

${ }^{9} \mathrm{M}$ Rosenblum, "Design requirements for reactor power systems for lunar exploration," Final Report, Vol. II, Lockheed Missiles and Space Company Report No. LMSC-677879-II, September 1967.

${ }^{10}$ R. I. Vachon, L. H. Wood, and R. N. Seitz, "Space electrical power - quo vadis?" Astronautics and Aeronautics, pp. 58-63, November 1967 .

${ }^{11}$ R. W. Harrison and E. E. Hoffman, "Advanced refractory alloy corrosion loop program," G.E. Quarterly Progress Report No. 10, dated November 5, 1967

${ }^{12}$ J. H. DeVan, B. Fleischer, and A. P. Litman, "Status of program on lithium corrosion of refractory alloys at the Oak Ridge National Laboratory," RDT/SNS Meeting on Materials Development for Space Reactor Power Systems, USAEC, Washington, D.C. April 23-24, 1968. 


\section{3} mowrence Radiation Laboratory, Livermore, "Advanced space nuclear power program," Progress Report No. 6, UCRL-5000467-1, July 25, 1967.

${ }^{14} \mathrm{~V}$. Hampel et al., "Adaptation of ' ZOOM' to small fast systems by means of linearly anisotropic corrections to asymptotic diffusion theory," Lawrence Radiation Laboratory, Livermore, UCRL-70983, February 1968 .

${ }^{15}$ K. M. Case, F. deHoffman, and G. Placzek, "Introduction to the theory of neutron diffusion," Los Alamos Scientific Laboratory, June 1953.

${ }^{16}$ E. T. Pitkin, "Optimum radiation temperature for space power systems," Am. Rocket Soc. J., August 1959, pp. 596-598.

${ }^{17} \mathrm{E}$. Blue and J. H. Ingold, in "Direct energy conversion," G. W. Sutton, Editor, McGraw-Hill, New York, 1966.

18 Wilson and Lawrence, "Advanced energy conversion," Vol. 4, pp. 195-221, 1964.

${ }^{19}$ A. Leonard, "Out-of-pile thermionic space power systems using a gaseous heat transfer fluid," RM-4469-PR, RAND Corporation, September 1965.
${ }^{20}$ R. W. Werner and G. A. Carlson, "Heat pipe radiator for a 50-MW thermal space power plant," Lawrence Radiation Laboratory, Livermore, UCRL-50294, June 30, 1967.

${ }^{21}$ D. D. Mackay, "Design of space power plants," Prentice-Hall, Inc., Englewood Cliffs, New Jersey, pp. 83-94, 1963.

${ }^{22} \mathrm{~J} . \mathrm{H}$. Pitts and M. H. Jester, "Rankine cycle system studies for nuclear space power," Lawrence Radiation Laboratory, Livermore, UCRL-70863, March 1968.$$
23
$$

${ }^{3}$ A. Pietsch, AiResearch Manufacturing Company, personal communication.

${ }^{24}$ R. F. Redemske, "Materials for thermoelectric conversion," Proc. 14th Annual

Power Sources Conf. Red Bank, New Jersey, pp. 4-7, May 1960.

${ }^{25}$ C. M. Henderson, R. G. Ault, E. R. Beever, D. H. Harris, W. H. Hedley, and R. J. Janowiecki, "High temperature thermoelectric research," Tech. Report No. AFAPL-TR-64-135, Wright-Patterson Air Force Base, December 15, 1964.

${ }^{26}$ W. E. Loewe, "Out-of-core thermionic space power," Lawrence Radiation Laboratory, Livermore, UCRL-70816, May 1968. 


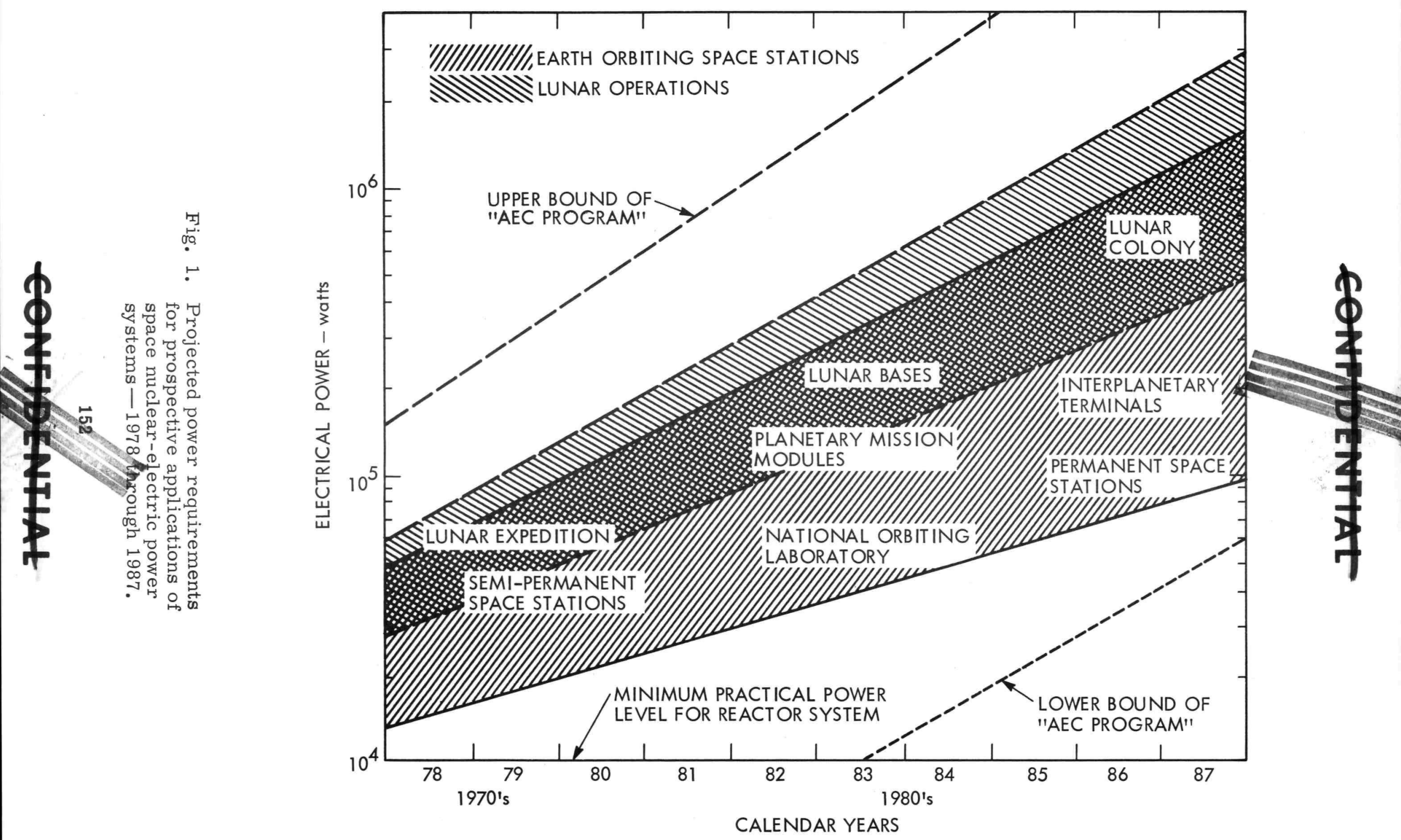




\section{,

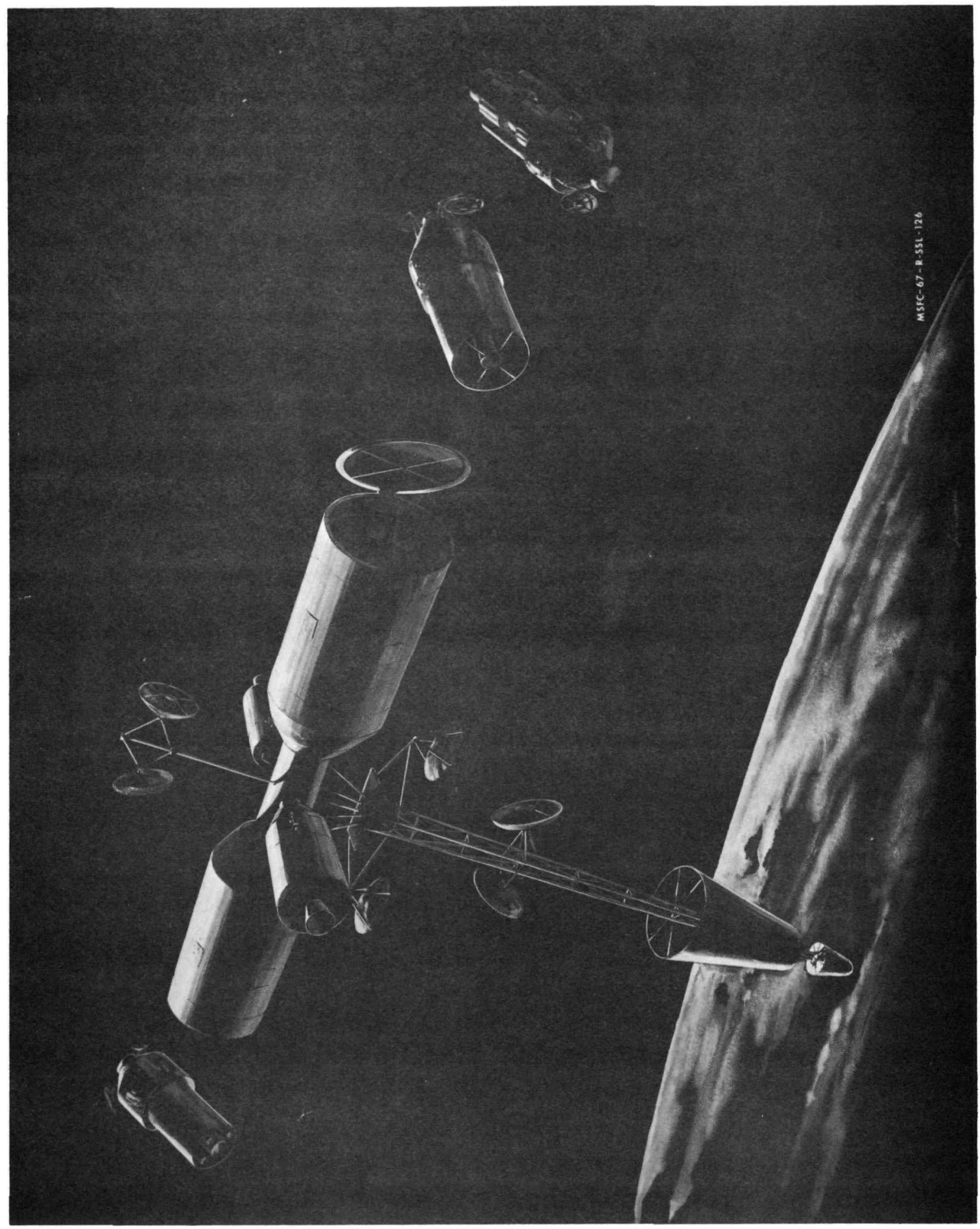

Fig. 2. Semipermanent, multipurpose, earth orbiting space stationearly 1980's (Space Sciences Laboratory, NASA-MSFC). 


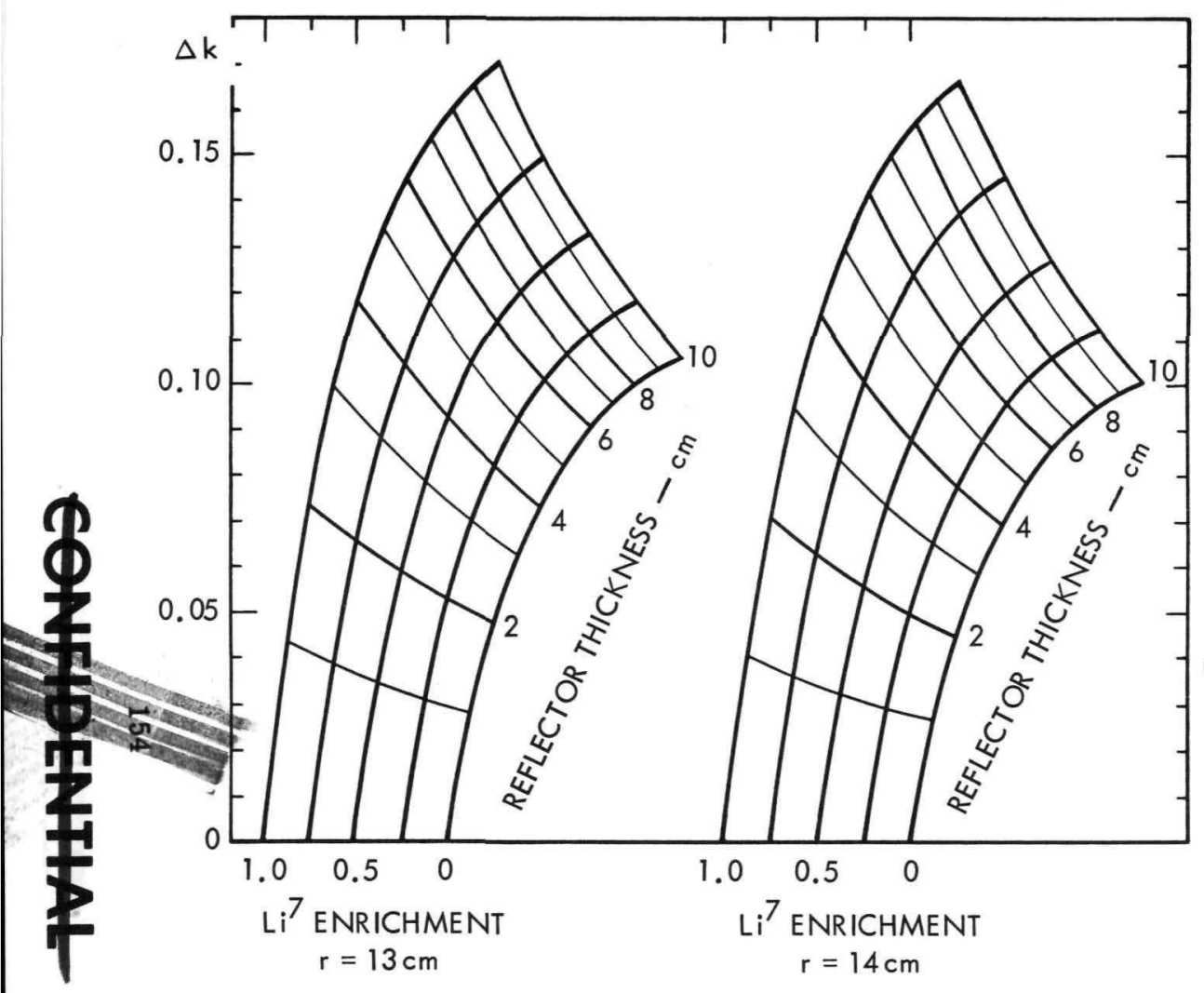

Fig. 4. Reactivity worth of beryllia (BeO) side reflectors as a function of reflector thickness and $\mathrm{Li}^{7}$ enrichment in the coolant, for a core radius of $13 \mathrm{~cm}$ and $14 \mathrm{~cm}$.

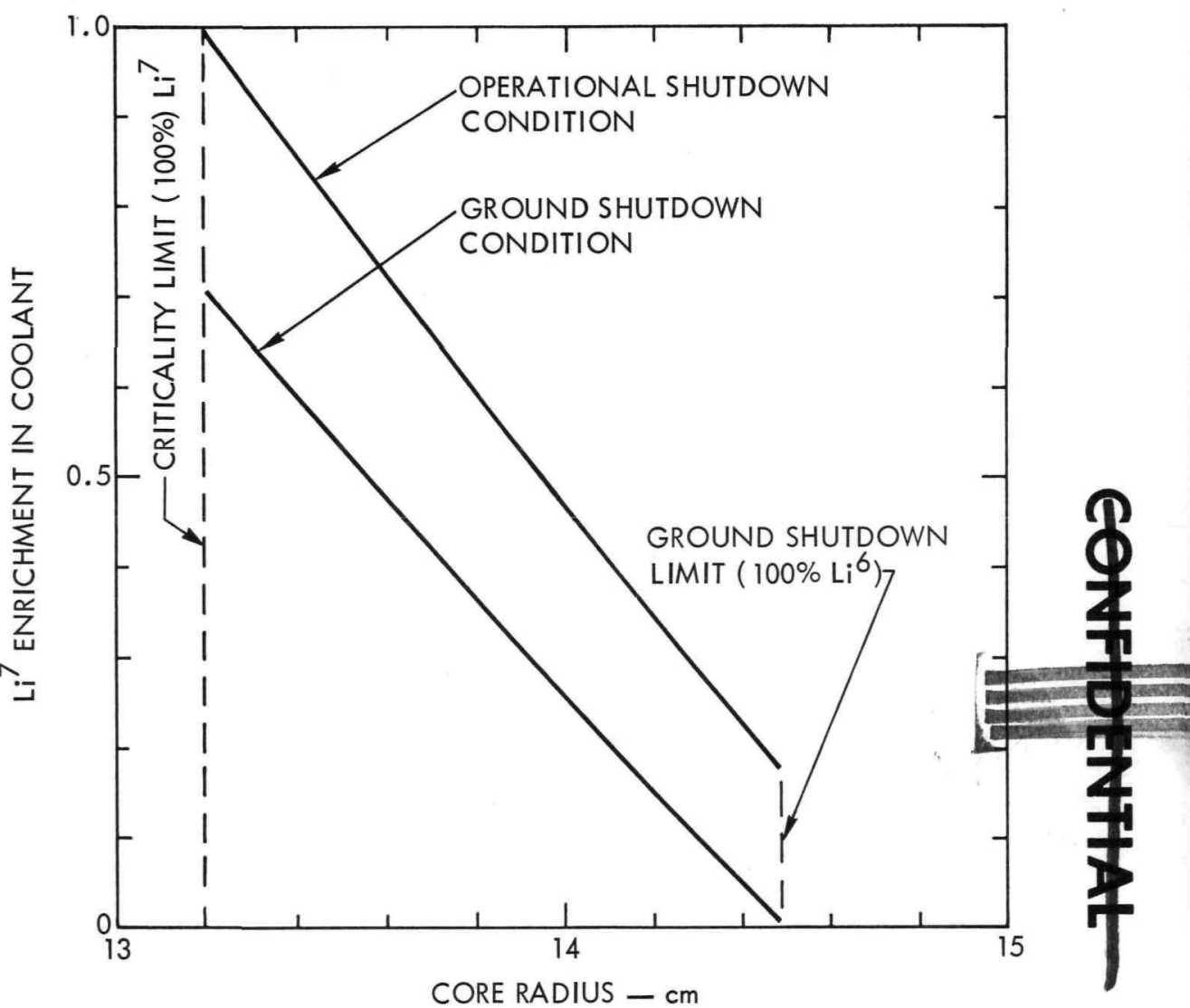

Fig. 3. Enrichment of $\mathrm{Li}^{7}$ in the coolant, as a function of core radius, corresponding to ground and operational shutdown conditions for a $U^{235}$-fueled core having a length-to-diameter ratio of unity and a composition of $65 \mathrm{vol} \%$

fuel, 20 vol $\%$ clad, and 15 vol $\%$ coolant. 


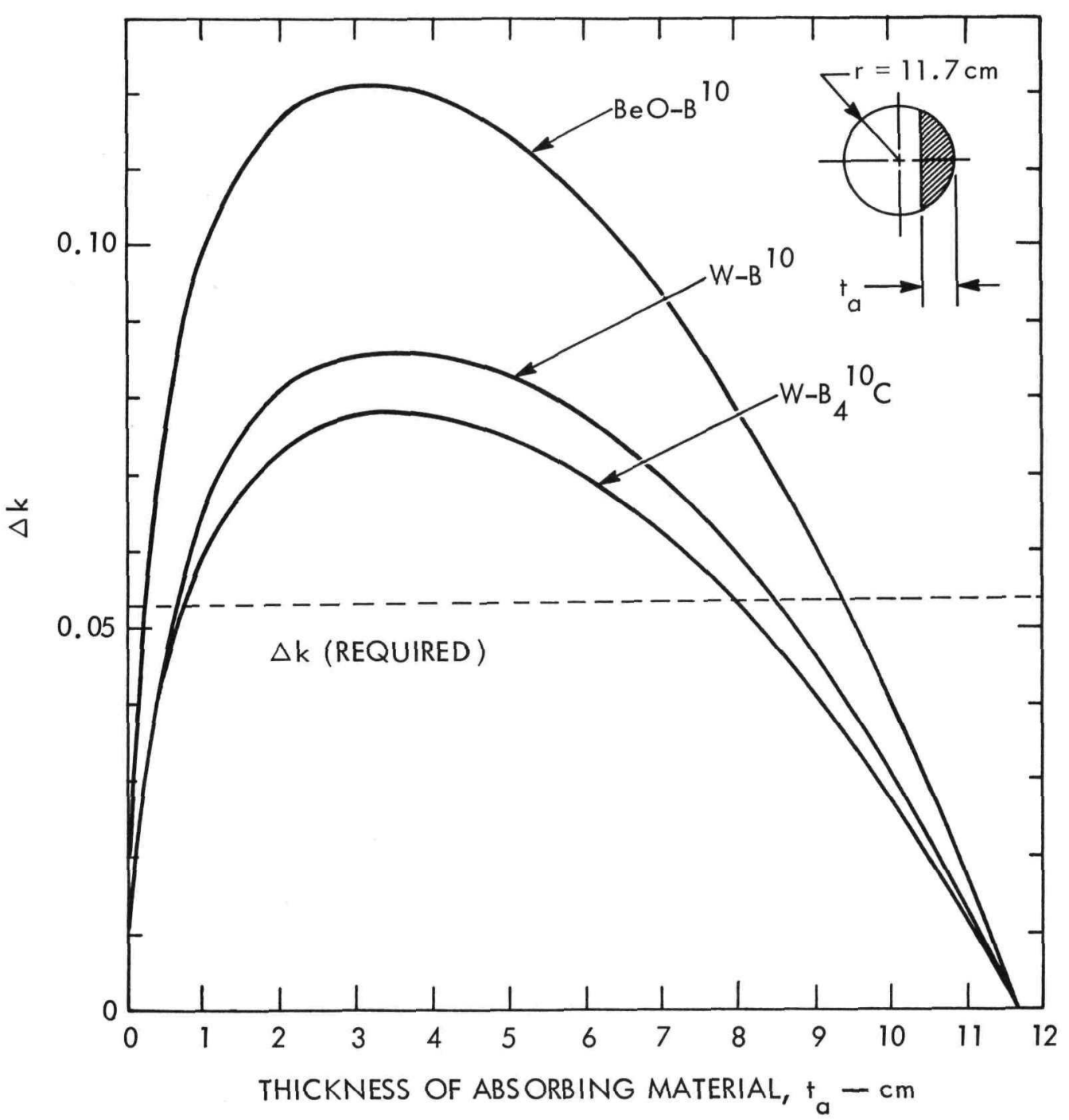

Fig. 5. Reactivity worth associated with complete rotation of twelve control drums, each $11.7 \mathrm{~cm}$ in diameter, placed circumferentially about a $13.2-\mathrm{cm}$-radius core. The reactivity change is shown as a function of the thickness of the absorbing material for three material combinations. 


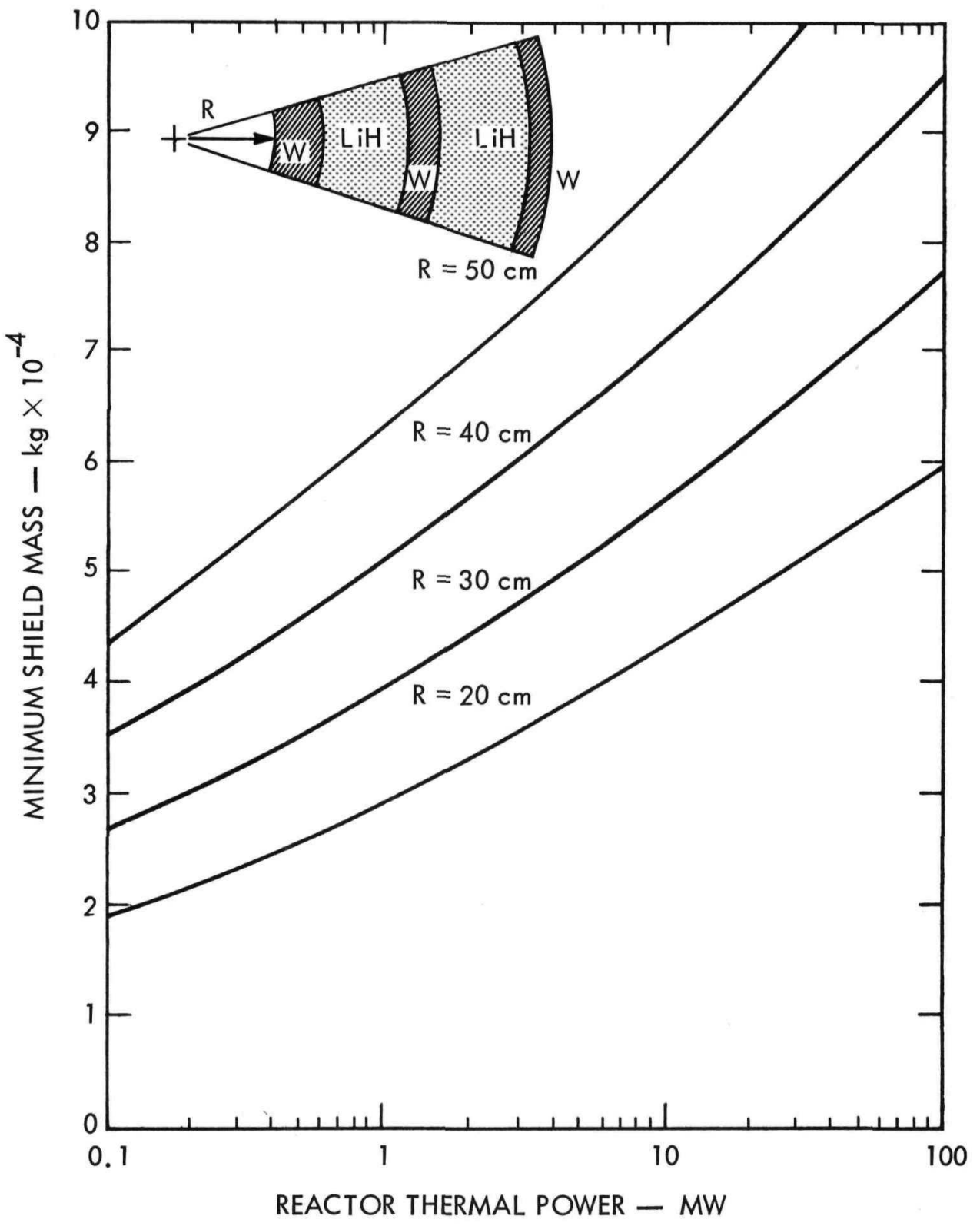

Fig. 6a. Minimum mass of a $4 \pi$ shield in the form of a spherical shell as a function of the thermal power level of the reactor, for four values of the inner radius, $R$, of the shell. 


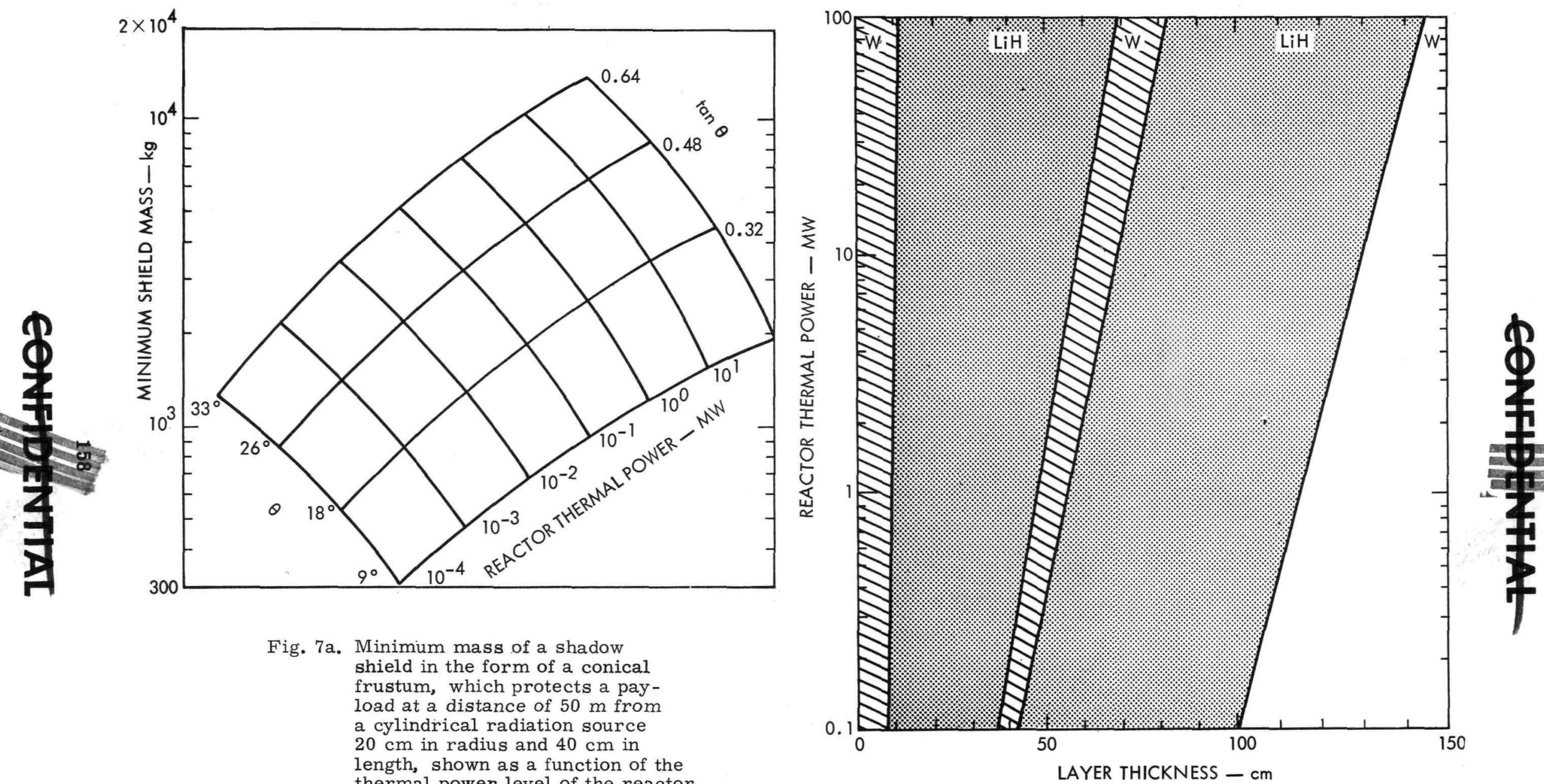

Fig. 7a. Minimum mass of a shadow shield in the form of a conical frustum, which protects a payload at a distance of $50 \mathrm{~m}$ from a cylindrical radiation source $20 \mathrm{~cm}$ in radius and $40 \mathrm{~cm}$ in length, shown as a function of the thermal power level of the reactor and the half-angle $\theta$ of the cone.

Fig. 7b. Thickness of the material layers, as a function of thermal power. of a shadow shield having a minimum mass for a half-angle of $18^{\circ}$, as given in Fig. 7 a. 

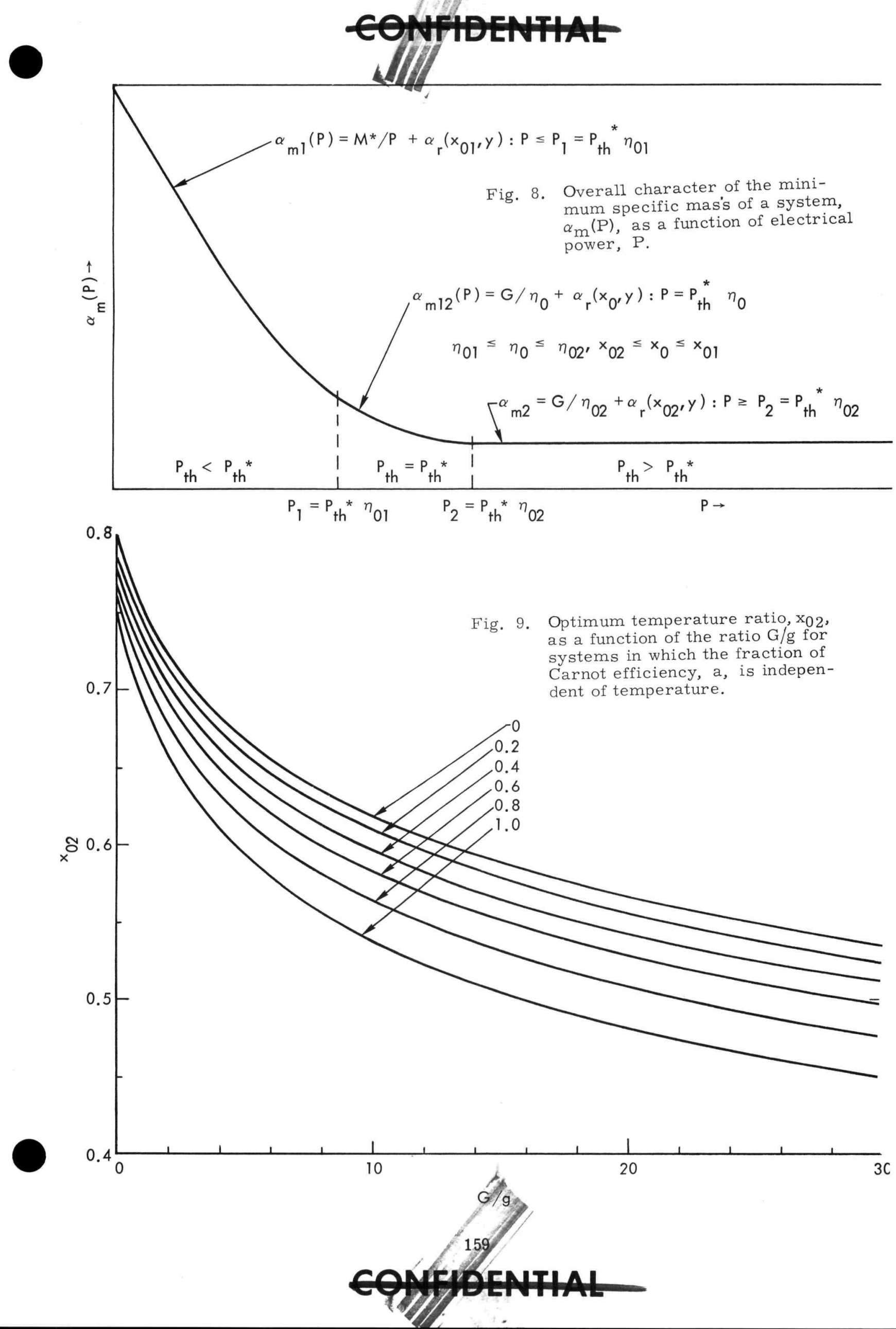


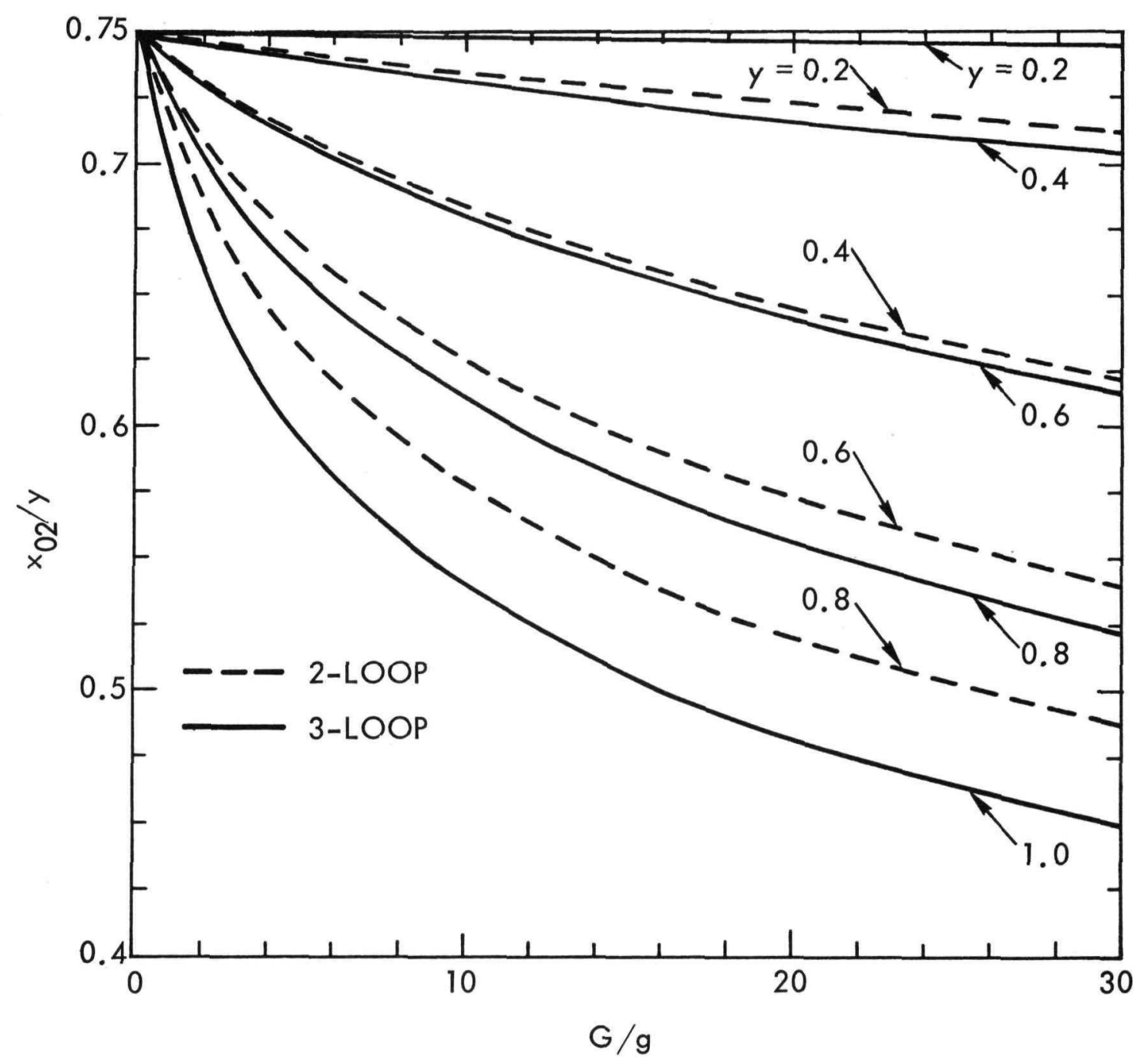

Fig. 10. Optimum temperature ratio, $x_{02} / y$, across the turbine for an ideal Brayton-cycle system operating with a compressor inlet to turbine outlet temperature ratio y. The dashed curves correspond to a two-loop system, and the solid curves to a threeloop system. 


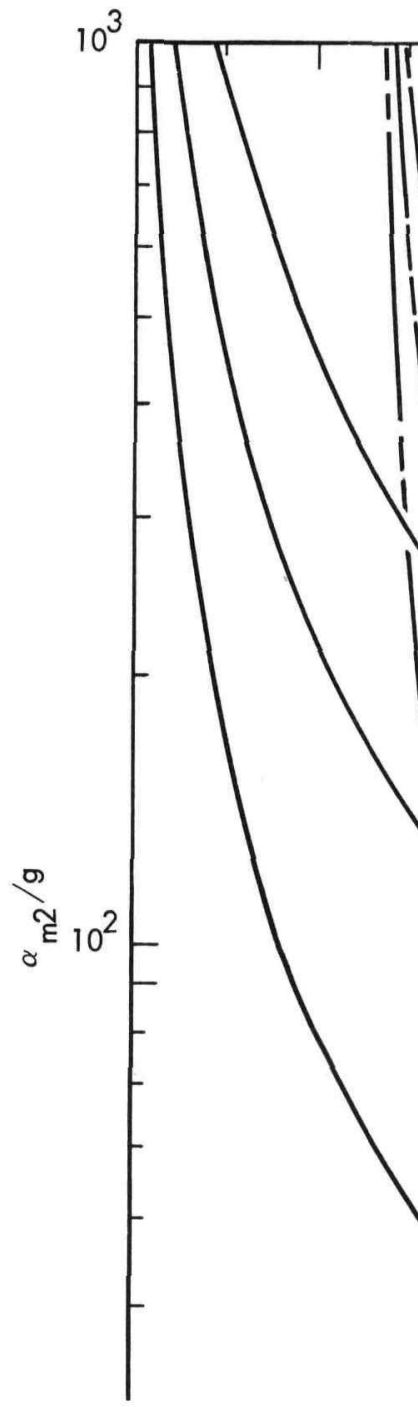

Fig. 11. Minimum specific mass, $\alpha \mathrm{m} 2$, in units of the quantity $g$, as a function of the fraction of Carnot efficiency, a, for three values of the ratio G/g. The solid curves correspond to systems in which the fraction of Carnot efficiency is independent of temperature, and the two groups of dashed curves to two- and three-loop Braytoncycle systems.

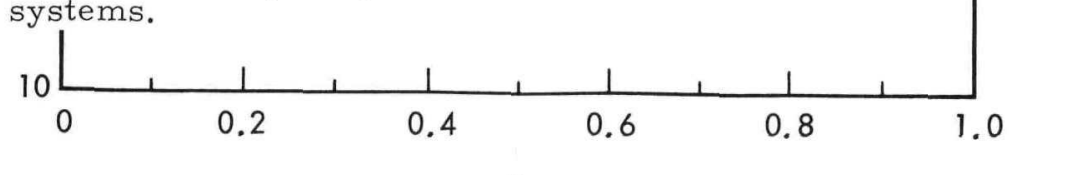




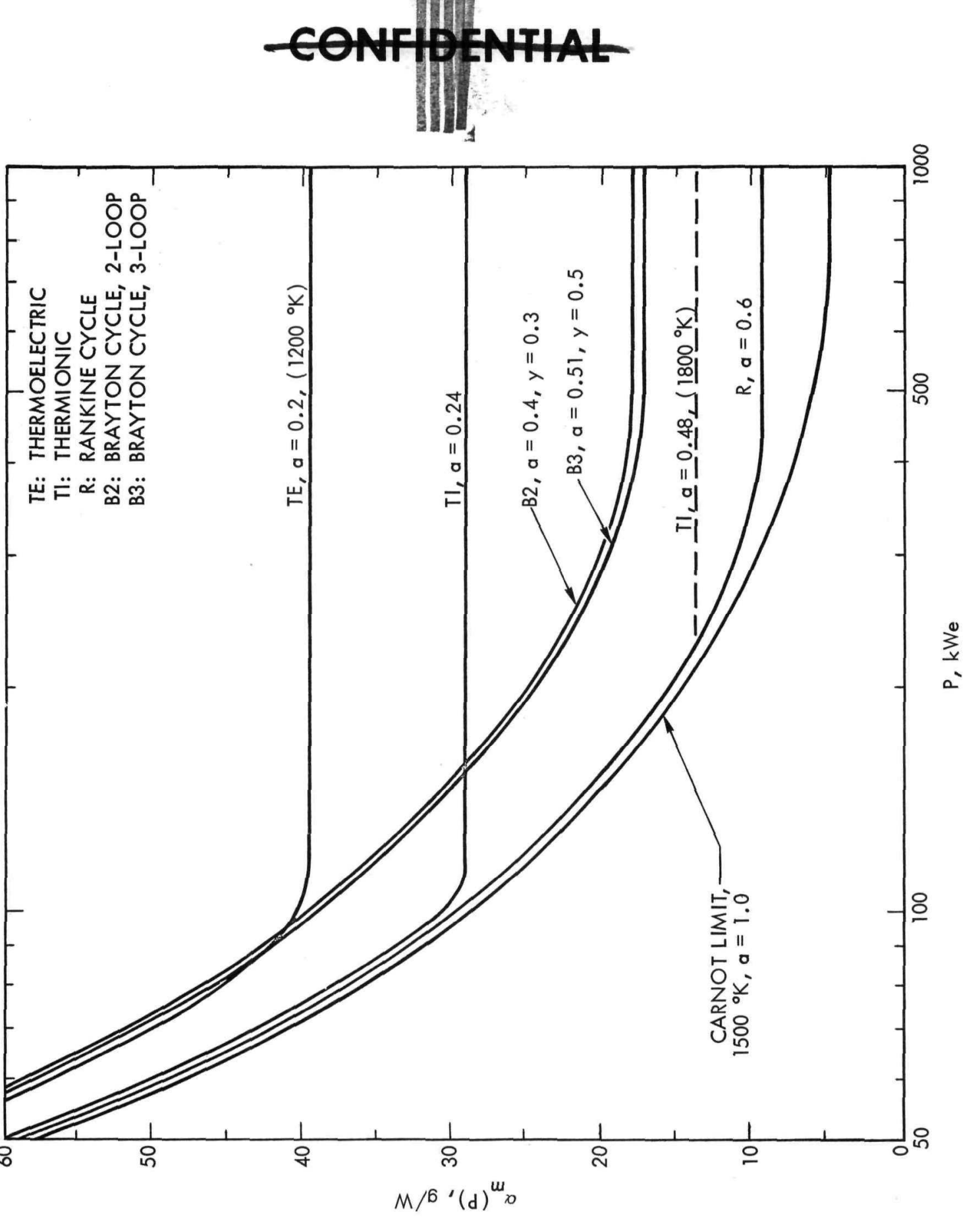

Fig. 12. Comparison of minimum specific masses of Rankine-cycle, Brayton-cycle, thermoelectric, and thermionic systems throughout the electrical power range of 50 to $1000 \mathrm{kWe}$, for the larger values of the fraction of Carnot efficiency, a, given in Table III. The heat source temperature is $1500^{\circ} \mathrm{K}$ except as noted. 


\title{
A 15 KWE MODULAR THERMIONIC THERMAL $\underline{\text { REACTOR (MATTRAC) }}$
}

\author{
Marshall B. Eck \\ Hittman Associates, Inc. \\ Columbia, Maryland
}

\section{SUMMARY}

The $15 \mathrm{Kwe}$ Modular Advanced Thermionic Thermal $\overline{R e A C t o r}$ (MATTRA C) system is configured from 18 basic modules of the general type shown in Figure 1 and discussed in detail in Ref. 1. This system has an unshielded weight of 1482 pounds. The reactor power density and external dimensions approximate those of the SNAP-8 system. Therefore, shield weights will approximate those required for SNAP-8 mission configurations. Although the reference system design power level is $15 \mathrm{Kwe}$, the basic module could be applied in systems up to $100 \mathrm{Kwe}$. At power levels above $100 \mathrm{Kwe}$, the relatively low power density of the system tends to lead to excessive shield weights.

\section{INTRODUCTION}

Early in 1965, Hittman Associates' personnel began a search for an energy conversion system which would be adaptable to a broad range of power levels. From these early studies it became apparent that nuclear systems which could cover the power range from hundreds of watts to hundreds of kilowatts should be synthesized from a varying number of energy conversion modules.

Further investigation showed that the basic module should be capable of operation over a wide range of heat source power densities. This flexibility was necessary to allow the energy conversion modules to be configured into a reactor when they are loaded with a fissile fuel and to be used as individual power supplies when loaded with an isotopic fuel. The problem of designing for wide variations in power density was solved by using heat pipe coupling between the heat source and the energy conversion device. The heat pipe also accommodates variations in heat generation rate which occur in a reactor due to axial and radial power distribution.

The thermionic diode was chosen as the most desirable energy conversion device because of its relatively good efficiency and high waste heat rejection temperature. High waste heat rejection temperature is very important in minimizing system size and weight.

Figure 1 shows how an energy conversion module may be synthesized from basic components and how that module may be configured into a number of power systems covering the range from 1.0 to $500 \mathrm{Kwe}$.

In October 1966, the U. S. Army Engineer Research and Development Laboratory (ERDL) contracted with Hittman Associates to perform a preliminary design of a basic energy conversion module. The purpose of this study was to determine the feasibility of developing a module for the $100 \mathrm{Kw}$ M Modular Thermionic Thermal ReACtor (MATTRAC) system. This study has been completed and the results may be obtained from Ref. 1.

The information presented in this document draws heavily on the experience gained from the ERDL feasibility study. The basic module design approach has been taken intact from that study. The detailed modifi- 
cations which are necessary to configure the basic MATTRAC module for space systems as well as some preliminary experimental effort to determine some material design limits are presented in the following chap ters.

\section{SYSTEM DESCRIPTION}

A 15 Kwe thermionic thermal reactor system has been configured from 18 basic energy conversion modules of the general type discussed previously. The system is divided into three subcomponent areas. These are:

- Reactor

- Module

- Diode

Detail features in these areas will be discussed in subsequent paragraphs. The overall system is illustrated in Figure 2 and the major system characteristics are presented in Table 1.

The 18 energy conversion modules are configured in two concentric rings within a $\mathrm{ZrH} 1.85$ moderator calandria. The inner ring contains six modules and the outer ring contains 12 modules. There are 12 diodes on each of the modules in the inner ring and six diodes on each of the modules in the outer ring. This variation in the number of diodes per module results from a desire to match the power consumption rate with the power generation rate caused by a radial power distribution peak in the central module zone. Pairs of outer ring modules are connected in series to provide a series string of $12 \mathrm{di}-$ odes in series. This combination of series and parallel connections results in improved reliability over what could be obtained by connecting all the diodes in series. In addition, 12 strings of 12 diodes result in an unconditioned output voltage of approximately 8.4 VDC. This value is well within the capability of electrical insulators operating at $1500^{\circ} \mathrm{C}$. The output current from the system is 178 amperes. With an assumed power conversion efficiency of 85 percent, the overall system efficiency is 11.5 percent.

The high heat rejection temperature which can be obtained from the anode of the thermionic diode allows the use of direct radiation. Direct radiation from the diode anode greatly simplifies the design of the waste heat rejection system and is the largest contributing cause of the favorable(10 watts/ lb) specific weight for the $15 \mathrm{Kwe}$ system.

\section{REACTOR FEATURES}

A cutaway view of the Space MATTRAC is shown in Figure 3. A summary of the reactor features is presented in Table 2.

The Space MATTRAC reactor has a thermal neutron spectrum with thermal neutrons accounting for approximately 75 percent of the fissions. The reactor thermal power is 130 kilowatts, and it is fueled with fully enriched $\mathrm{UO}_{2}$ pellets which are approximately 0.175 inch in diameter and 0.38 inch long. The fuel loading is 18.5 kilograms of U-235. Eighteen fueled modules are located in two rings within the zirconium hydride moderator to form concentric fuel zones. The core diameter is 12 inches and the active core length is 18 inches. The beryllium reflector is approximately eight inches thick in the radial direction and four inches thick in the axial direction. Control is provided by 10 drums.

The reactor coolant is Li-7. Lithium-7 was chosen because it does not exhibit the $n-\alpha$ reaction found in lithium- 6 and therefore affords improved neutron economy over natural lithium. The maximum reactor coolant temperature is $1500^{\circ} \mathrm{C}$ and the maximum fuel temperature is $1700^{\circ} \mathrm{C}$. The low maximum fuel temperature is a result of the low linear heat rate which is employed in the Space MATTRAC system. A maximum fuel temperature of $1700^{\circ} \mathrm{C}$ is substantially lower than that presently used in commercial power reactors and is one of the keys to the predicted fuel cladding reliability.

The reactor is moderated with zirconium hydride which is maintained at a temperature of $472^{\circ} \mathrm{C}$. The moderator is clad with Hastelloy- $\mathrm{N}$ and the maximum moderator cladding temperature is $468^{\circ} \mathrm{C}$. A hydrogen diffusion barrier is required at the operating temperature of the moderator.Thermal insulation is located between the moderator calandria and the beryllium reflector to minimize the heat inflow from the reflector to the moderator. Moderator cooling is accomplished by a central heat pipe which is two inches in diameter and uses sodium as the working fluid.

The reactor has a negative temperature coefficient and should exhibit the same control characteristics as would be expected of a thermal reactor having this neutron spectrum. The choice of construction materials for the heat pipe and the comparatively low operating temperature of $1500^{\circ} \mathrm{C}$ have allowed the use of materials which do not have strong resonance cross sections. This has allowed fuel loading to be minimized and has removed a great deal of the doubt which would otherwise be associatedwith the design of an adequate control system. 


\section{MODULE FEATURES}

An exploded cross section view of the fuel element end of the energy conversion module is shown in Figure 4. This view of the fuel block end of the energy conversion module shows the manner in which the fuel pins are located around the central heat pipe. The features of the module are presented in Table 3 . There are 17 fuel pins per module. Each pin is 0.205 inch in outside diameter and 18 inches long. The fully enriched $\mathrm{UO}_{2}$ pellet is 0.175 inch in diameter and 0.38 inch long.

Fission gas containment is a serious problem in any thermionic reactor. This is true because of the low creep strength of materials operated at thermionic temperatures. The material chosen for the fuel block is TZM-molybdenum alloy. This material is not as good as tungsten in creep; however, it does not have the strong nuclear resonances that tungsten exhibits. The use of tungsten would preclude the use of a thermal reactor in the Space MATTRAC system. The advantages of a thermal reactor were felt to outweigh the advantages of using a high creep strength material. As a result, the decision was made to vent each fuel pin into a gas collection plenum. The problem here is to assure that $\mathrm{UO}_{2}$ does not diffuse excessively through the fission gas vent. The design has minimized the driving force for $\mathrm{UO}_{2}$ diffusion by running the plenum as near the $\mathrm{UO}_{2}$ hot spot temperature as possible. The possibility of $\mathrm{UO}_{2}$ diffusion through vents will require further investigation.

As previously stated, each fuel pin is vented into a plenum at the end of each energy conversion module. This plenum collects the fission gas produced during operation. The approximate volume of the plenum is $80 \mathrm{cc}$ per module. The fuel volume is approximately $120 \mathrm{cc}$. One hundred percent of the fission gas generated will be released and, at the fuel volume to void volume ratios shown, a creep life of approximately two years at a maximum cladding temperature of $1540^{\circ} \mathrm{C}$ is provided.

Thermal insulation of the energy conversion module from the $\mathrm{ZrH}_{1} .85$ moderator calandria is achieved by the use of molybdenum foil. Forty layers of thorium oxide coated molybdenum foil are wrapped around the fuel block region of the energy conversion module. This insulation limits the amount of heatwhich will be conducted into the moderator to less than one percent of the total heat being generated.

The heat generated in the fuel pellets is transferred from the fuel elements by conduction to a TZM-molybdenum alloy heat pipe. Lithium-7 is vaporized at the surface of the heat pipe wick and conducted axially down the pipe to the diode region of the module. The maximum heat transport is $12.1 \mathrm{Kwt}$ per module. The inside diameter of the heat pipe is 0.935 inch. The wick thickness is 0.125 inch. The maximum length of the heat pipe is 8.35 feet.

Each energy conversion module is fitted with an excess heat dissipation radiator. This radiator is used to reject the heat which results from changes in electrical load and loss of electron cooling in the diode. It is also used to dissipate the excess heat which results from the radial power distribution in the core. Axial power flattening is attained by flux integration along the length of the active fuel zone.

\section{DIODE FEATURES}

Figure 5 shows an exploded view of a cross section taken through typical thermionic diodes and portions of the heat pipe. A summary of the features of the thermionic diodes is presented in Table 4.

The diodes used in the energy conversion module design are cylindrical and are of the cesium adsorption reservoir type. Conventional cesium reservoir diodes could be used in this design since there is a direct view of space. However, the cesium adsorption reservoir diode offers significant advantages in design simplicity and has been chosen for this application because of its higher potential reliability. The diode emitter is made of molybdenum as is the collector. The use of similar materials for emitter and collector is necessary at the design operating temperature because of the speed with which a monolayer of material can be deposited.

Electrical insulation between the emitter and the heat pipe is accomplished by the use of cast sapphire. Cast sapphire has adequate insulating properties at the diode operating temperature. Thermal insulation of the heat pipe between the diodes and insulation of the diode seals is provided by molybdenum foil. The diode emitter surface temperature is $1465^{\circ} \mathrm{C}$ and the collector temperature is $700^{\circ} \mathrm{C}$. The output power is 125 watts per diode. These diodes are approximately 2.5 watts per square centimeter. The equivalent diode output voltage under load is $0.7 \mathrm{VDC}$. This equivalent value includes all lead losses from the diode to the end of the module. The heat pipe is used as one of the circuit conductors. This is accomplished by not insulating the emitter of the diode closest to the reactor end of the heat pipe. Electrical energy is taken 
from the anode of the last diode and from the heat pipe to form the two circuit leads. The efficiency of the diode is 13.8 percent, including the internal lead losses.

Heat rejection from the diode is accomplished by direct radiation. Each collector has three molybdenumfins attached to provide the necessary area. The back $120^{\circ}$ of the collector is not assumed effective in the calculation of the area. The string area of the forward $240^{\circ}$ was used to determine the effective radiation area. The fins are 2.2 inches in height and 3.9 inches wide at their widest point. The fin root thickness is $30 \mathrm{mils}$ and the tip thickness is $15 \mathrm{mils}$. Each diode has an effective heat rejection area of 0.37 square foot.

Diodes of the general design described here have been fabricated and tested by various manufacturers. The most successful of these tests was reported in Ref. 1 .

\section{SHIELDING}

Figure 6 shows a comparison of the $15 \mathrm{Kwe}$ Space MATTRAC system with other systems which have been proposed. The competitive systems use the advanced SNAP-8 reactor and thermoelectric conversion. All of the systems shown in this figure have shieldweights calculated on the basis of a 10 foot diameter dose plane and a boom extension of 120 feet. The allowable payload dose rateis $10^{11}$ nvt per year for neutrons and $10^{6}$ rad per year for gamma. Examination of Figure 6 shows that the MATTRAC system uses its high heat rejection temperature to advantage. This high temperature allows the radiator area for the $15 \mathrm{Kw}$ e system to be only 53.2 square feet. The equivalent $15 \mathrm{Kw}$ e thermoelectric system requires a radiator area of 790 square feet. The advantages of high heat rejection temperature when working in a space environment are obvious on examination of Figure 6 . The $7.1 \mathrm{watt}$ per pound specific power for the Space MAT TRAC system is considerably higher than any system which has been proposed in this power range.

The weights shown by the curves in Figure 7 may be added to the basic system weight of 1482 pounds to arrive at a manrated shielded system weight. In order to use these curves, it is first necessary to establish the allowable dose rate at the surface of the manned package. The values shown here are energy deposition rates and do not include the biological factors for fast neutrons. The shield weights are based on the geometry requirements of a 60 foot diameter dose plane. The 1.5 pounds per foot for boom and cabling which was shown in Figure 6 is also included in the shield weight shown in this figure.

Radiation streaming down the heat pipe has not been considered in either Figure 6 or 7; however, the heat pipe is offset within the shield in a double dogleg configuration to minimize the effects of streaming. The shieldweights of the MATTRAC system should closely approximate those of the SNAP-8 system since the overall reactor dimensions of the two systems are almost identical and the active core regions are identical.

\section{UNIQUE CHARACTERISTICS}

The unique characteristics of the 15 Kwe Space MATTRAC system are summarized in Table 5 .

The minimization of high cross section material allows the use of a thermal reactor and a greatly reduced fuel inventory over what would be required for a fast reactor.

The use of a thermal reactor has safety advantages and control advantages over a fast reactor. Since 75 percent of the fissions come from thermal neutrons in the Space MATTRAC system, the kinetics of this reactor are easily predictable. The use of a $\mathrm{ZrH}_{1} 85$ moderator provides a negative temperature coefficient and this is useful in establishing safe operating characteristics.

Dynamic control is not necessary in this system. The constant thermal power in the reactor eliminates the need for control drum movement to accommodate load changes. The fuel burnup is less than one percent and the change in reactivity which this incurs may be accommodated by passive means.

The low linear heat rate in the fuel has significant advantages in terms of fuel cladding reliability. The use of the out-of-core concept allows the linear heat rate to be low since it is not necessary to match the heat generation rate with the high power density requirements of the emitters of thermionic diodes. As a corollary to this, the fuel cladding temperature is relatively low even at its maximum hot spot. The combination of low linear heat rate and relatively low fuel cladding temperature allows the fission gas containment problem to be minimized. However, the creep in the fission gas containment vessel remains the controlling mechanism for module failure. 
The use of relatively low thermignic emitter temperatures and low linear teat rate minimizes the creep problem sinde creep is a strong function of the absolute operating temperatures of the system.

Probably the most significant advantage of the out-of-core thermionic system is that the thermionic constraints may be separated from the nucleonics constraints. The use of heat pipe coupling between the fuel and the diode allows heat flux transformation (gain). This in turn allows low hot spot temperatures in the fuel and cladding in relation to what can be obtained when one attempts to match the heat consumption requirements of a diode with the heat generation requirements of a nuclear fuel. Radiation damage of the diode (such as cesium activation products, etc.) are eliminated. Separation of nuclear and thermionic constraints allows the use of a thermal reactor with the attendant low fuel loading of only $18.5 \mathrm{Kg}$ and the known behavior of a thermal reactor.

Axial and radial power and temperature flattening are provided by the gasdosed heat pipe. In reactors which do not use thermal power flattening, the average diode emitter temperature is limited to the core hot spot temperature. The use of heat pipes and thermal power flattening allows the average diode temperature to approximate closely the core hot spot temperature. The net result of this capability is an increased electrical output for a system which is limited in maximum temperature by material compatibility considerations.

In out-of-core heat pipe systems where excess power dissipation is allowed, there is no critical need for power flattening in the axial and radial directions within the core. This allows for a much more easily developed and fabricated fuel element than is the case in concepts where it is necessary to match the power generation rate to the power consumption rate.

The heat pipe system allows elimination of pumped loops. Since a direct energy conversion technique is used, no dynamic machinery is required. The elimination of pumped loops and dynamic machinery should improve the ultimate reliability of the developed system.

Direct radiation from the collector of each diode allows a high heat rejection temperature. High heat rejection temperature minimizes radiator weight. An often overlooked consideration in radiator size calculations is the structural requirements which must be met during launch. In deployable radiator concepts, it is usually necessary to add a pound of structural weight for every pound of heat rejection surface weight. Nondeployable systems usually require threequarters of a pound of structure for every pound of heat rejection surface.

The Space MATTRAC system has good power-to-weight ratio in both shielded and unshielded configurations. Since the reactor is only slightly larger than the SNAP- 8 system and can be extrapolated to $50 \mathrm{Kwe}$, it can be shown to compete favorably in any power range of interest for which the SNA P-8 systems are presently under study.

The Space MATTRAC system is highly developable. The modular approach allows components to be developed with a low risk of interface problems at final assembly. A corollary of this feature is that it is unnessary to commit large amounts of money to a system development program before the feasibility or validity of the concept being developed is established. The fundamental premise of the concept is that of initially developing energy conversion modules rather than developing complete systems.If the basic module can be developed successfully, extrapolation to a complete reactor system may be undertaken with a high degree of confidence. By adopting the modular approach, one can assess the developability of the complete reactor system with a minimum investment in hardware and with a minimum budgetary risk.

\section{REFERENCE}

Eck, Marshall B., Editor, "MATTRAC Module Feasibility Study (U), Final Technical Report," HIT-269, Hittman Associates, Inc., 1 November 1967. 
ISOTOPE
FUEL
CAPSULES

ENERGY SOURCE

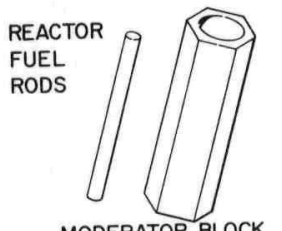

MODERATOR BLOCK

THERMIONIC

DIODES

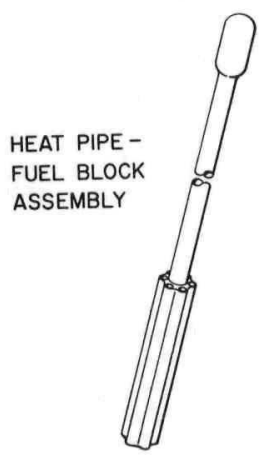

THE FUELED ENERGY CONVERSION MODULE
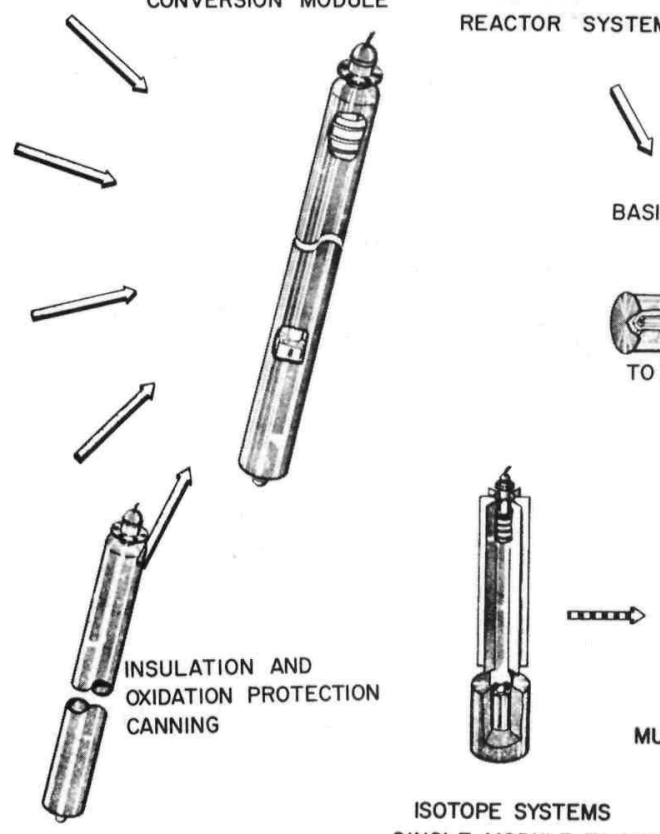

NATURAL CONVECTION

+ RADIATION COOLING

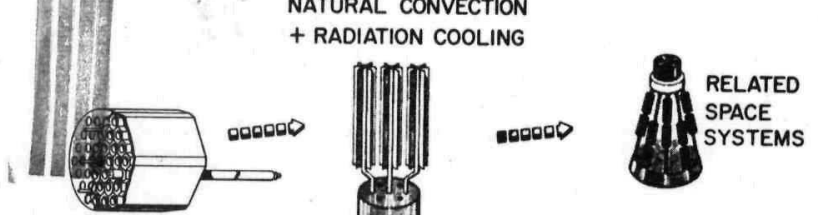

REACTOR SYSTEMS

TO $35 \mathrm{KW}$.

0000 RELATED UNDERSEa
SYSTEMS

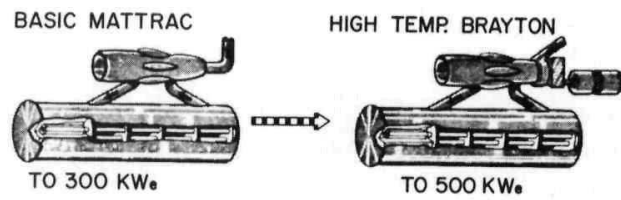

ISOTOPE SYSTEMS

SINGLE MODULE TO $2 \mathrm{KW}$.

FIG. 1. COMPONENT FLOW CHART

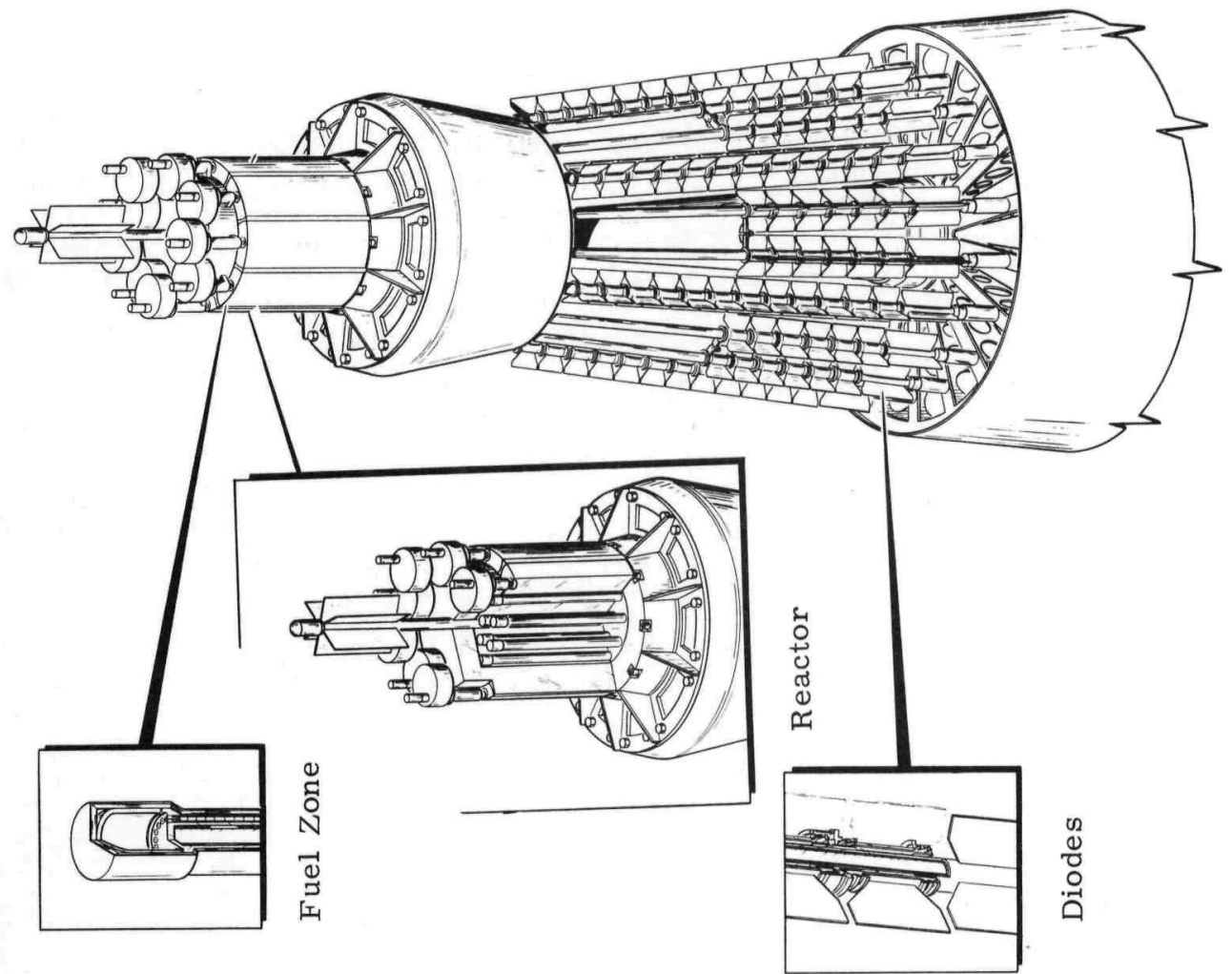

要 

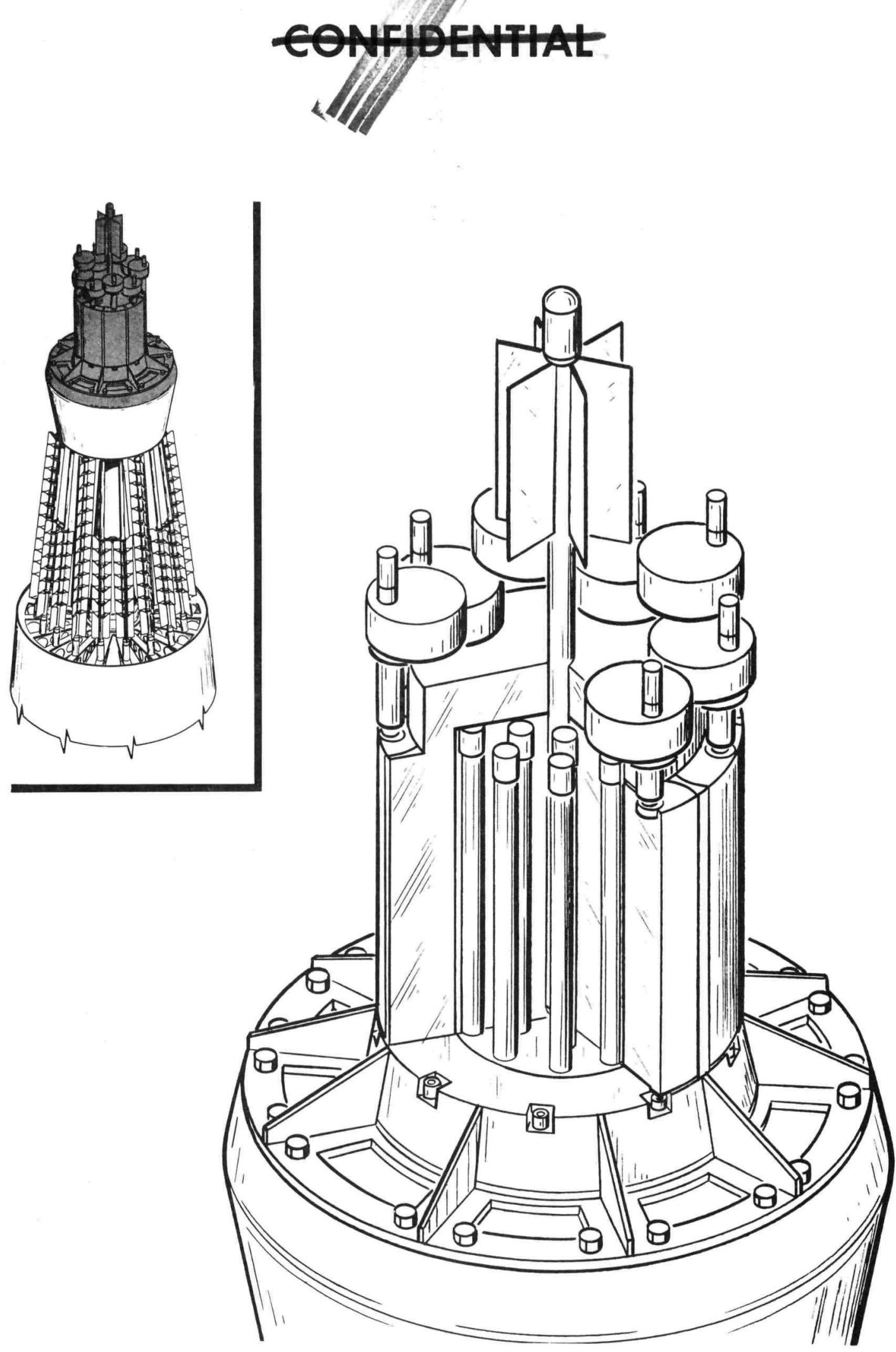

FIG. 3. REACTOR CROSS SECTION 

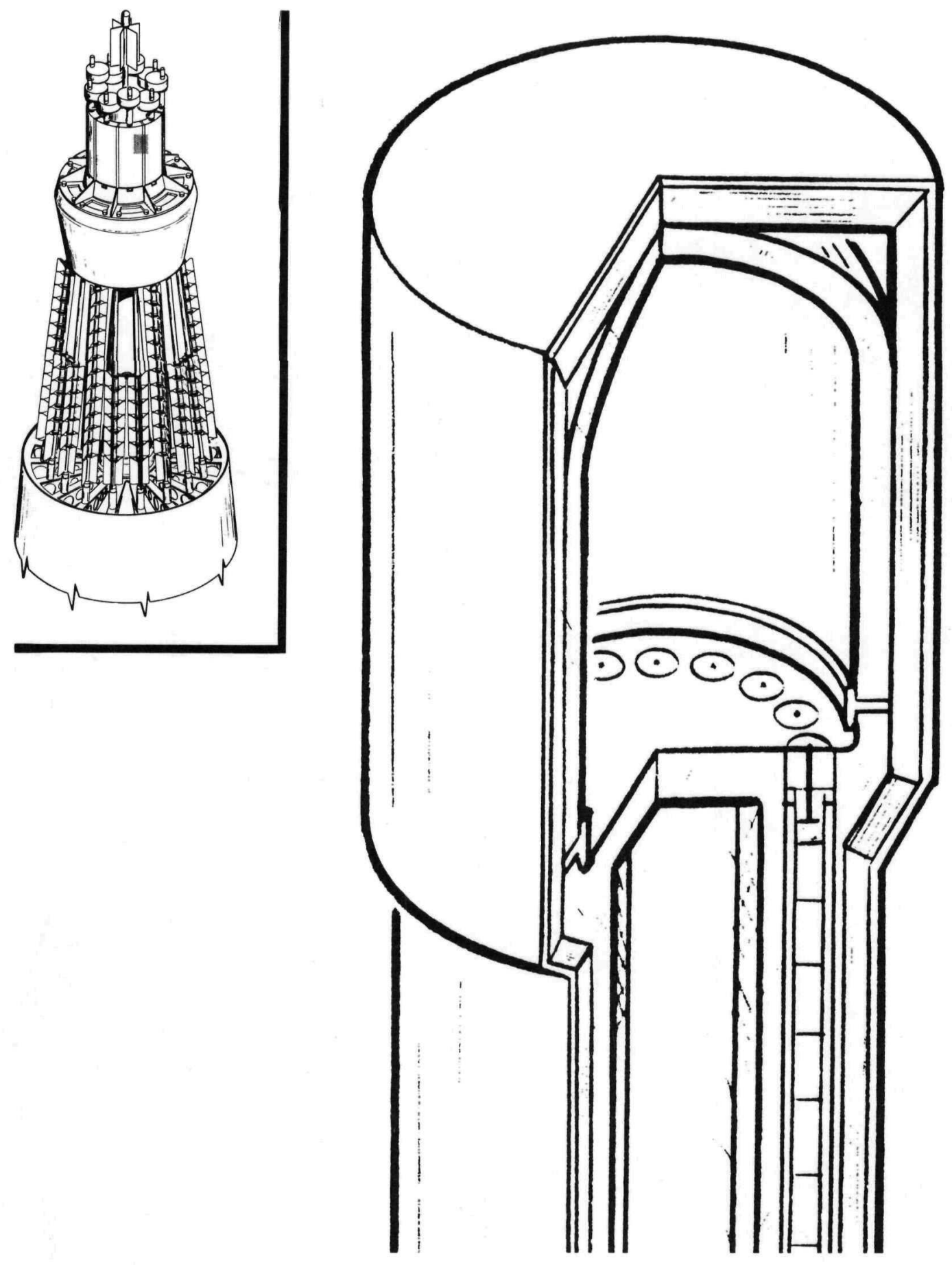

FIG. 4. MODULE FUEL ZONE 

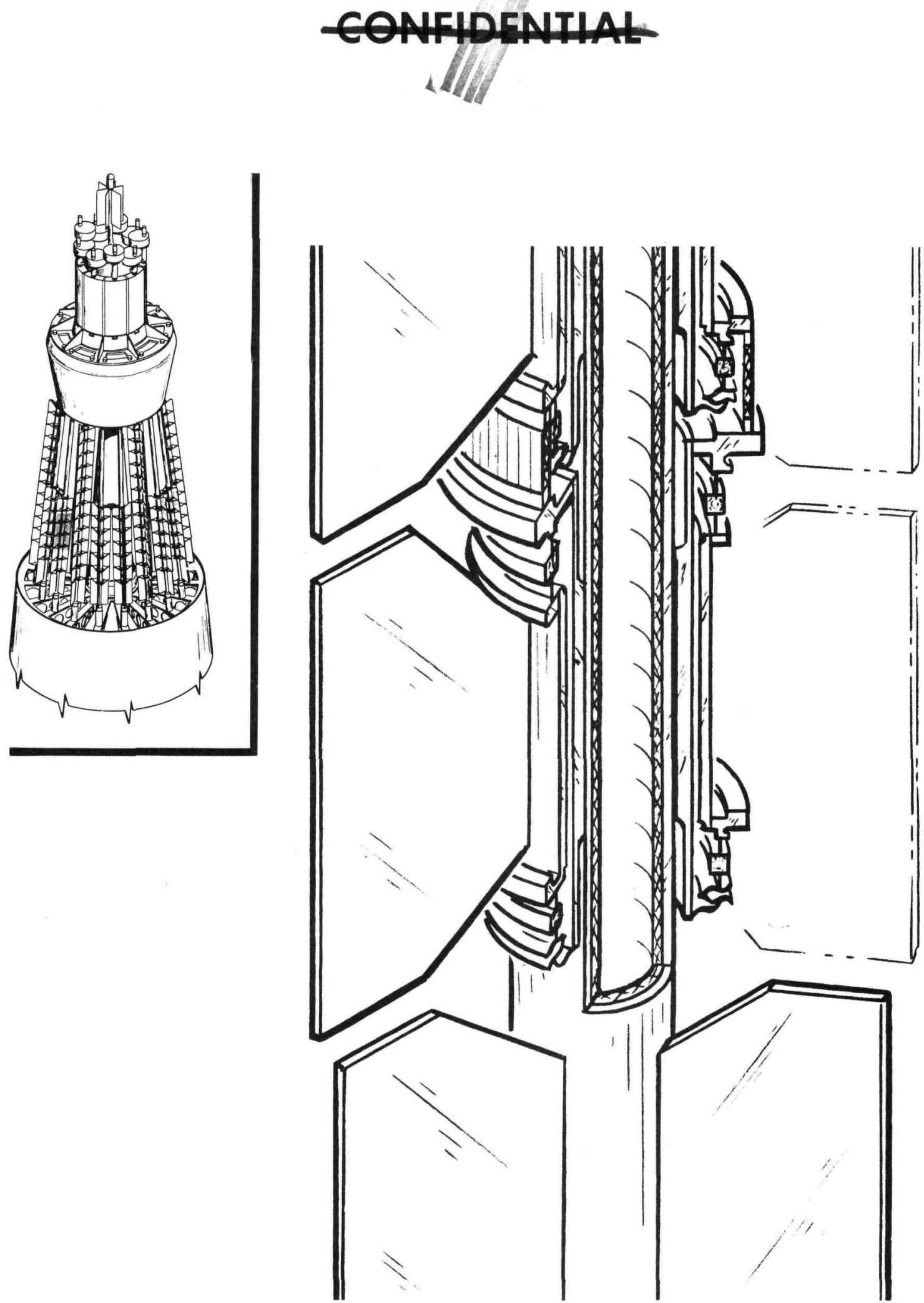

FIG. 5. HEAT PIPE AND bIODE CROSS SECTION

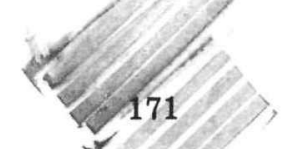


Shield weights based on a $10 \mathrm{ft}$. diameter dose plane and boom extension to $120 \mathrm{ft}$.

Boom and cable weights included at $1.5 \mathrm{lb} / \mathrm{ft}$.

Payload dose rate:

Neutrons: $10^{11}$ nvt/yr

$\gamma$ - rays: $<10^{6} \mathrm{rad} / \mathrm{yr}$
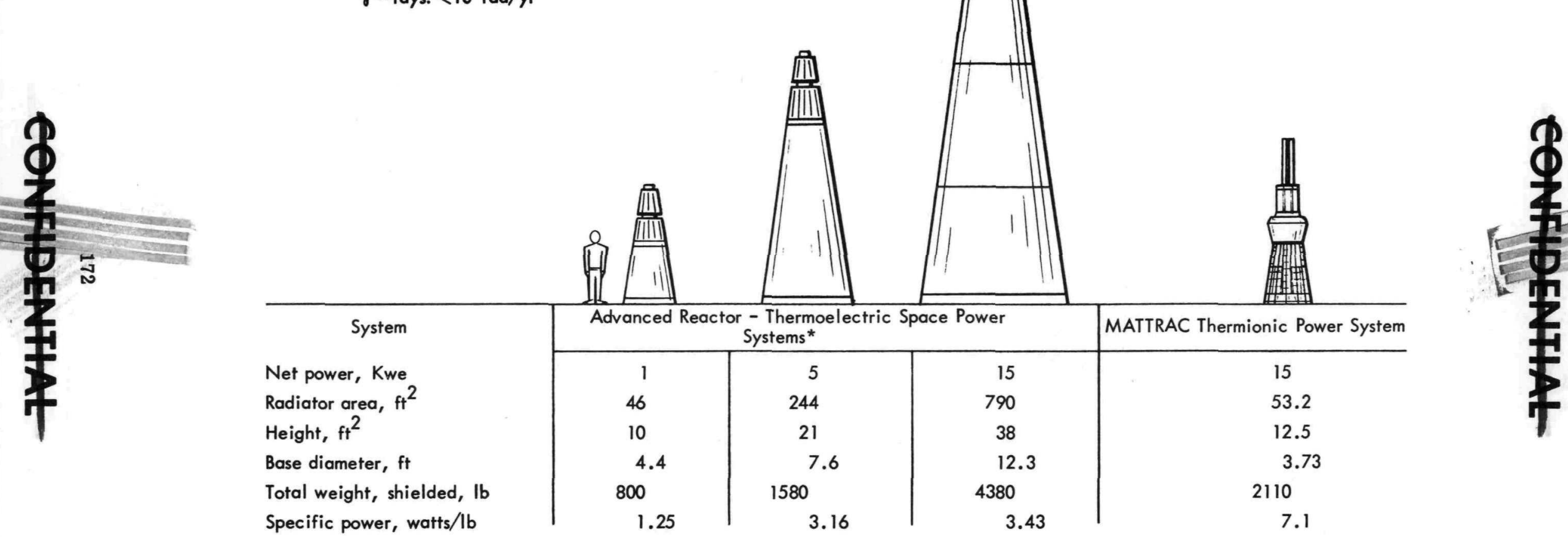

*SNAP Reactor Systems for Unmanned Applications, J.D. Gylfe and J.D. LaFleur, Jr., April 13, 1965.

FIG. 6. COMPARISON OF $15 \mathrm{Kwe}$

MATTRAC WITH OTHER

PROPOSED SYSTEMS 


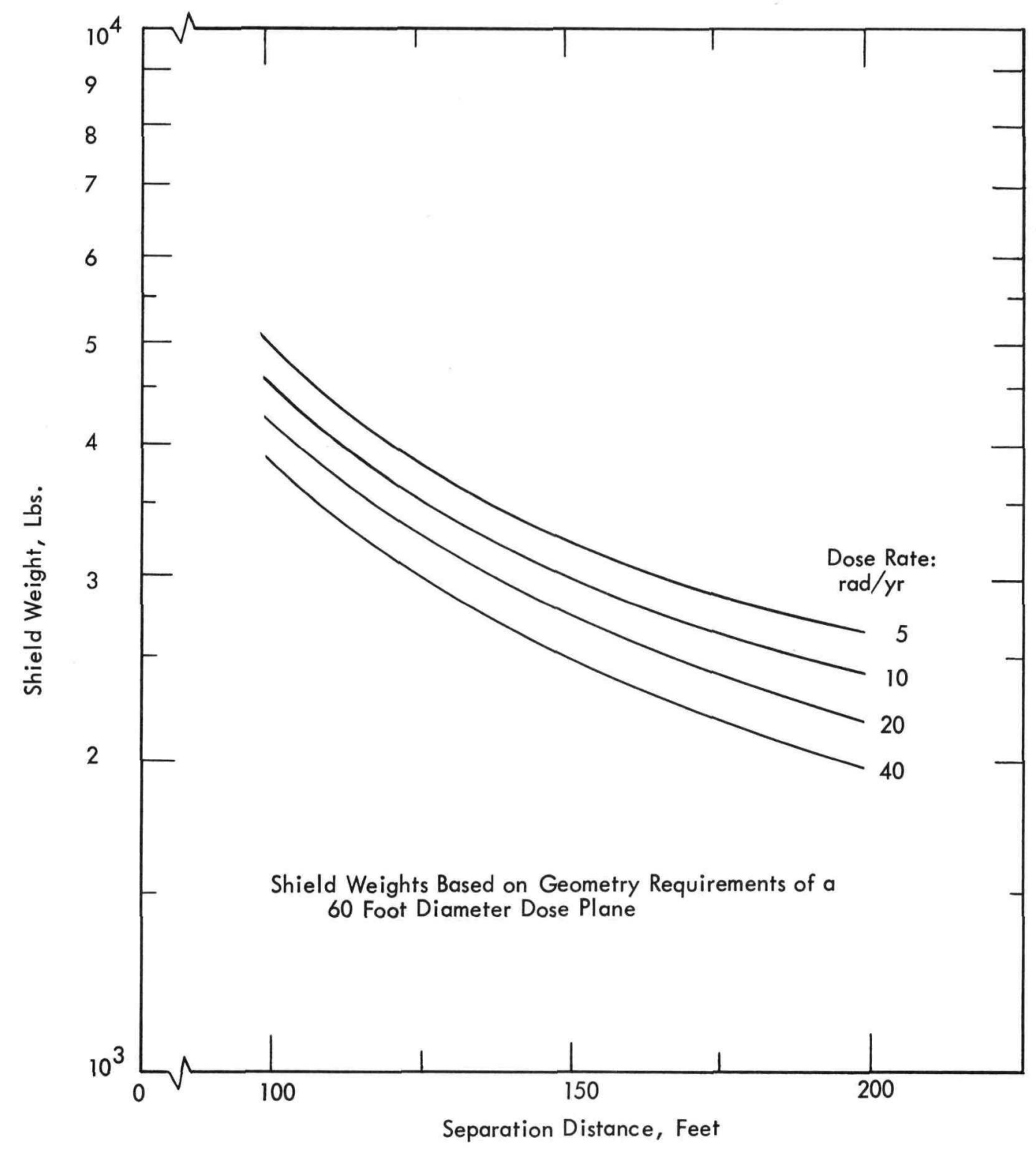

FIG. 7. MATTRAC SYSTEM SHIELDING CHARACTERISTICS 
TABLE 1. $15 \mathrm{KW}$ T THERMIONIC THERMAL REACTOR SYSTEM FEATURES

Fuel

Moderator

Reflector

Height overall, ft.

Base diameter, $\mathrm{ft}$.

Weight unshielded, lbs.

Number of modules Inner ring

Outer ring

Number of diodes in series

Number of parallel strings

Output voltage (unconditioned), VDC

Output current (unconditioned), amp

$\mathrm{UO}_{2}$

$\mathrm{ZrH}_{1} .85$

$\mathrm{Be}$

12.5

3.74

1,482

18

6

12

12

12

8. 4

178

Power conditioner efficiency, $\% \quad 85$

Overall system efficiency, $\%$

11.5

\section{TABLE 2. REACTOR FEATURES}

Type

Power, Kwt

Fuel

Fuel loadings (U-235), Kg

Geometry

Number of fueled modules

Core diameter, in.

130

$\mathrm{UO}_{2}$
(fully enriched)

Concentric fuel zones

18

12

18

Reflector thickness, in.

Maximum reactor diameter, in. 28

Control

10 drums

Coolant

Li-7

Maximum coolant temperature, ${ }^{\circ} \mathrm{C}$

Moderator

Maximum moderator temperature, ${ }^{\circ} \mathrm{C}$

1500

$\mathrm{ZrH}_{1.85}$

472

Moderator cladding

Hastelloy-N

Maximum moderator cladding temperature, ${ }^{\circ} \mathrm{C}$ 468

Moderator cooling

Maximum fuel temperature, ${ }^{\circ} \mathrm{C}$
TABLE 3. MODULE FEATURES

FUEL

Block material

T ZM

Number of elements

17

Element outside diameter, in.

0.205

Element length, in.

18. 0

Pellet diameter, in.

0.175

Loading, $\mathrm{Kg} /$ element

0.0588

Fuel volume, cc

120

Void volume, cc

80

Cladding

T ZM

Maximum cladding temperature, ${ }^{\circ} \mathrm{C}$

1540

INSULATION

Mo foil

HEAT TRANSPORT

Maximum heat transport, Kwt

Mechanism

12. 1

Heat pipe, inside diameter, in.

Heat pipe

Wick thickness, in.

0. 935

Maximum length, feet

0.125

8. 35

Coolant

Lithium-7

POWER FLAT TENING

Axial

Flux integration

Radial

Excess heat dissipation

Change in load

Excess heat dissipation 
Type

Emitter material

Collector material

Electrical insulation

Thermal insulation

Emitter temperature, ${ }^{\circ} \mathrm{C}$

Collector temperature, ${ }^{\circ} \mathrm{C}$

Output power, watts/diode

Voltage(load), *VDC

Current, amps

Efficiency, ${ }^{*}$ percent

Heat rejection

Radiator fin

Dimensions, in.

Thickness, in.

Root

Tip

Effective area, $\mathrm{ft}^{2}$

Weight, lbs
Cylindrical, Ce adsorption reservoir

Mo

Mo

Cast sapphire

Mo foil

1465

700

125

0.7

178

13.8

Direct

Radiation

$2.2 \times 3.9$

0.030

0.015

0. 37

2. 2

*Includes losses in all leads to the end of the module.

- High cross section material minimized

- Thermal reactor

- Need for dynamic control eliminated

- Low linear heat rate in fuel

- Relatively low fuel cladding temperature

- Fission gas containment problem minimized

- Thermionics constraints may be separated from nucleonics constraints

- Axial and radial power and temperature flattening provided

- No pumped loops required

- No dynamic machinery required

- High heat rejection temperature

- Good power to weight ratio in shielded as well as unshielded configurations

- High developability 